\title{
Designing a sustainable, medium density housing solution that is an affordable alternative for developers
}

Milla Josefien Saris

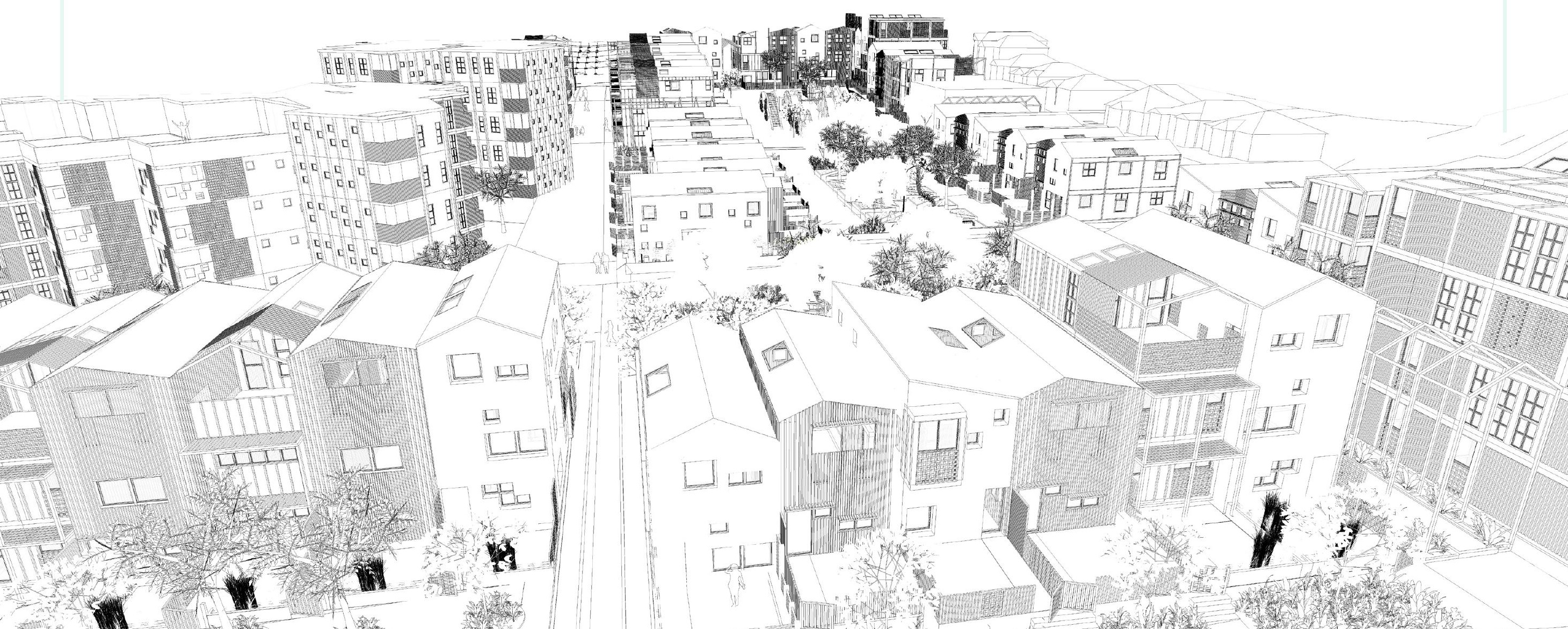




\section{DESIGNING A SUSTAINABLE, MEDIUM DENSITY HOUSING SOLUTION}

THAT IS AN AFFORDABLE ALTERNATIVE FOR DEVELOPERS

\section{BY}

\section{MILLA JOSEFIEN SARIS}

A thesis submitted to the Victoria University of Wellington,

in fulfilment of the requirements for the degree of

Master of Architecture (Professional)

Victoria University of Wellington

2017 


\section{Acknowledgements}

This year would not have been possible without the support of some wonderful people that I would like to thank:

My supervisor Morten Gjerde for his calm direction. It has been an absolute pleasure working under your guidance.

The industry professionals that let me bend their ear many times over.

My fantastic family and friends for their continuous support. 


\section{Abstract}

It has been acknowledged that there is a housing crisis in New Zealand (NZ), particularly in the large urban centres (Hulse, 2015). As a solution, medium density housing developments are becoming more prevalent. However, these developments are controversial in a country that prides itself on its generous housing and open spaces.

Sustainability is also an issue in the NZ architectural environment. NZ is a small country isolated in the South Pacific, so 'sustainable' materials must often be imported, this longdistance transportation increasing their cost as well as their carbon footprint. Many products also reference 'green washing', with companies misleading consumers into believing their product is environmentally friendly (EnviroMedia Social Marketing, 2017). Legitimately sustainable technologies and materials are often seen as unaffordable, and people (particularly property developers) are not prepared to consider eco-friendly building practices if they do not believe they will get an economic return for their investment.

Because of these factors, New Zealand does not have a dynamic and sustainable medium density housing vernacular. The current research addresses these issues by seeking out materials and technologies for use in a theoretical medium density housing development. The project focuses on finding innovative and sustainable potential solutions for architects, developers, property buyers, and wider community stakeholders. It argues that architectural materials and processes should aim to fit as closely as possible within cradle-to-cradle frameworks involving closed loop production, construction and reuse systems (Braungart \& McDonough, 2010). 


\section{Acknowledgements}

Abstract

\section{Contents} pg5

Introduction $p g 6$

Informing the design

pg7

Literature review

$p g 9$

Stage 1 - Case studies

pg17

Stage 1 - Site Study

.pg24

Stage 1 - Design Process

pg38

Stage 1 - Feedback and Analysis

pg50

Stage 1 - Summary

Stage 2 - Design Precedents
Stage 2 - Materials Research

Stage 2 - Site Planning

Stage 2 - 2 Bedroom Unit 1:100@A4

Stage 2 - 3 Bedroom Unit 1:100@A4

Stage 2 - 4 Bedroom Unit 1:100@A4 .........pg80

Stage 2 - Site Figures $\operatorname{pg} 102$

Stage 2 - Feedback and Analysis .pg 108

Stage 3 - Design Process pg117

Stage 3 - Feedback and Analysis. pg155

Stage 3 - Summary / Self-Reflection ........pg166

Conclusions and Future Potential pg168
End Notes

\section{Bibliography}

$\operatorname{pg} 173$

List of Tables

$\operatorname{pg} 178$

List of Figures pg180

\section{List of Appendices}




\section{Introduction}

The human population is growing exponentially, space is at a premium, and the world's resources are diminishing. The quarter acre section is a thing of the past and the concept of 'home' is changing. Low density suburban living has become unsustainable, so architects and developers are shifting towards medium density housing to cope with urban intensification and market demand. In Wellington, medium density housing was introduced as a major urban planning solution in 2010 and it has since featured heavily in suburbs around the city (Gray Partners Limited, 2014).

As population increases, so do the effects of housing construction on the environment. At the forefront of the construction process, it is the duty of architectural designers to consider natural, sustainable materials that minimise negative environmental impacts.

This research investigates sustainability in the medium density housing typology, with the aim of providing an assessment and comparison between the traditionally unsustainable housing model and a sustainable alternative. It addresses the stigma associated with sustainable solutions, which are commonly viewed as either unaffordable or risky, and often incorrectly marketed as being more sustainable than they are. For example, the Roxbury development, part of Boston's energy plus $(\mathrm{E}+)$ green building program, is "an example of both high performance and high style" but fits the stereotypical high-cost sustainable typology. Its build cost was estimated to be approximately $15 \%$ higher than traditional developments in the same area (American Institute of Architects [AIA], n.d. para. 44). Its medium density units incorporate solar panels, triple glazed windows, heat recovery ventilators, Energy Star appliances, and on-site water management systems. However, the building shell is primarily constructed of unsustainable fibre cement siding and metal composite panelling (AIA, n.d. para. 23-28).

At the opposite end of the scale are ecological homes, constructed completely from natural and locallysourced materials (Chiras, 2004). The risks associated with uncertified materials and construction techniques make this typology unrealistic for large-scale city developments. Stylistically, eco-homes also fail to meet the sleek and modern aesthetic of urban living.

The purpose of this project is to find a middle ground where common concerns around affordability and risk are balanced. It aims to unmask commercially available sustainable materials that are underused or overlooked, and use innovative design to integrate them into an alternative model. The intention is that the project could be used a tool for convincing stakeholders that sustainable building can fit within the current market without affecting profits. Throughout the research, the perspectives and opinions of developers and architects are considered, to ensure the project is realistic and market-focused.

The research question for this thesis is therefore: How can design contribute to a sustainable medium density housing solution that is an affordable alternative for developers?

Ethics approval was granted No. 0000023047. 


\section{Methodology}

The development designed for this thesis proposes a contribution to the current medium density discourse, as well as an affordable sustainable vernacular for New Zealanders. The aim is to incorporate architectural technologies and materials for sustainable living.

The thesis is formatted by a qualitative methodological framework. Specifically, it incorporates case study methodology with action research. In the text 'Doing Research in Design', the authors state these methodologies are valid as they "... have become well established because of their coherence and usefulness" (Crouch \& Pearce, 2012).

\section{Case study}

Case study is "qualitative research that may be an object of study, as well as a product of the inquiry" (Creswell, 1994, p. 97). In this thesis, several existing comparative case studies were used to gather foundations for the specification of materials and technologies, to find examples of excellent design, and to learn from the mistakes or setbacks others have encountered.

The case studies were used as a tool for comparison while proposing a new design, to provide evidence that a sustainable medium density housing option can be designed to be affordable.

\section{Action research}

Action research is the process of examining and evaluating one's own practice to come to the best possible solution to the research question. This methodology is particularly useful in architectural research, as it is a visual and iterative process.

Discussed by Crouch and Pearce, "the process of action research is typically cyclical", involving a series of phases of research including observing, reflecting, planning and acting (2012, p. 144). For this thesis, the action research process has been visualised (see Figure 1). Adapted from Kurt Lewin's (1946) "spiral of steps", the approach recognises a requirement for action research to be "flexible and responsive" (Kemmis \& McTaggart, 1981 , p. 8). As has been found through this project, the process is messy and constantly changing. "Each change leads to further consequences, that in turn need to be researched" (Crouch \& Pearce, 2012, p. 144).

It can be noted that not every aspect of action research is done objectively. The researcher is a central concern which is vital to "humanising" the project (Crouch \& Pearce, 2012, p. 144). Unlike traditional research involving the simple collection of facts, action research is personable. This acts as a persuasive technique for making the information attractive to home owners, developers and other industry professionals. Presented in a design context, 
they may be more inclined to apply the research to their own projects.

Action research also allows a level of design freedom and innovation that would not typically be possible on a real-world project.

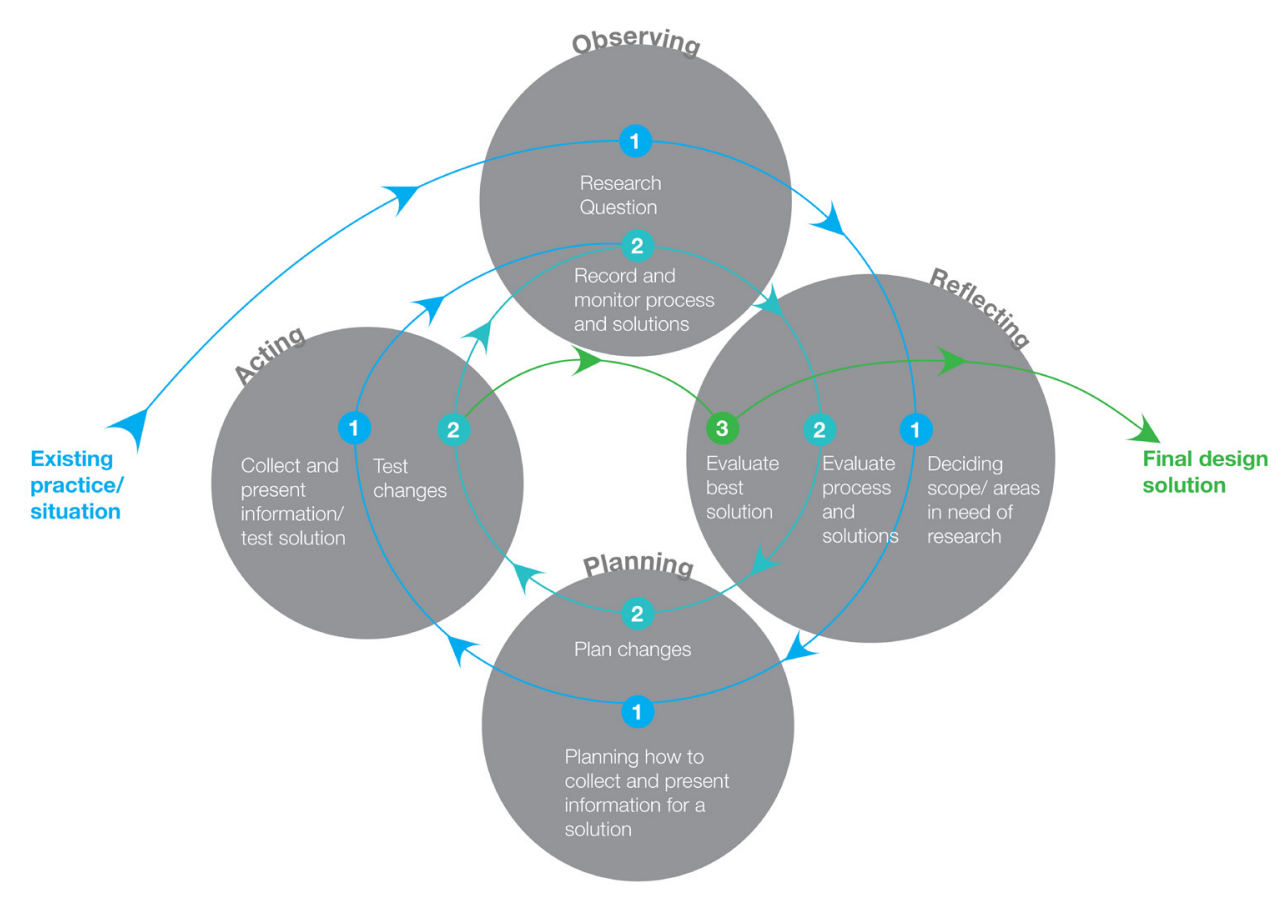

Figure 1: Action research diagram showing it's application to this thesis 


\section{Sustainability}

Key texts that were reviewed throughout this research tended to focus on three pertinent themes: sustainability, medium density housing concerns, and market factors.

\section{Environmental Sustainability}

Sustainability can be defined in terms of its weakness or strength. Strong sustainability means that no subsidy can be made in terms of the depletion of natural capital. Moderate sustainability is the attitude that allows natural capital to be depleted if it is compensated for, such as oil extracted for the production solar panels. Weak sustainability has concern for natural capital only when it is critical (Dresner, 2008). In this sense, 'natural capital' encompasses all unrefined natural resources (Pearce, Markandya, \& Barbier, 1989).

People that design for or work with sustainable principles have a position within this scale, and there are many ways of thinking about architectural sustainability. For example, Braungart and McDonough (2010) assert that designers and manufacturers must develop products with full consideration for their environmental impact and end use. Specifically, they should develop closed-loop systems that favour a 'cradle-to-cradle' scenario and avoid the common 'cradle-to-grave' outcome .

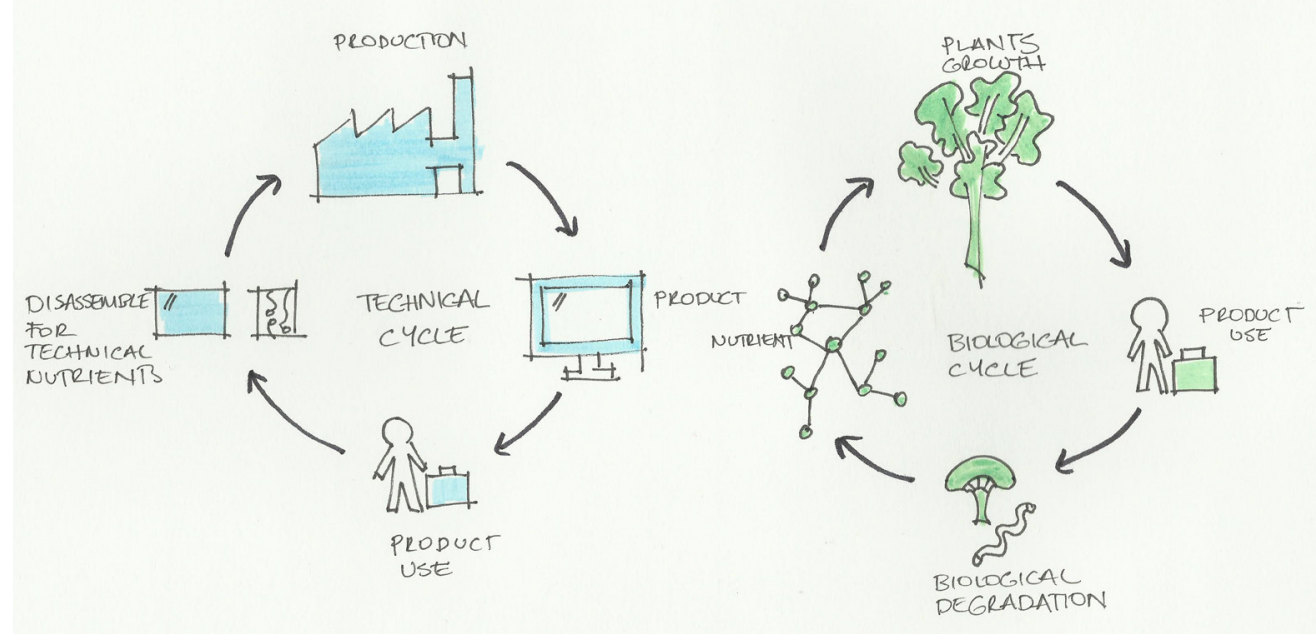

Figure 2: Visual representation of the cradle to cradle cycles. Adapted from Understanding Labels Part 3: Cradle To Cradle, or A Cautionary Tale, by L. Alter (http://www treehugger.com/green-architecture/understanding-labels-part-3-cradle-to-cradle-or-acautionary-tale.html). Copyright 2017 by Narrative Content Group.

A 'cradle-to-cradle' approach is based on the principle of longevity, where all products and bi-products of a process are continuously reused and never wasted. Braungart and McDonough (2010) argue that an awareness of the environmental consequences at every stage of design, construction, use, and post-use should be a driving force behind all design decisions (see Figure 2). 
Specific 'cradle-to-cradle' building methods and techniques are discussed by Van Lengen (2008), who promotes the use of natural materials or 'bioarchitecture'. Expansive real world examples of this building approach were also sourced from his website (Intuitive Technology and Bio-ArchitectureTIBÁ, n.d.) By reviewing Van Lengen's projects, it became clear that a large development would be difficult to construct entirely from natural materials. While it would undoubtedly sit within an optimal cradle-to-cradle framework, several issues would arise.

Time is a major issue in the construction of large-scale developments. A completely sustainable earth home requires sourcing, preparing, drying and assembling materials (Van Lengen, 2008). This is lengthier and more labourintensive than a traditional build, and would compromise the affordability of a large project. Presumably, most architects and builders would also be unfamiliar with the construction process of an earth building, and developers are unlikely to venture into unknown territory while they are liable for any risks.

Although Van Lengen's ideology inspired thought around using materials creatively and resourcefully, the practices he utilises in his own work are unlikely to be viable for a medium density housing project. Realistically a sustainable development requires a holistic view based on affordability and risk, as well as environmental concerns.

Friedman (2012) discusses the dichotomy between an environmental perspective focused primarily on sustainability, and a private sector perspective focused primarily on the economy. Friedman positions himself in the mid-ground, where environmental and social sustainability meet an expected return for the investor. He believes that "four fundamental aspects need to be given equal weight", these principles being culture, economy, environment, and society. To achieve balance, he suggests that development should "follow the path of least negative impact"(Friedman, 2012, p. 5).

Friedman provides information about new and existing building principles that achieve sustainability while adhering to real world constraints. He also sets out sustainable guidelines for designers. Guidelines relevant to this thesis focused on sun and natural lighting, urban planning, landscaping, water efficiency, and construction waste management (Friedman, 2012). This thesis has aligned itself with Friedman's perspective due to his realistic interpretation of sustainable principles and achievable cradle-to-cradle concepts. It also supports Friedman's view that medium density housing developments are beneficial to environmental and social sustainability through their efficient use of land and energy, and their focus on creating 
public spaces that invite neighbourliness (Friedman, 2012, p. 55).

\section{Social Sustainability}

Social sustainability is a complex topic, involving discourse around human development and economic growth. Social sustainability can be defined as "development that meets the needs of the present without compromising the ability of future generations to meet their own needs" (World Commission on Environment and Development, 1987, p. 40).

Vallance, Perkins, and Dixon (2011) contend that the importance of social sustainability and the need for meaningful societal change have been lost. They believe that the "practice associated with the concept has failed to substantially improve the conditions of the poor" (p. 343), and that present societal conditions cannot be sustained.

Vallance, Perkins, and Dixon (2011) highlight three types of social sustainability: 'development sustainability', focusing on poverty and inequity; 'bridge sustainability', which addresses changes in behaviour to achieve environmental goals; and 'maintenance sustainability', referring to "the preservation of socio-cultural patterns and practices in the context of social and economic change" (p. 345).
This thesis addresses two of the three issues, specifically 'bridge sustainability' and 'maintenance sustainability', by aiming to a create residential development that benefits the community as well as the environment. 


\section{'Medium Density Housing' Defined}

Medium density housing (MDH) in New Zealand is a growing industry that is evolving to address urban land shortages, the need for affordable housing, and a shortage of homes to house the population (Litten, 2016, p. 44).

The term 'medium density housing' is often confusing or misunderstood, and is defined differently across literature. It can be used to refer to all housing other than detached dwellings or high rise flats. It can also be used to refer to single and two-storey attached houses with a group title. In either case, while 'medium density' refers to the intensity of a development, it does not necessarily define the housing typology (Judd \& Gamble, 1993).

Furthermore, 'density' itself creates variance in expression. For example, it can to refer to people per unit area, dwellings per unit area, or floor space ratio. The recurrent theme in literature is that the concept of 'density' and the nature of 'medium density housing' have no universal or standard application (Turner, Hewitt, Wagner, Su, \& Davies, 2004).

For clarity, this thesis followed the definition of 'medium density housing' used by most New Zealand City Councils and the Housing New Zealand Corporation. This is "housing at densities of more than 150m2/unit and less than 350m2/unit, or 30-66 dwellings per hectare". It also considered MDH as "small lot subdivision, or multi-unit development, ... attached, [with] no lifts", and as "horizontally attached dwellings... [which] rarely exceed three stories above the ground, with individual access and private open space at or near ground level” (Turner, et al., 2004, p. 22; Judd, 1993, p. 8).

\section{$\mathrm{MDH}$ Concerns}

$\mathrm{MDH}$ is a necessary solution to manage forecasted population increases in New Zealand's urban centres. However, while city councils push for greater density, local residents who are already settled in their chosen areas do not tend to welcome disruption or change.

Addressing this public concern is a matter of quality assurance, as well as exposure to the medium density typology. For communities to understand the advantages of $\mathrm{MDH}$, they must be shown examples that are of an excellent standard. As New Zealand Planning Institute chair Bryce Julyan has suggested, "the key is ensuring developments are high quality, with good design standards, plenty of sunlight, and privacy between houses". He argues that public opinion will change when MDH neighbourhoods are more common (Stewart, 2016, p. 45).

Increasing public awareness around densification is the first step, although this is no easy task. After public consultations in the Wellington suburbs of Khandallah, Johnsonville and Kilbirnie, residents initially resisted new zoning 
proposals, with the Johnsonville Community Association even taking their dispute to the NZ Environment Court (Stewart, 2016).

To ease community concerns, it is important that limits and standards around size, density and design are established by appropriate authorities and not controlled solely by the economic interests of developers. Higgins (2010) describes the effective regulation of urban intensification as essential, explaining "the substantial amount of effort going into rewriting planning policies to ensure better urban design is to be welcomed" (p. 19).

Dixon and Depuis (2003) outline several other issues associated with urban densification in New Zealand. While the authors, who are urban planners, argue for $\mathrm{MDH}$ as a solution to the housing crisis, they discuss criticisms that $\mathrm{MDH}$ developments put additional pressure on suburbs already at perceived capacity, increasing stress on current infrastructure. They also recognise that social values and needs are shifting the market, but that MDH developments display an obvious lack of individuality which does not tend to deliver housing for a wide range of family sizes (Dixon \& Depuis, 2003). This point has illuminated the idea that this thesis should focus on designing a development that appeals to and accommodates a diverse community.
The Living Ark, a project by New Zealand architect John Gray, extensively researched and tested the effect of house size on comfort and efficiency. The Living Ark concluded that a reasonable minimum area for multi-person households is $18-25 / \mathrm{m} 2$ per person. Single person and couple households may need more space due to the disproportionate area allocated to service rooms (Bierre, Howden-Chapman, \& Early, 2013).

Spaces within the Living Ark are subdivided "to utilise the concept of the universal room borrowed from Georgian and Edwardian era architecture in which each room is of a similar (generous) size with certain minimum dimensions, .... [allowing] many possible furniture arrangements, thus many possible uses" (Bierre et al., 2013, p. 119). The Living Ark project proposes that by being generous in dimensions where possible, a space can be flexible in it use.

A version of this idea is supported by Friedman (2012), who discusses the challenges of designing for a small footprint. He suggests "an open plan that contains few or no subdivisions increases adaptability and allows multiple functions to be assigned to the same space" (p. 38).

MDH Design 
In terms of aesthetic characteristics favoured by the public, research has pointed to preferences for "bright, light, modern buildings, with big windows" (Tutt \& Adler, 1979, p. 301). Externally, buyers look for "a sense of spaciousness, plentiful greenery, good maintenance, pleasant entrances, convenient access, and car parking that can be easily supervised by passing residents. Exposed concrete finishes are strongly disliked" (Tutt \& Adler, 1979, p. 301). These aspects are very broad and allow plenty of creative freedom, but provide a point of reference for this design project. 


\section{The MDH Market}

Historically, the predominant age group occupiers of $\mathrm{MDH}$ units have been the young (under 25) and aging (over 55). Younger occupiers typically choose medium density living for reasons of affordability, whereas older buyers are attracted by the lower maintenance requirements and good security (Judd \& Gamble, 1993).

However, $\mathrm{MDH}$ is also a typology designed for the changing demographics in New Zealand cities. Projects with 10 or fewer units account for almost $50 \%$ of all new multi-unit developments in New Zealand (Page, 2016, p. 48). Statistics New Zealand reported a $13 \%$ rise in building consents for medium density-type dwellings in 2015, such as townhouses and flats. Currently $\mathrm{MDH}$ accounts for $20 \%$ of all dwelling units in NZ (25\% in Wellington), and this is expected to increase by about $10 \%$ in the next few years (Page, 2016, p. 48). These statistics suggest that MDH developments are a significant market not only catered to the young and old.

The typical New Zealand home, a single detached dwelling on a $1 / 4$ acre, is no longer affordable for many families in the current market climate (Bierre et al., 2013). While the government argues that the commercial market will itself promote the production of housing for all income groups, others believe that it does not handle "public goods adequately" (Bierre et al.,

\section{Market Factors}

2013 , p. 13) and that government assistance is required to regulate the market and financially support affordable, quality housing as part of the national infrastructure (Bierre, et al., 2013).

While affordability is such an issue, medium density housing offers an economy of scale. Creating more homes per plot of land reduces construction time and cost. This idea was utilised during the production of state housing in the 1930's and 1940's when New Zealand faced a similar housing crisis (Bierre et al., 2013). "Standardised components like windows, roofing tiles and toilet bowls introduced economies of scale into the scheme, increasing productivity and lessening construction times. Further efficiencies in construction were realised through the prefabrication of framing and in some cases whole walls" (Bierre et al., 2013).

Within the commercial market, MDH developments could offer more affordable purchase prices compared to conventional stand-alone housing; an appealing middle ground between detached housing and high density multi-story options that do not provide the same outdoor amenities and privacy.

The MDH typology also offers livelihood and amenity benefits. "The different forms of this type of housing give greater choice, which is important in 
terms of affordability and allowing people to live closer to where they work or study, ... [homeowners] can get their preferred lifestyle in higher density areas close to amenities" (Stewart, 2016, p. 45).

This thesis has therefore focused on creating a development that could offer affordable, quality housing to multiple market demographics, including housing for families looking to buy their first home.

\section{Sustainable Housing Market}

Sustainable or eco-friendly housing is a relatively new area of architecture and not one that receives a lot of interest in the current market climate. Sustainable homes tend to be a niche at the middle-to-upper end of the market, rather than the status quo (Bierre et al., 2013).

Developers are unwilling to invest in green building features when it will lower their profit margins, but this thesis aims to explore whether sustainable building is always more expensive. Rather than wait for developers to see it as their ethical duty, or for governing policies to enforce appropriate building codes, this research aims to find materials and techniques that will not affect the profitability of a development. 


\section{Stage 1- Case studies}

To best interpret the design principles of medium density and sustainable housing, three specific case studies were used: (1) The Altair, Wellington; (2) Regent Park Apartments, Wellington; and (3) Hobsonville Point, Auckland.

Through the case study research, guidelines were developed to inform the design decisions for this thesis project.

The Altair, in Wellington's suburb of Newtown, is a medium density housing project designed by Architecture Plus for developers Stratum Management Ltd (see Table 1). A multi-unit residential development, it has been chosen as a case study because of its inner suburban position and target towards first home buyers. The project provided an initial starting point for the feasibility studies done later in this thesis (see Table 2).

Plans and images of The Altair were sourced from an existing Ministry of Environment case study (Boffa Miskell Limited, 2012), and information was also collected from site visits, to make observations and conclusions that would benefit the current research (see Figures 3-5).

\section{Planning}

The simple interior floorplans of the units are instantly understandable and allow for a comfortable living flow. Situating living areas on the ground floor separates them from the private areas upstairs, makes the units instantly inviting, and encourages the use of outdoor space. In some cases, the outdoor spaces of individual units open onto a larger communal area, giving the illusion of more green space and inviting occupants to be part of a community beyond their own dwelling. Unit heights vary from two to four storeys, adding an appealing dimension and variety to the overall external look of the development.

Forms and design

The form of the units is exemplary of how individuality can be achieved within a large development. A staggering of the units and slight shifts in the roof slopes make the distinctions between unit titles obvious. Individuality is also achieved through material use. While not every unit is different, variations in colour and façade materials articulate a difference. Each block has its own style, allowing for economies of scale and efficient material use.

The main negative aspect to the development's design, as mentioned in the Ministry study, is that it can be difficult for visitors to distinguish the front of the units from the back (Boffa Miskell Limited, 2012). The garage door is positioned at the front of each unit, while the garden is positioned at the back. 


\section{The Altair Quick Facts}

\section{Guidelines}

The Altair development is exemplary of good design. General rules have are established and used in the development of this research. These rules include:

1. Façades are articulated, vertically and horizontally.

2. Façade depths are varied to create volume shifts.

3. Roof pitches are varied.

4. Units are divided into blocks.

5. Shared open green areas are provided.

6. Planning is clear and uses space efficiently, both internally and externally.
Town houses 2,3,4 storey urban infill: 20-24m2 Courtyards

$1.2 m \times 3 m$ Balconies

$1.1 \mathrm{~m}-1.3 \mathrm{~m}$ Fences

2-3 bedrooms

Laundry

\section{Dimensions:}

$11.4 m$ length

$4.5 \mathrm{~m}$ width

Floor height 2.35

\section{Materials exterior:}

Shadow clad on $20 \mathrm{~mm}$ cavity

Brick veneer on $40 \mathrm{~mm}$ cavity

texture2000 plywood on $20 \mathrm{~mm}$ cavity

Profiled metal roofing

Structure:

Timber framing and steel portal frames

Windows and doors:

Aluminium with powder coat finish 


\begin{tabular}{|l|l|}
\hline Project name & The Altair townhouses \\
\hline Year Completed & 2013 \\
\hline Address & 116 Rintoul st, Newtown, Wellington \\
\hline Site area & $9964 \mathrm{~m} 2$ \\
\hline Density & 69 dwellings per hectare \\
\hline Parking & 54 double garage, 15 single garages \\
\hline Client & Stratum Management Limited \\
\hline Architect & Architecture + \\
\hline
\end{tabular}

Table 1: Altair project details.

\begin{tabular}{|l|l|l|}
\hline Sale price per unit & $\begin{array}{l}\text { Unit } \\
\text { amount }\end{array}$ & Sale price \\
\hline $\mathbf{\$ 4 8 5 , 0 0 0}$ & 54 & $\mathbf{\$ 2 6 , 1 9 0 , 0 0 0 . 0 0}$ \\
\hline $\mathbf{\$ 5 2 5 , 0 0 0}$ & 15 & $\mathbf{\$ 7 , 8 7 5 , 0 0 0 . 0 0}$ \\
\hline Total & $\mathbf{6 9}$ & $\mathbf{\$ 3 4 , 0 6 5 , 0 0 0 . 0 0}$ \\
\hline Total profit & $\mathbf{\$ 1 4 , 4 6 5 , 0 0 0 . 0 0}$ \\
\hline Total construction cost \\
\hline excl. gst & $\mathbf{\$ 1 5 , 9 7 0 , 0 0 0 . 0 0}$ \\
\hline incl. gst & $\$ 19,600,000.00$ \\
\hline Construction cost per & unit \\
\hline excl. gst & $\$ 231,449.28$ \\
\hline incl. gst & $\$ 284,057.97$ \\
\hline
\end{tabular}

Table 2: Altair costing details.
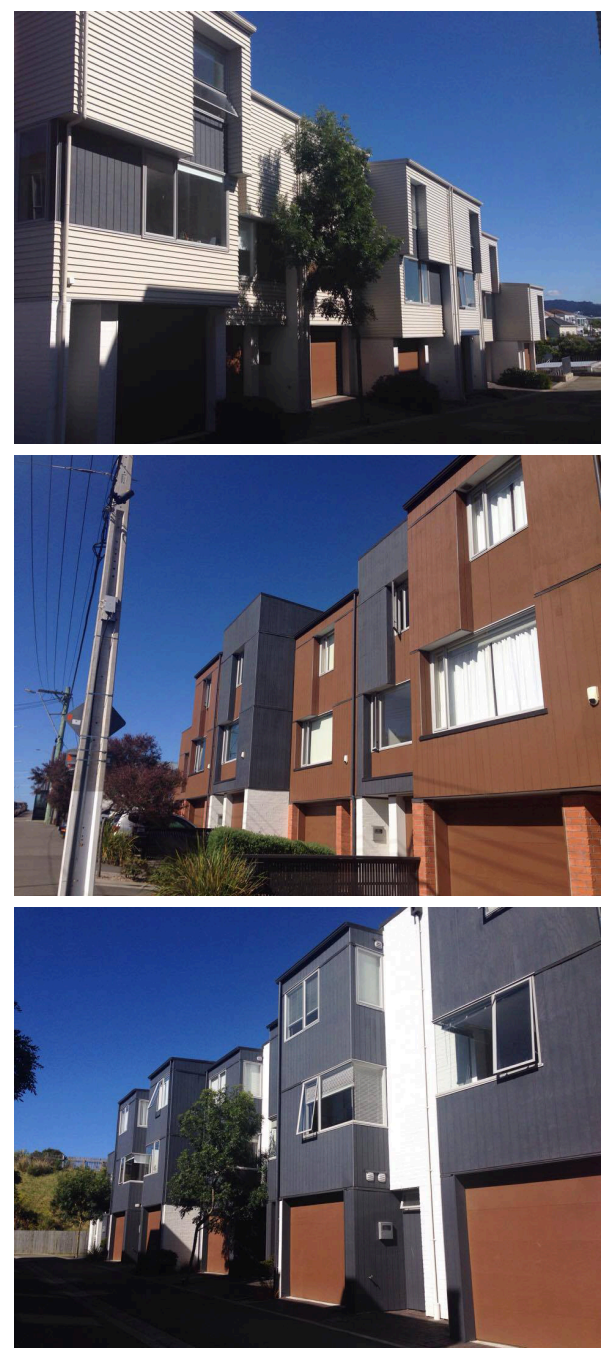

Figure 3: Photos of the Altair, showing exterior articulation.
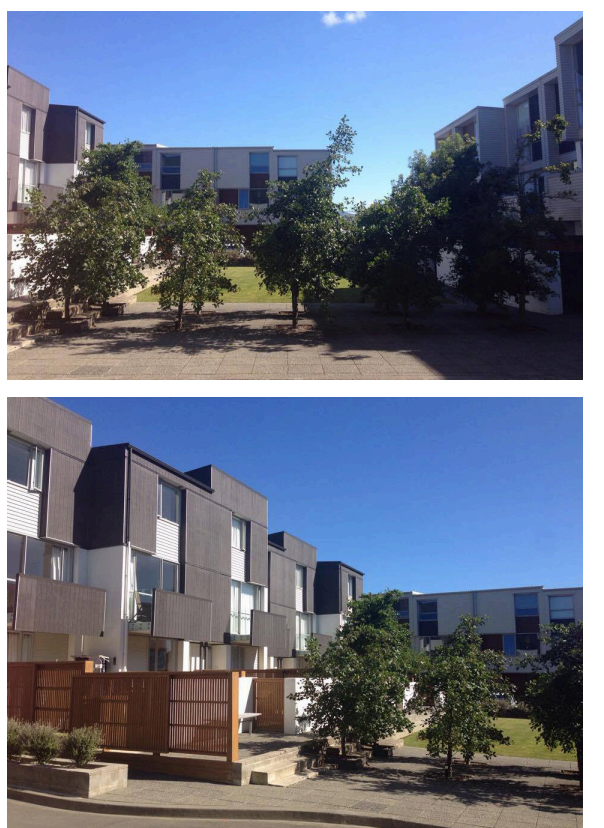

Figure 4: Photos of the Altair, showing shared open space.

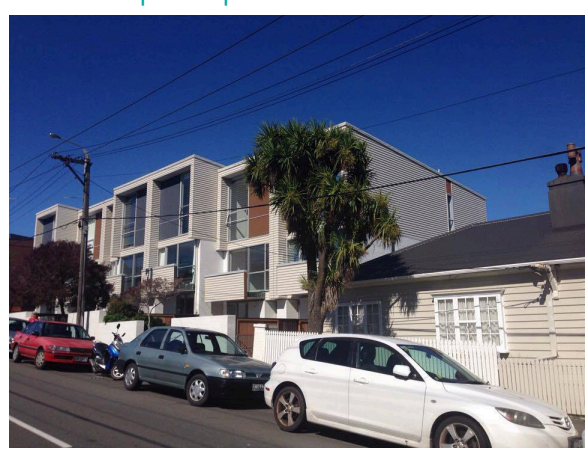

Figure 5: Photos of the Altair,showing context. 


\section{The Regent Park Apartments}

The Regent Park Apartments, also in the Newtown area of Wellington, are a social housing development by design group Stapleton Elliott (see Figures 6 and 7). The apartments are considered to be at the forefront of modern medium density architecture in New Zealand, successful in both cost efficiency and design appeal (Wellington City Council [WCC], 2012a).

While the Regent Park project has already been used as a council exemplar (Auckland City Council [ACC], n.d), and while the exemplar serves as a reference for this case study, site visits were also undertaken to make additional observations. It was concluded that, despite being governmentsubsidised housing, the apartments exemplify commercial MDH projects through their materiality and aesthetic.

\section{Town house and apartment style}

The development offers a range of unit types, from two bedroom apartments to four bedroom townhouses. The range of housing types helps to create a sense of community rather than uniformity, and building heights are also graduated throughout the site.

While the buildings all sit within a similar aesthetic, the development is small and so there is less need to vary the design style significantly. Vibrant panels of colour are carried through each building. While this may not appeal to all tastes, social housing is aimed at supporting struggling families, so the bold bright colours are helpful in creating a positive atmosphere.

Contemporary design

A flaw in the design of the Regent Park development is that it does not relate its aesthetic to the local historical context, which mainly includes Victorian-style villas and bungalows. Its scale, modern lines and strong structural elements do not compliment surrounding houses. By simply adding a pitched roof or softer façade articulation, it would potentially be more sympathetic to the context. The development is set back from the street, which does help to provide some softening of this respect.

\section{Complete redevelopment}

It is understood that in completely redeveloping the old state housing, there was opportunity to create new spaces and pedestrian connections through the site, which may have been impossible had the previous flats not been demolished. These elements provide a sense of community and ownership for the target families.

Overall, the development has achieved visual continuity and provides a cohesive space. However, a complete redevelopment involved demolishing the existing units rather than rehabilitating them. A design that was less 
severely modern may have meant that the previous units could have been deconstructed thoughtfully, with parts reused where possible.

\section{Guidelines}

The following general rules have been formulated through this case study and used in the development of the overall thesis design solution. These include:
1. Aesthetic themes are continued between unit types to create a sense of community.

2. Pedestrian connections are provided through the site.

3. The architectural style should be sympathetic to its local area.

4. Building heights are varied to avoid uniformity.

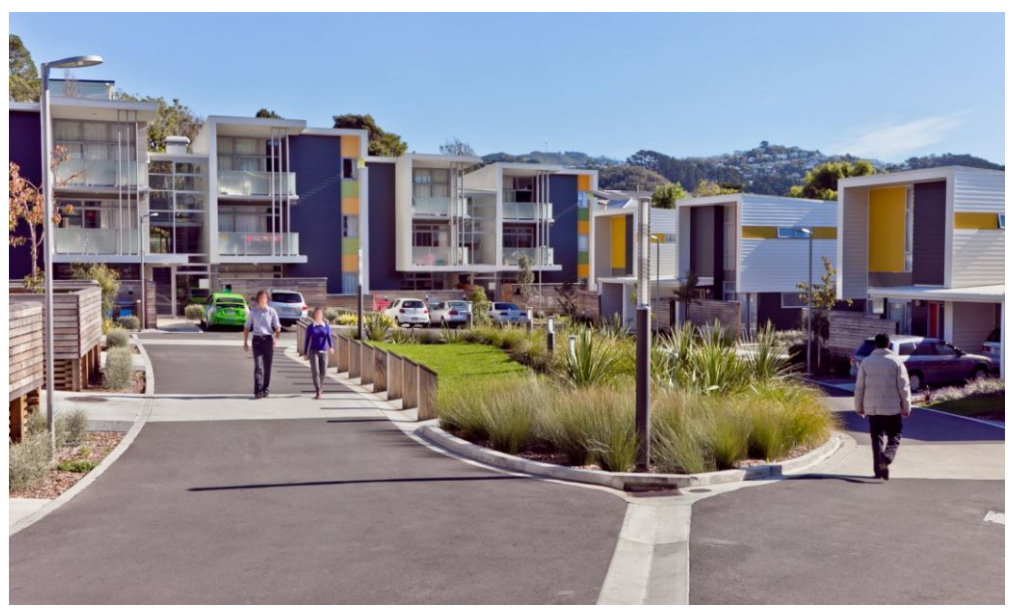

Figure 6: Regent park Internal site photo. From http://content. aucklanddesignmanual.co.nz/ADM\%2OImages/Carousel/004\%20 Housing\%20Case\%20Studies/004\%2017\%20Regent\%20Park Case\%20study_Apartments_Regent\%20Park.pdf Copyright 2017 by Auckland City Council. Reprinted with permission.
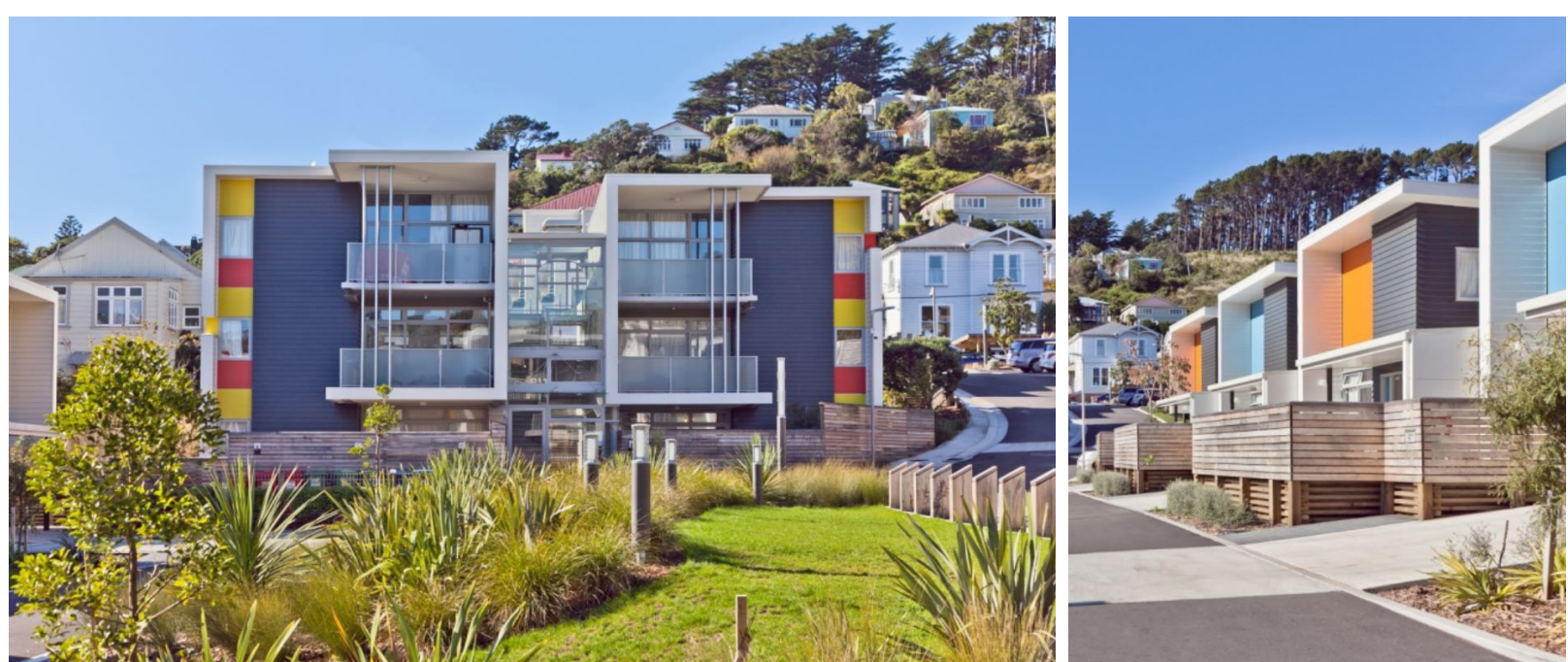

Figure 7 : Contextual site photos Regent St. From http://content.aucklanddesignmanual.co.nz/ADM\%20 Images/Carousel/004\%20Housing\%20Case\%20Studies/004\%2017\%20Regent\%20Park/Case\%20study Apartments_Regent\%20Park.pdf Copyright 2017 by Auckland City Council. Reprinted with permission. 


\section{Hobsonville Point}

The Hobsonville Point development focuses on idyllic suburban living. Located on an Auckland peninsular, it involves the construction of 4500 homes and many amenities, including new primary and high schools (see Figure 8). Land is divided into precincts, each with its own character. Low density housing is offered, as well as medium/high density living that is nonintrusive and keeps within the suburban ideals (Hobsonville Land Company Limited, 2016).

Design

Many architecture companies are involved in the Hobsonville Point development, so no single architect or firm has ruling authority. However, architects for Hobsonville Point typically design entire blocks at a time, which helps to create cohesiveness, harmony and character (although sometimes leads to rows of 'cookie-cutter' houses that all looks the same from the exterior). A language of colour is evident throughout the development, inspired by the coastal landscape and overseen by a review panel of design industry experts who give final approval to every plan. As explained by Melanie Yonge, architect and colour consultant for Hudsonville Point, "people want somewhere that has its own identity and its own beauty" (Hobsonville Land Company Limited, 2016, p. 25).

\section{Affordability}

Of the Hobsonville Point homes currently on the market, the lowest valued property is a $67 / \mathrm{m} 2$, one bedroom and one bathroom house at $\$ 649,00$. The most expensive is $245 / \mathrm{m} 2$, with five bedrooms and three bathrooms, at $\$ 1,850,000$. (Hobsonville Land Company, 2017). These are not affordable homes and are a poignant example of the current housing crisis, which is particularly problematic in Auckland. It appears little effort was made to include additional affordable housing options in the area.

\section{Sustainability Rules}

The master planners for this substantial development have ensured that building partners are designing and building for a sustainable future. They have developed seven rules that must be followed in every new house (Hobsonville Land Company Limited, n.d):

1. Heat pump or solar hot water heating.

2. Insulation levels above the building code, plus double glazing .

3. Energy efficient lights.

4. A tank to catch rainwater, for use in toilets and gardens. 
5. Water efficient showers, toilets and taps.

6. Fold-away washing lines, to reduce dryer usage.

7. Positioning so that the house faces the sun.

These rules are a very positive aspect of the development. However, they could have been pushed further to include material sustainability, as a development of this size would provide extensive economies of scale for sustainable products (Hobsonville Land Company Limited, n.d) .

\section{Guidelines}

The Hobsonville Point case study highlighted several points that formed rules for the design component of this thesis. These include:

1. Diverse housing types are offered.

2. Colour concepts give the area a sense of place and tie into the natural landscape.

3. Affordable, entry-level housing must be provided.

4. Material use must be sustainable and controlled.

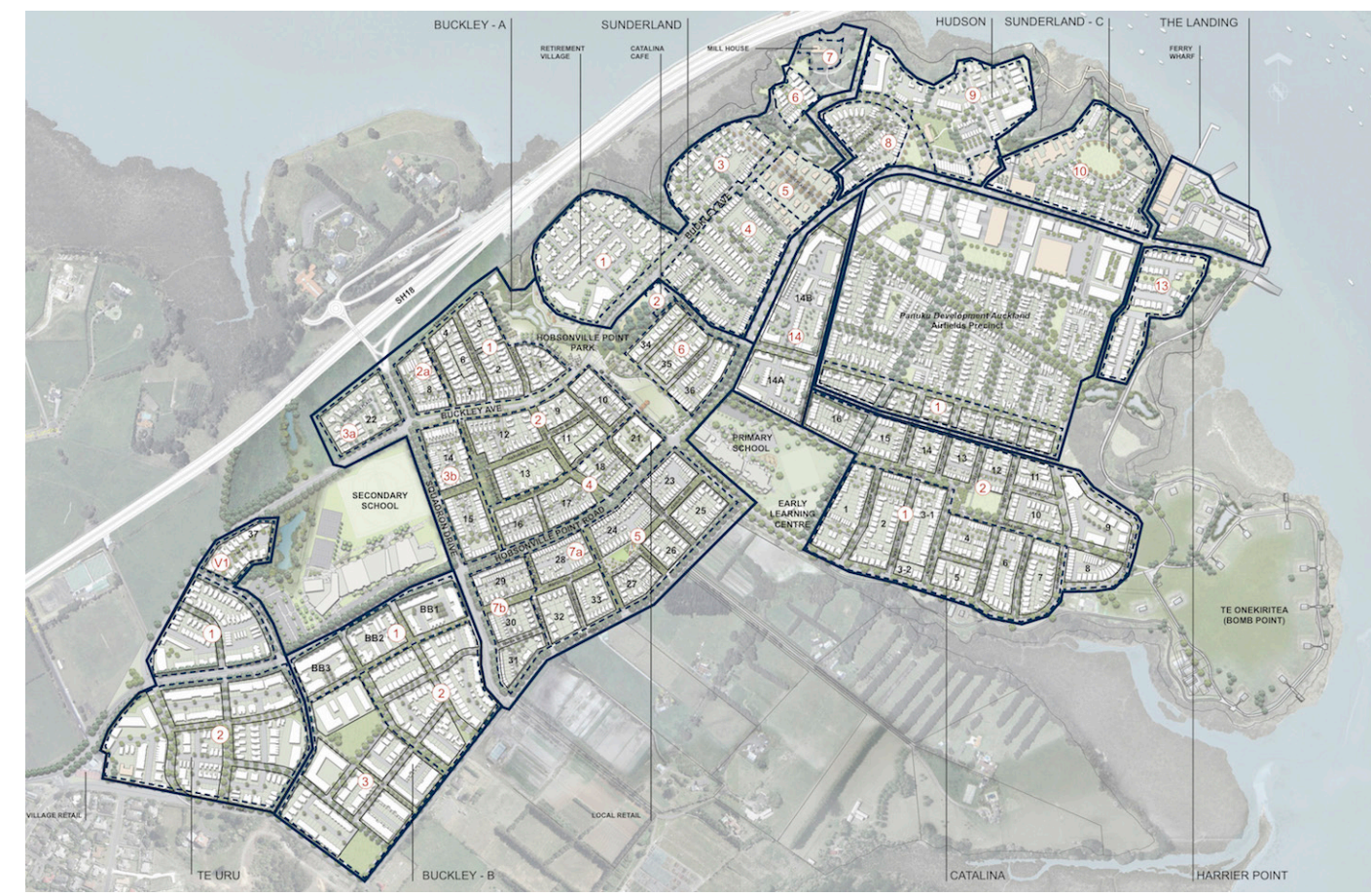

Figure 8: Hobsonville point development plan. From http://www.hobsonvillepoint.co.nz/ vision/precincts Copyright 2017 by Hobsonville Land Company Limited. Reprinted with permission. 
The site for this design project will be the vacant plot of land on the corner of Rugby and Tasman Streets, in the Wellington suburb of Mount Cook. This site was long held for a supermarket development by Foodstuffs, but was eventually sold to the Chinese Embassy in 2015, who have not yet repurposed it (Jackman, 2014) (see Figure 9).

Although purely theoretical, this design project is based on real industry costs and presents a concept that may be achieved on the site if the opportunity was available. The site sits within an area that has already been ear-marked for intensification (Wellington City Council [WCC], 2014), so a development of this kind would fit within the real-world situation.

\section{City selection}

Two of the chosen case studies are based within the central Wellington area. It was therefore important that the chosen site was similarly located, to control for environmental and contextual factors and ensure reliable comparisons could be made.

Wellington was also chosen because the researcher is a local with an existing understanding of the Wellington climate, housing typologies, and market, as well as specific knowledge about life in Wellington's medium density housing.
Compared with Auckland, medium density housing units are more affordable in Wellington. Statistics show that "Wellington average home asking prices per square metre have fallen 2.6 percent since 2013, compared to Auckland's, up more than 75 per cent in that time" (Gibson, 2015, para. 1).

While the housing situation in Wellington is not yet as desperate as in Auckland, the city's population is expected to grow by around 50,000 people over the next 30 years (WCC, 2014). The Wellington City Council has put forward an 'Urban Growth Plan' that aims to manage population growth, and an aspect of this plan is intensification of housing around suburban centres (WCC, 2014). This design project therefore targets a need for more information on how future urban planning needs could be met sustainably and affordably.

\section{Site selection}

The chosen site was selected for its large and relatively clean slate, from which a substantial development could be investigated from a number of architectural considerations (see Figures 10-26).

The topography of the site varies significantly from one side to the other, presenting challenges that any Wellington architect would face. It was concluded that if a medium density development could work on a difficult 
site, then it could work almost anywhere. The elevated topography also capitalises on views of the harbour and hills surrounding the city (see Figure 22).

The land borders Tasman, Rugby and Belfast streets, meaning multiple streetscapes needed to be developed in a way that complemented the surrounding residential housing. This created a perfect opportunity to consider the place of cultural significance in modern architecture.

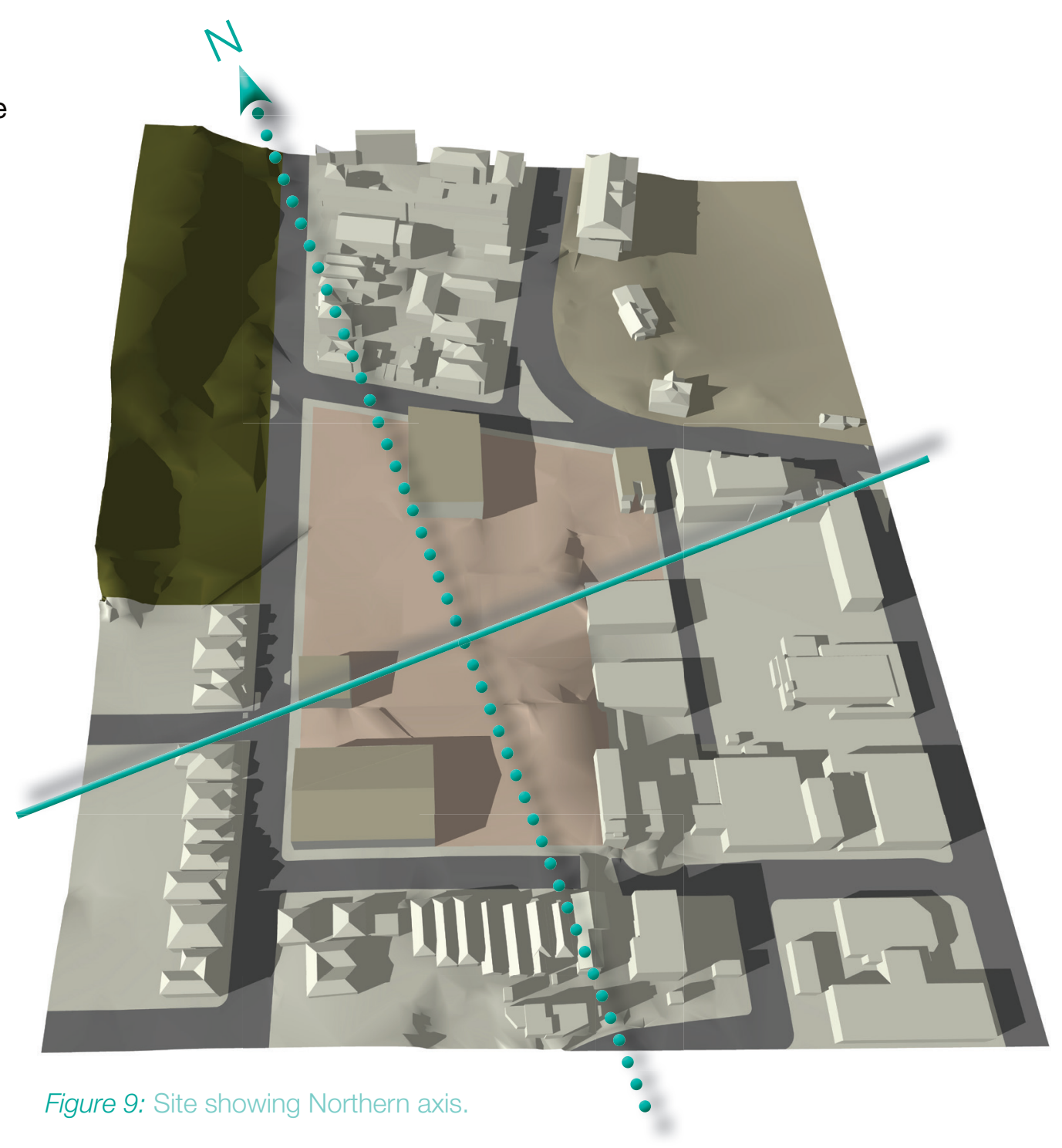




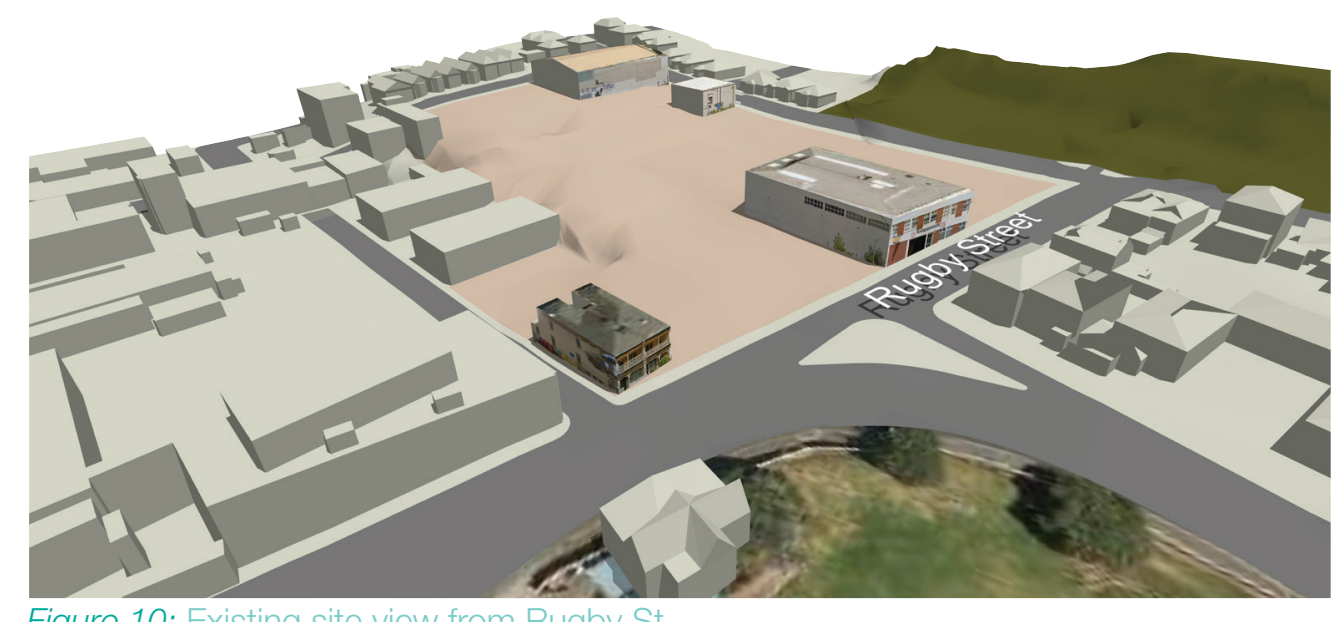

Figure 10: Existing site view from Rugby St.

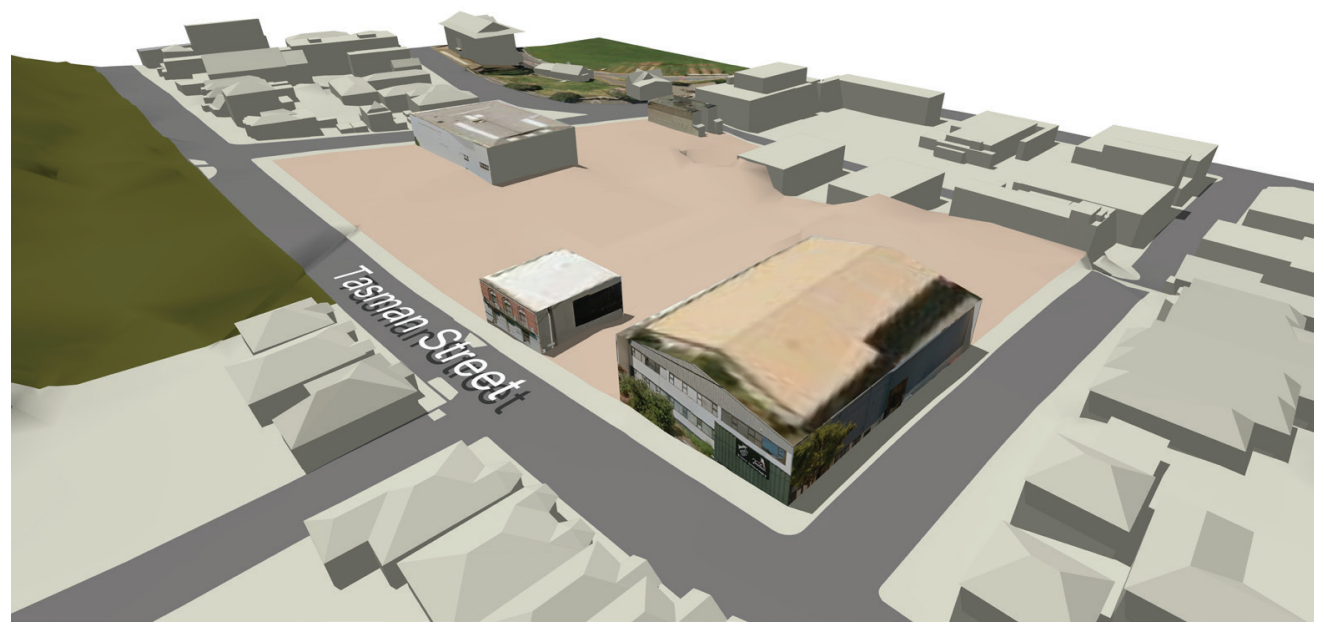

Figure 11: Existing site view from Tasman St

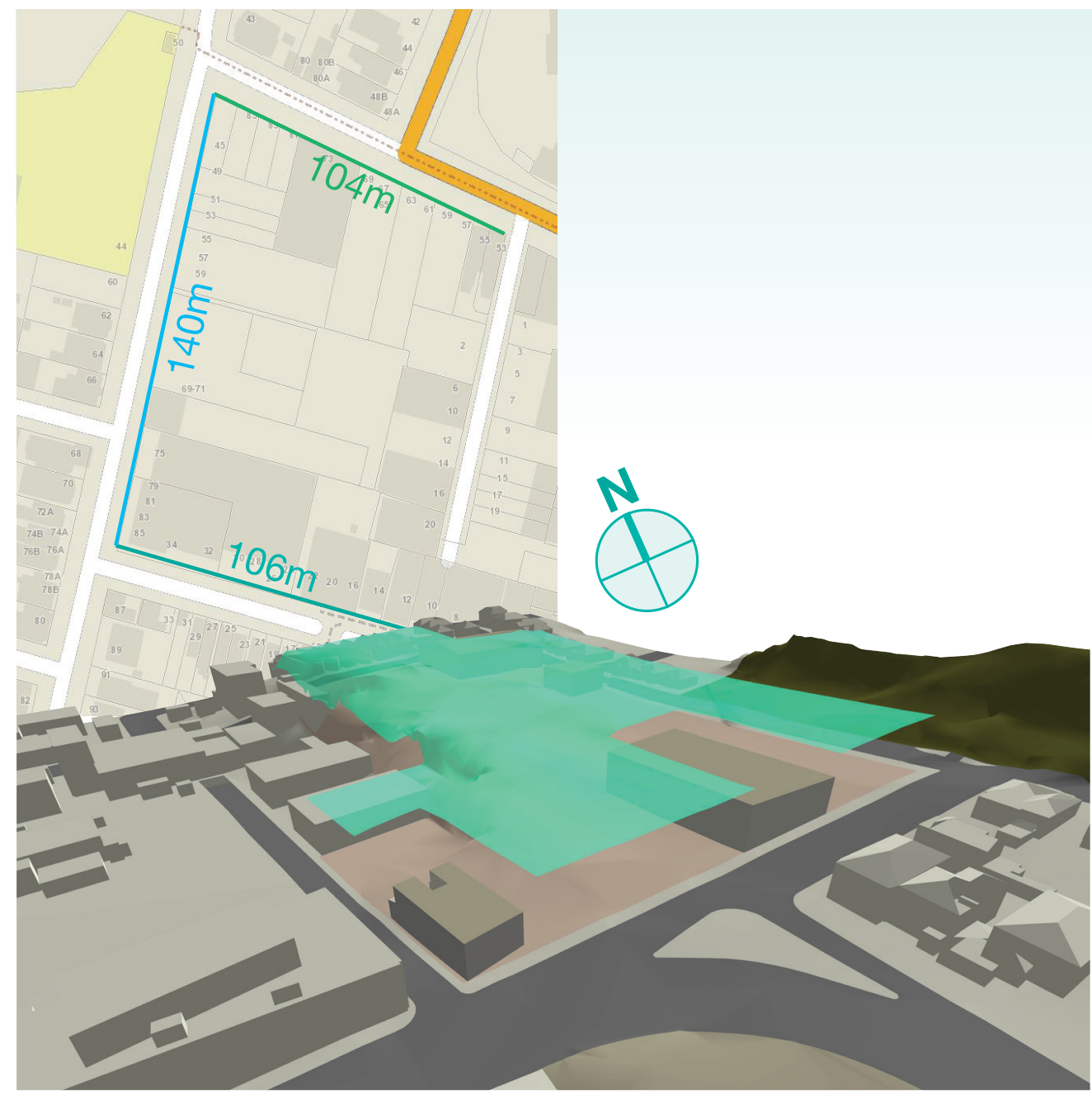

Figure 12: Existing site with $12 \mathrm{~m}$ height limit. 


\section{Shading: last minutes of sunshine}
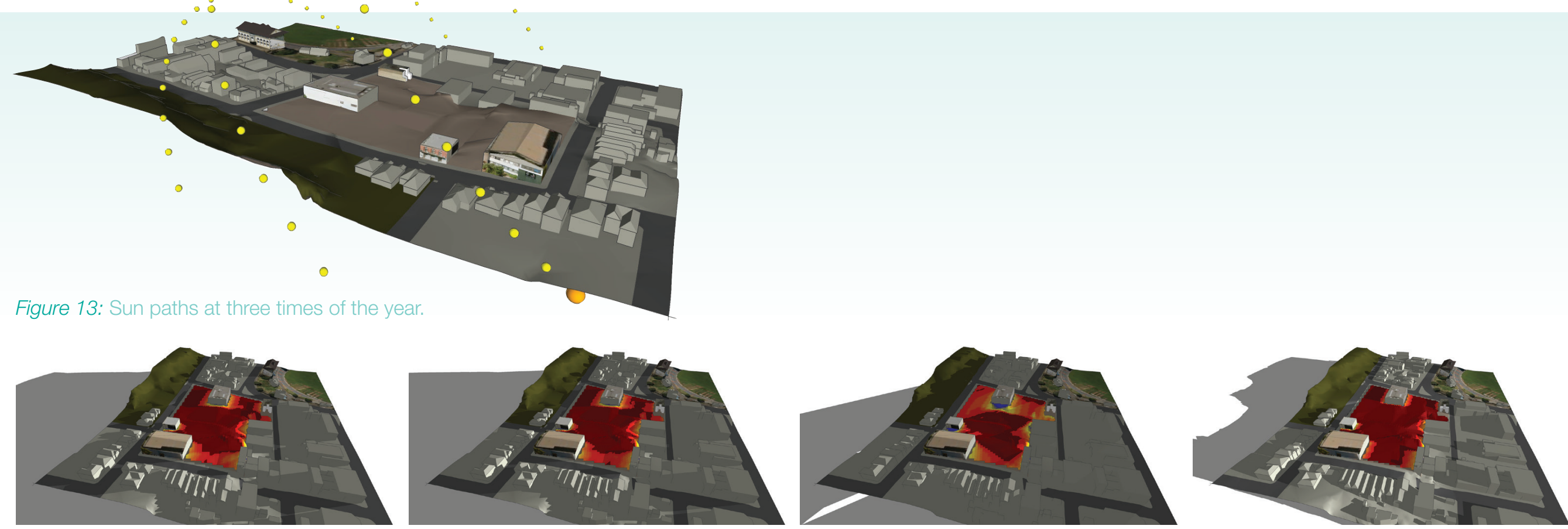

Figure 14: September equinox 7 am.

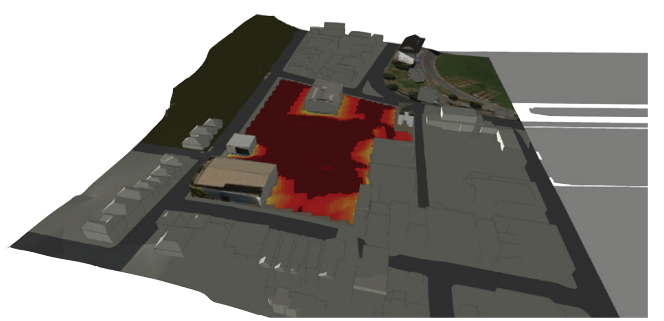

Figure 18: September equinox 6pm
Figure 15: March equinox 7 am.

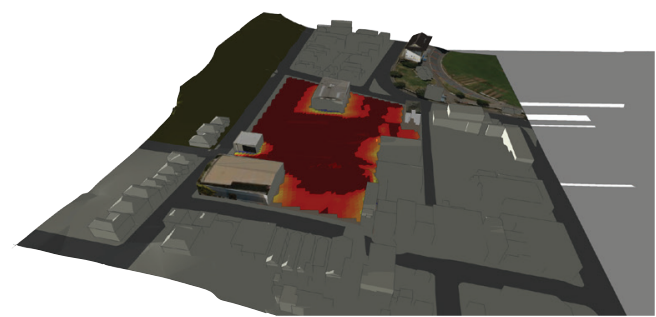

Figure 19: March equinox 7:10pm.
Figure 16 June winter solstice 8 am.

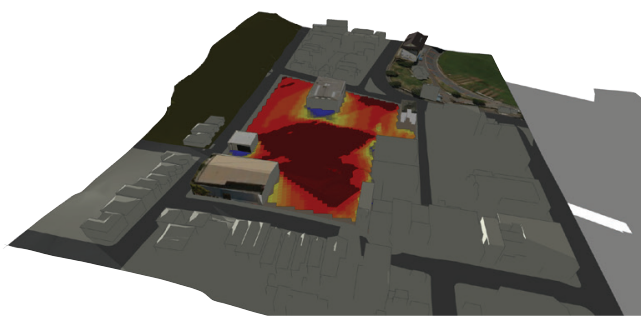

Figure 20: June winter solstice 4:30pm.
Figure 17: December summer solstice 7 am.

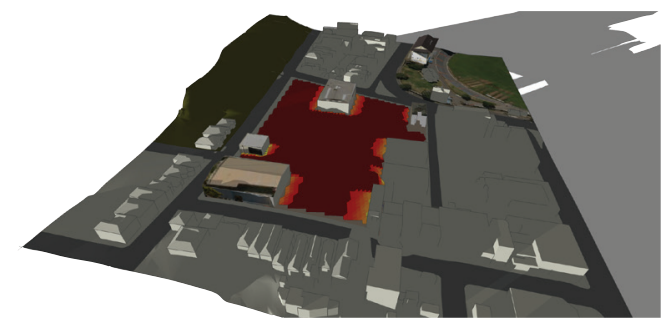


Lines of Sight

Key:

- Primary

- Secondary

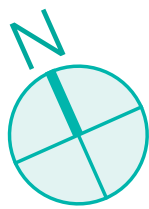

Figure 22: Existing site view points.
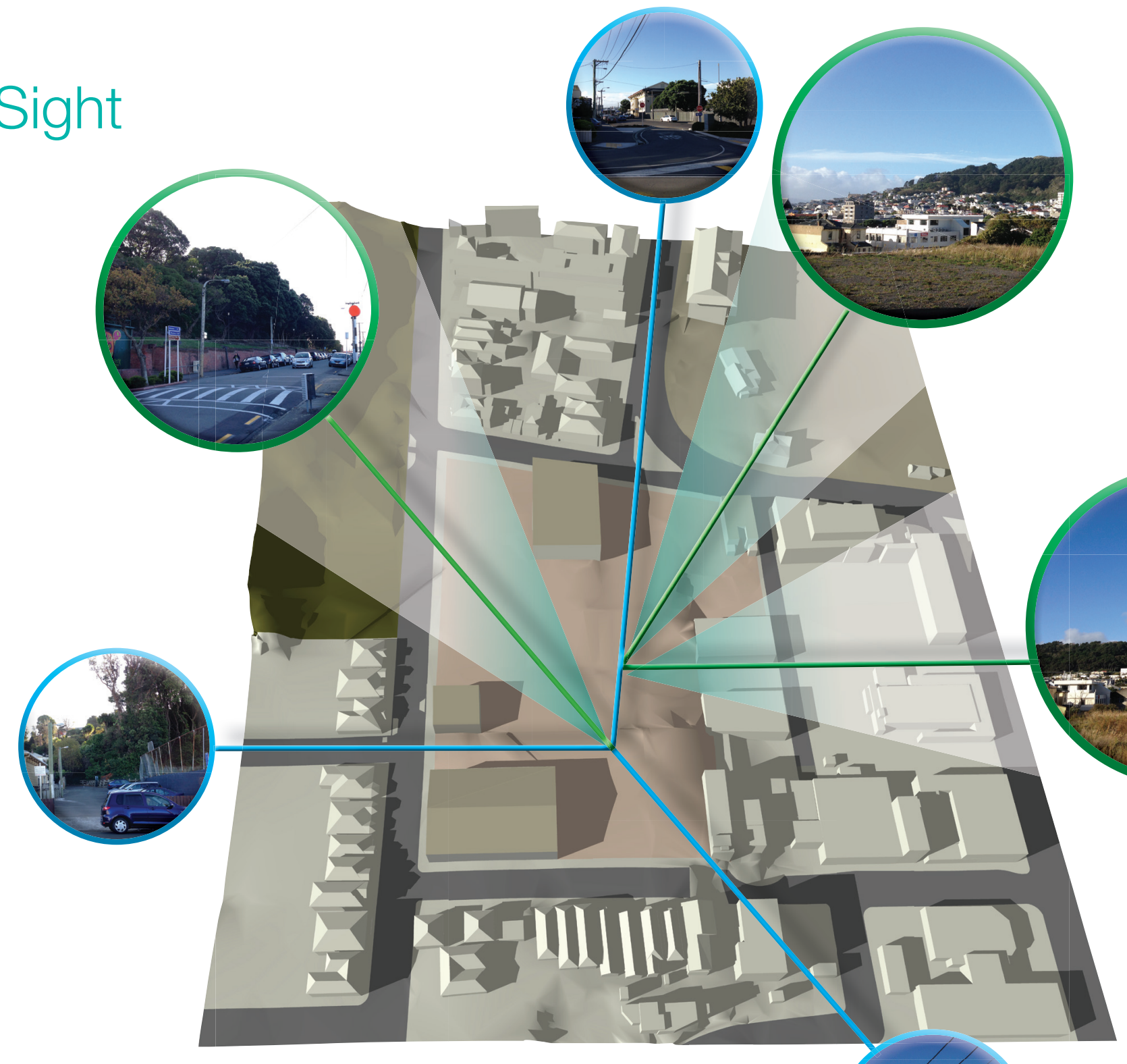

ris.

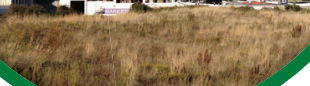

(2) 
Pedestrian Routes
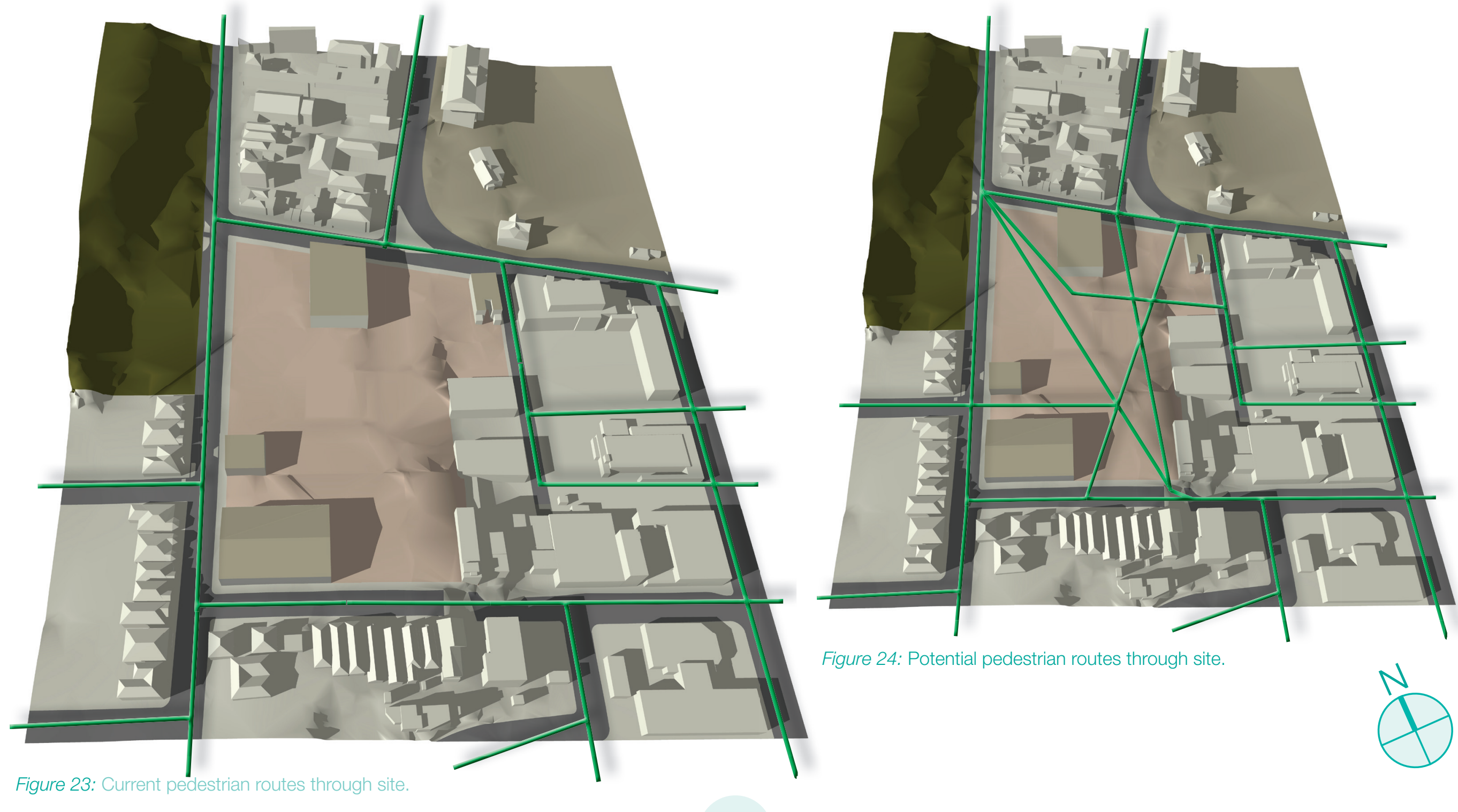

Figure 24: Potential pedestrian routes through site. 
Vehicular Routes

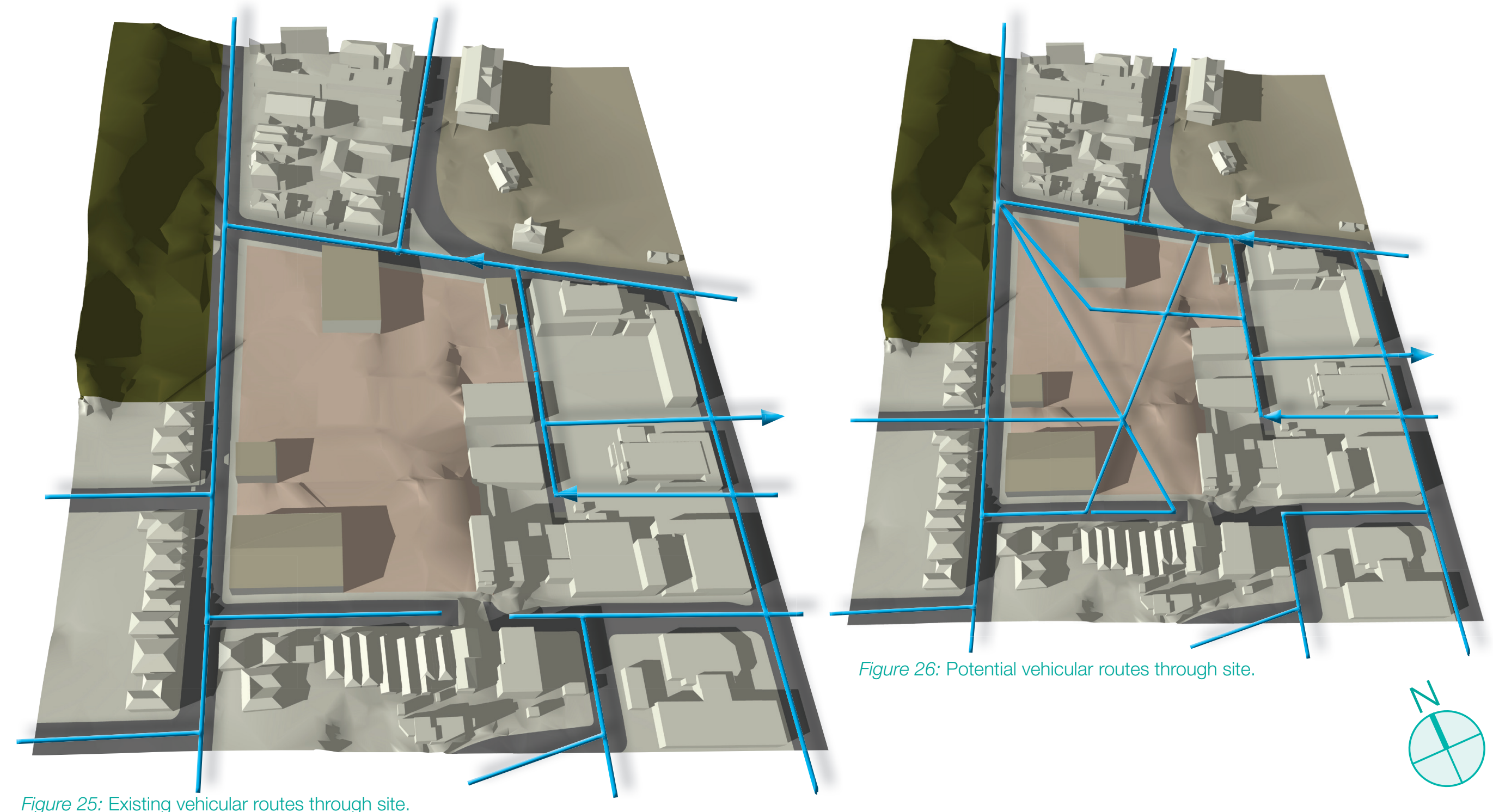


There is a distinct architectural character across houses in the central Wellington area, consistent in building style and materials. This is derived from a high concentration of villas and cottages, originally designed as low cost housing in the early 1900's (see Figures 27-29). Development in Mt Cook started in the 19th century, with the most intense construction period between 1900 and 1920 (WCC, n.d). Since then, changes have been minor and the late-Victorian/Edwardian buildings continue to prevail. Preservation of this historical character was important to this design project, so the significant features around the site location were analysed (see Figure 30). These are outlined below:

\section{Period feature observations}

- Small-scale detached dwellings.

- Symmetry and balance.

- Large windows in pairs or threes. Bay windows are common.

- Hipped or gable roofs. Steep roof pitch on smaller dwellings.

- Pressed metal ceilings internally and under balconies.
- Intricate ornamental fretwork and detailing.

- Front verandas act as a public-private barrier.

- Low picket fencing.

- Garages uncommon, but typically located on high side of street.

Most older buildings are generally in good condition and remain unchanged. A few new developments are also present, in the form of multi-story apartment blocks. These tend to contrast against the original houses.

\section{Material observations}

- Painted weatherboard exterior walls, mostly light in colour.

- Corrugated iron or shingled roofing.

- Some brick housing. 
- Topography is a dominating feature and accounts for the variation in street edge definition.

- The elevated side of Tasman street is visually dominant, with houses set back further from the road.

- Lower sides of surrounding streets are less dominant and roofs are the main streetscape feature.
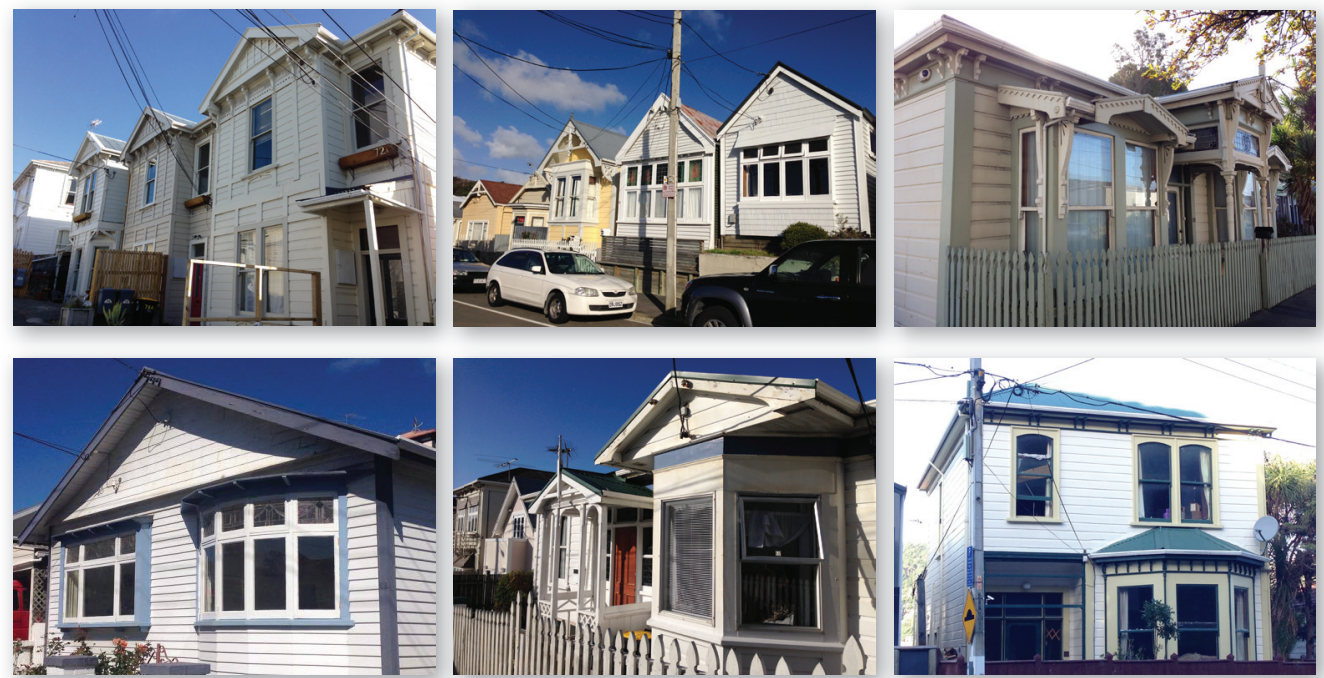

Building sizes (WCC, n.d):

- Building width 7-9m

- Building length $10 \mathrm{~m}$

- Side yards $1.2-2.4 \mathrm{~m}$

- Rear yards 6-15m

- $30-45 \%$ site coverage
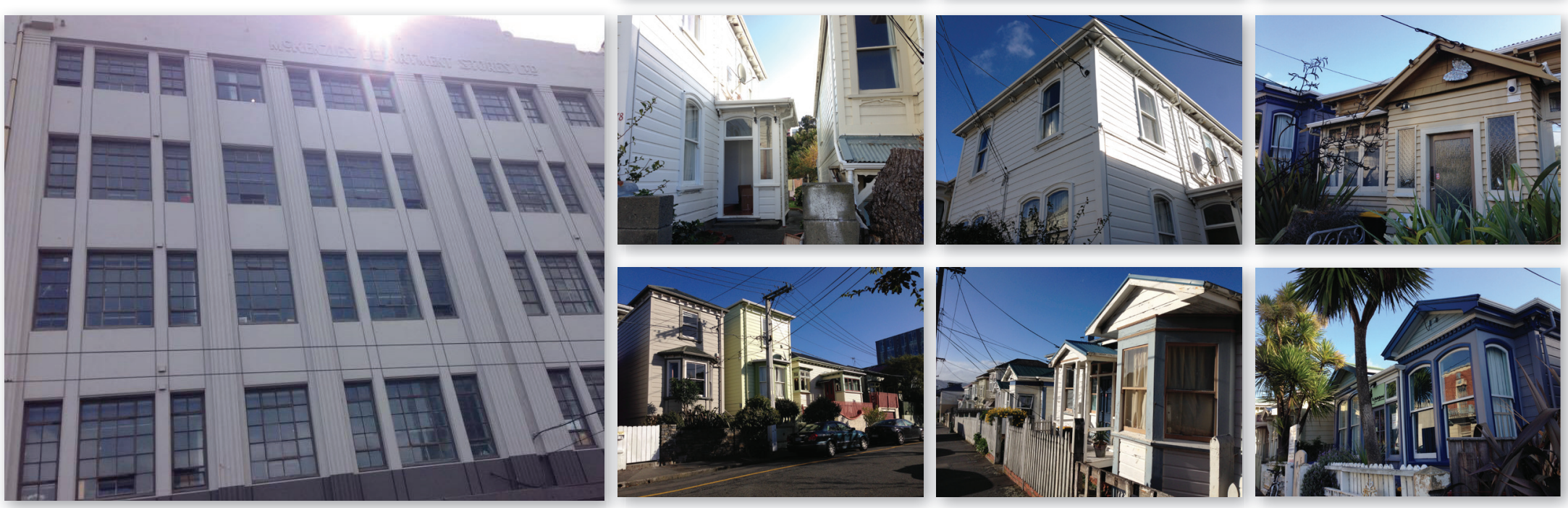

Figure 27: Contextual photos of character houses.
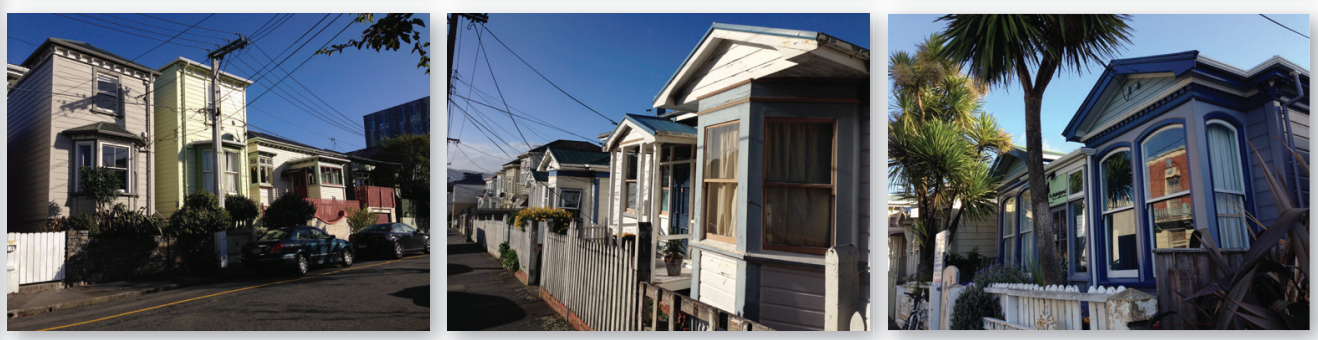

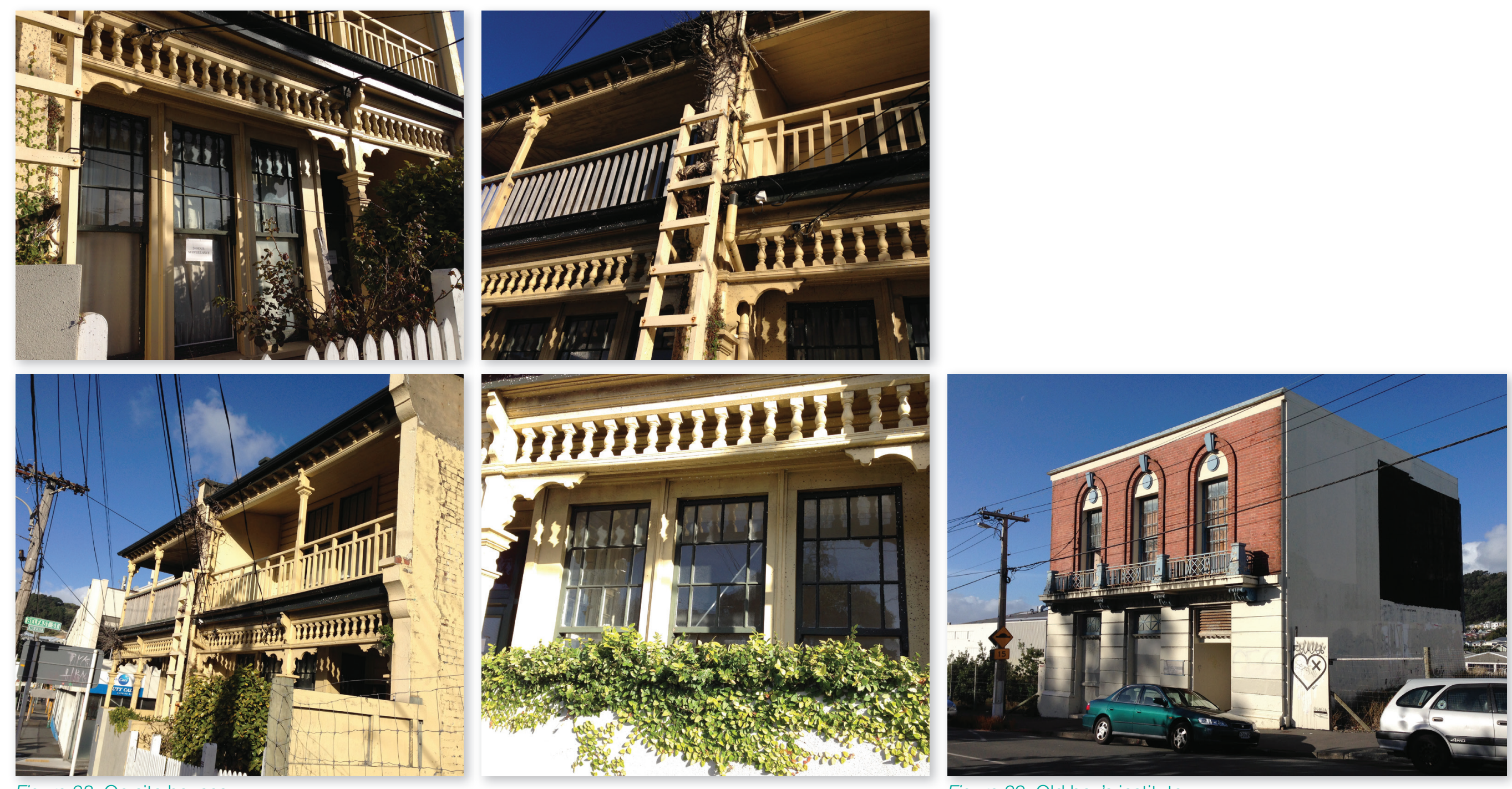

Figure 28: On site houses. 


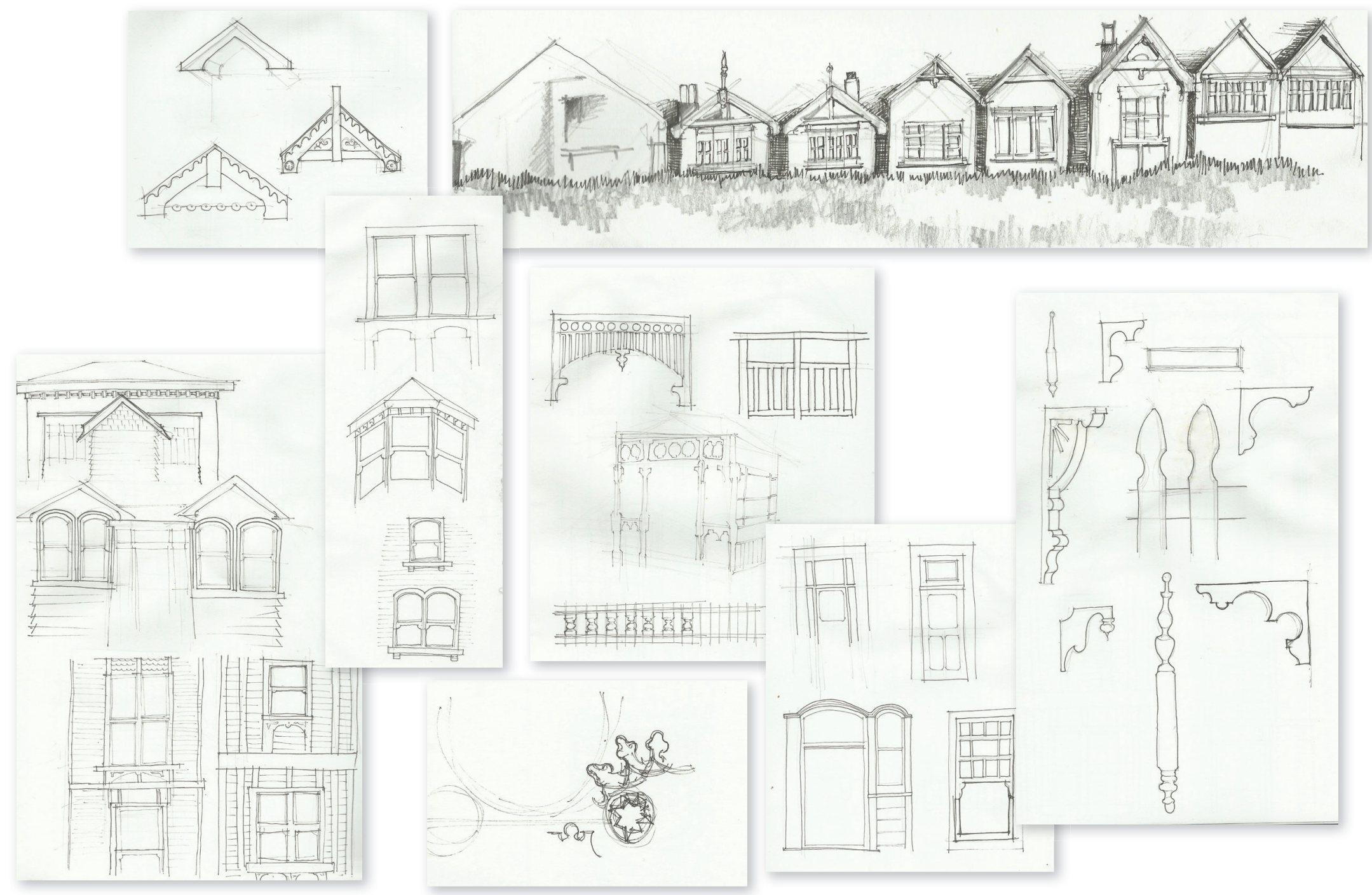


With advancements in public transport and online shopping, carparks can be an unnecessary constraint on multiunit developments. Around the site location, the last New Zealand Census found that $38.1 \%$ of households in the Mount Cook area did not own a car, a decline from previous years (Statistics New Zealand [SNZ], n.d) (see Table 3). As such, the decision was made to keep car parking facilities to a minimum in this design project. Located a short walk or bus ride from anywhere in the central city, the site location easily caters to the many professionals and other workers based in the CBD (see Table 4). This not only encourages a more active and environmentally-friendly lifestyle, but also creates a safer and more enjoyable site for the inhabitants.

Market research also found that there was a need for single-person living in the area, with $30 \%$ of Mt Cook's households containing only one person in 2013, the most dominant household size in the area (SNZ, n.d)

(see Table 5, 6 and 7).

\section{Market Research}

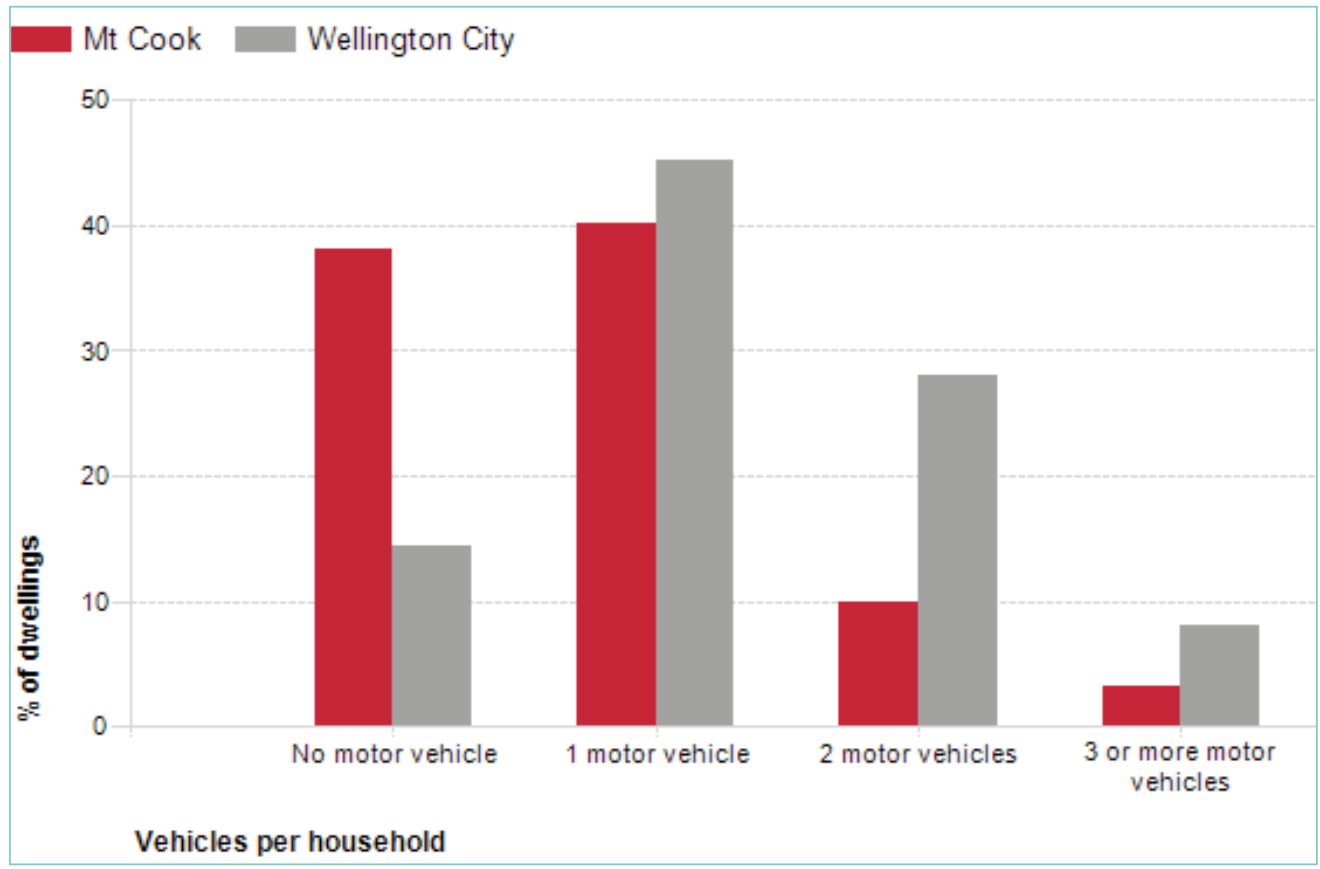

Table 3: Car ownership 2013 in Mount Cook.

Retrieved from http://profile.idnz.co.nz/wellington/carownership?WeblD=300 Copyright 2017 Statistics New Zealand. Reprinted with permission. 


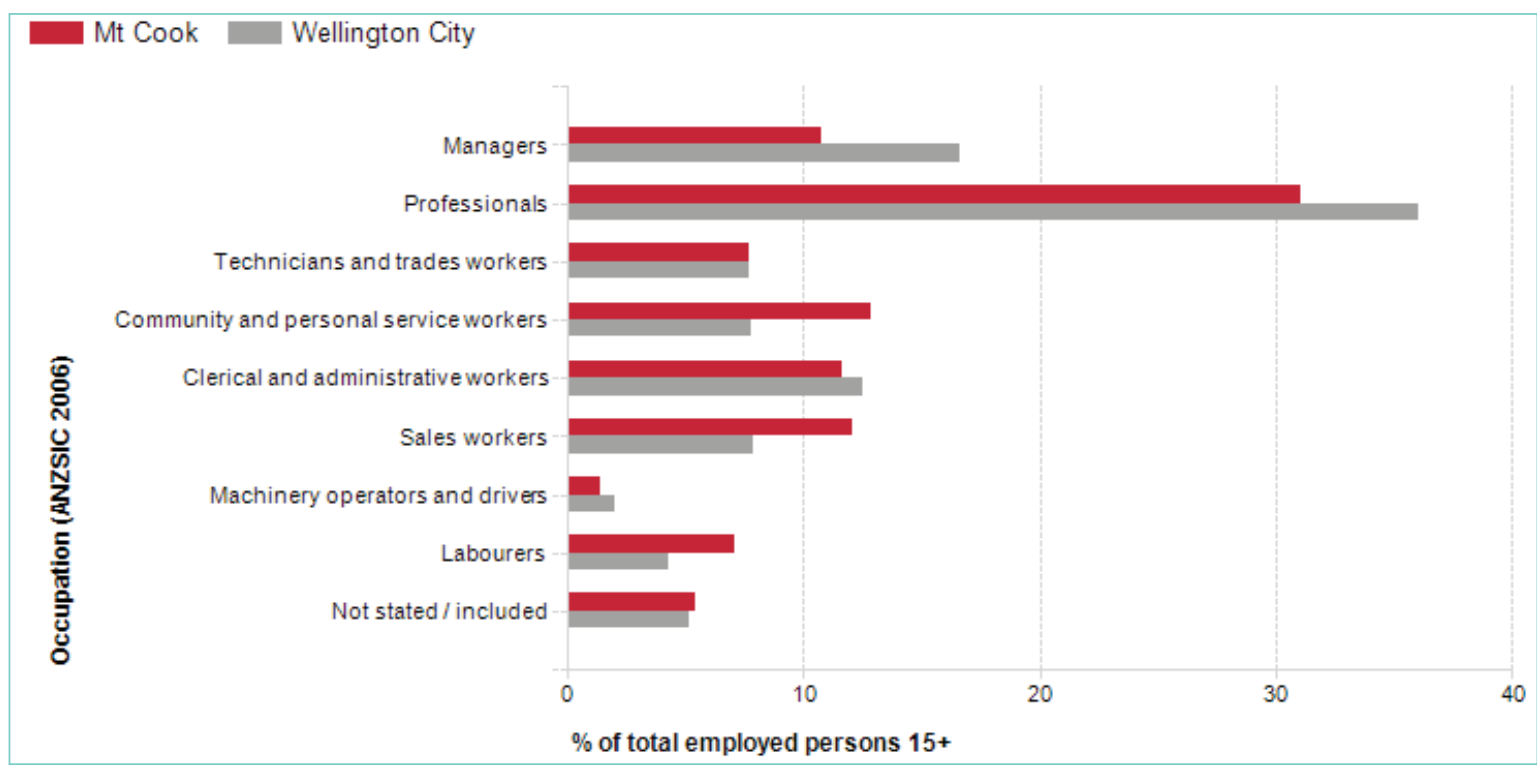

Table 4: Occupation of employment 2013 in Mount Cook. Retrieved from http://profile.idnz.co.nz/wellington/ occupations?WebID=300 Copyright 2017 Statistics New Zealand. Reprinted with permission.

Mt Cook Wellington City

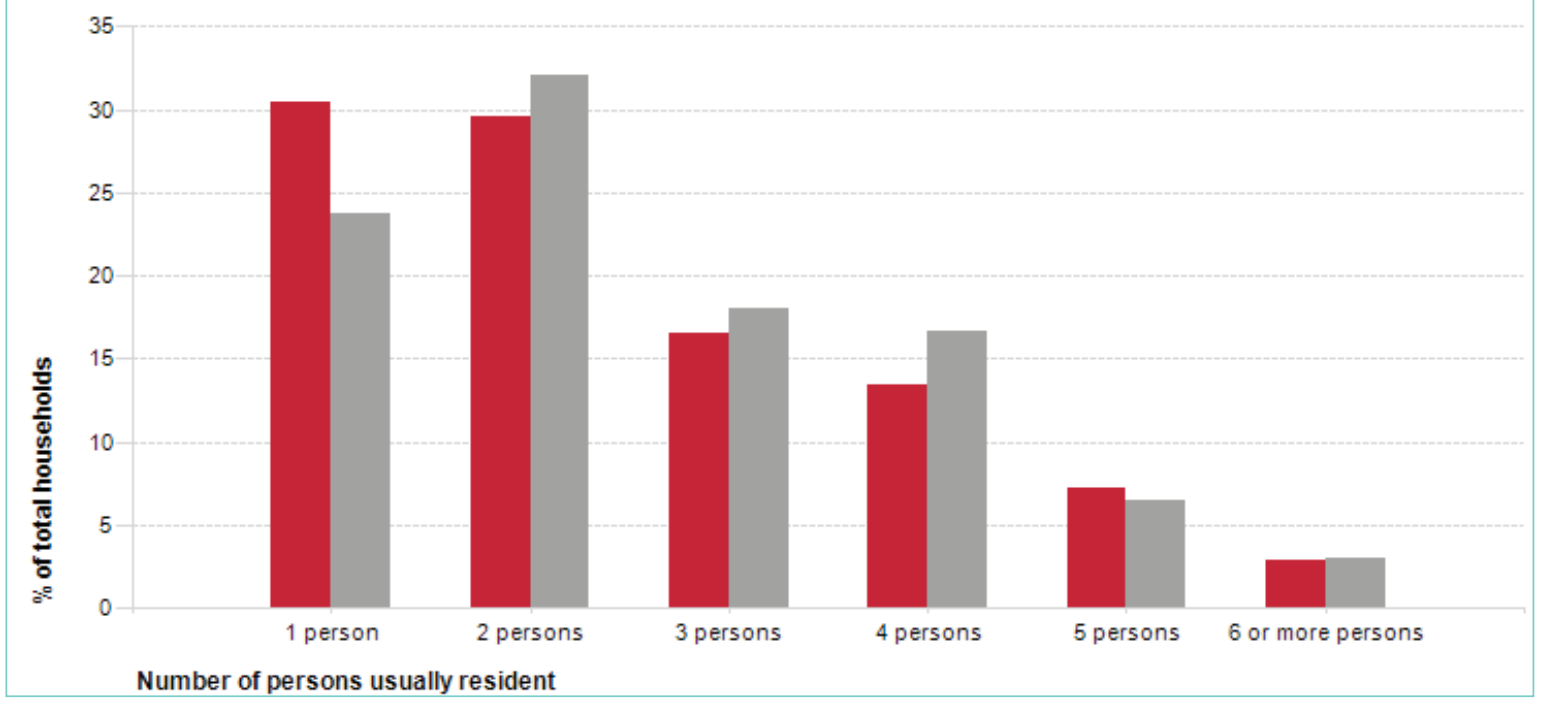

Table 5: Household size 2013 in Mount Cook. Retrieved from http://profile. idnz.co.nz/wellington/householdsize?WebID=300 Copyright 2017 Statistics New Zealand. Reprinted with permission. 


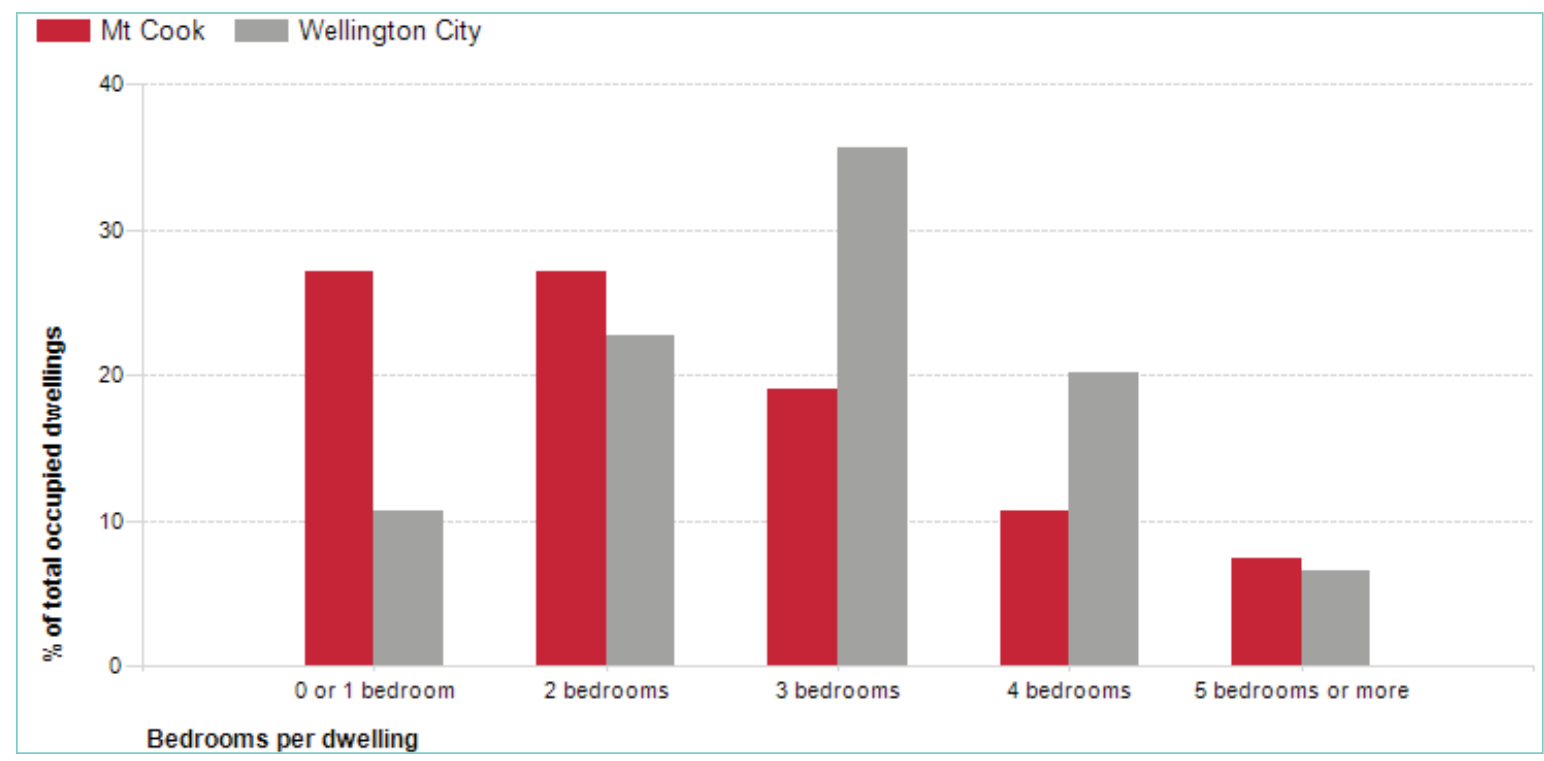

Table 6: Number of bedrooms per occupied dwelling 2013 in Mount Cook. Retrieved from http:// profile.idnz.co.nz/wellington/ bedrooms?WebID=300 Copyright 2017 Statistics New Zealand. Reprinted with permission.

Mt Cook Wellington City

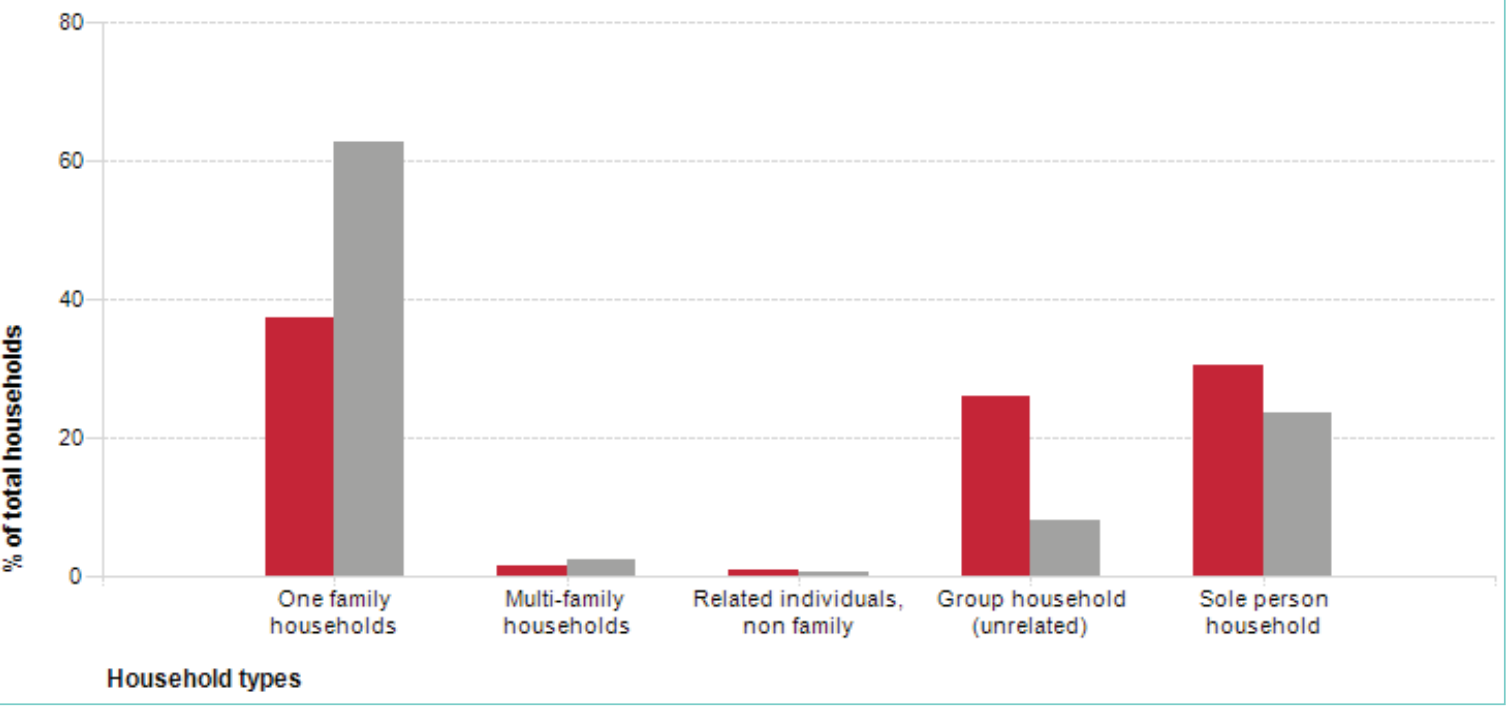

Table 7: Household types 2013 in Mount Cook. Retrieved from http://profile.idnz.co.nz/wellington/ households?WebID=300 Copyright 2017 Statistics New Zealand. Reprinted with permission. 


\section{Stage 1-Design Process}

\section{Style Direction}

The style direction for this project fits the aesthetic of contemporary residential architecture, while also modernising historical characteristics and components. Traditional gable and lean-to roofing concepts are explored, natural materials such as timber and clay bricks are reimagined, and features such as the bay window and architectural detailing have also been articulated (see Figure 31). The overriding reason for this approach comes from a personal philosophy that understands cities should respond to the contemporary period, but remain respectful to the past.
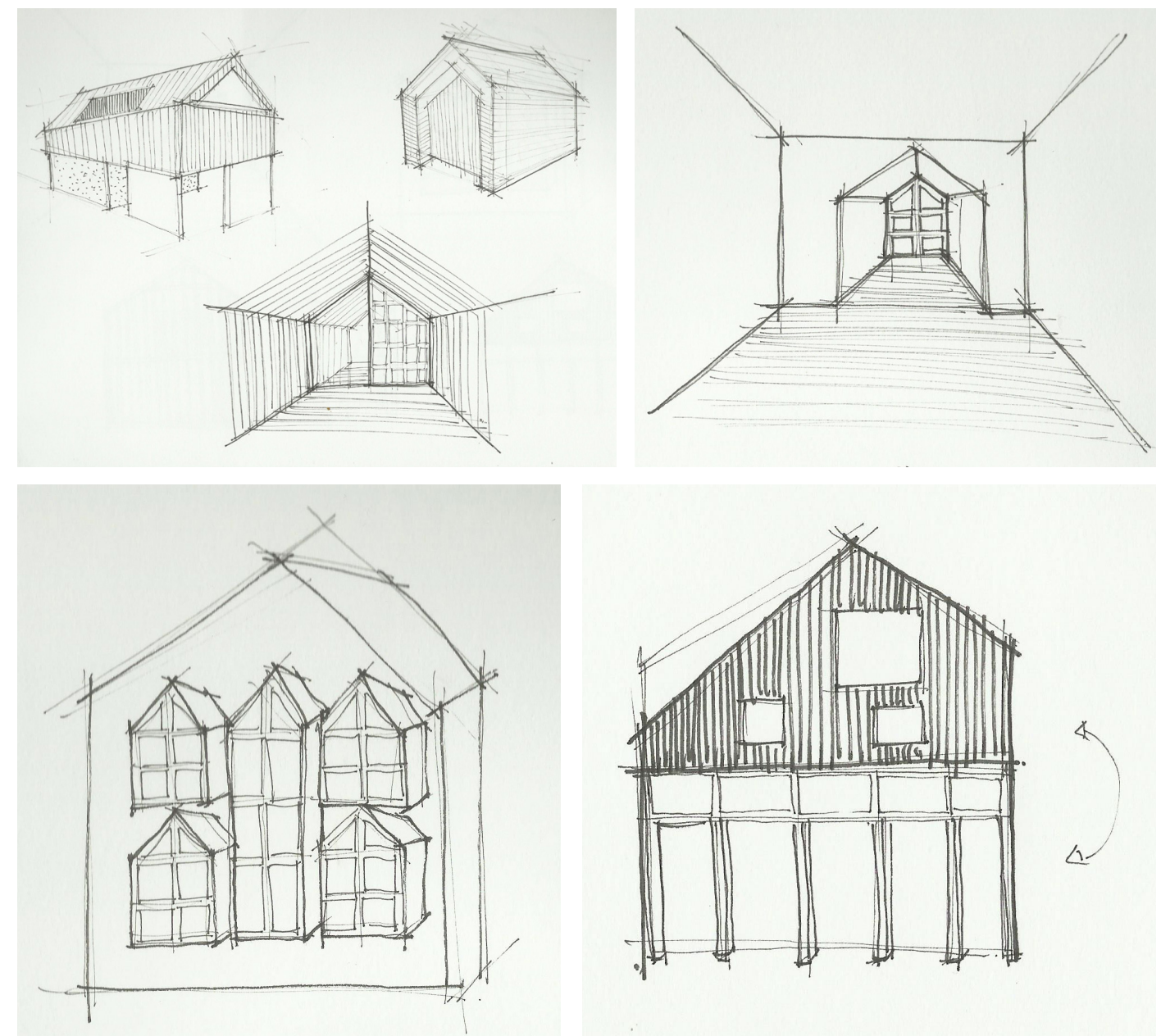
In the very first stage of design it was thought that a typical unit could be extracted from a case study and then reinterpreted with sustainable concepts. However, due to intellectual property concerns, it was decided a new base model needed to be designed that would consider sustainable principles and materials from the very beginning (see Appendix A for additional concept sketches).

Terraced housing allows for material efficiency within inter-tenancy walls and reduces the built footprint. However, initial exploration of the unit structure questioned the rectangular massing that is typical of terraced housing. $\mathrm{MDH}$ tends to be uninspired in terms of form and architectural significance. Creating slight protrusions and extrusions in the basic rectangular shape provided opportunities for architectural moments (see Figures 32, and 33), as demonstrated in the Altair case model.

The initial planning for the 2, 3, and 4 bedroom units was done in three dimensions because the designer felt that the spatial relationship could be better visualised and it was clearer where alterations needed to be made (see Figures 34-37). At this stage, it was determined that the base level of all units would house the living, dining and kitchen functions. This enabled the most efficient flow from the interior to the exterior for family living. A direct connection from indoor to outdoor living areas gave the illusion of more

\section{Initial Unit Configuration}

space. Further investigation of architectural moments also led to the design of upstairs balconies, where there was the potential to create additional outdoor spaces with more privacy. 


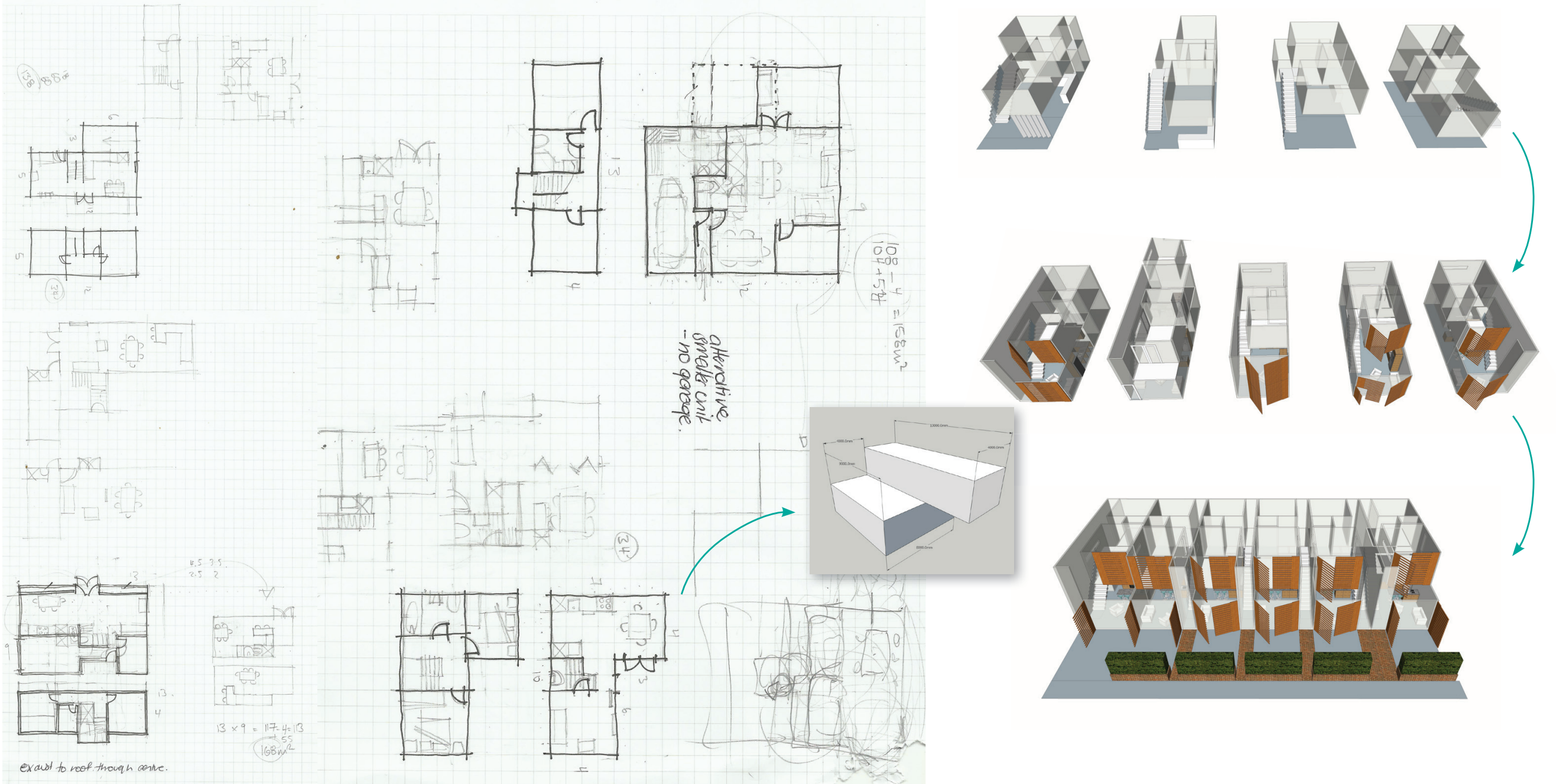

Figure 32: Initial 2D sketch unit planning.

Figure 33: Initial 3D sketch unit planning. 


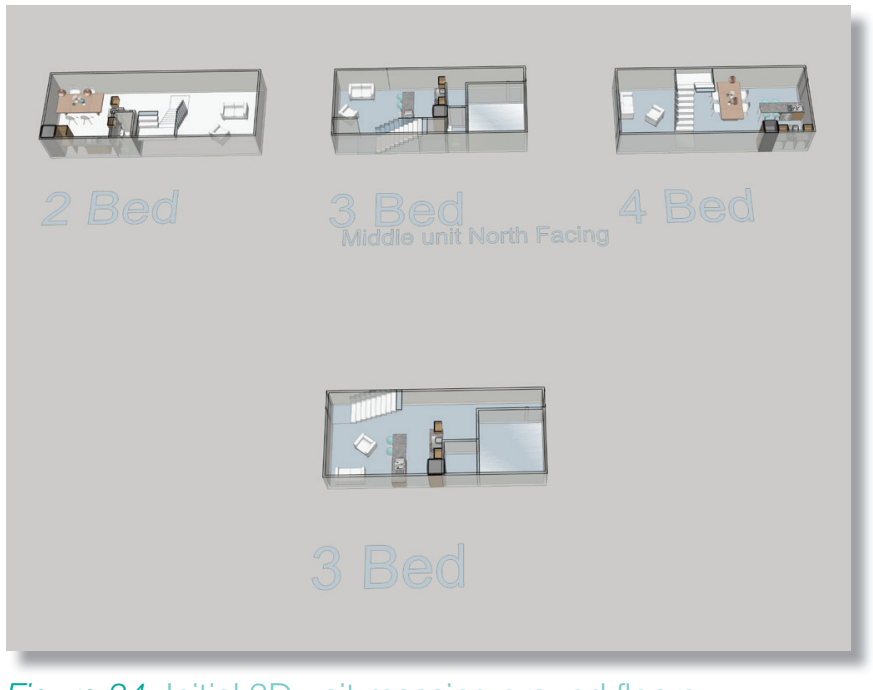

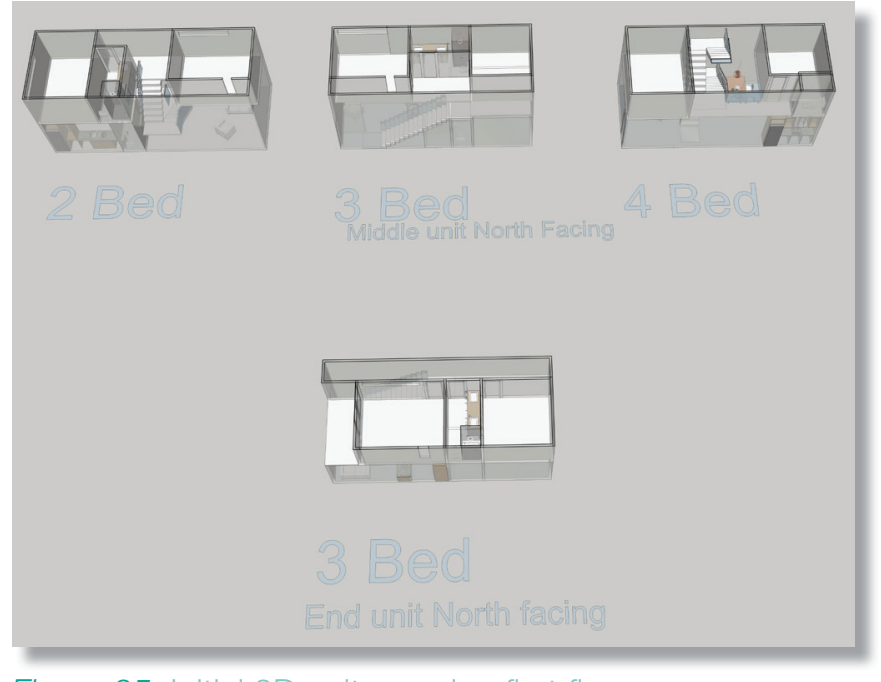

Figure 35: Initial 3D unit massing first floors.

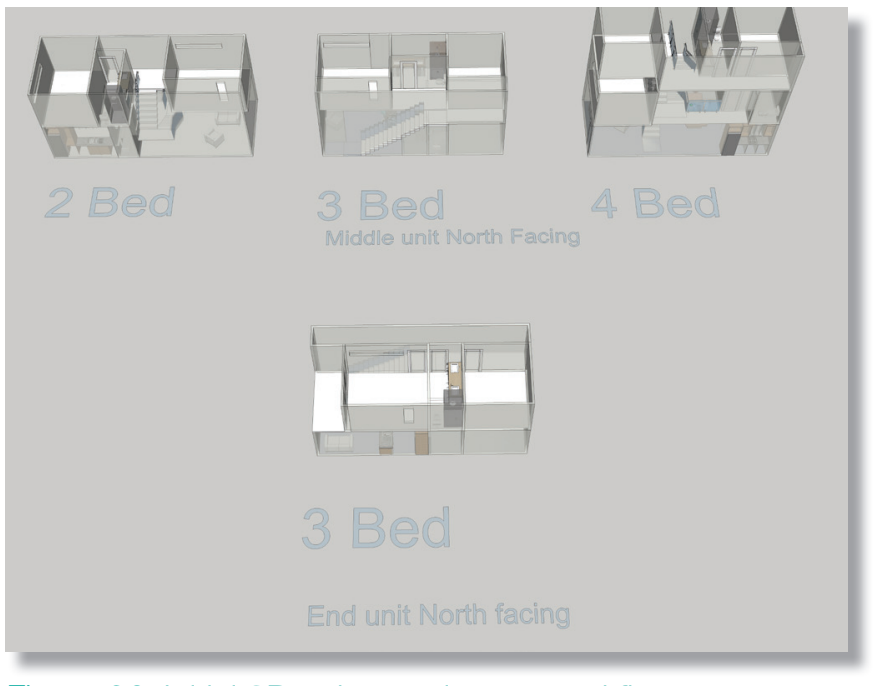

Figure 36: Initial 3D unit massing second floors.
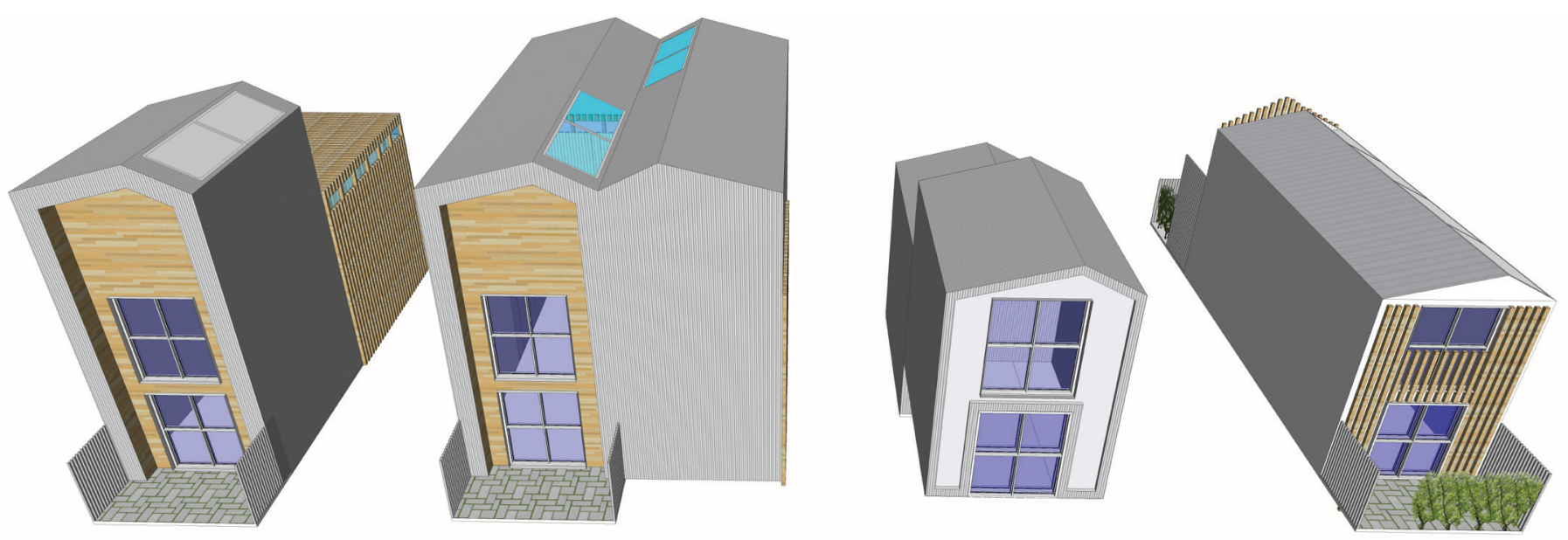

Figure 37: Initial 3D exterior articulation. 


\section{Site configuration}

The very first site configuration involved mapping out paths through the site and positioning the building masses on the periphery, with the all existing buildings also integrated (see Figures 38-43). Priority was put on efficient pedestrian and traffic access, so a diagonal route was created. This option had severe issues, however. The diagonal route significantly limited the available building area, as well as the possibility for community green spaces. Carparking and road access became the overriding focus of the development, which was never the intention.

Inspiration was sought from a wider aerial view of the suburb. At this scale, it was clear the project site did not sit within the smaller urban grain of $\mathrm{Mt}$ Cook. The site was subsequently divided into parts that would reflect the surrounding grain. Two axis were defined to create movement through the site, and connectivity to destinations beyond it (see Figure 52-54).

Further studies were done to explore the unit positions on the site in these newly formed sections (see Figures 44-52). The South-East section was an especially difficult topographic area. This area of steep land was left undeveloped, as it was decided that the significant ground works required to build units on the area would make the project unaffordable.

Unit massing was done to explore how many units could fit on the remaining sections while still maximising sun light hours. The ideal position was found to be East-West facing rather than North-South facing, as this offered more direct sunlight to each unit through the exposed front and back ends (see Figures 59-60). However, it was not possible to make all the buildings EastWest facing. Privacy solutions had to be considered, as the units were going to be in such close proximity. The development also needed to visually integrate into the surrounding streetscapes, so some units were oriented with the principal façade addressing the street (see 55-56).

After creating two site options for unit configuration, positive space was explored and areas for community amenities were highlighted for further design development (see Figures 57 and 58). 


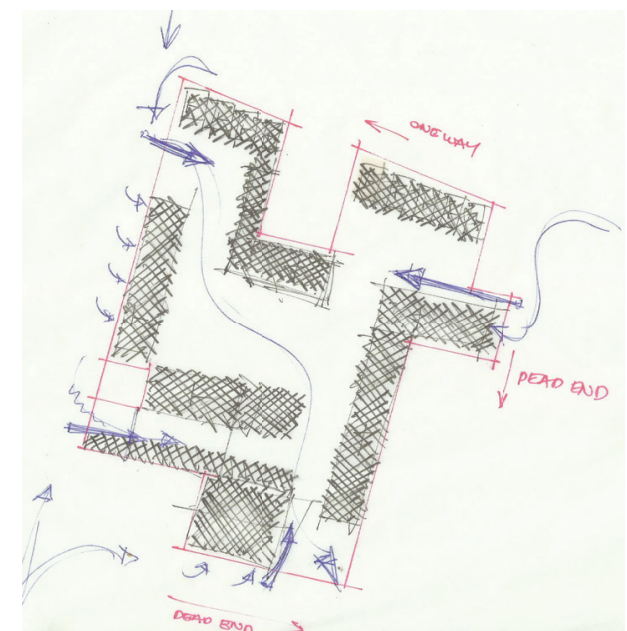

Figure 38: Potential figure ground study on site.
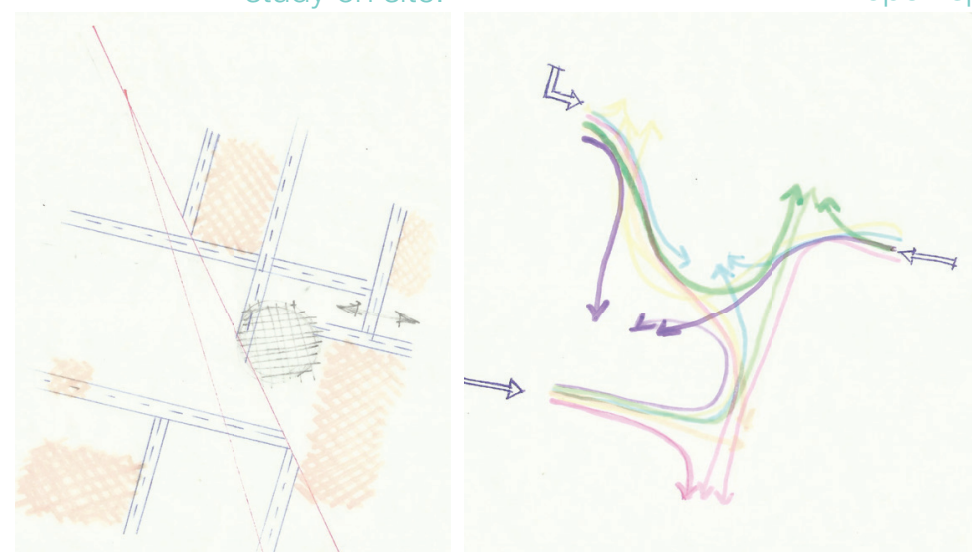

Figure 40: Axis through site. Figure 41: Movement through site.

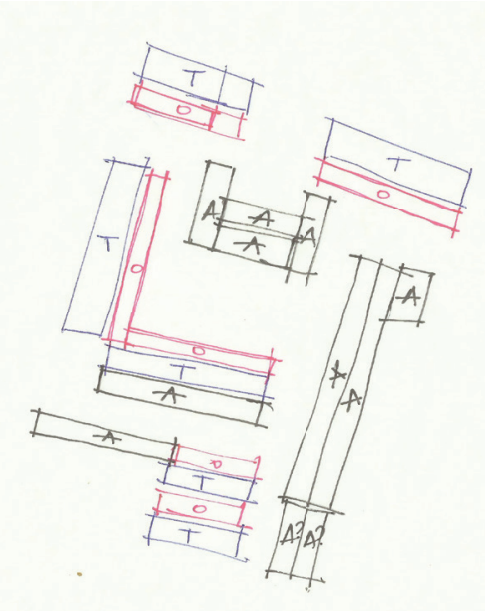

Figure 39: Apartment, town-house, open space distribution.

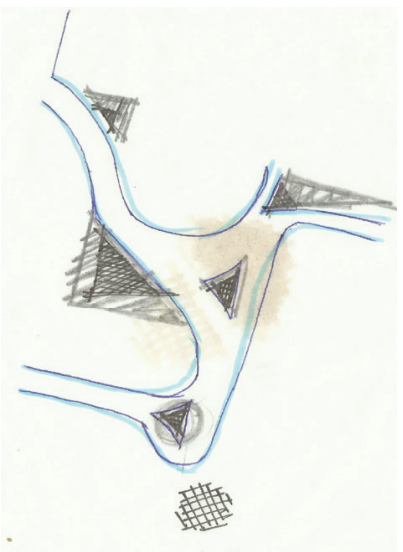

Figure 42: Potential vehicular access

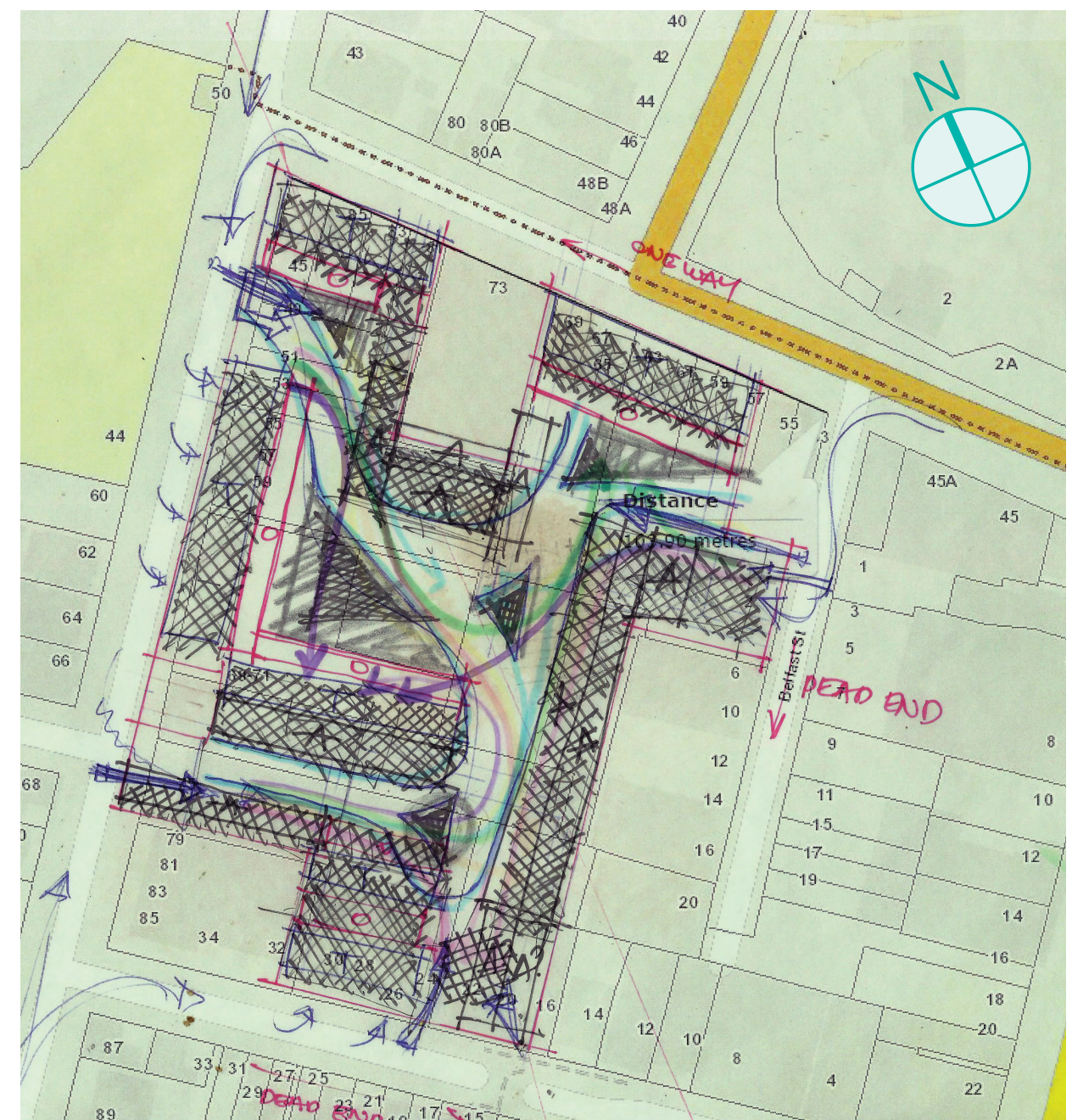

Figure 43: Overlay of figures 34-38. 


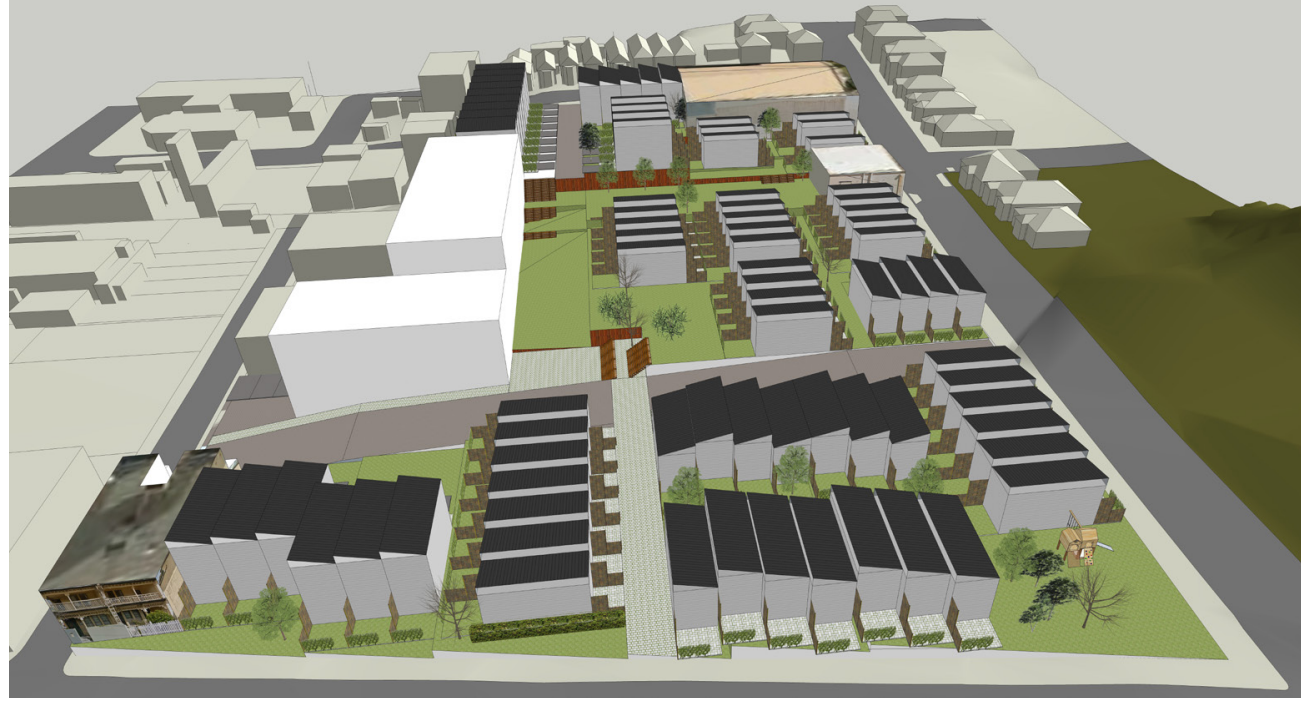

Figure 44: Site massing option 1.

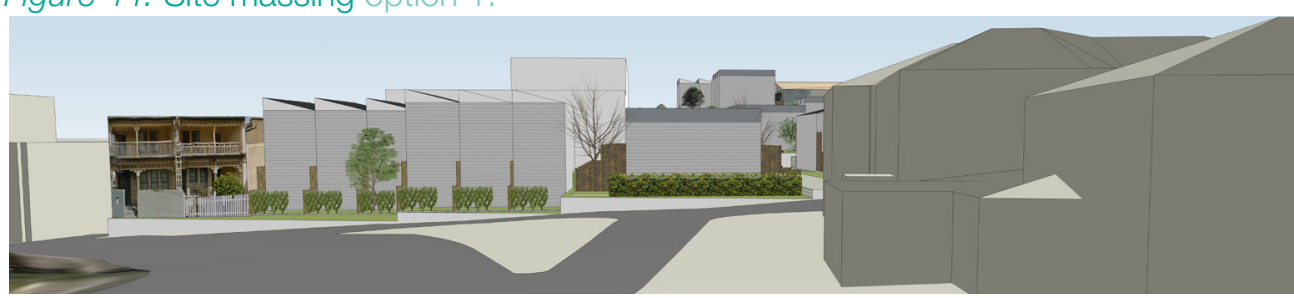

Figure 45: Sussex street option 1 .

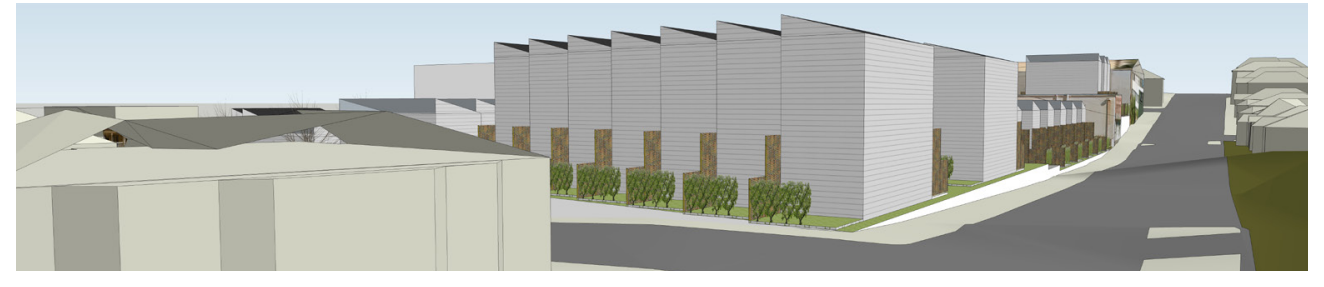

Figure 46: Tasman street option 1.

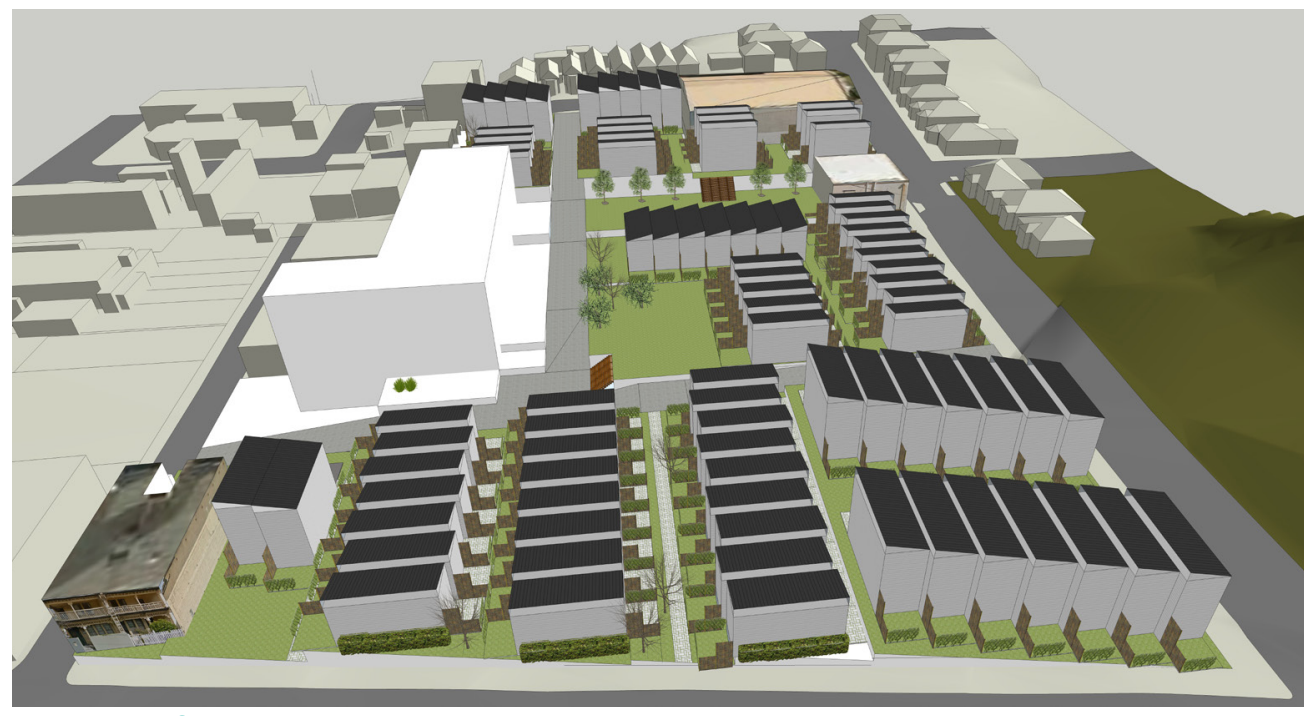

Figure 47: Site massing option 2.

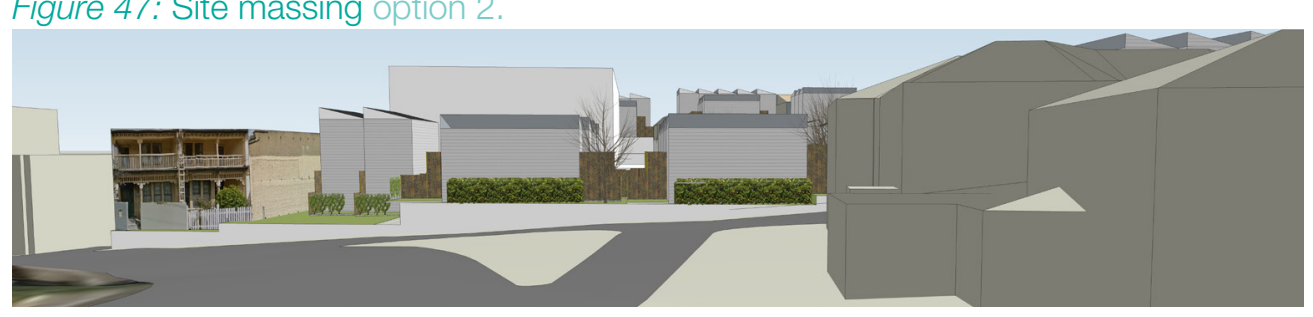

Figure 48: Sussex street option 2.

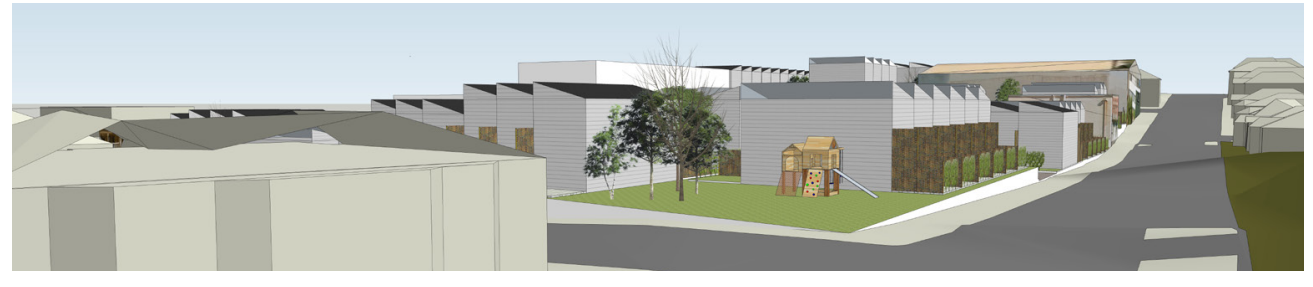

Figure 49 : Tasman street option 2. 


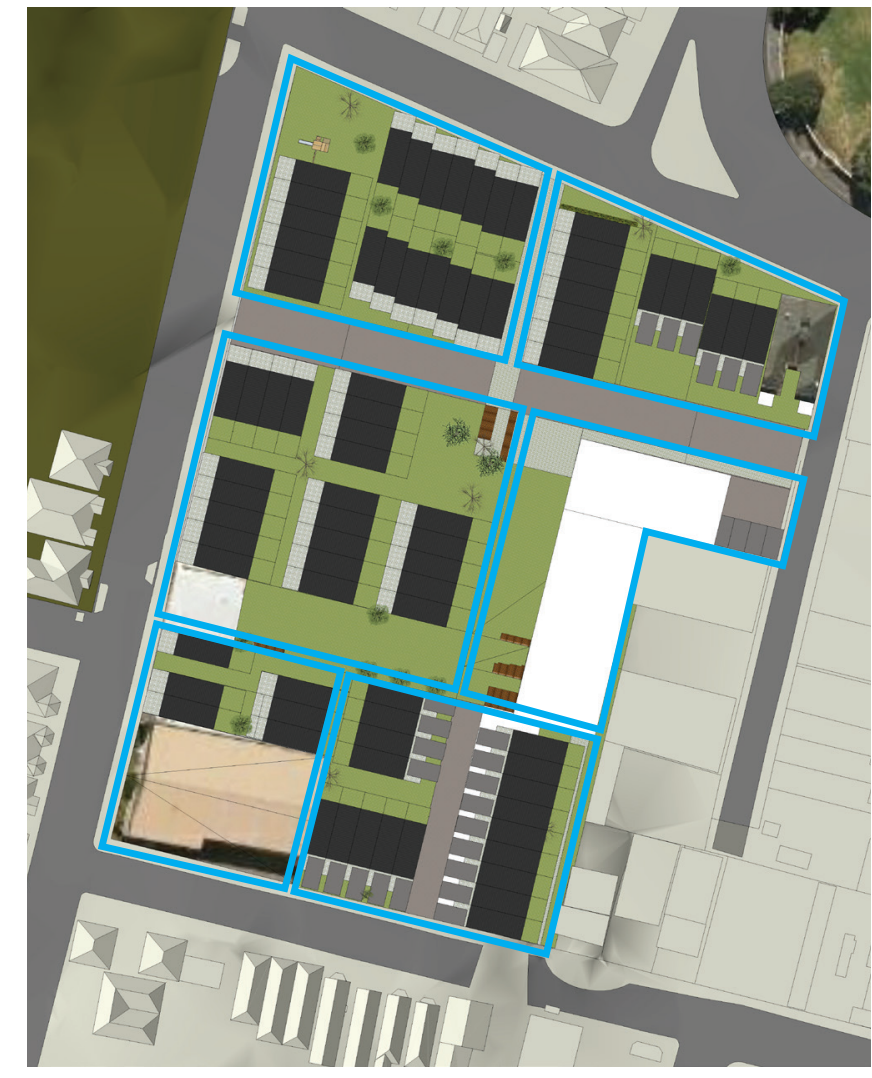

Figure 50: Site grain option 1.

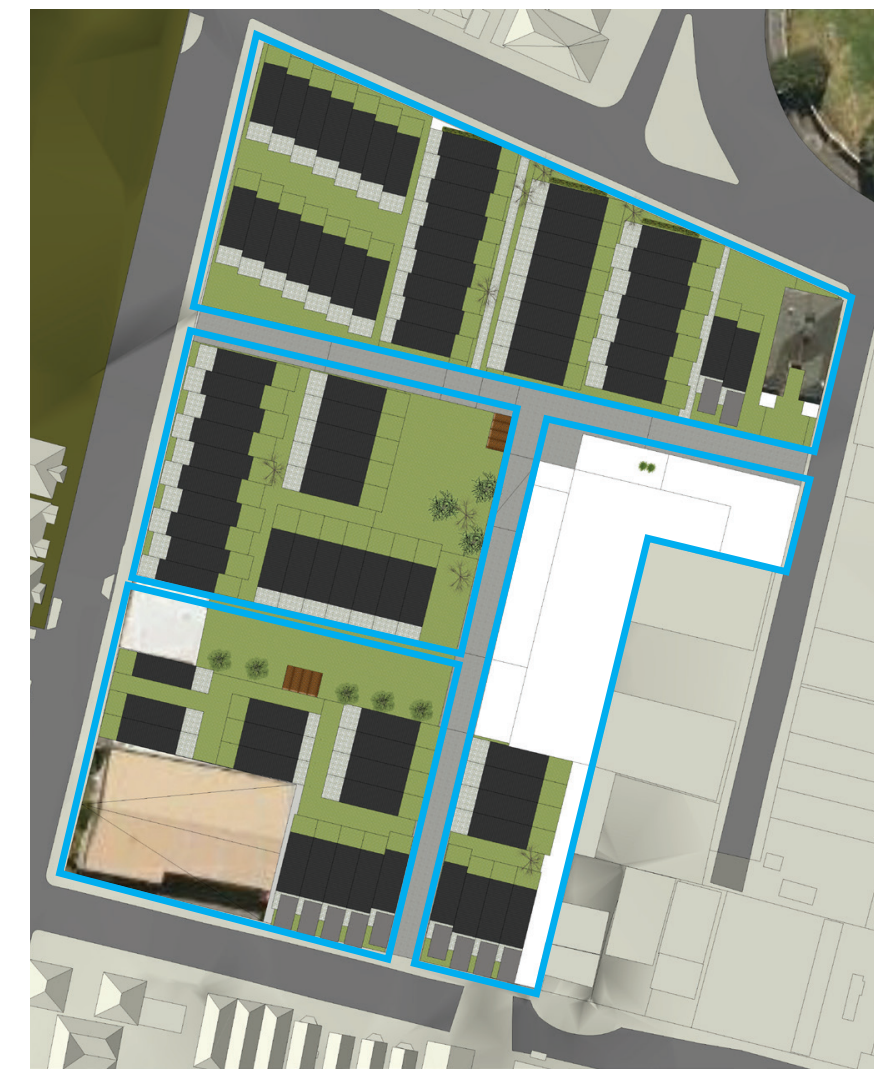

Figure 51: Site grain option 2.

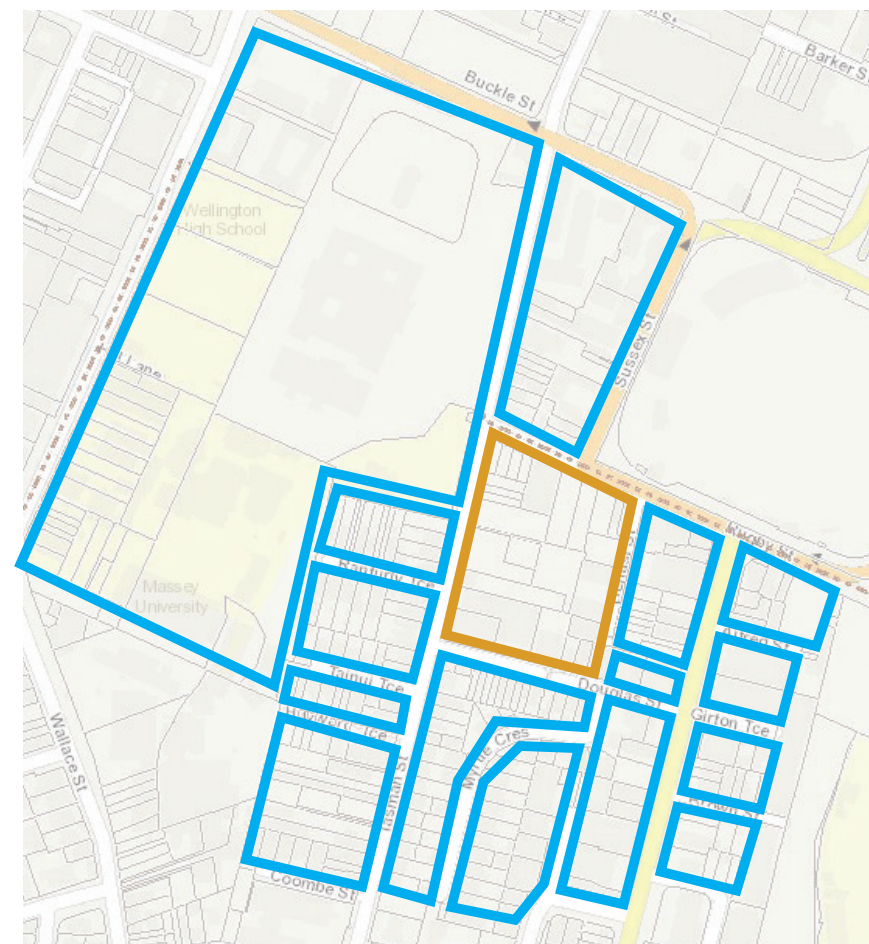

Figure 52: Surrounding suburban grain. 


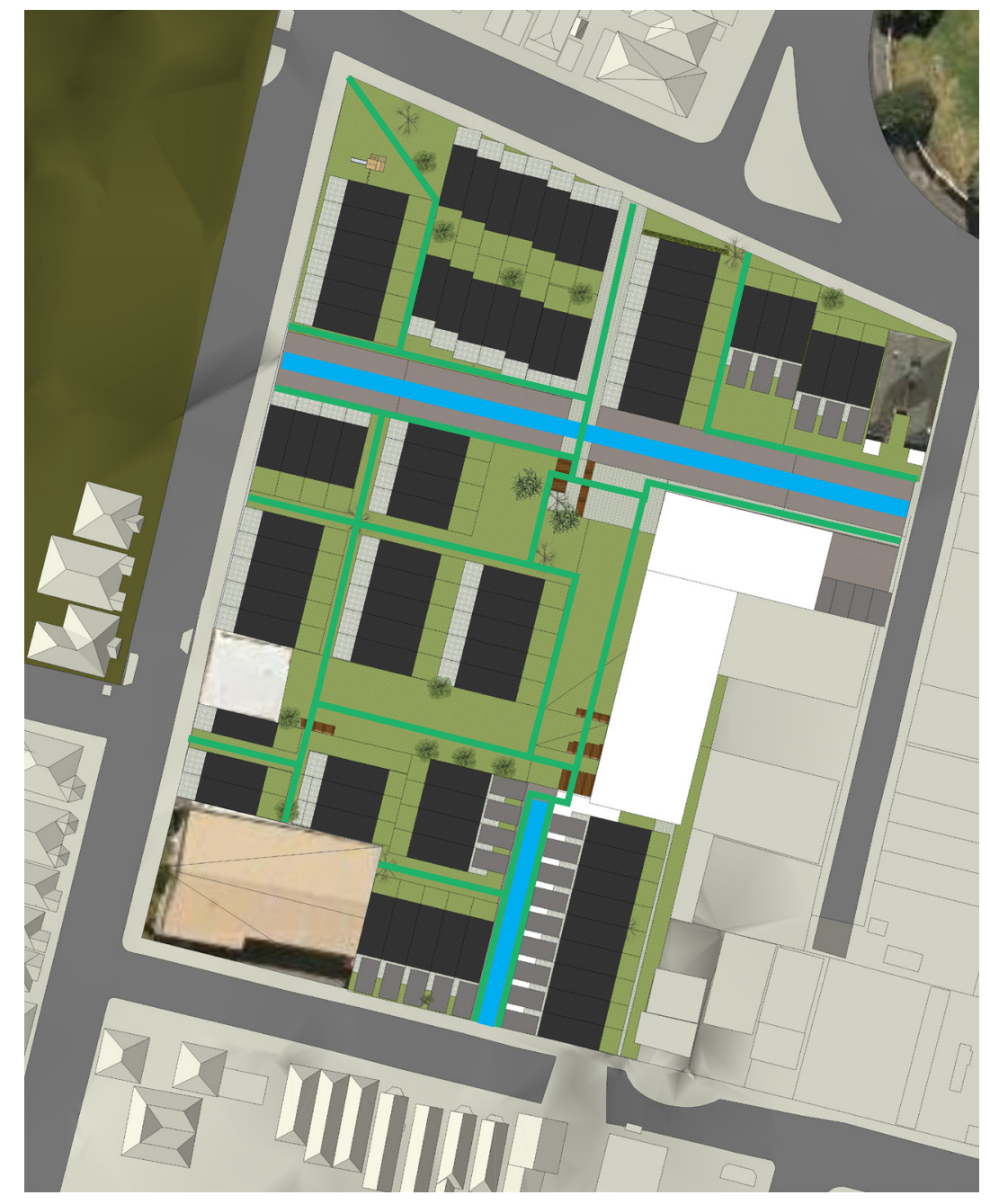

Figure 53: Routes through site option 1.

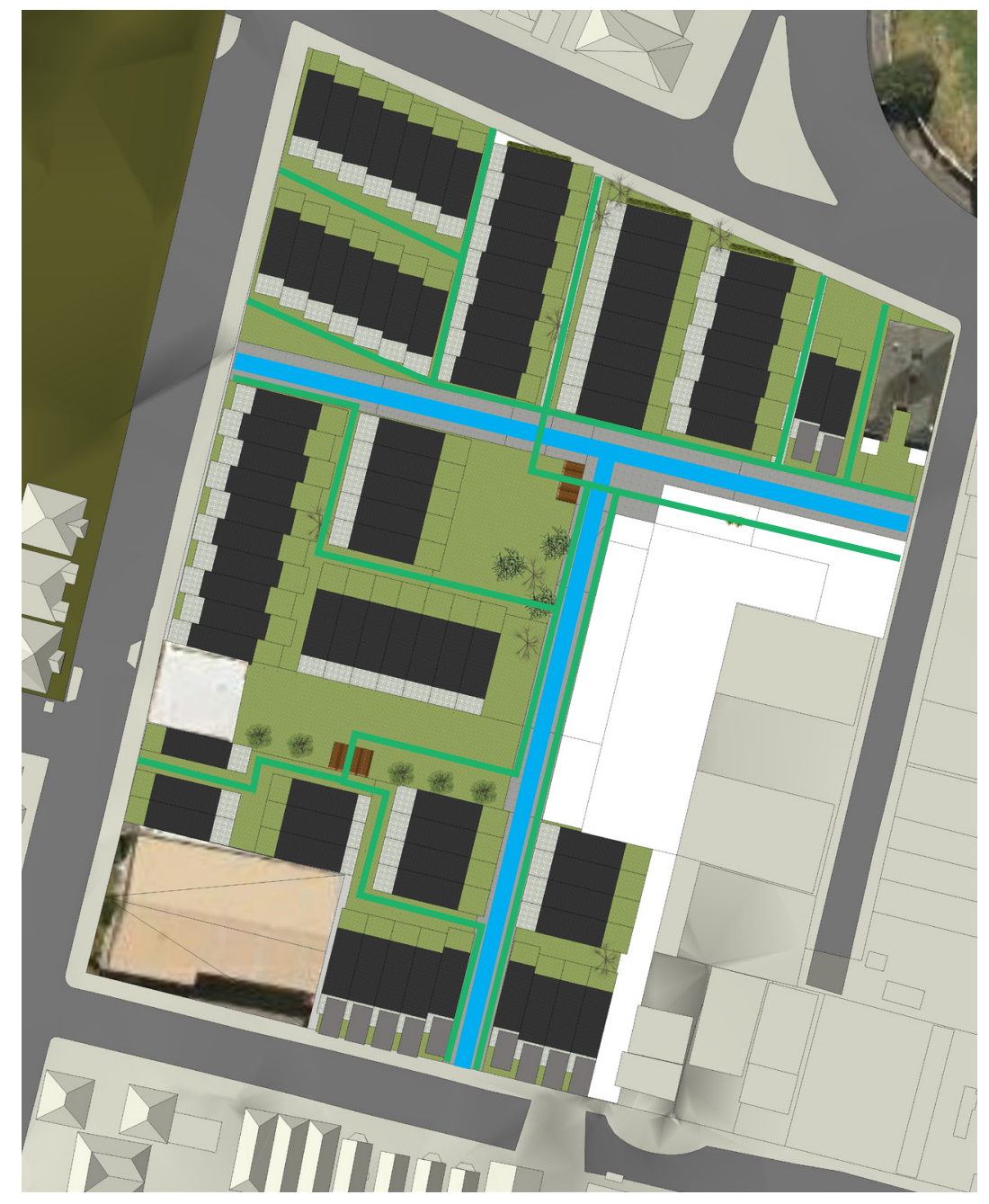

Figure 54: Routes through site option 2.

\section{Key:}

Vehicular - Blue

Pedestrian - Green 


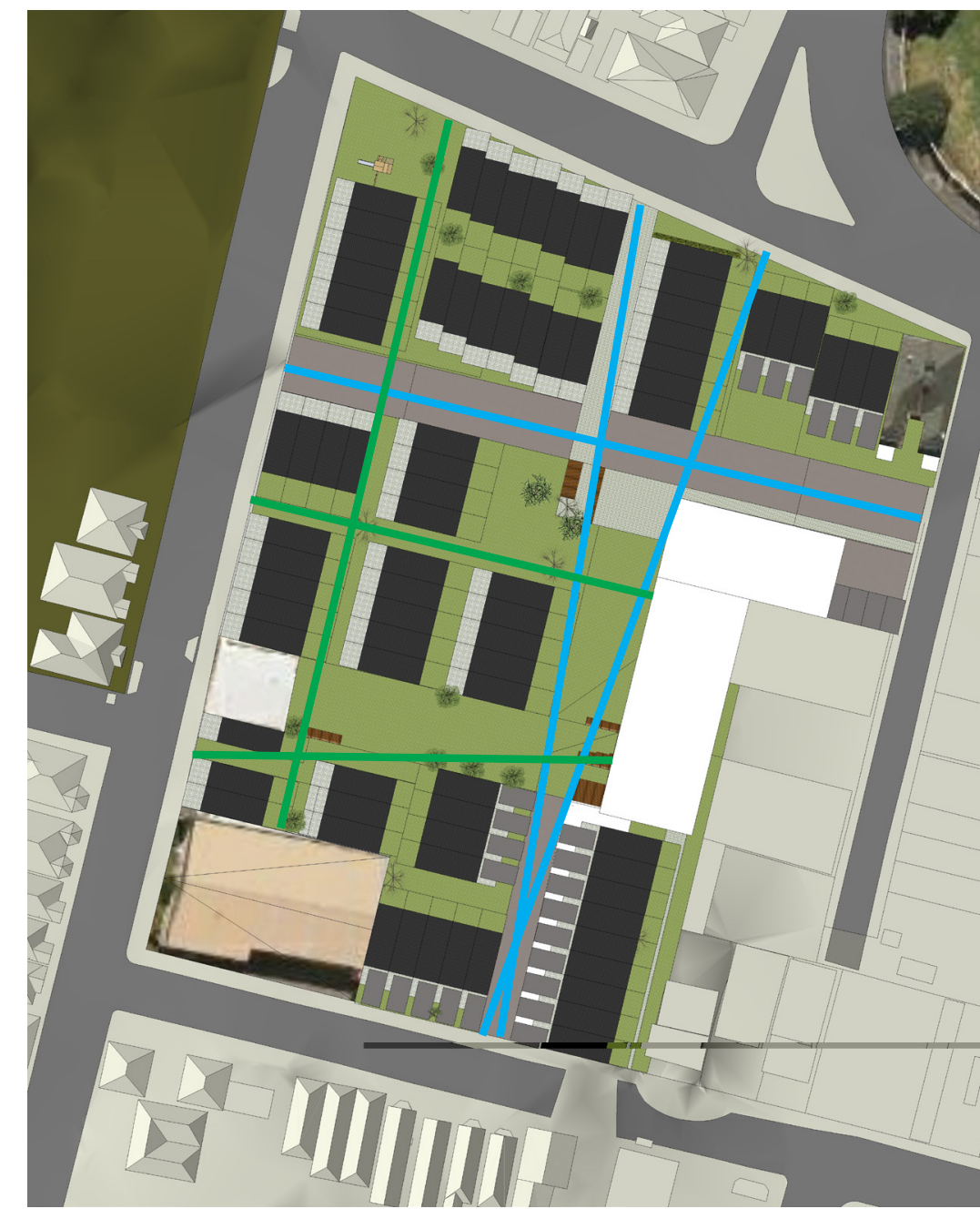

Figure 55: Visual permeability though site option 1.

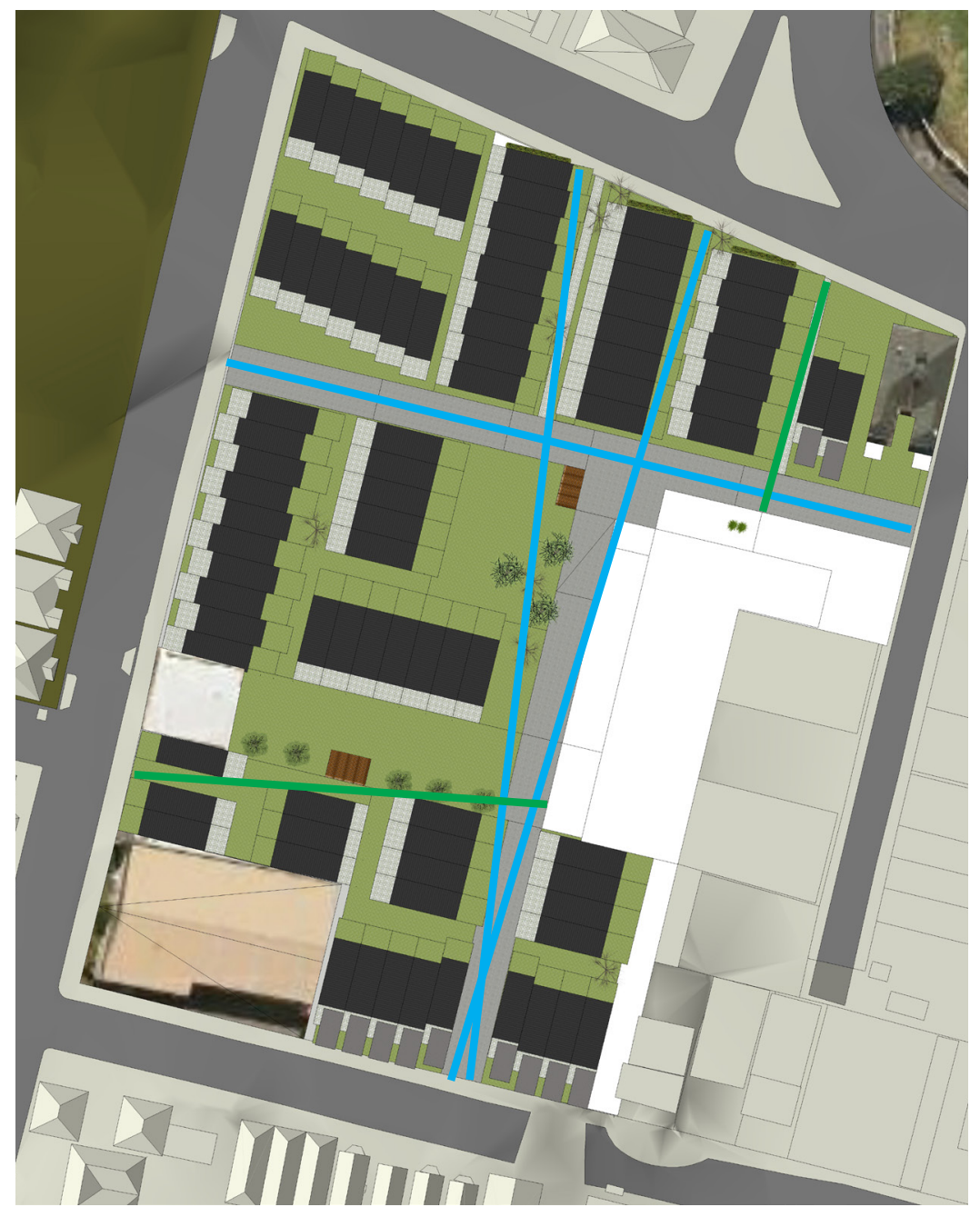

Figure 56: Visual permeability though site option 2.
Key:

Primary (through entire site) - Blue Secondary (through large portion of site)- Green 


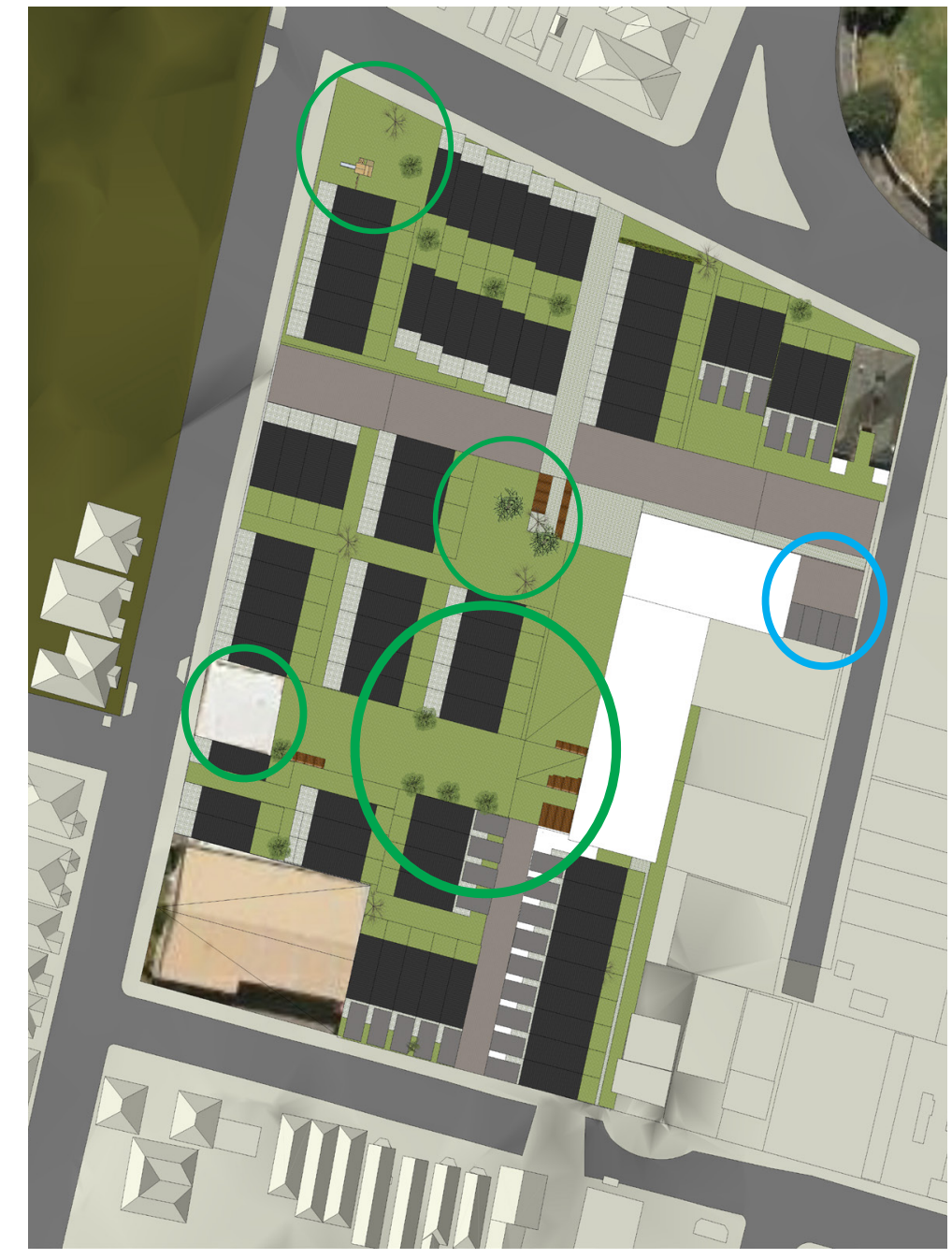

Figure 57: Facilities option 1.

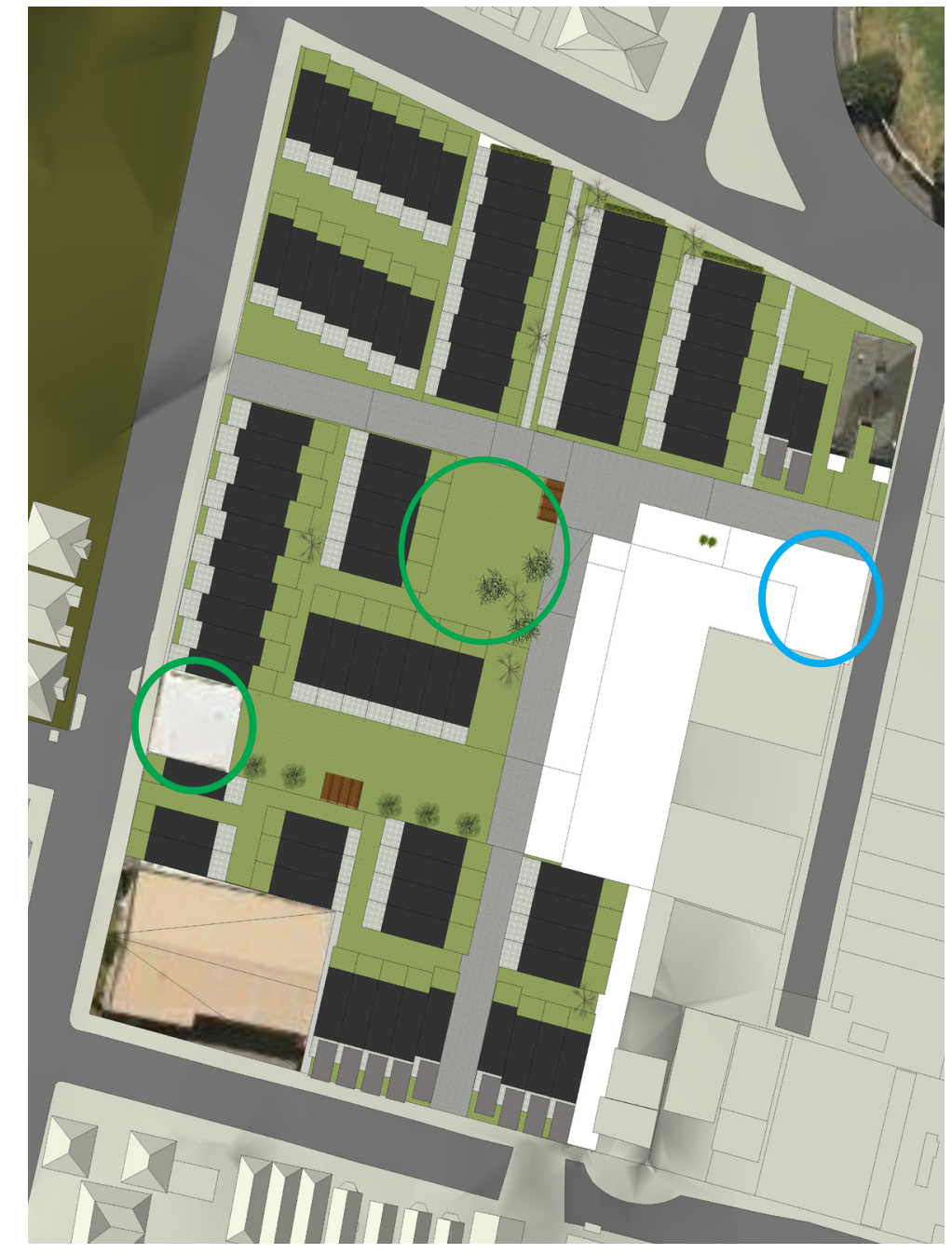

Figure 58: Facilities option 2.

\section{Key:}

Alternative transport parking (uber / city hop) - Blue Community building / Parks - Green 


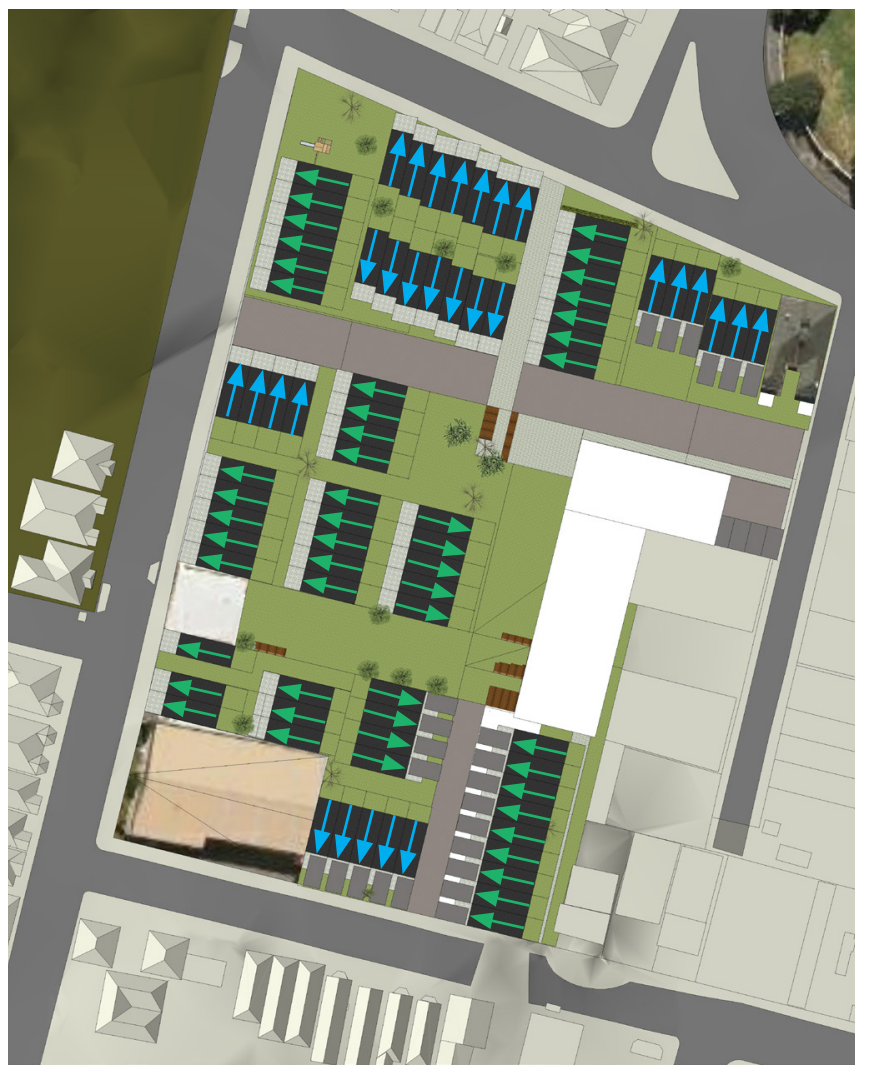

Figure 59: Unit orientation option 1.

Number of units:

East West units:

North South units:

Two storey units:

Three storey units:

Carpark units:

80

51

29
56

24

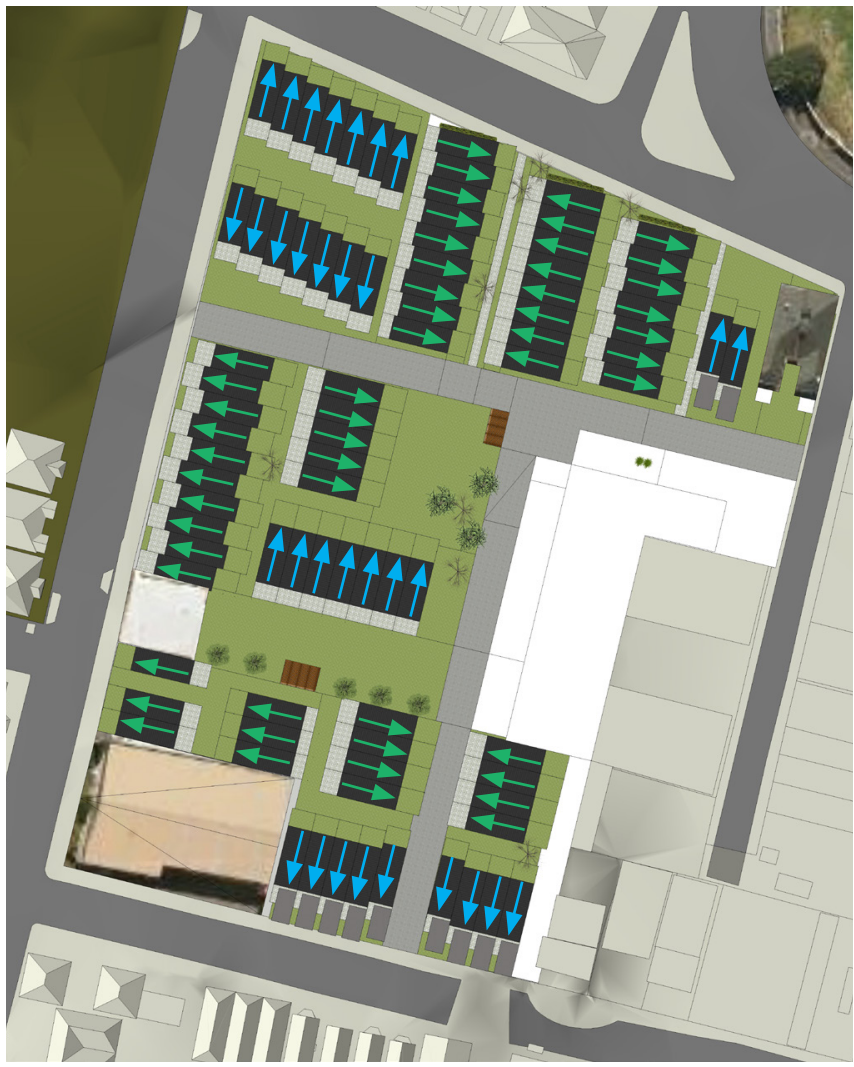

Figure 60: Unit orientation option 2.

Number of units: $\quad 85$

East West units: $\quad 53$

North South units: 32

Two storey units: $\quad 54$

Three storey units: $\quad 31$

Carpark units: $\quad 11$ 


\section{Stage 1-Feedback and Analysis}

\section{Feasibility Study 1}

To gain the interest of potential stakeholders, a rudimentary feasibility study was put together, showing that a development on the site could be profitable. This used the Altair case study as a base line.

First, the buildable area of the site was divided to find out how many units could theoretically fit on it, taking into account council site coverage regulations (see Table 9). The number of units was then multiplied by the average build cost of a unit in the Altair development, and added to the council's estimated CV (capital value) for the land (WCC, 2017) (see Table 8 and Figure 61). This gave an approximate total cost for the development (see Table 9).

Next, the market value of the development was found by looking at the sale price of similar properties that existed on the market at the time, which was estimated at around $\$ 500,000$ for a 3-bedroom unit in Mt Cook (PropertyNZ Limited, 2017) This gave an overall profit of around $\$ 10$ million (see Table 9).

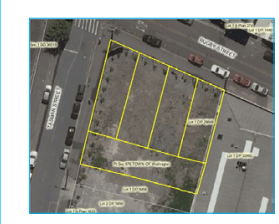

1

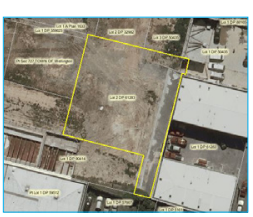

11

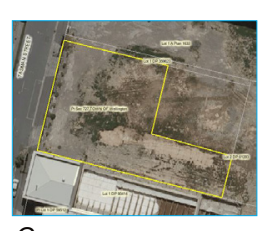

6

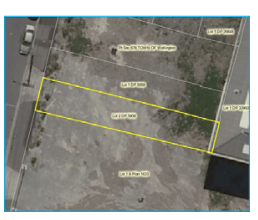

3

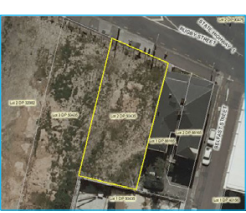

13

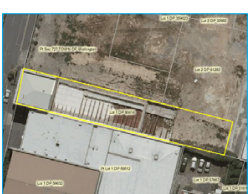

8

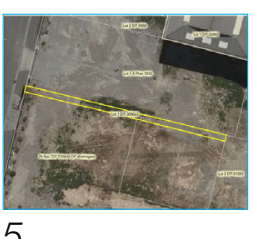

5

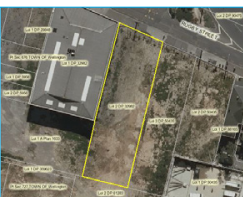

15

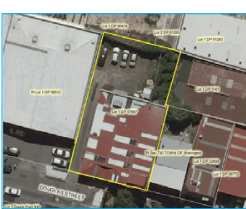

10

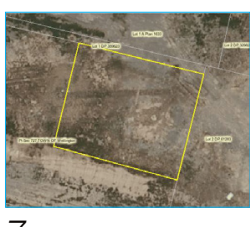

7
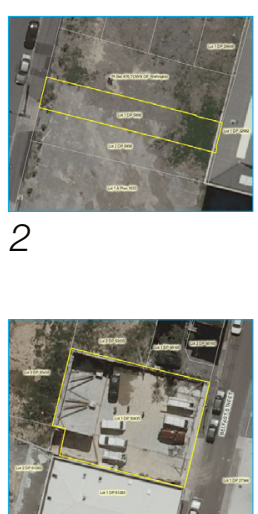

12
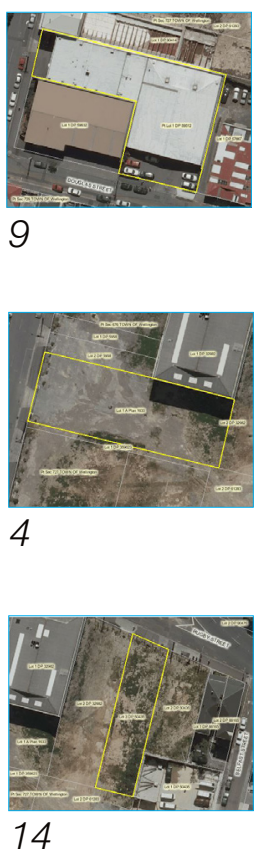

Figure 61: Lots on site. From http://wellington.govt.nz/webmap/wccmap.html Copyright 2017 by Wellington City Council. Reprinted with permission. 


\begin{tabular}{|l|l|l|}
\hline Lot No. & CV (capital value) & Land Area (m2) \\
\hline 1 & $\$ 1,800,000.00$ & 832 \\
\hline 2 & $\$ 200,000.00$ & 147 \\
\hline 3 & $\$ 200,000.00$ & 154 \\
\hline 4 & $\$ 990,000.00$ & 943 \\
\hline 5 & $\$ 34,000.00$ & 74 \\
\hline 6 & $\$ 1,000,000.00$ & 1024 \\
\hline 7 & $\$ 260,000.00$ & 396 \\
\hline 8 & $\$ 955,000.00$ & 895 \\
\hline 9 & $\$ 1,520,000.00$ & 1467 \\
\hline 10 & $\$ 760,000.00$ & 817 \\
\hline 11 & $\$ 890,000.00$ & 998 \\
\hline 12 & $\$ 610,000.00$ & 453 \\
\hline 13 & $\$ 580,000.00$ & 420 \\
\hline 14 & $\$ 920,000.00$ & 550 \\
\hline 15 & $\$ 1,080,000.00$ & 749 \\
\hline Total & $\$ 11,799,000.00$ & 9919 \\
\hline
\end{tabular}

\begin{tabular}{|l|l|}
\hline Site coverage 35\% & $3471.65 \mathrm{~m} 2$ \\
\hline Max number of units at 45m2 & 77 units \\
\hline Total build cost at \$215k per unit & $\$ 16,555,000$ \\
\hline Total build cost+ total land CV & $\$ 28,354,000$ \\
\hline Total sale value at \$500k per unit & $\$ 38,500,000$ \\
\hline Profit & $\$ 10,146,000$ \\
\hline
\end{tabular}

Table 9: Cost feasibility 1.

Table 8: Section lots included in project 


\section{Developer Interview 1}

It was established that speaking directly with a developer would be crucial to this thesis. They would become the hypothetical client for which the project would be designed. Finding a developer that had the time or interest was difficult, but one willing developer was found and formally interviewed multiple times. The first interview covered their perspectives on sustainability and medium density housing, their motivations, what risks they are prepared to take, and other useful information (Anonymous, personal communication, July 8,2016$)$.

- Developer Profile:

Director of Stratum Management, a company targeted towards middle and upper-middle markets.

- Relationship with architects is "very good and successful, so long as they understand that it's a numbers game, and that they generally understand that we need to make money otherwise it won't happen. While we don't always agree, we get there in the end".

- Understands the benefit of architectural service, respects design and its process, enjoys creating imagined ideas.

- Dislikes "dealing with bureaucracy". Says about the local council, "I know where the senior policy wants the city [Wellington] to go to, but at an officer level they constantly put obstacles up".

\section{The Basics of Property Development:}

The developer began by explaining that any housing development starts with a calculation of its potential profit. By the time the developer speaks with an architect, they have typically already purchased the site or have it under contract. Based on their previous experience, they have done the basic calculations and know whether their housing model will work within the site. The land must be used as efficiently as possible, so the architect's brief will therefore include non-negotiable room parameters and minimal circulation space. He explained that in Wellington, developers are often required to be particularly innovative, as the topography of the city's hilly town belt limits opportunities for cheap land development.

Each project has a target market in mind. In the case of medium density housing, this is usually first and second home buyers, and investors. This particular developer contracts a specific marketing company to create a 'brand image' for each development, with a campaign of marketing materials that can be sent to real estate agents and other stakeholders. This means the developer is in control of the development from its initial design through to the sale of each unit. 
When questioned about renting rather than selling, the developer said that there have been times that he has decided to rent parts of a development. However, he explains that his work is "extremely capital intensive". For his business to continue growing, it needs to make a quick profit that can be used towards funding the next project.

\section{Sustainability:}

The developer spoke of his position on sustainability as being "neutral". When discussing a Green Star-rated office building that he had previously worked on, he said he did not believe the point-based Green Star assessment method was logical or useful. As an example, he explained that the sustainable deconstruction of the previous building gained them more points than using renewable energy product, which made little sense to him.

He also made the comment that property development is driven by the market, and that the current market is not concerned with sustainability. $\mathrm{He}$ believes practices like double glazing and heat retention are only in demand because buyers know it will make a difference to their physical comfort. He says that discussions about other sustainable materials do not ever come up during his projects. This is because he believes that " $70 \%$ of the time", sustainable materials would automatically fail code compliance, due to issues such as waterproofing. He doesn't feel the sustainability industry offers many options that would meet the regulations he needs to consider. $\mathrm{He}$ also added that building for the affordable medium density bracket does not allow for extra 'sustainable costs'.

However, the developer explained that his company is always open to learning about new products. He admitted he would consider using the findings of this research project if they turned out to involve no risk to him and could be used as features to help sell his developments. When asked whether he would ever invest in a complete cradle-to-cradle development, he said he would not because "at the end of the day my job is managing risk".

Cost:

When the initial pre-interview feasibility calculations were discussed, it very quickly became clear that they were unrealistic. They did not consider additional costs, such as excavation work, landscaping, council fees, and GST.

Furthermore, the study was based on out-of-date construction costs from The Altair development, which had been completed almost a decade earlier. The developer also mentioned that The Altair had a low profit margin around $13-14 \%$. To be successful and worthwhile for the developer, and to gain the 
support of a bank, the profit margin for a project needs to be around 20-

$25 \%$.

Because it was clear the figures were incorrect, the developer explained the model he uses, starting from the market value and working backwards.

\section{Conclusions:}

The most important lesson from this first interview was that developments are almost exclusively market driven. At least for this developer, sustainable materials and practices are only considered when the market demands them, such as in the case of double glazing. Inadvertently, he also makes environmentally friendly decisions if they increase his profits, such as when he specifies a small built footprint and minimal carparking. In general, he sees sustainable architecture as unprofitable and unviable, opinions which served to motivate the completion of this project.

A second lesson was about affordability. The developer thought about affordability in terms of the price of entry level housing in a specific area. His definition shifted the perception of affordability for this project, which had previously been considered in terms of social affordability for the average New Zealander. To design a development that realistically addressed developer motivations, affordability needed to be deemed market entry value. 
With new information provided by the developer about project feasibility, a second study was made. The process for this feasibility study involved several calculations (see Figure 62 and Tables 10 and 11):

1. The number of unit footprints that could be built on the site to achieve a maximum of $35 \%$ site coverage, as per council regulations for outer residential zones (WCC, 2012b). The size of a unit was based on The Altair model of a $45 \mathrm{~m} 2$ footprint.

2. The total cost of the development. An estimated build cost per unit and estimated 'other' costs (landscaping, council fees, marketing, and so on) were given by the developer based on his extensive experience. These were added to the total value of the land, as per council CV estimates (WCC, 2017) (see Table 10).

3. The total profit and profit margin. The total sale value for the development was based on the developer's estimate that a market entry 3-bedroom unit in the city would currently sell for around $\$ 600,000$ (see Table 11).

As well as being more accurate than the initial feasibility study, the second study also included the theoretical purchase of four additional properties neighbouring the main site. These included the derelict historical buildings

\section{Feasibility Study 2}

on the corner of Rugby and Belfast streets, plus the sites currently occupied by two run-down warehouses. While the initial costs were greater in this second study, the extra land allowed for an increased number of units on the site and therefore a higher financial return. The total profit was found to be over $\$ 16$ million, or $30 \%$. Therefore, as long as a sustainable solution could be kept at or even slightly above the developer's figures, the project was found to be potentially feasible at this stage. 


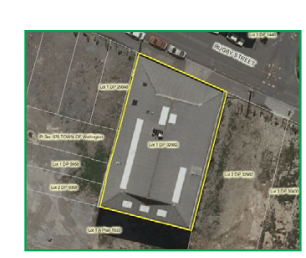

73 Rugby St

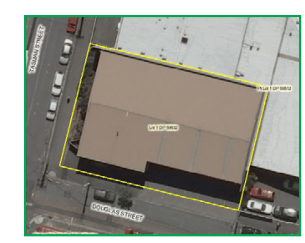

85 Tasman St

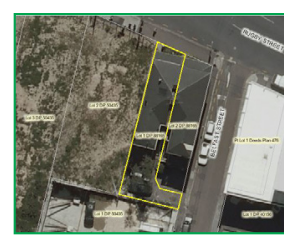

55 Rugby St

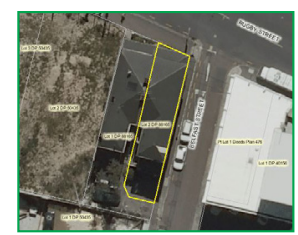

53 Rugby St

Figure 62: Building lots on site. From http://wellington.govt.nz/webmap/wccmap.htm Copyright 2017 by Wellington City Council. Reprinted with permission.

\begin{tabular}{|l|l|l|}
\hline Lot No. & CV & Land Area $(\mathrm{m} 2)$ \\
\hline 73 & $\$ 1,130,000.00$ & 736 \\
\hline 85 & $\$ 1,350,000.00$ & 783 \\
\hline 55 & $\$ 770,000$ & 188 \\
\hline 53 & $\$ 770,000$ & 137 \\
\hline Total & $\$ 4,020,000.00$ & 1844 \\
\hline Total incl. main site & $\$ 15,819,000.00$ & 11763 \\
\hline
\end{tabular}

Table 10: Additional section lots included in project.

\begin{tabular}{|l|l|}
\hline Site coverage 35\% & $4117.05 \mathrm{~m} 2$ \\
\hline Max number of units at 45m2 & 91 units \\
\hline Build cost at \$175k per unit & $\$ 16,555,000$ \\
\hline Other costs at \$75k per unit & $\$ 5,775,000$ \\
\hline Total cost (land CV+build+other costs) & $\$ 38,149,000$ \\
\hline Total sale value at \$600k per unit & $\$ 54,600,000$ \\
\hline Profit & $\$ 16,451,000$ \\
\hline Profit margin & $30 \%$ \\
\hline
\end{tabular}

Table 11: Cost feasibility 2 


\section{Architect Interview 1}

As well as from the developer, this project sought input from a successful Wellington architect. A director of the firm Architecture Plus, with more than 20 years of experience in the industry, which includes many developer-led residential projects. The initial interview covered the architect's design perspective, position on sustainability, understanding of the market, and view of the architect-developer relationship (Anonymous, personal communication, June 13, 2016).

The architect explained that there are developers at every spectrum within the market. Low-end developers are happy developing anywhere. They are not so much concerned with quality, as there is always a market for inexpensive housing in Wellington. Mid-range developers are concerned with quality insofar as it will earn a better return. High-end developers deal with large-scale specialised projects, and cater to top-tier buyers who expect the best.

When asked where sustainability fit into the spectrum, the architect admitted that there did not seem to be a market for low-cost sustainable housing, as they had not personally worked on any sustainably-driven projects. He explained that most developers would question the monetary value in a sustainable feature before even considering it's integration. While developers may ask about the value it may add, they would be unlikely to consider it in terms of environmental benefits. However, he did add that the importance of environmental solutions and their perceived value would depend on the developer in question.

When asked about the market's disinterest in sustainability, the architect suggested that it was a matter of educating the consumer in order to encourage a demand. For prompt industry changes to be made, however, new regulations would need to be implemented.

When shown the conceptual first stage of the site plan, the architect commented that the primary importance should be on sun, and on addressing the street directly. He reflected that minimal carparking would appeal to a developer but may lower property values. 


\section{Real Estate Agent Interviews}

Developers tend to target only a single area of the market, so may not necessarily have an understanding of niches outside their own speciality. Two realtors were therefore interviewed as secondary stakeholders, to see if they could provide insight into the needs and issues of a more diverse range of buyers. Their comments are outlined below - 'Agent 1', from Century 21 (Anonymous, personal communication, July 19, 2016), and 'Agent 2' from Ray White Real Estate (Anonymous, personal communication, July 21, 2016).

Is there a current market for sustainable medium density housing?

Agent 1: "There is a market for any kind of housing, and the market for eco housing is growing because buyers are leaning towards it. There is a future for eco/sustainable housing.

Agent 2: "Town houses or houses, yes. Apartments, not so much."

What is the biggest issue people have with sustainability?

Agent 1: If it is different from what is standard, people are weary. Once they get past that, and once one person is happy and feels safe, they tell others."
Agent 2: "The biggest hindrance people have [about sustainable housing] is their ability to actually purchase a property they can afford."

Where is the biggest need in Wellington's current real estate market?

Agent 1: "The first home buyer bracket is always in need of housing. It is harder to buy homes than 20-30 years ago. First home buyers need financial help desperately. Kiwisaver is a big help but rates are dropping from year to year. More needs to be done, but I don't know if the help needs to come from the government or the private sector."

Agent 2: "The biggest need in the current market is supply. There are not enough houses on the market and buyers are finding they are competing and missing out."

What are the top features clients want in the entry level market?

Agent 1: "First home buyers generally don't have kids yet, they just want to get into the homeownership cycle."

Agent 2: "They are looking for easy care, quality build, good insulation and double glazing, outdoor living, garaging, 3 bedrooms, 2 bathrooms (or at least a second toilet), and a good modern kitchen." 
What do you predict for the future of the market, considering the current crisis?

Agent 1: "We have to build thousands of houses because prices will just keep skyrocketing. It is a sellers market. Rentals skyrocket and housing skyrockets, it's a self-perpetuating cycle."

Agent 2: "Real estate markets are cyclic. The media however, has a lot to do with how markets react in Wellington. In fact, they are the driver of knee jerk reactions. Houses go down in price, stay stagnant and then rise in price, all due to supply and demand."

Is there a market for MDH without individual carports / garages in the innercity suburbs? How much would this take from the sale price?

Agent 1: "People will still buy housing without carparking, if that's all they can get, because there is such limited choice. If there was a lower demand for housing, there would be more demand for carparking. It [no carpark] does not take a huge amount away from the value of the property."

Agent 2: "A carport or single garage is worth about $\$ 15000-\$ 35000$, possibly more." 


\section{Design Review 1}

At the first thesis review, a panel of design experts reviewed the first stage of design, including the massing studies, site studies and initial design concepts. At this level of detail, the review involved a critique of the general concept. Discussions included:

- The possibility for flexibility in the use of the units, through adaptable spaces that could increase or decrease in size with the movement of temporary walls or other building components. It was decided this was beyond the scope of the project and that the additional mechanisms would also fall beyond the feasibility of an affordable design.

- Acoustic issues with the density of the development, and possible sound-reducing solutions.

- The target market and the importance of social urban planning. The development had been designed with community living in mind, including areas for social gathering and outdoor living with protection from the street front. It was determined that it would be useful to consider the socioeconomic context of the area and the amenities inhabitants might like to have in these communal areas. It was suggested that the communal greenspace be increased and privatised outdoor living space be decreased, to allow for additional capabilities of shared space.

- Automotive transportation within the site. Mistakenly, after the decision was made to keep car use and parking to a minimum, emergency entry and exit to the dwellings had not been considered. Mobility for both pedestrians and vehicles was a critical issue to develop the next design stage. 


\section{Stage 1- Summary}

The initial stage of design experimentation and discussion led to a more realistic view of residential development, and of sustainable construction in the current market.

The need for research projects like this one was confirmed by the industry professionals. It was clear that the only mechanism for swaying the minds of developers towards sustainability would be a convincing design scheme and detailed economic evidential support. However, it also became clear that to reach a level of risk tolerable to the developer, some sacrifices would potentially be necessary in terms of the complete sustainability of the project. A fully cradle-to-cradle solution would be difficult.

Critically, it also became clear that affordability needed to be considered in terms of market entry prices, rather than as a concept of social affordability. In the conceptual stages of the project, affordability had been thought about in relation to the average New Zealand income. Without government support, socially affordable housing is not within the realm of current residential development. Without regulation, the developer is most concerned with their bottom line and the architect must accommodate this.

However, not all feedback was as disheartening. As explained by the real estate agents, there is a definite market for medium density housing in
Wellington and some interest in sustainable housing too. For the market to improve, more housing needs to be built quickly. To improve the public's openness towards sustainable building on-mass, a solution needs to be found that they will be less weary of, fitting within their traditional understanding of a healthy, quality home. 


\section{Stage 2-Design Precedents}

\section{Stone Street Wellington}

When exploring possible design options, it was necessary to look at current precedents of medium density housing and sustainable materials.

During this thesis, a 16-unit MDH development on Stone Street was constructed in Miramar, Wellington (see Figures 72-77). It provided an up-to-date example of architecture developed for the current market. A site visit with the developer provided insight into its methods of construction (Anonymous, personal communication, October 28, 2016) (see Figures 63-71).

- Construction efficiency is important. At the completion of one stage, the next stage is already part way through, allowing an overall timeline of 5 months for completion.

- Prefabricated elements are used. These include stairs and Posi-strut beams.

- Roof forms are simple and affordable, with slight variations to create individualisation.

- Units are duplicated to save on architect costs and allow for economies of scale.

- Cost savings on the exterior mean high quality finishes and fittings can be used in the interior.

- Bricks are used to create architectural interest.

- Palette of materials is limited after leaky homes of the 1990's.

- Open space "helps amenity value", for first home buyers with children.

- Site arrangement of units enables buyer choice depending on their preference for privacy or community.

\section{Stone St. Quick Facts}

Town houses 3 storey urban infill:

Ground floor indoor and outdoor living 900mm Fencing

\section{3 bedrooms}

16 units

\section{Dimensions:}

$11.4 m$ length

$4.5 \mathrm{~m}$ width

Floor height 2.35

\section{Materials exterior:}

Shadow clad on $20 \mathrm{~mm}$ cavity Brick veneer on $40 \mathrm{~mm}$ cavity texture2000 plywood on $20 \mathrm{~mm}$ cavity Profiled metal roofing

\section{Structure:}

Timber framing and steel portal frames

Windows and doors:

Double glazed aluminium with powder coat finish

Total construction cost:

$\$ 1597000$ gst (including road, services, landscaping costs)

Sale price:

\$575K- \$660K estimate (Oct 2016) 


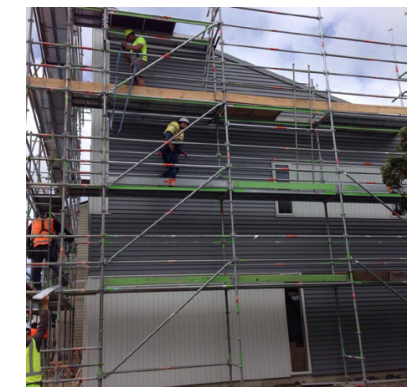

Figure 63: Photo showing many construction

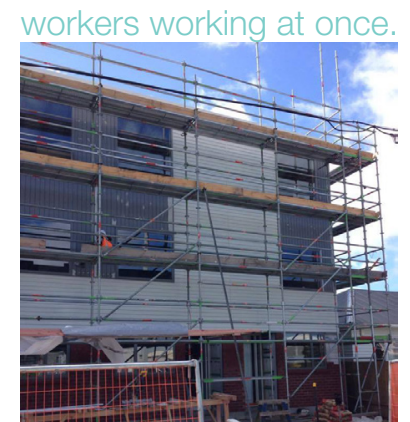

Figure 64: Weatherboard

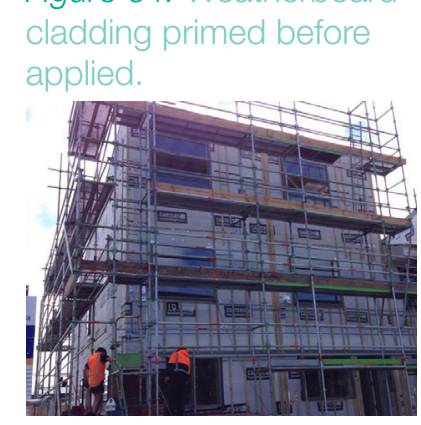

Figure 65: Cavity battens to meet regulations.

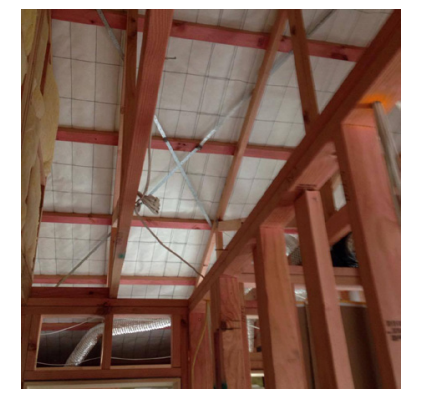

Figure 66: Framing with

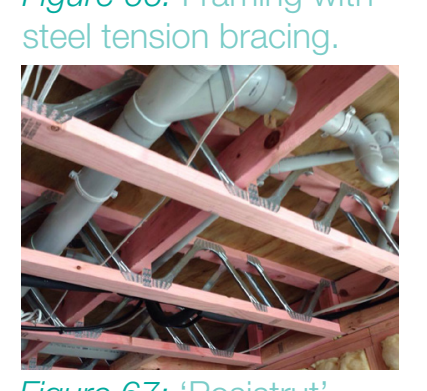

Figure 67:

beam system provides

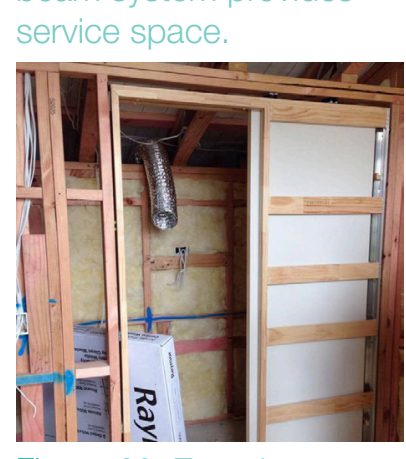

Figure 68: En-suite

addition by owner, with pocket door.

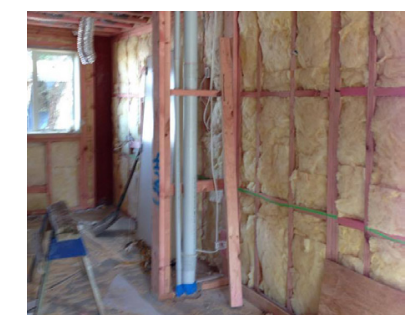

Figure 69: 'Bradford gold'

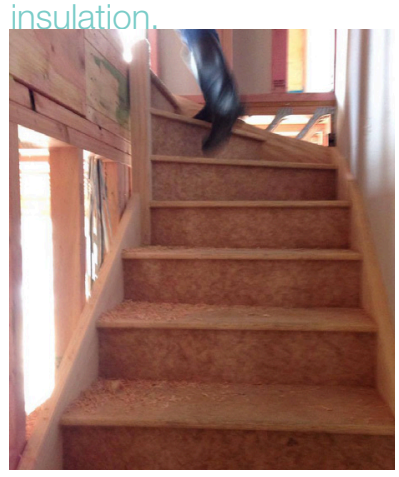

Figure 70: Prefabricated

Plywood stairs.

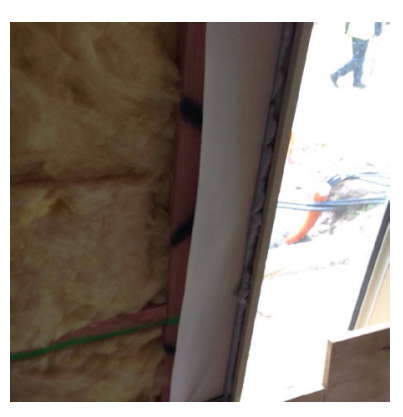

Figure 71: Expansion foam seals windows and doors

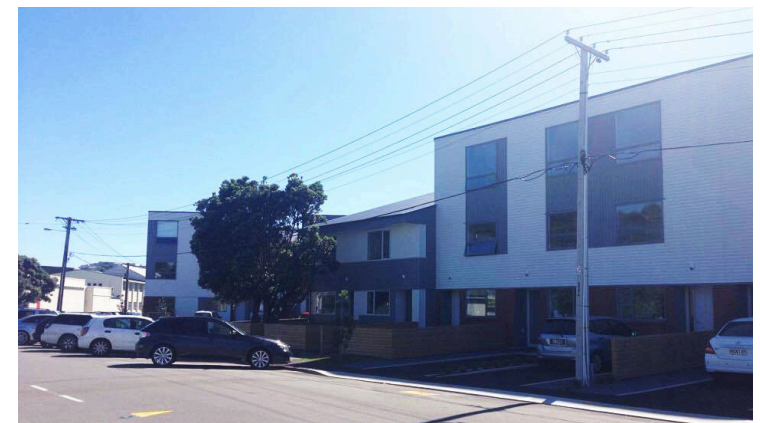

Figure 72: Street elevation of final development.

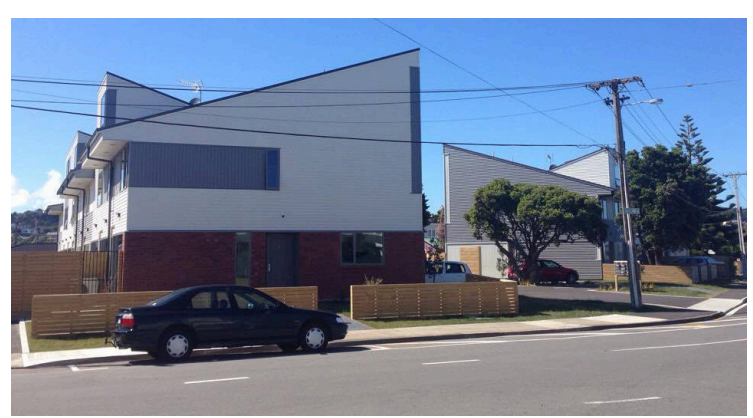

Figure 73: Alternating roof line.

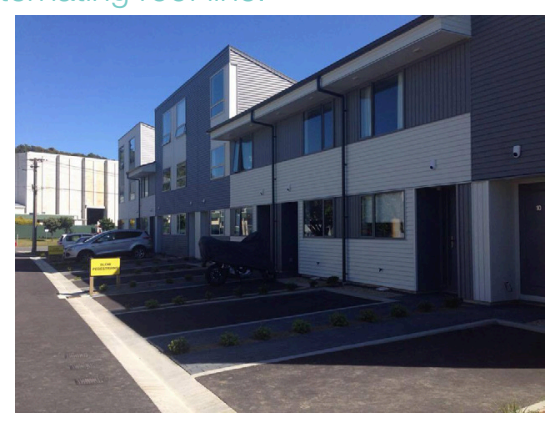

Figure 74: Shared driveway.

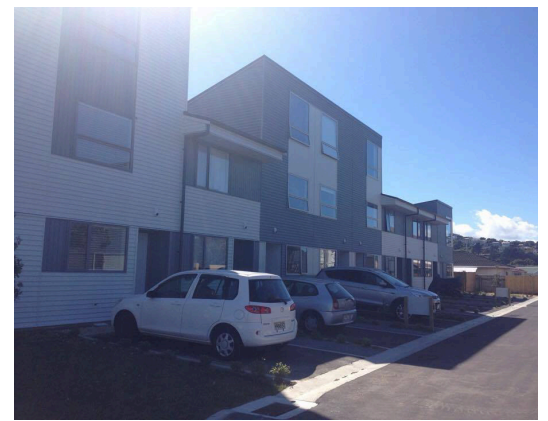

Figure 75: Alternating articulation.

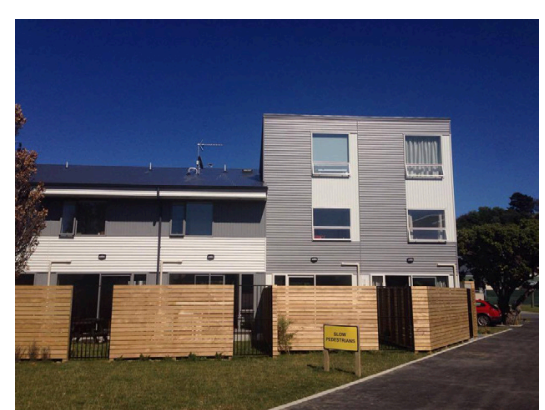

Figure 76: Shared green space.

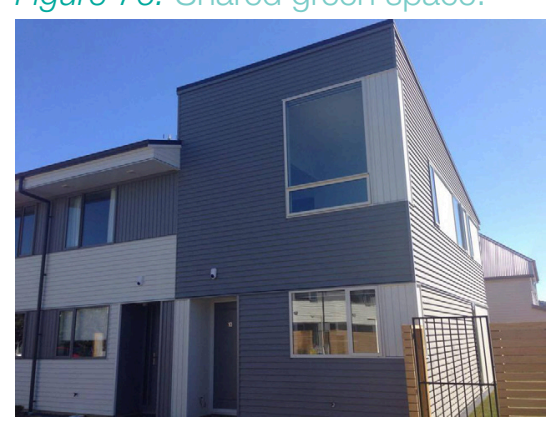

Figure 77: Detail of cladding. 


\section{Sporenburg Amsterdam}

The Sporenburg development in Amsterdam is an example of cohesive and beautiful high-end MDH design. Urban planners created design guidelines for unit sizes, colours and materials. Architects then created a range of units with maximum architectural variation within the guidelines.

A few of the most popular units were repeated across the large site (Farooq, 2012) (see Figure 78). The units balance visual diversity with a cohesive sense of community.

The scale and colours of the units are also reminiscent of the historical canal houses in the city. The architects have not mimicked the character features of the canal houses but have created a modern vernacular that responds to the historical context (see Figure 79).
At the scale of this thesis development, visual diversity could be achieved to a certain extent, but it needed to be more limited than in the Sporenburg development so that economies of scale could be maximised for an affordable, entry-level solution. A modern reinterpretation of the historical context was also a definite focus.

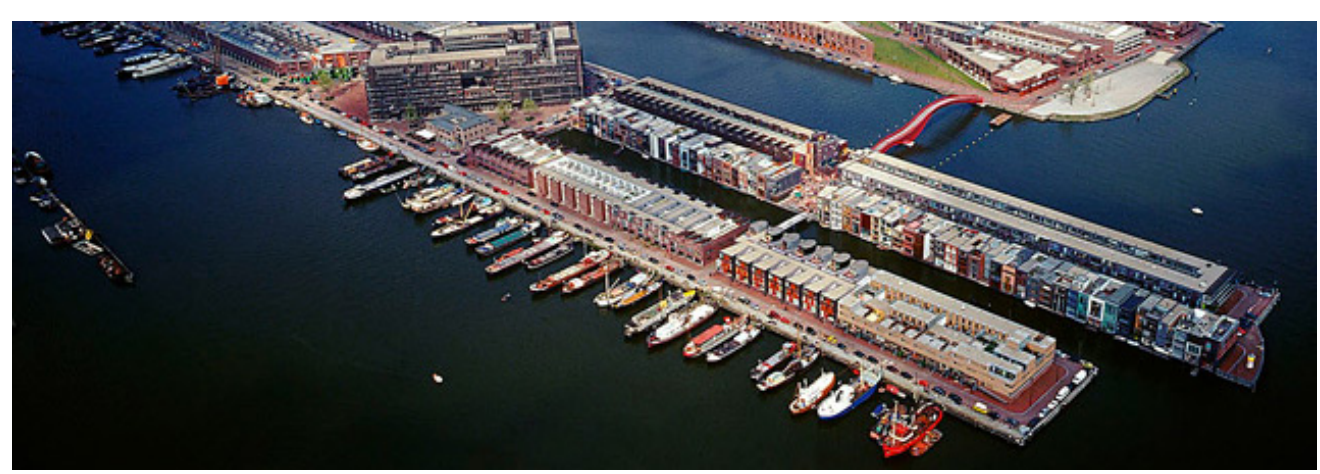

Figure 78: Individual architecture on the Amsterdam Borneo island. From http://www. west8.nl/projects/selected_projects/borneo_sporenburg/

Copyright 2017 by WEST8. Reprinted with permission.
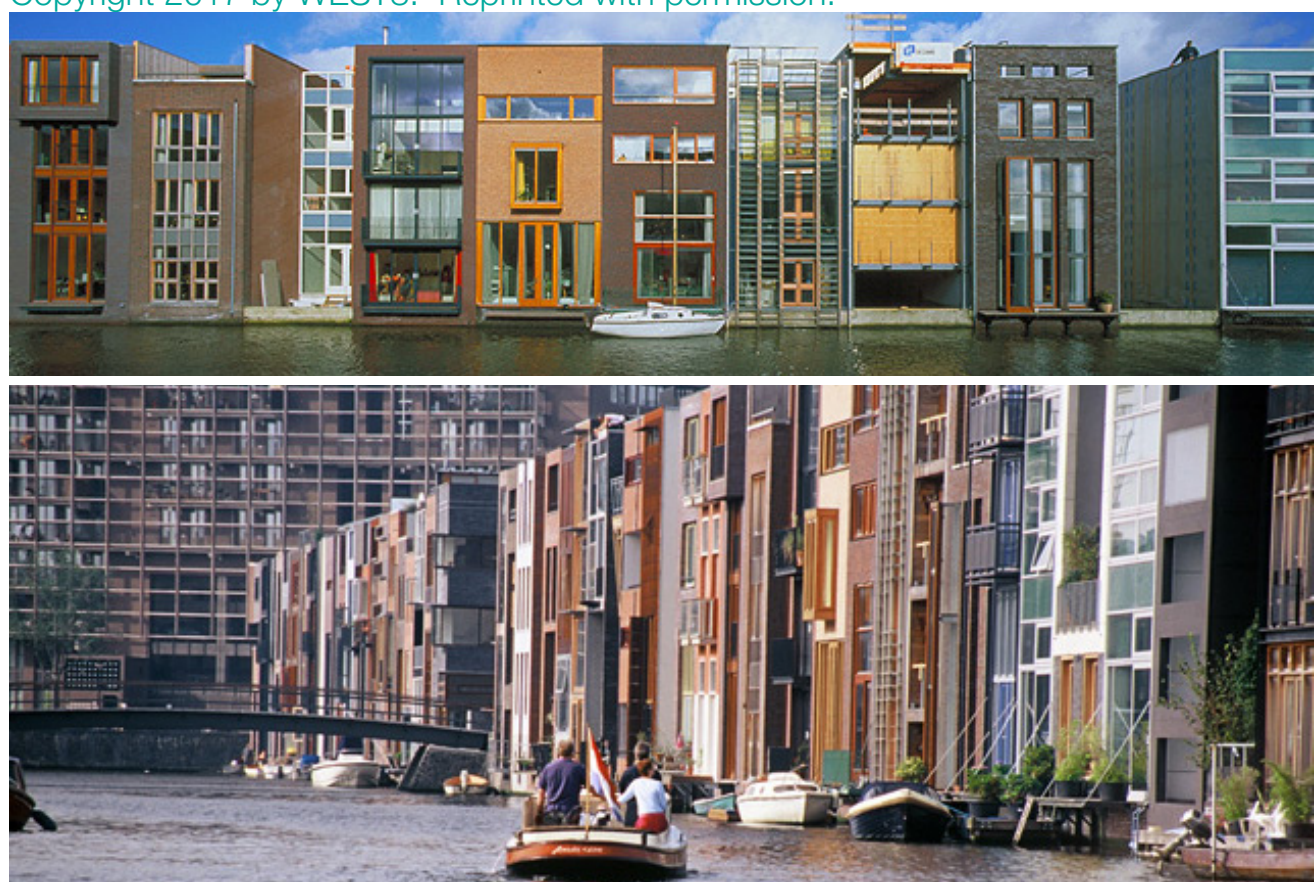

Figure 79: Typologies along the canal on Amsterdam Borneo island. From http://www. west8.n//projects/selected_projects/borneo_sporenburg/ Copyright 2017 by WEST8. Reprinted with permission. 


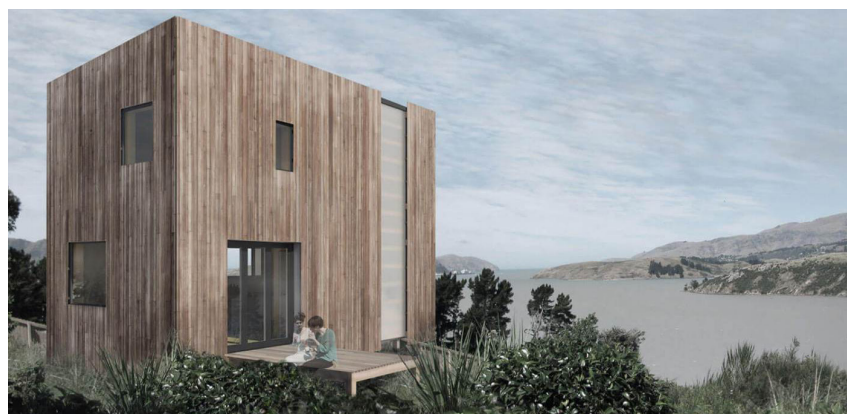

Figure 80: Artistic render of project. From http://www. makersofarchitecture.co.nz/approach/ Copyright 2016 by Makers of Architecture. Reprinted with permission.

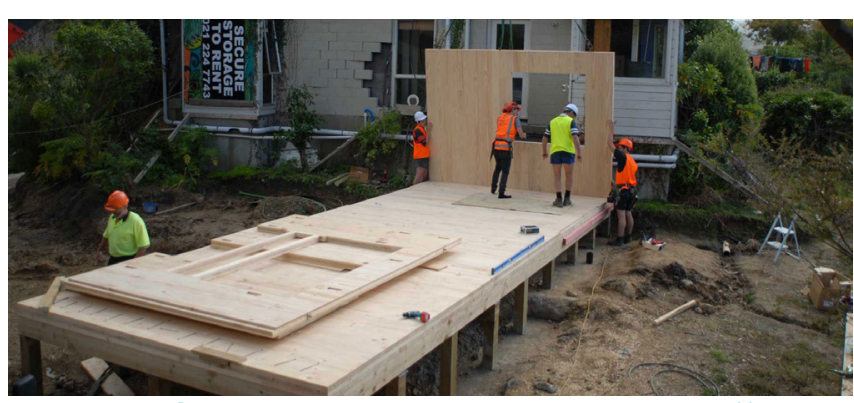

Figure 81: CLT panels placed on site. From http://www. makersofarchitecture.co.nz/approach/ Copyright 2016

by Makers of Architecture. Reprinted with permission.

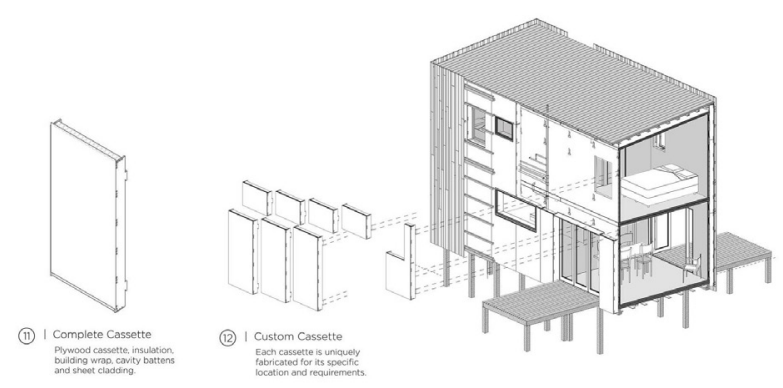

Figure 82: Cassette system. From http://www.

makersofarchitecture.co.nz/approach/ Copyright 2016 by Makers of Architecture. Reprinted with permission.
Makers of Architecture, a firm based in Wellington, has developed a sustainable prefabricated system to drastically reduce construction time, labour costs, and material wastage. The cassette system used in the 'Warrander Studio' integrates Cross Laminated Timber (CLT) and Computer Numerical Control (CNC) cut plywood to create a container for services and insulation (see Figure 80-82). The panels are locked into each other to create the house (see Figure 81). "The studio structure was constructed in 3 days due to the precision manufactured CLT panels being systematically lifted into place. The CLT structure was then clad with a new plywood based cassette system."

(Makers of Architecture, n.d, para. 1) (see Figure 82).

Elements of the 'Warrander Studio' could be used in this thesis project, including CLT and efficient design practise. The 'Warrander Studio' instigated research into the technology of CLT. It was found to be an extremely efficient and

\section{Warrander Studio}

sustainable element (Makers of Architecture, n.d). The specification of CLT in this design is due to a range of reasons including (XLam, n.d). Benefits of CLT include:

Can replace structural steel and concrete, and is more lightweight

- Extremely fast on-site construction.

- Prefabrication allows for exactness of measurements and less material waste.

- Provides thermal mass when exposed.

- Thermal bridging can be eliminated.

- Assembly requires limited skills.

- Internal loads are unrestricted compared to stud walls.

- Withstands earthquakes.

- Timber is renewable and stores carbon during growth and use. 


\section{Zero Energy House}

"The goal of the Zero Energy House project is to improve the quality of housing in New Zealand" (Evident, n.d). Sustainable materials and technologies have been applied to this model house, and their long-term performance and cost are being recorded over time. In particular, the Zero Energy House serves as a precedent for sustainable cladding. The model utilises untreated macrocarpa timber on the external walls. Macrocarpa's natural qualities give it the same durability as H3.1 treated pine, as well as resistance to rot and insect damage. It also weathers to produce a natural silvering effect (Evident, n.d) (see Figures 83 and 84). Untreated, it can be safely composted at the end of its life, fitting within an optimal cradle-tocradle scenario. These factors make it an ideal option for this thesis project.

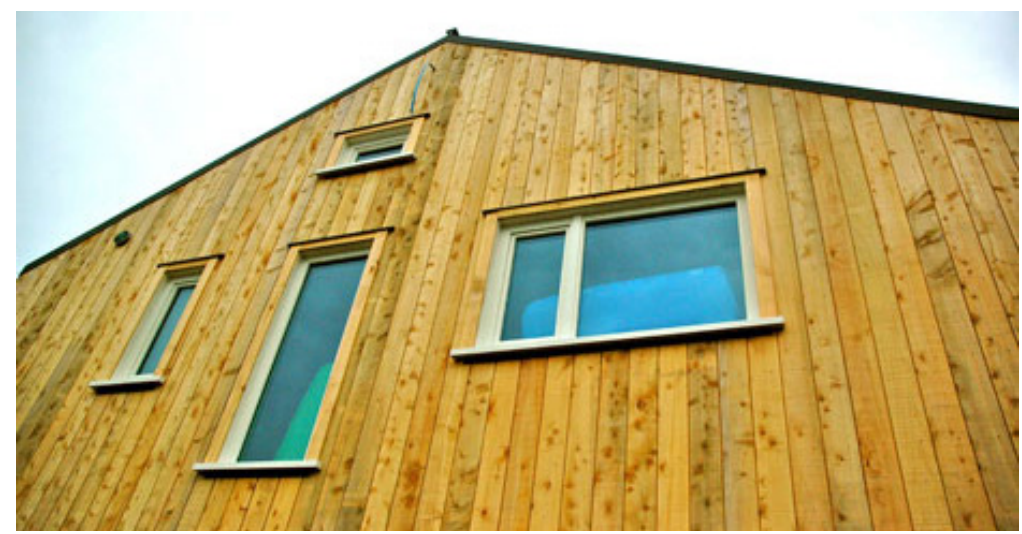

Figure 83: Macrocarpa cladding at time of construction. From

https://zeroenergyhouse.co.nz/cladding/ Copyright 2017 by A

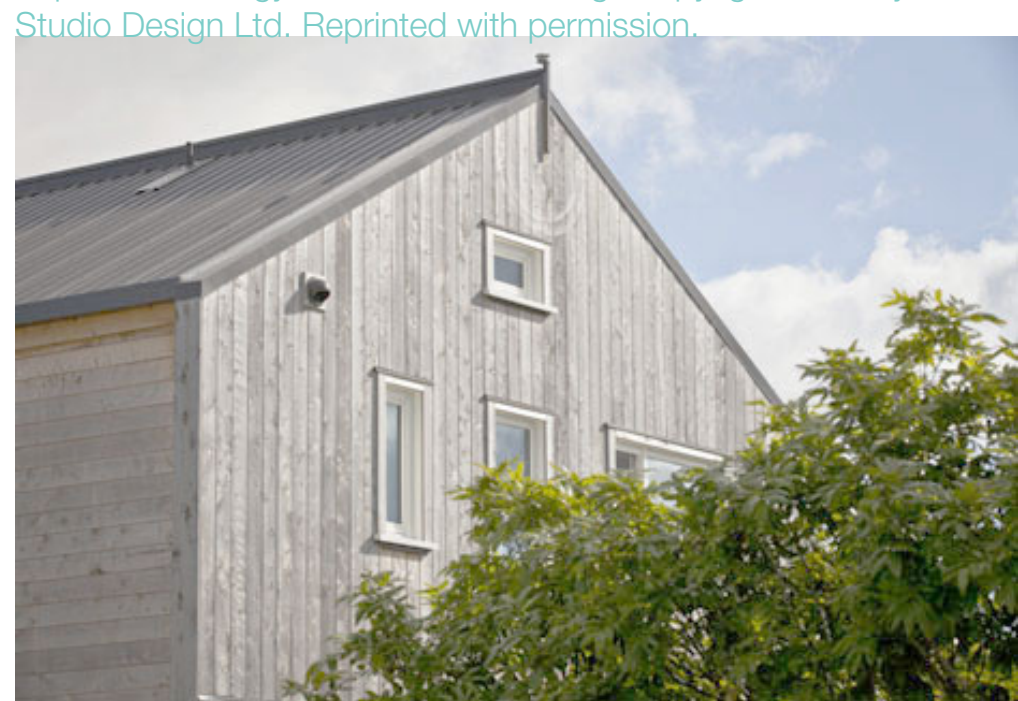

Figure 84: Macrocarpa cladding after less than a year after construction. From https://zeroenergyhouse.co.nz/cladding/ Copyright 2017 by A Studio Design Ltd. Reprinted with permission. 
New Zealand's small size is a real disadvantage for material acquisition and technological advancement. Recycled drywall, BioSIPS, specialised weather resistant sustainably forested timbers, BioConcrete, and sustainable glazing are a few examples of products that are readily available overseas but not found in NZ. Of the 173 certified 'cradle-to-cradle' products available around the world, only one could be found for sale in New Zealand Silestone's Eco Line series of bench tops, which is produced in Spain. The carbon footprint involved in transporting the product to NZ reduces its overall sustainability (Silestone, n.d.). While this shows a limited market interest in the area, examples such as macrocarpa and sheep's wool insulation (Terra Lana Products Limited, 2017), suggest that there may be local options which fit within the framework.

When researching possible materials, and coming to terms with their limited availability and sustainability, the selection became a process of finding the materials that aligned themselves most closely to the 'cradle-to-cradle' principles outlined at the beginning of this study. The chosen materials were not selected based on any industry rating systems, but by careful investigation. A review of global environmental standards, such as the USA's Leadership in Energy and Environmental Design Standard (LEED), the European Standard of Environmental Management, and NZ's Green Star rating system, found the standards were sometimes unreliable. This is primarily due to the levels of achievement that each rating system offers, and the fact that materials can claim to be certified despite only meeting one aspect of the respective rating system. For example, LEED promotes an insulated concrete form (ICF) system by ARXX Corporation, in which a concrete wall is poured between two panels of insulating styrofoam. While the system is highly insulating and therefore very energy efficient postconstruction, it uses two entirely unsustainable materials. LEED admits that this "may be unpleasant to hardcore environmentalists" but says it "has no effect on LEED credits" (Meisel, 2010, p. 26).

Instead, selected materials were analysed against a Life Cycle Assessment (LCA) (International Organization for Standardization [ISO], 2006). This process assesses materials from manufacture to disposal against 'cradle-tocradle' principles. The LCA was comprised of five categories that products could be compared against: Co2 footprint, toxicity, recyclability, operational energy, and price. Each category included subgroups of relevant issues, such as insulation value under operational energy, and life expectancy under recyclability. Information for every subcategory was not always available for each material, but the life cycle analysis gave a more holistic overview of the product's sustainability than the industry standards offered (see Appendix F for LCA). 


\section{Stage 2-Site Planning}

\section{Option 3}

Building on the site plan concepts from Stage 1, a new site plan option was created to address the issues that were mentioned in the first review, such as better vehicle access, increased shared space, and orientation of units towards the street (see Figures 85-92). Perimeter housing addresses all street fronts and also creates positive internal space and a sense of ownership for the residents.

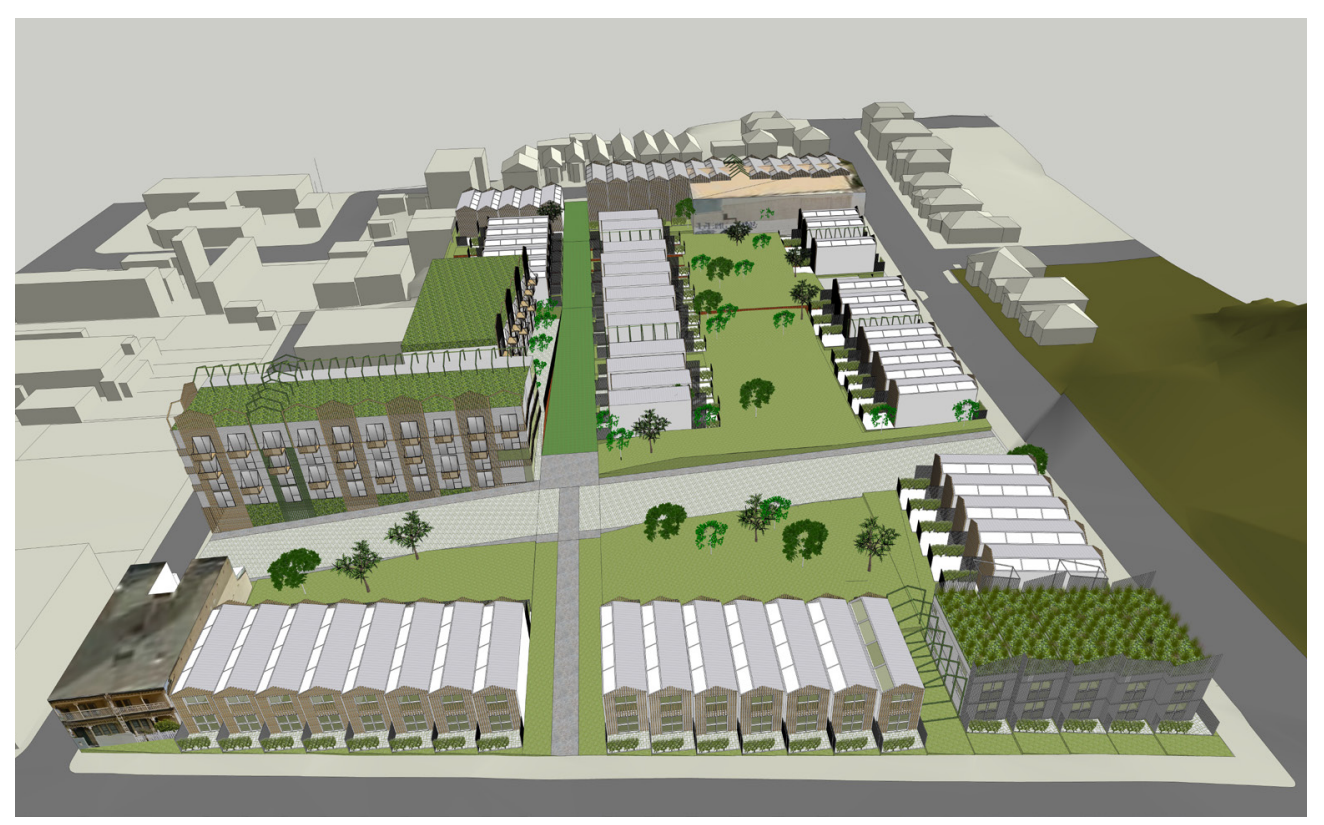

Figure 85: Site massing option 3.
A decision was made to include apartment buildings in this new site plan. This would meet the market demand for single-person living that was uncovered during the Site Study, and would also help to make the feasibility of the project more achievable.

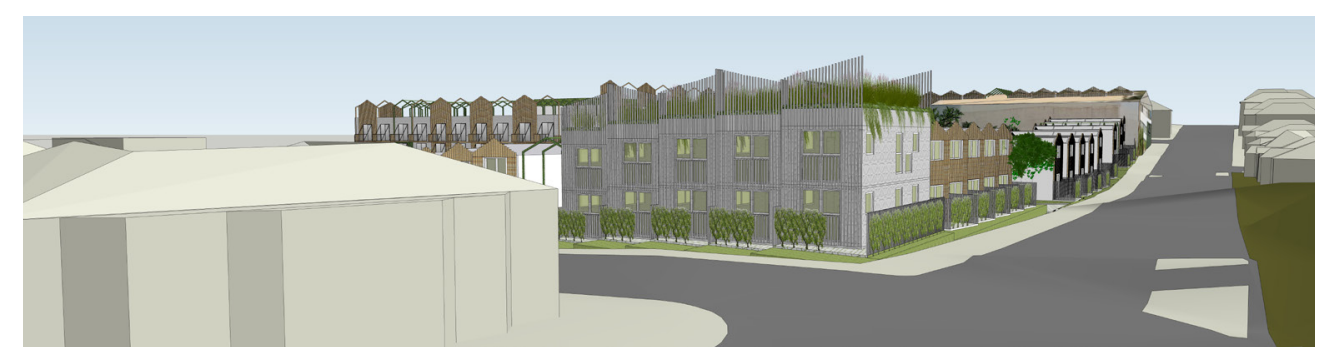

Figure 86: Tasman street option 3.

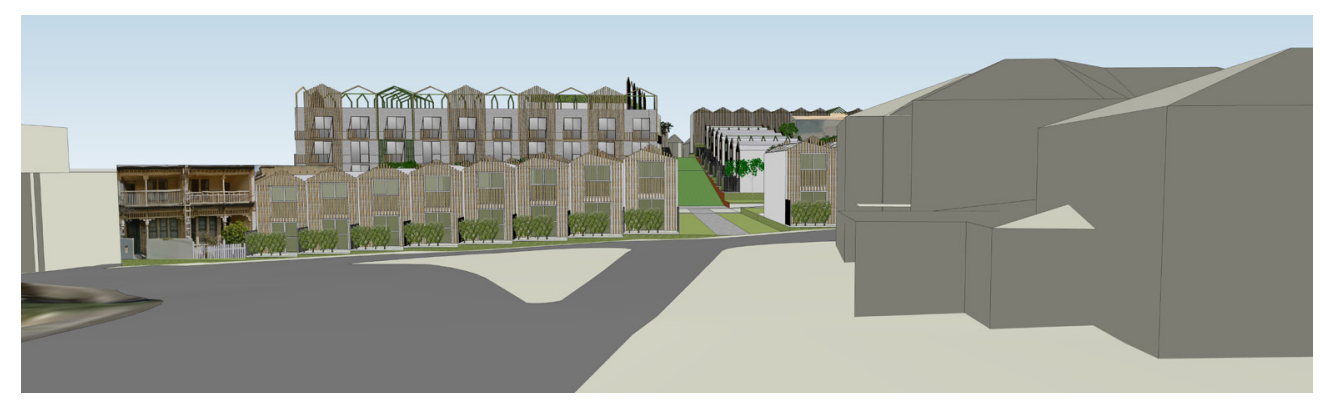

Figure 87: Sussex street option 3. 


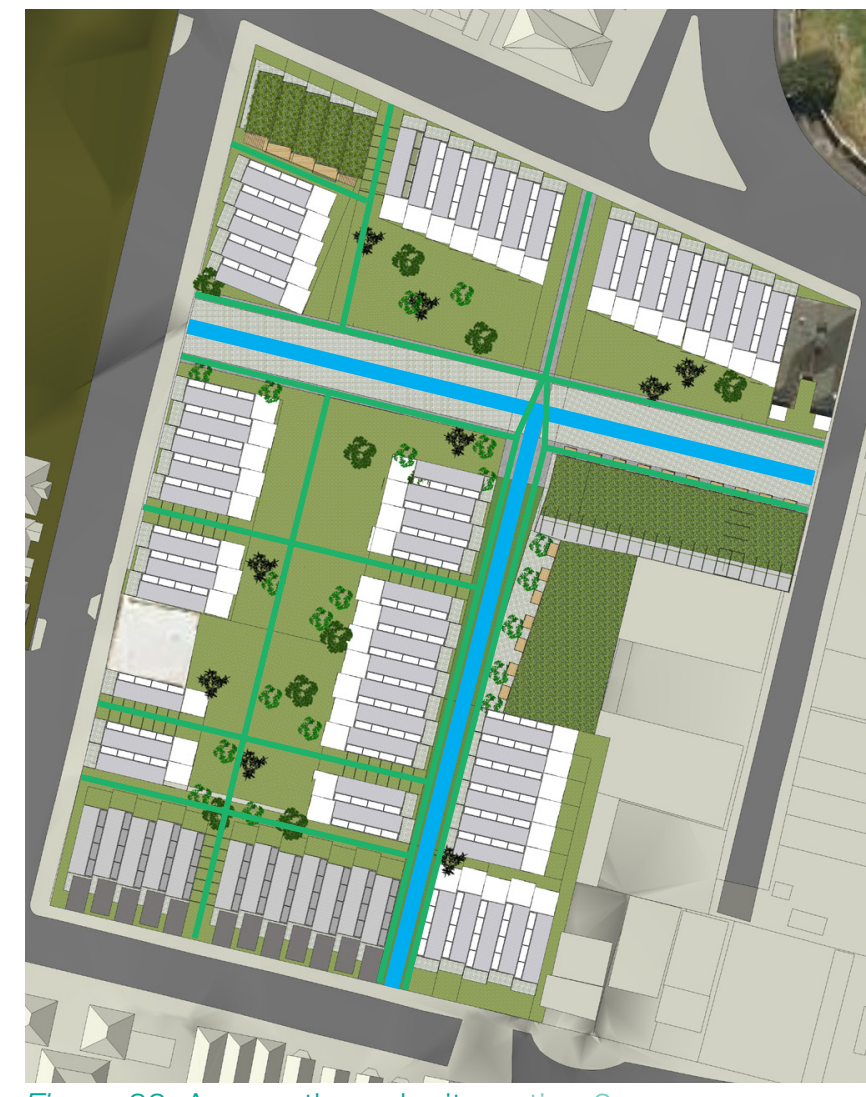

Figure 88: Access through site option 3.

\section{Key:}

Vehicular - Blue

Pedestrian - Green

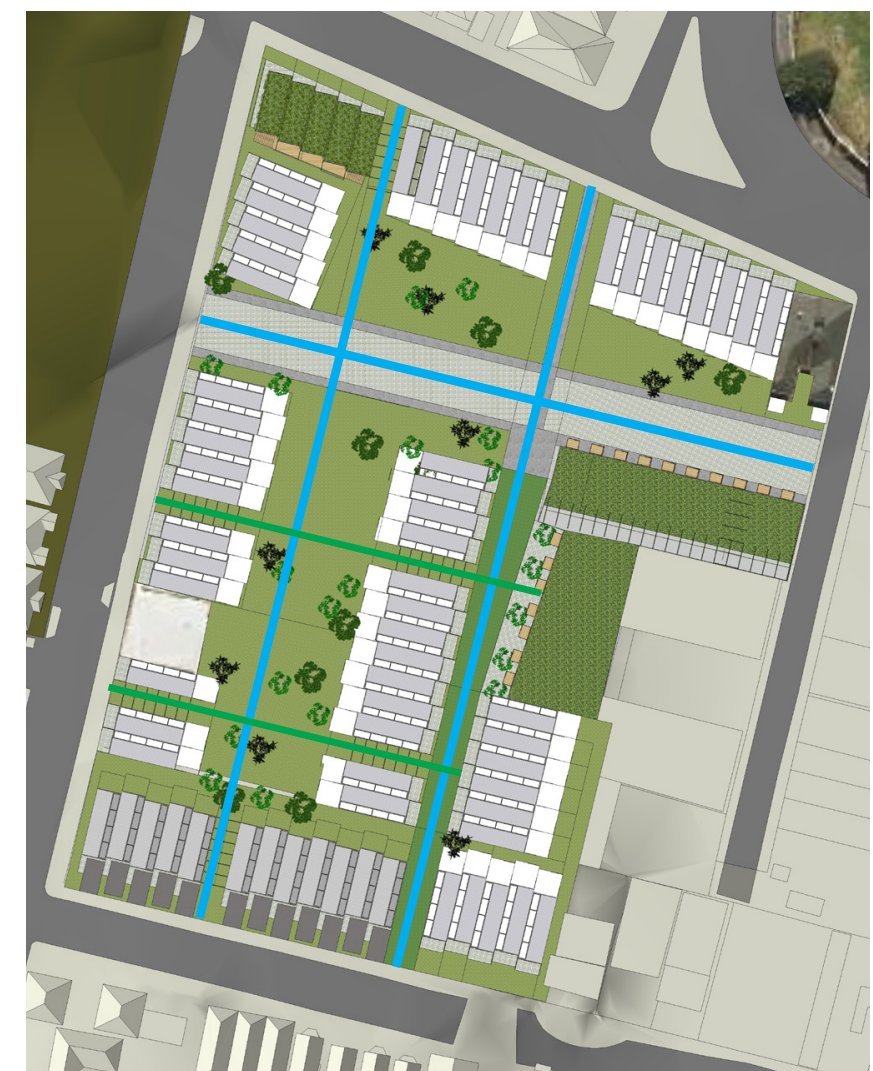

Figure 89: Routes through site option 3.

\section{Key:}

Primary (through entire site) - Blue

Secondary (through large portion of site) - Green

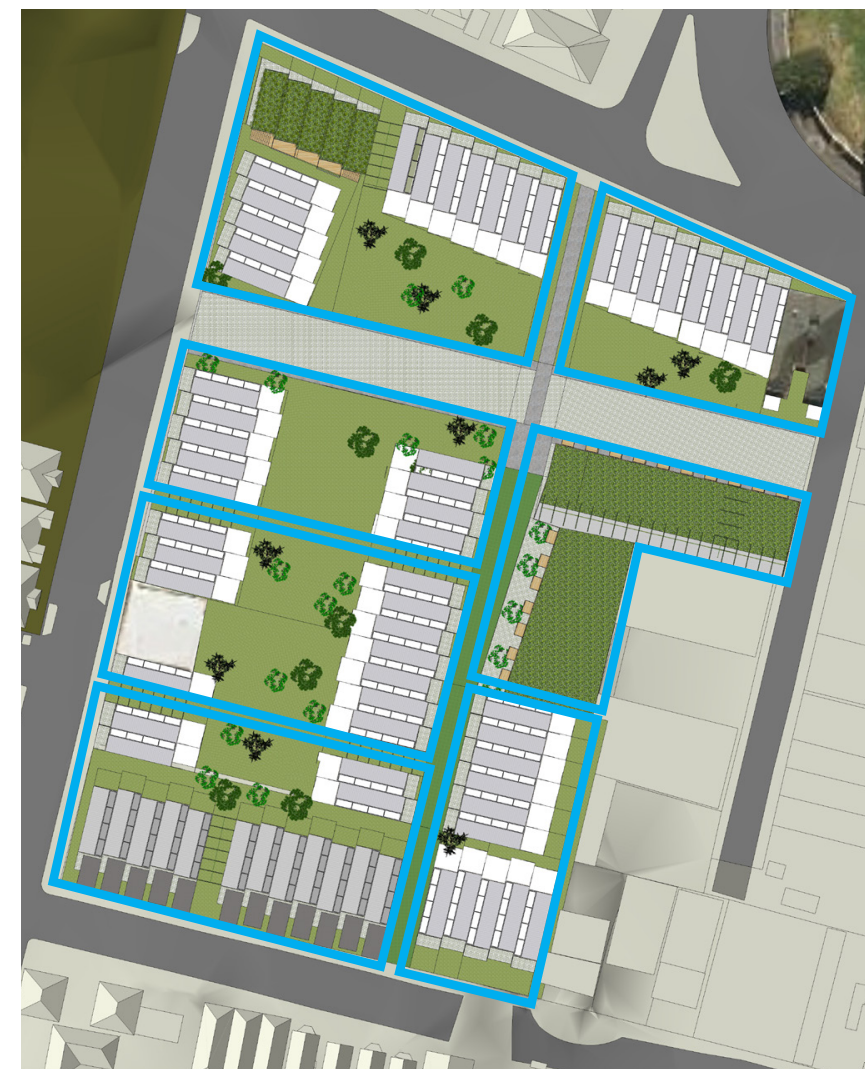

Figure 90: Site grain option 3

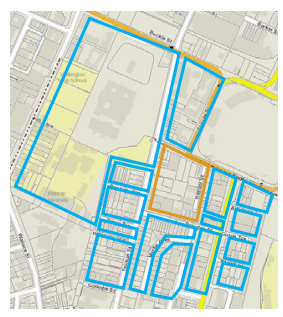




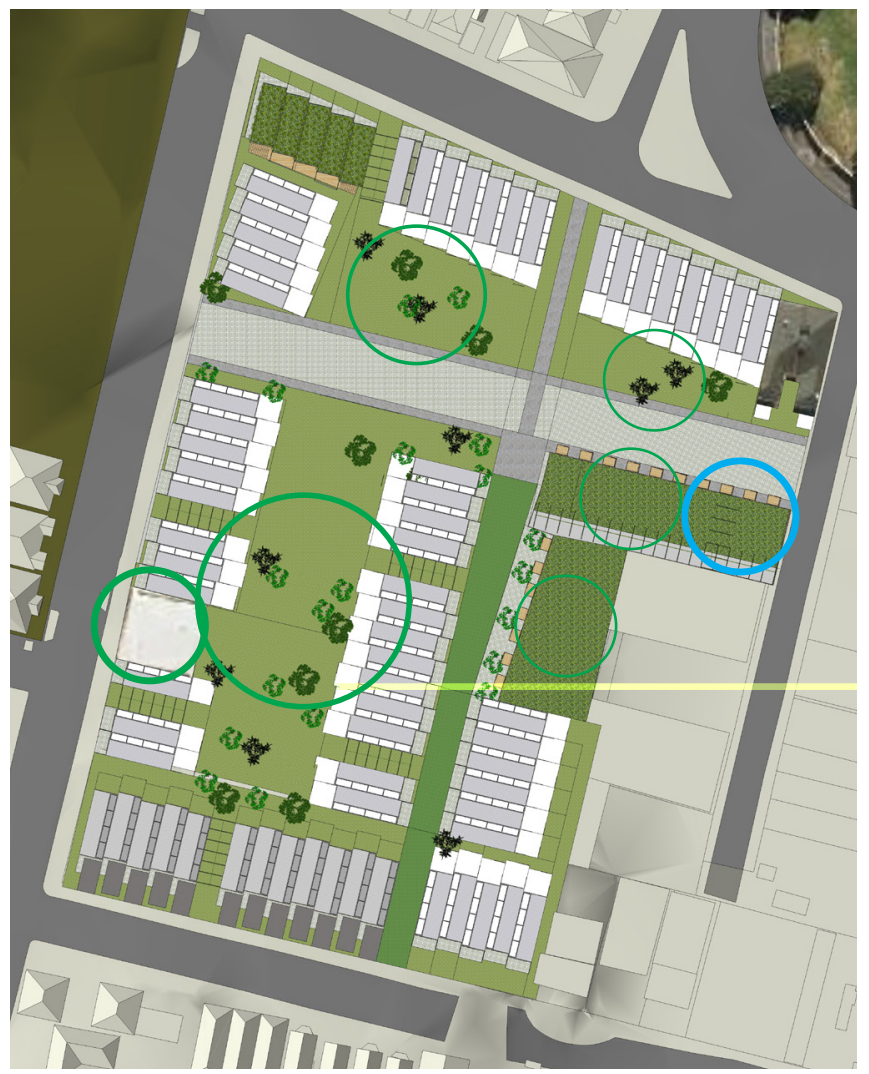

Figure 91: Facilities site option 3.

\section{Key:}

Alternative transport parking (uber / city hop) - Blue

Community building / Parks - Green

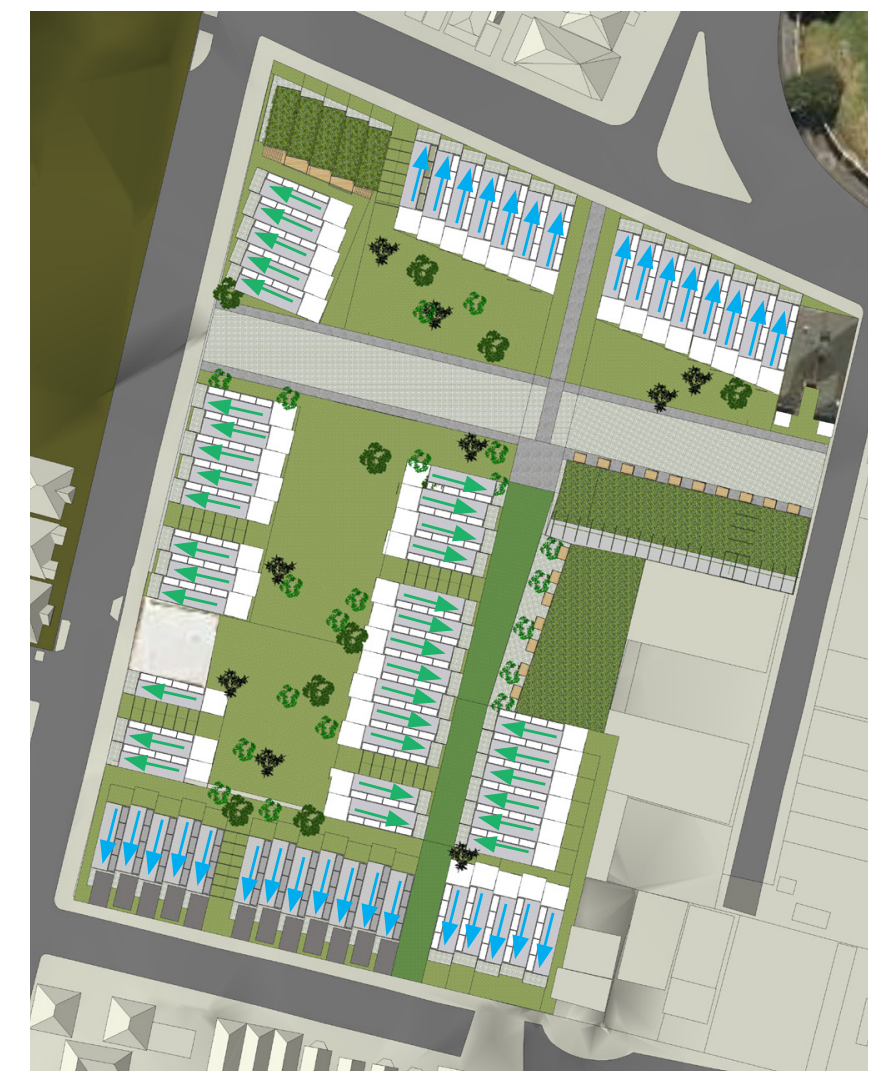

Figure 92: Unit orientation site option 3.

Option 3 Number of units: $\quad 67$

East West units:

North South units:

Two storey units:

Three storey units:

Carpark units:

67
35
32
55
12
12


The second stage of the unit development began with CAD-drawn floor plans, based on the 3D unit representations established in the first design stage (see Figures 94-97). Internal spaces were designed with the developer and architect interviews in mind. Privacy, function, and sustainability considerations were important (see Appendix B and C for additional development drawings). Points of focus included:

- Keeping the circulation space and overall footprint as small and efficient as possible

- Containing plumbing to minimise the distance between sanitation units

- Using space-saving techniques, such as cavity doors and multi-purpose areas

- Creating visual connections to the ground floor via a void in the first floor

- Providing generous spaces in important areas, particularly the kitchen and bathroom

A variety of external facades were also developed through 3D modelling (see Figures 98-100). After continued design experimentation, an external vernacular was formed that blended modern aesthetic with traditional materials and elements (see Figures 101-123). For example, it was decided that three roof forms would be offset against each other: the traditional gable, a modern asymmetric pitch, and a monopitch reminiscent of a villa lean-to. Cool coloured roofing was utilised here, as this is an easy way to make a building more sustainable (see Figure 93). Compared with dark coloured roofing, light roofing reflects more sun as light than heat, helping to counter climate change and reduce the energy required to keep a building cool in summer. Light coloured roofing is also longer-lasting because it expands and contracts less (Van Baaren, 2013)

The design process was constantly reflected upon, and each change to a plan or model aimed to create a more architecturally beautiful element or a more efficient space. Once a range of typologies made it through this stage of the design process (see Figures 101-123), they were integrated into the site in a visually random fashion similar to the Sporenburg development.

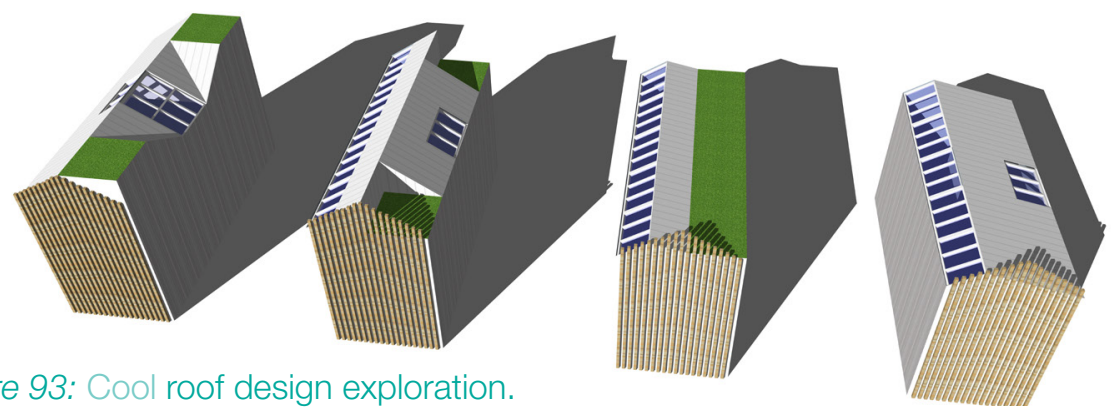




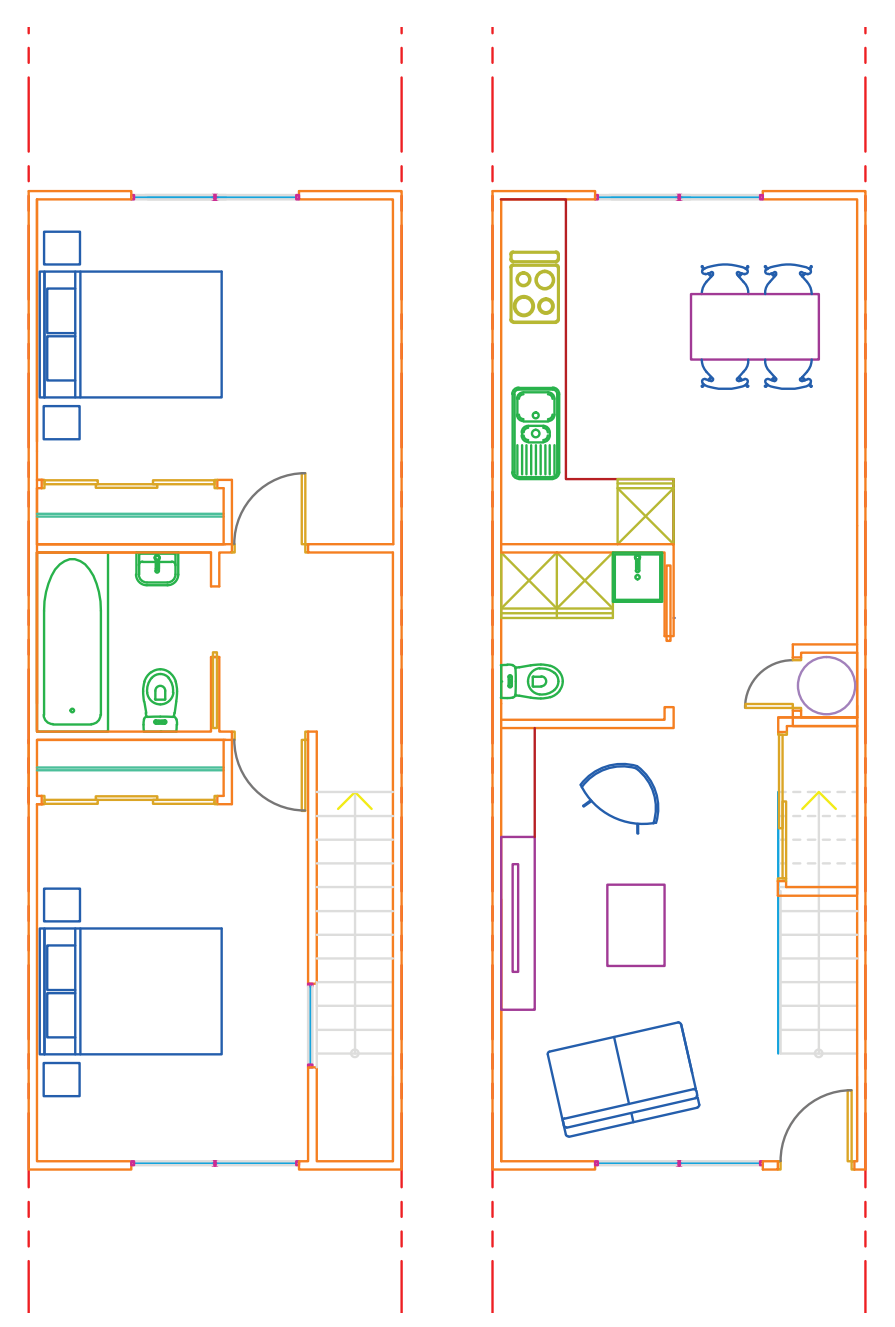

Figure 94: 2 bedroom unit. Plan not to scale.

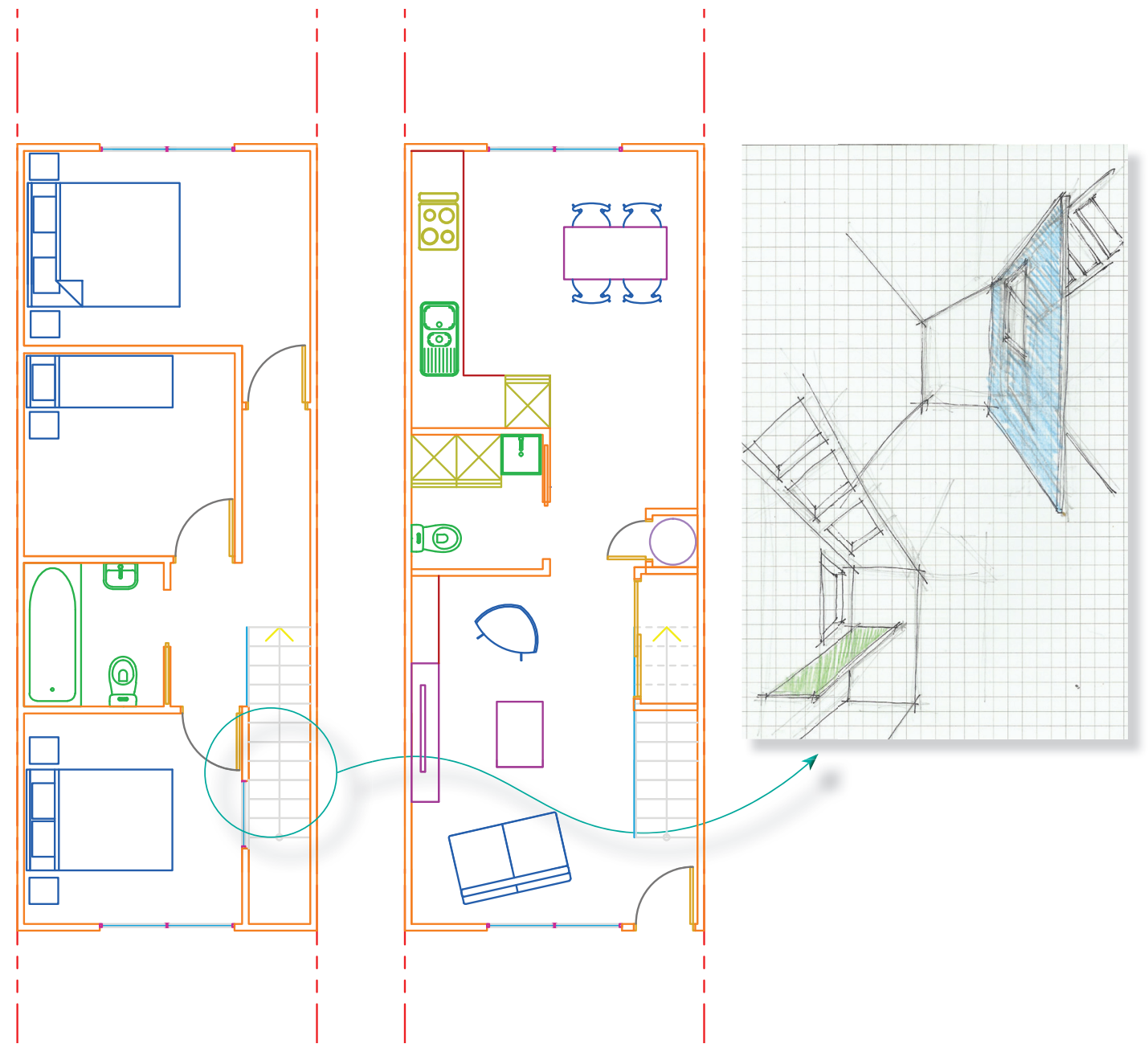

Figure 95: 3 bedroom unit. Plan not to scale. 


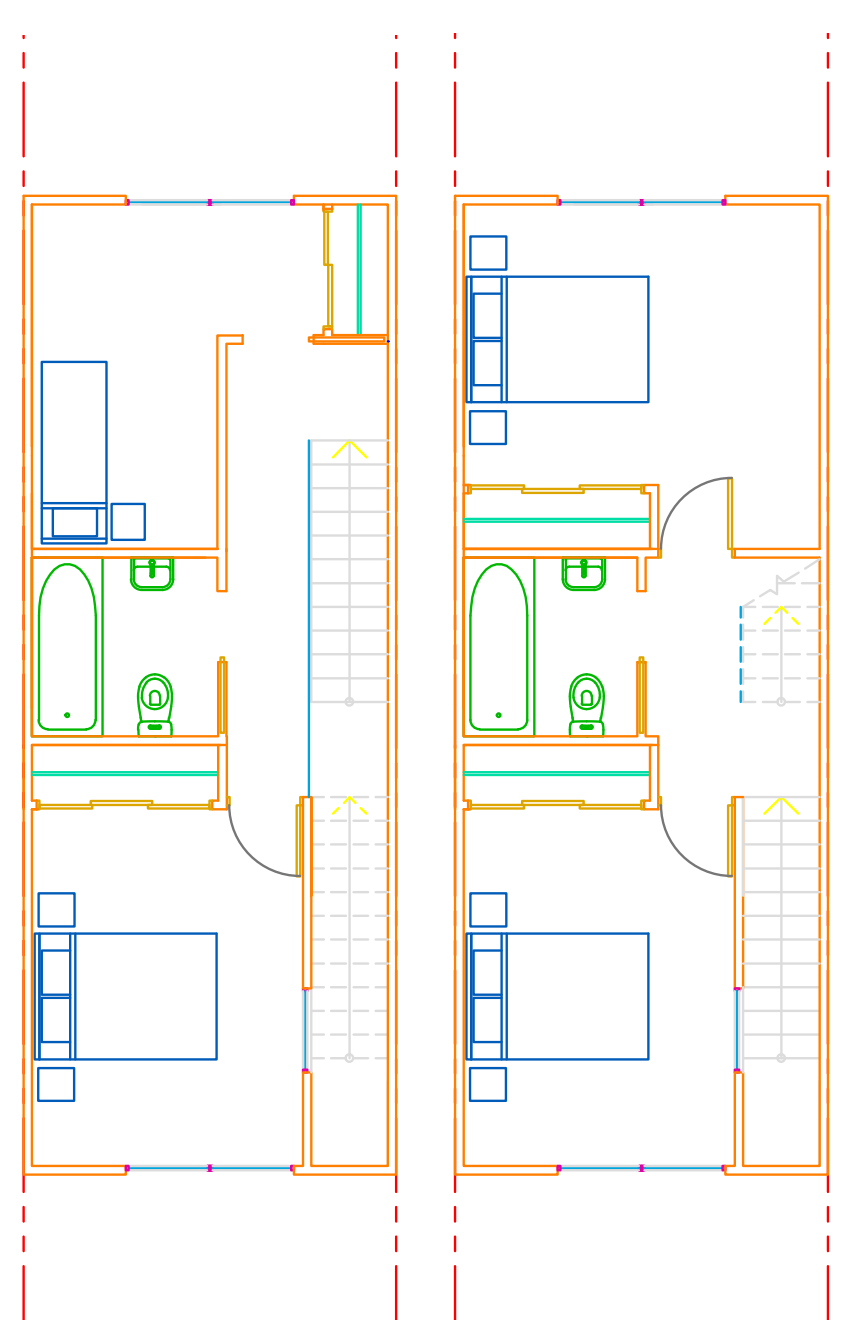

Figure 96: 4 bedroom unit. Plan not to scale.

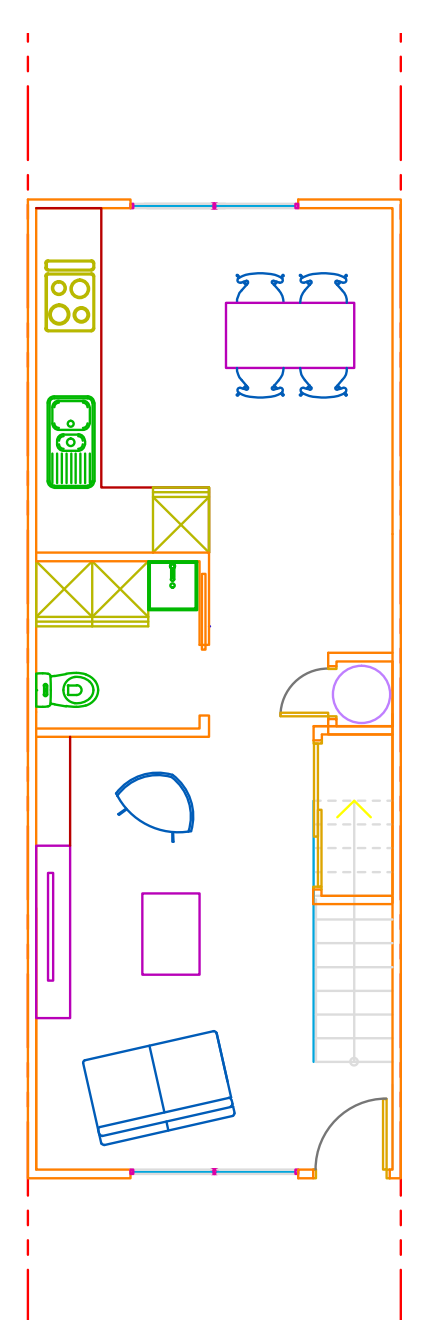

Figure 97: Unit plan exploration. Plans not to scale.
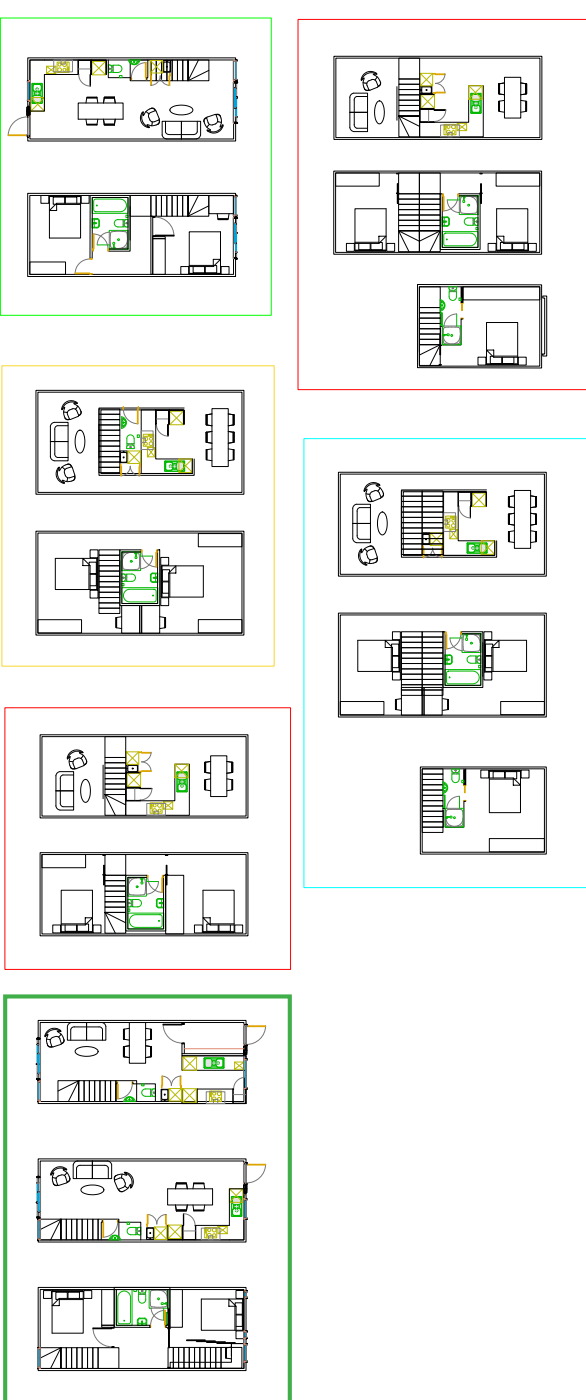


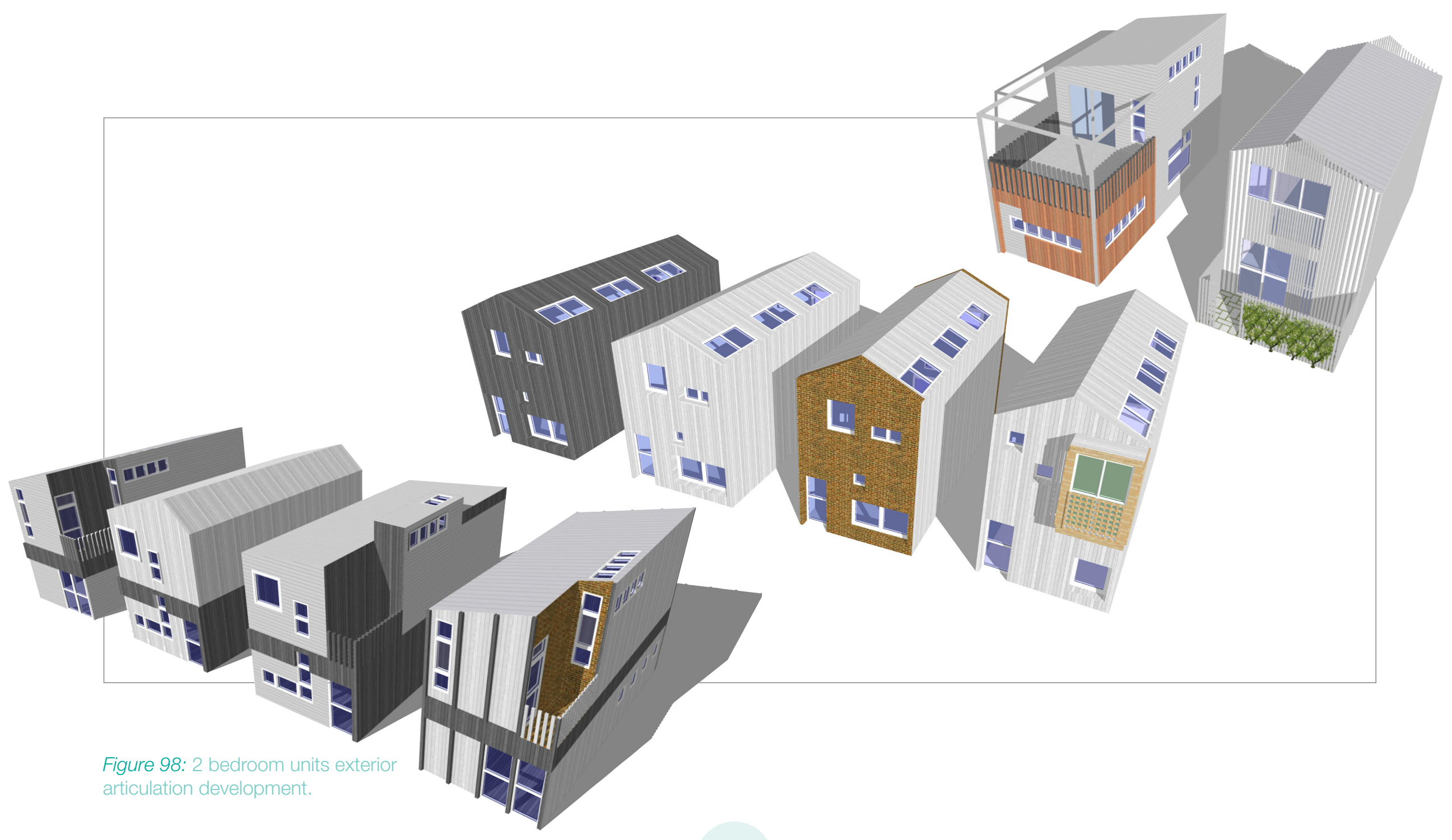



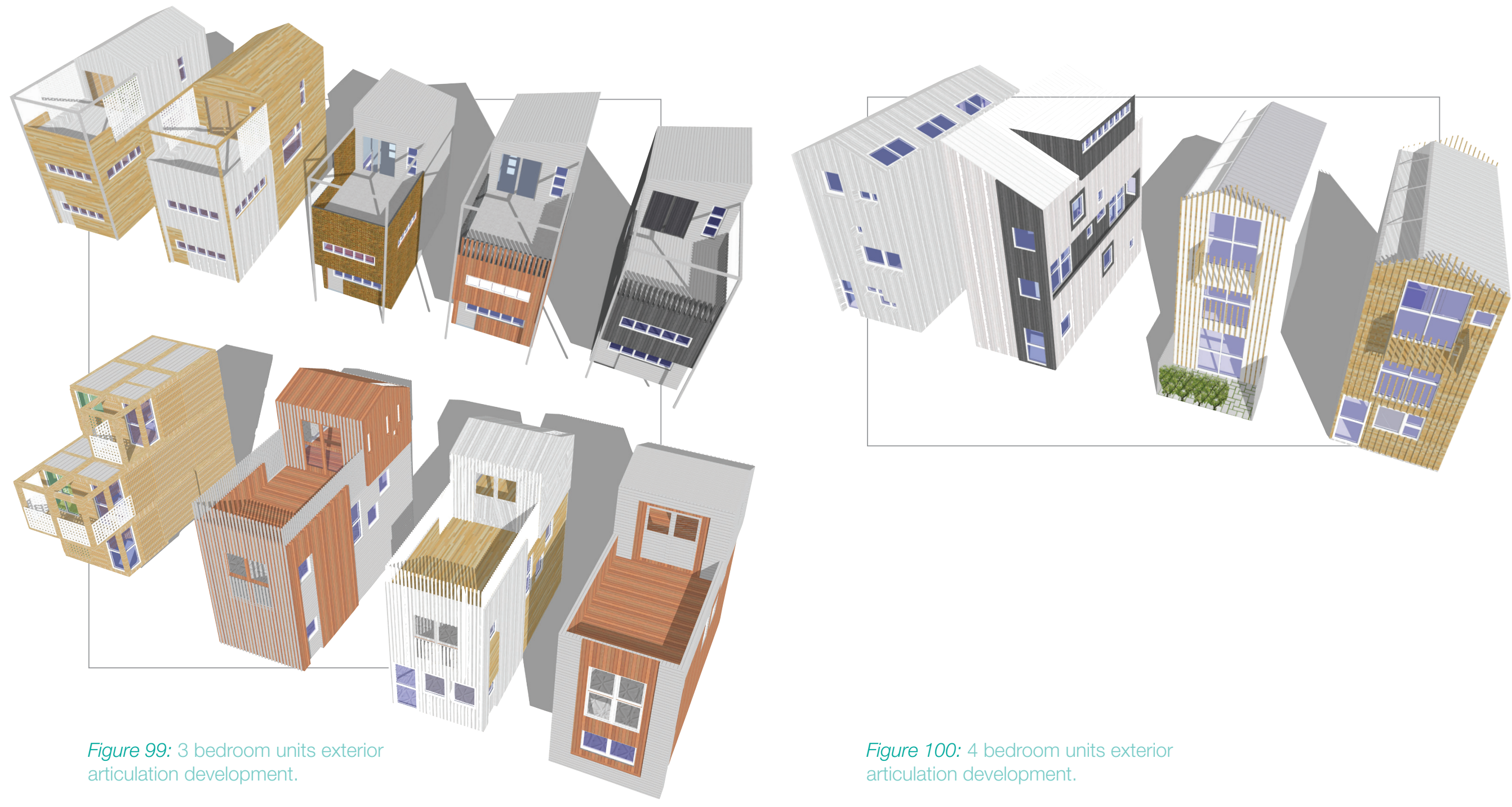

Figure 100: 4 bedroom units exterior articulation development. 


\section{Stage 2-2 Bedroom Unit 1:100@A4}

$>$

$\infty$

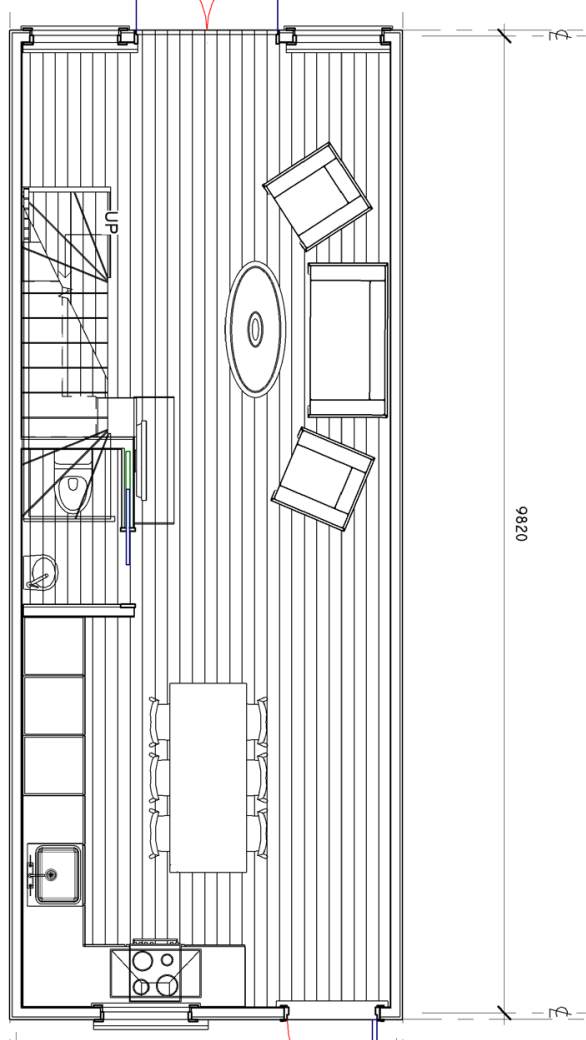

Figure 101: Stage 2, 2 bed ground floorphath 3820
D

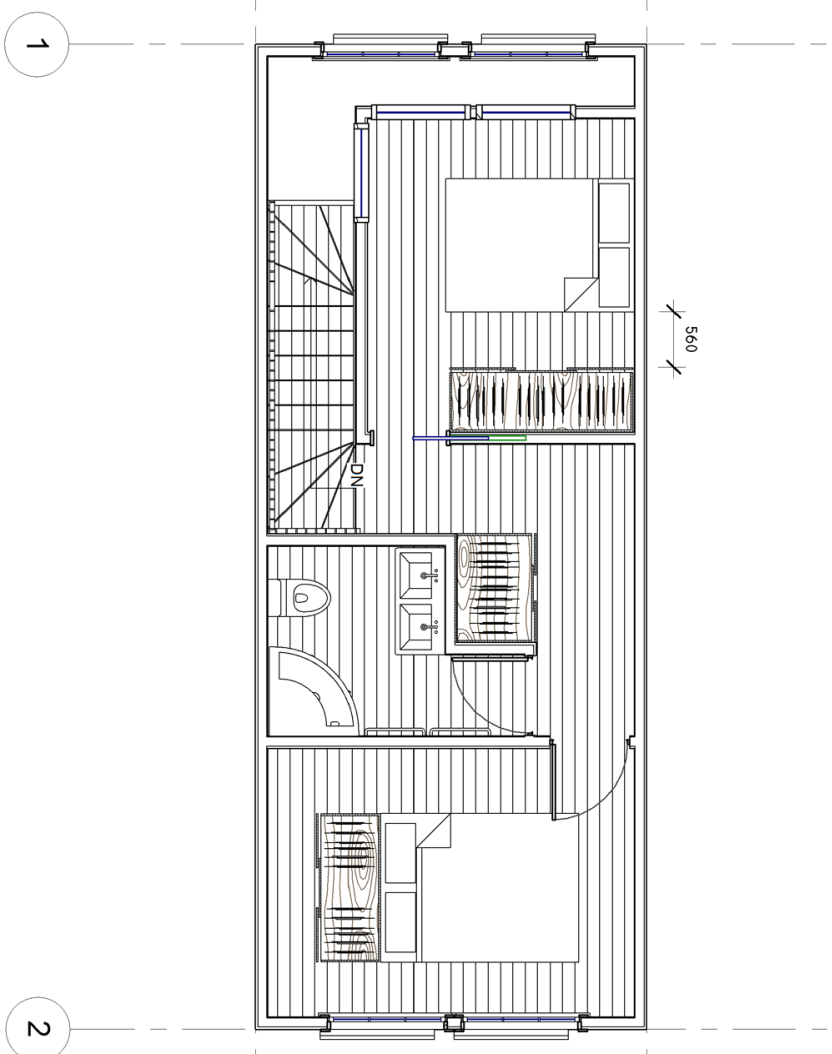

Figure 102: Stage 2, 2 bed first floor plan.

76

$\infty$ $\infty$

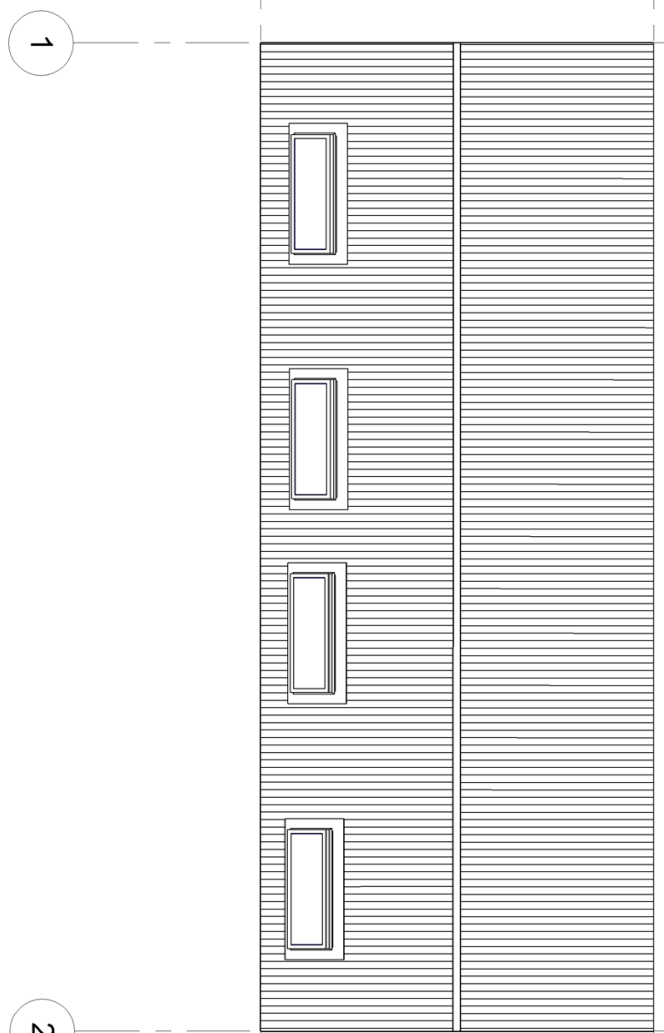

Figure 103: Stage 2, 2 bed roof plan. 

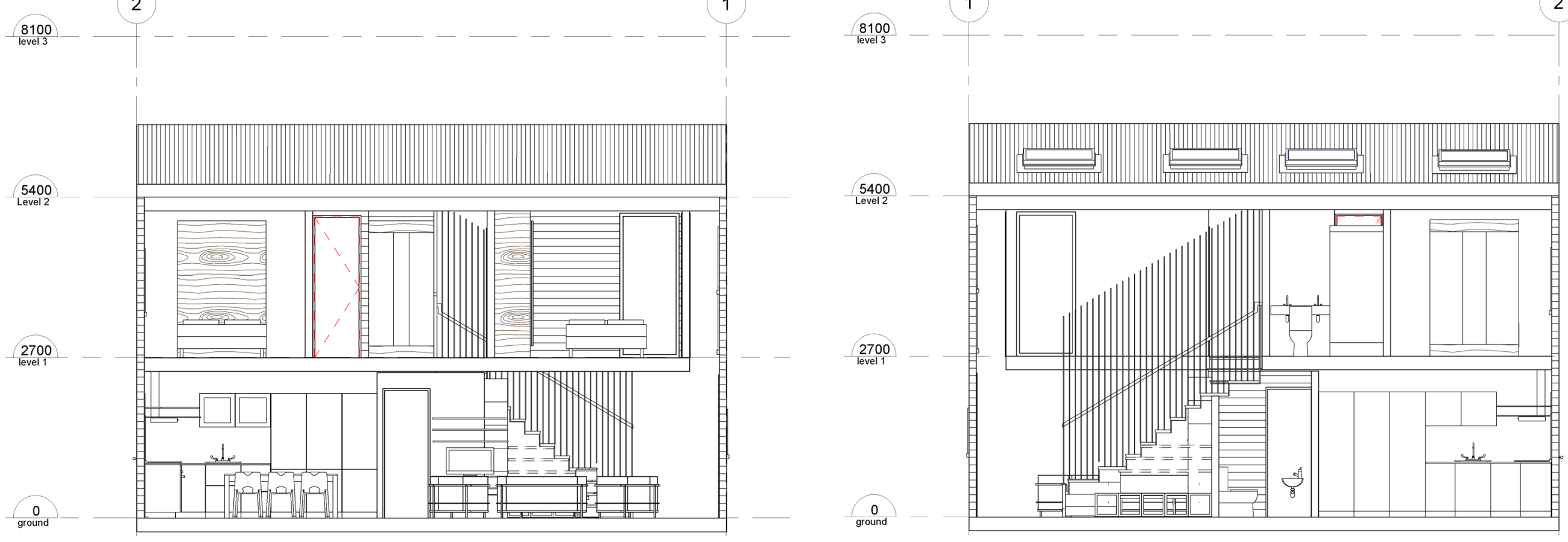


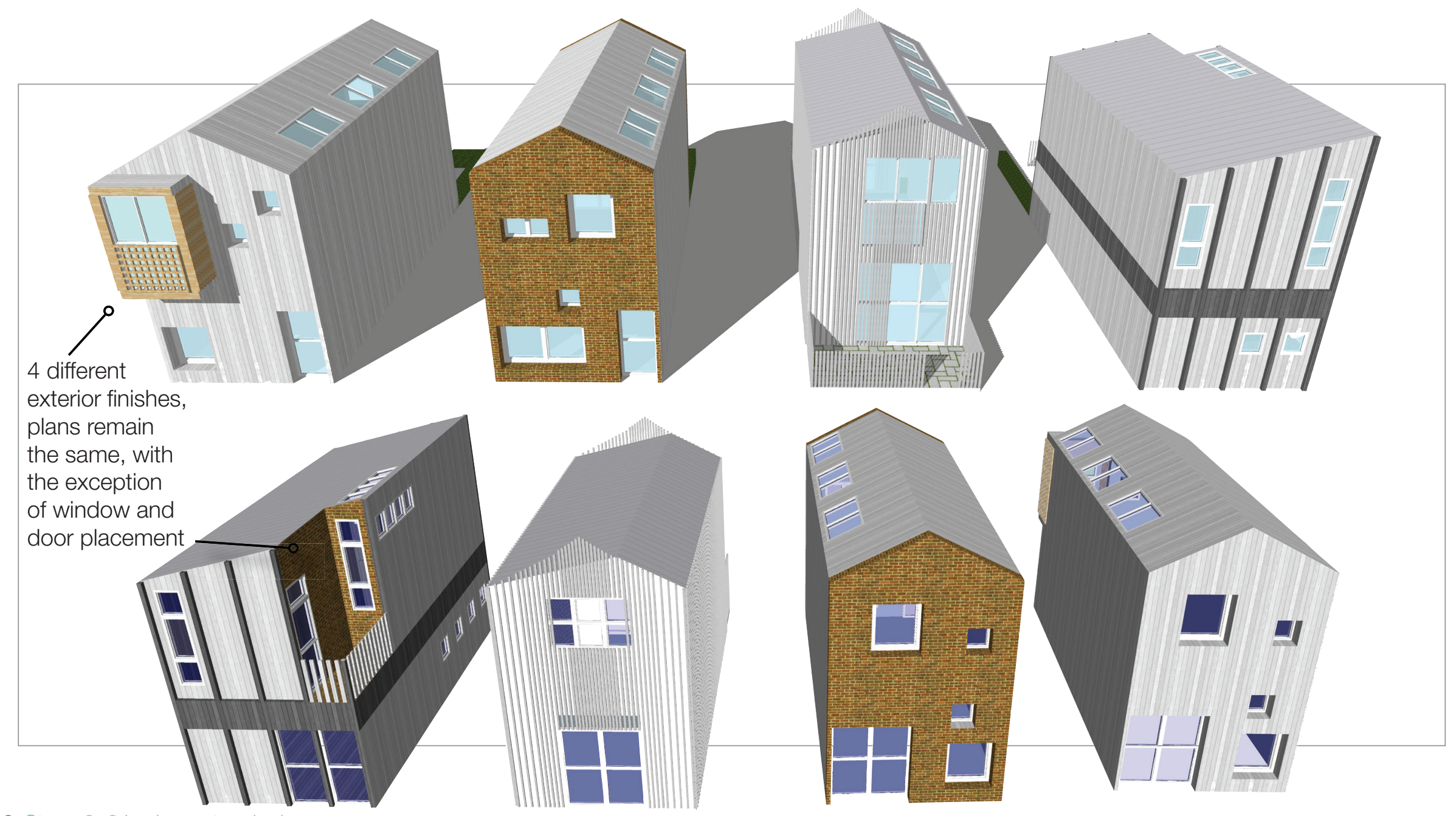

Figure 106: Stage 2, 2 bedroom typologies, 

majority of solar radiation to keep

temperature cooler indoors

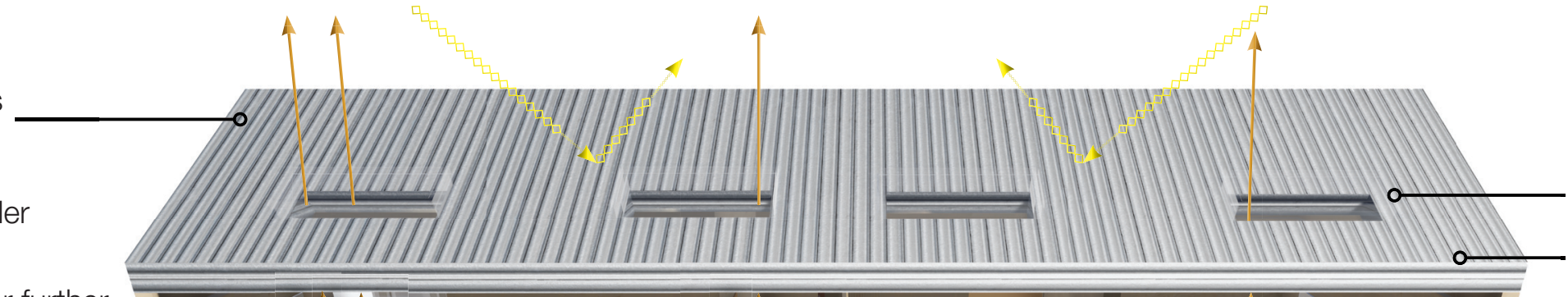

Operable skylights

High windows for further light depth

Stack effect, warm air floats up to the top of the building, movement pulls replacement cool air from outside

Natural cross ventilation through each level

Air tight envelope, when windows and doors are closed

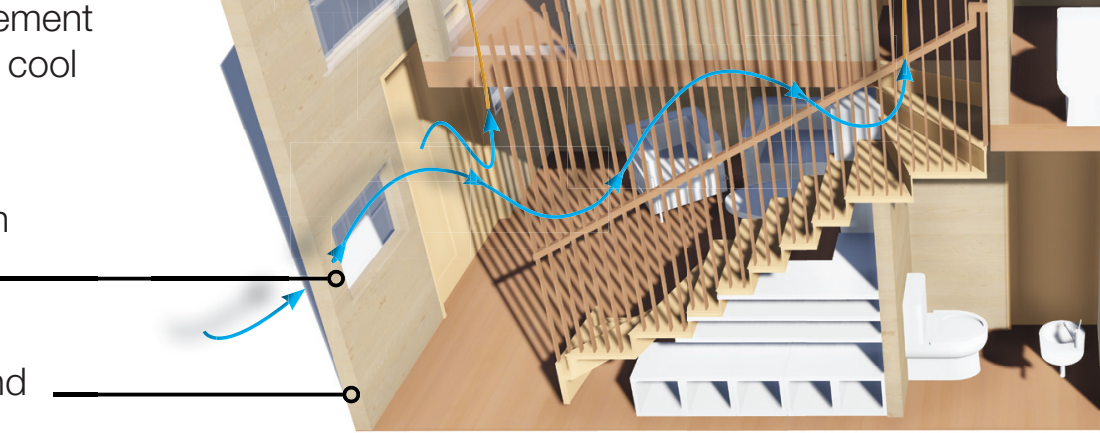

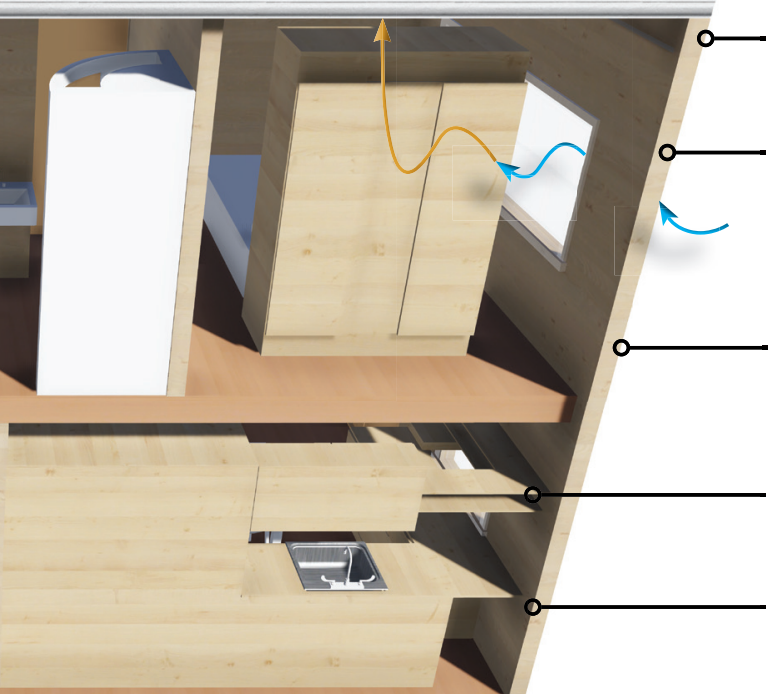

Walls and roof insulated to achieve high R-value

Sustainable timber cladding

Double glazing low E

Less glazing on South facing façades

CLT structural system for walls floors and roof 


\section{Stage 2-3 Bedroom Unit 1:100@A4}

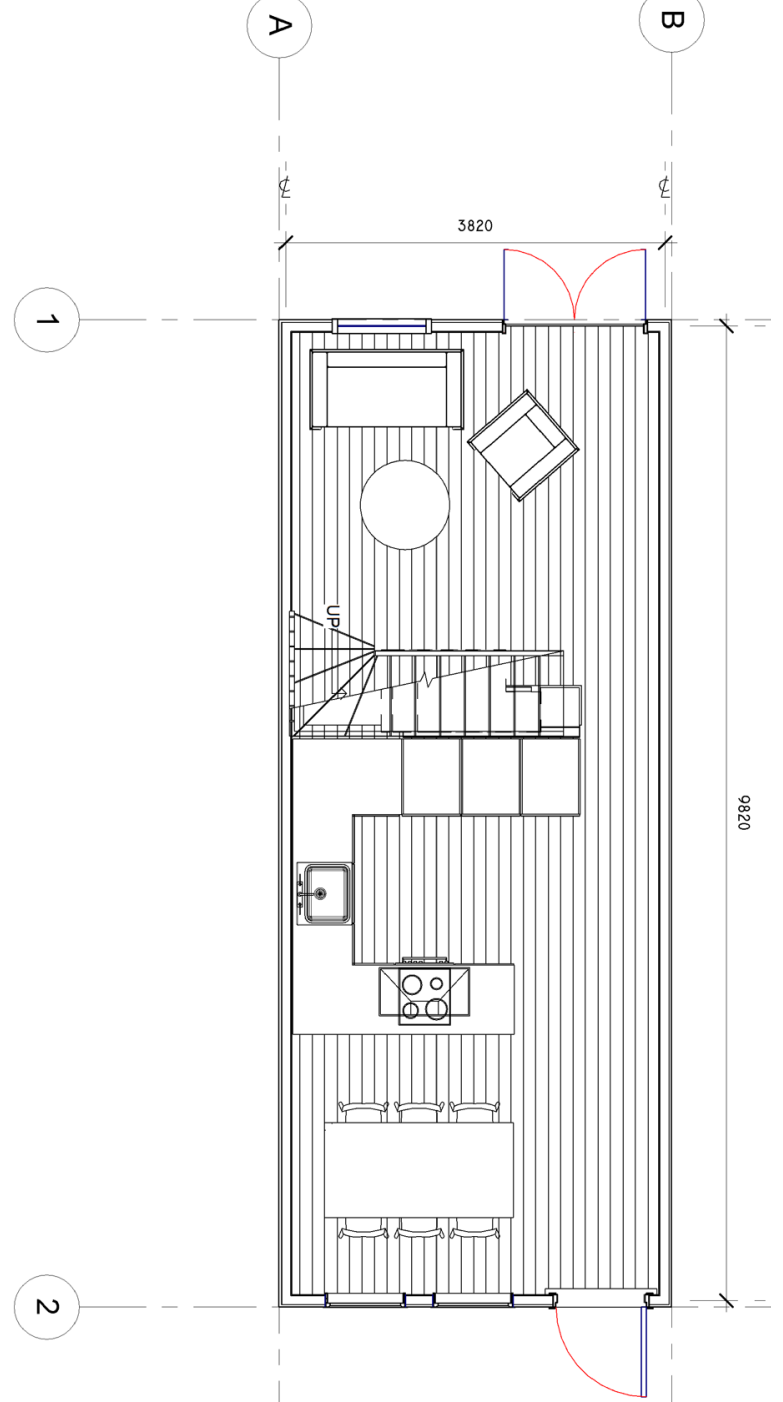

Figure 108: Stage 2, 3 bed ground floor plan.

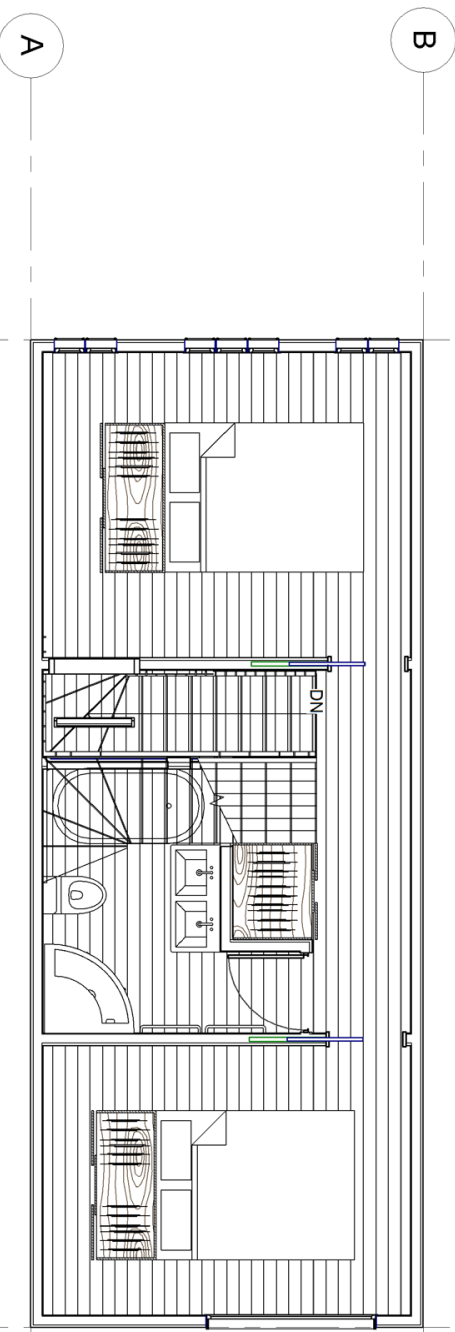

Figure 109: Stage 2 3 bed first floor plan.

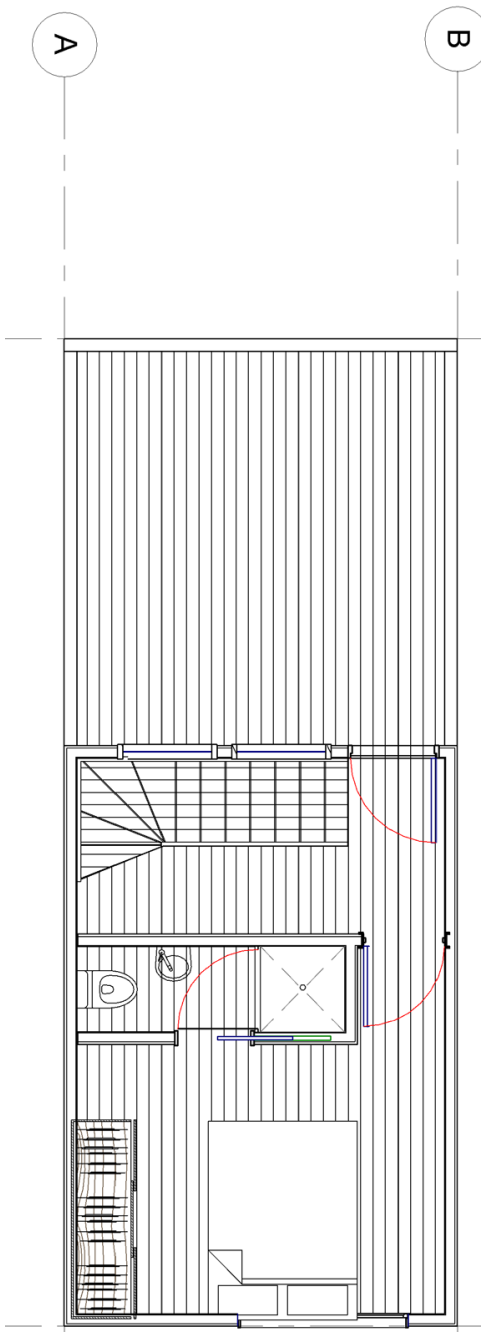

Figure 110: Stage 2, 3 bed second floor plan.
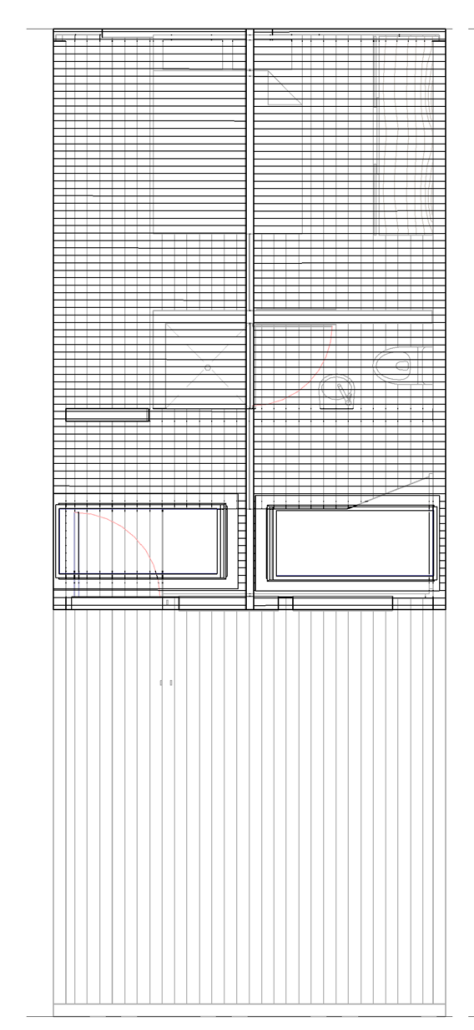

Figure 111: Stage 2, 3 bed roof plan. 

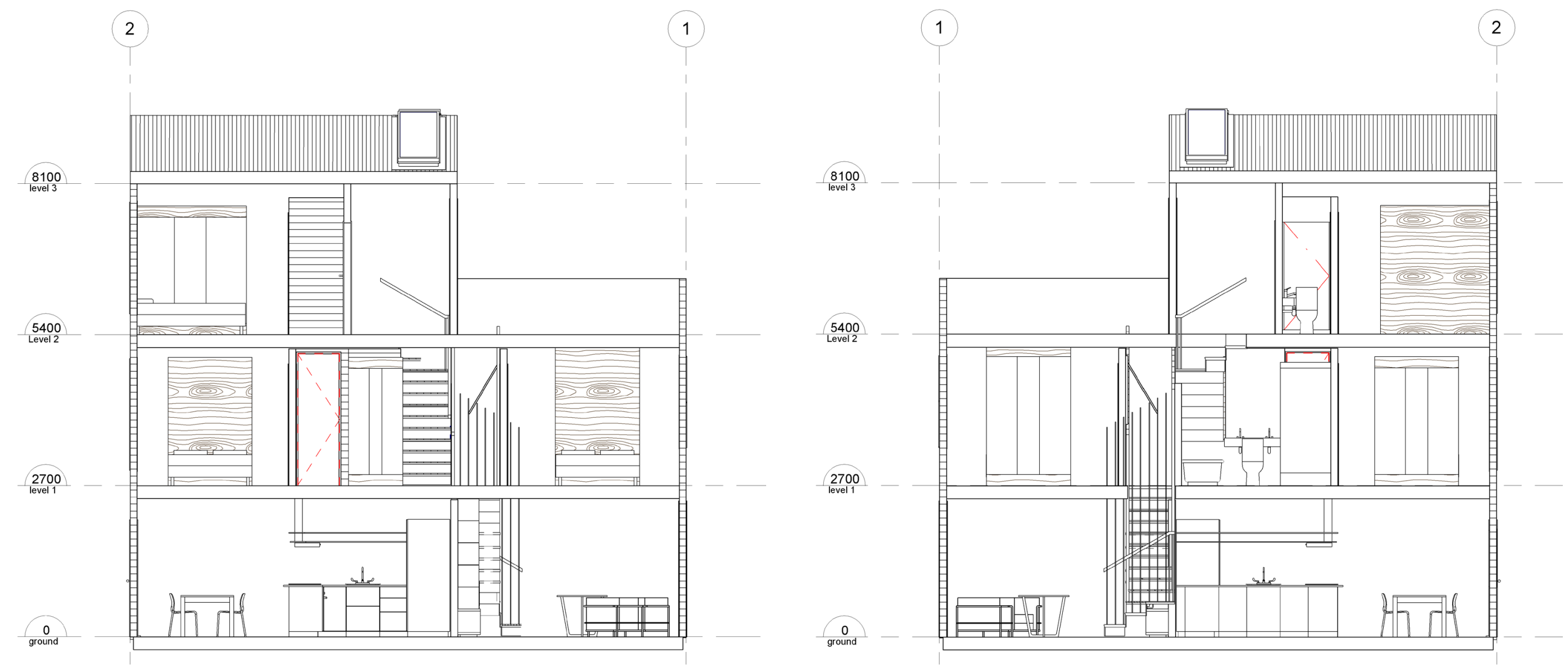


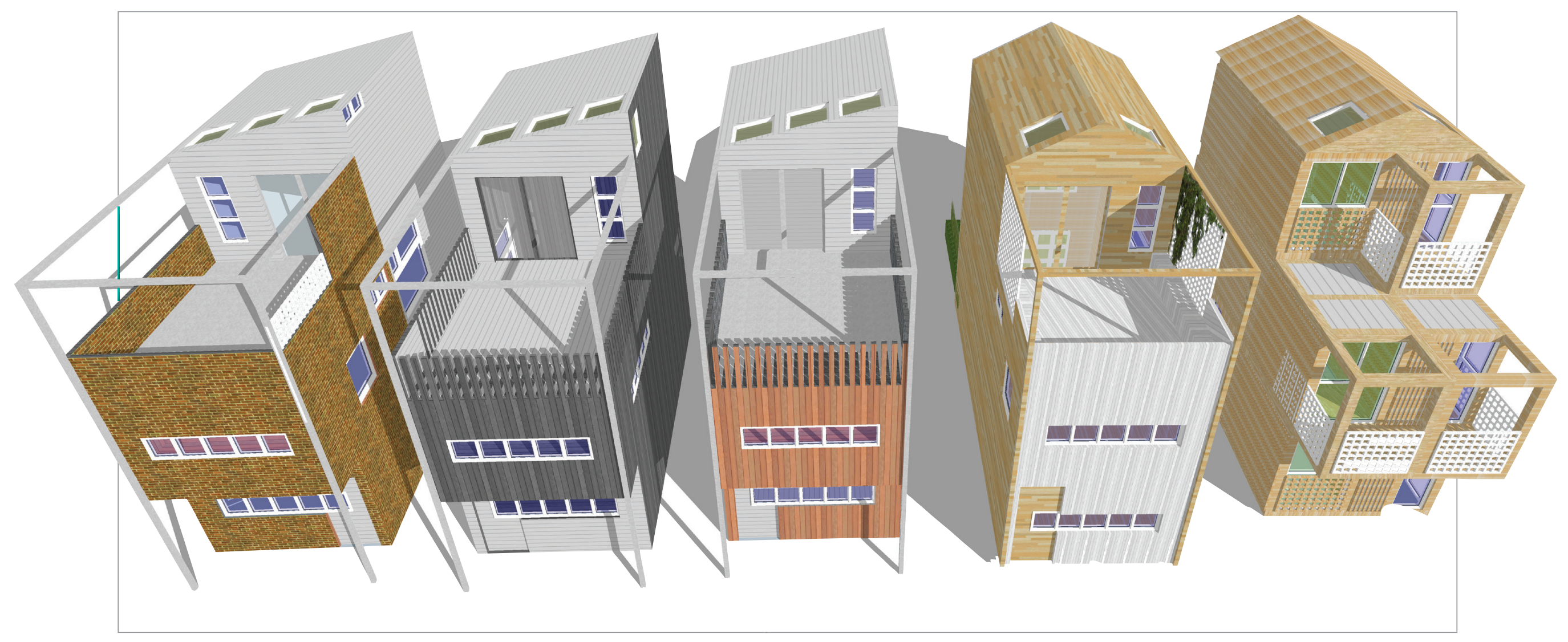

Figure 114: Stage 2, 3 bedroom typologies. 


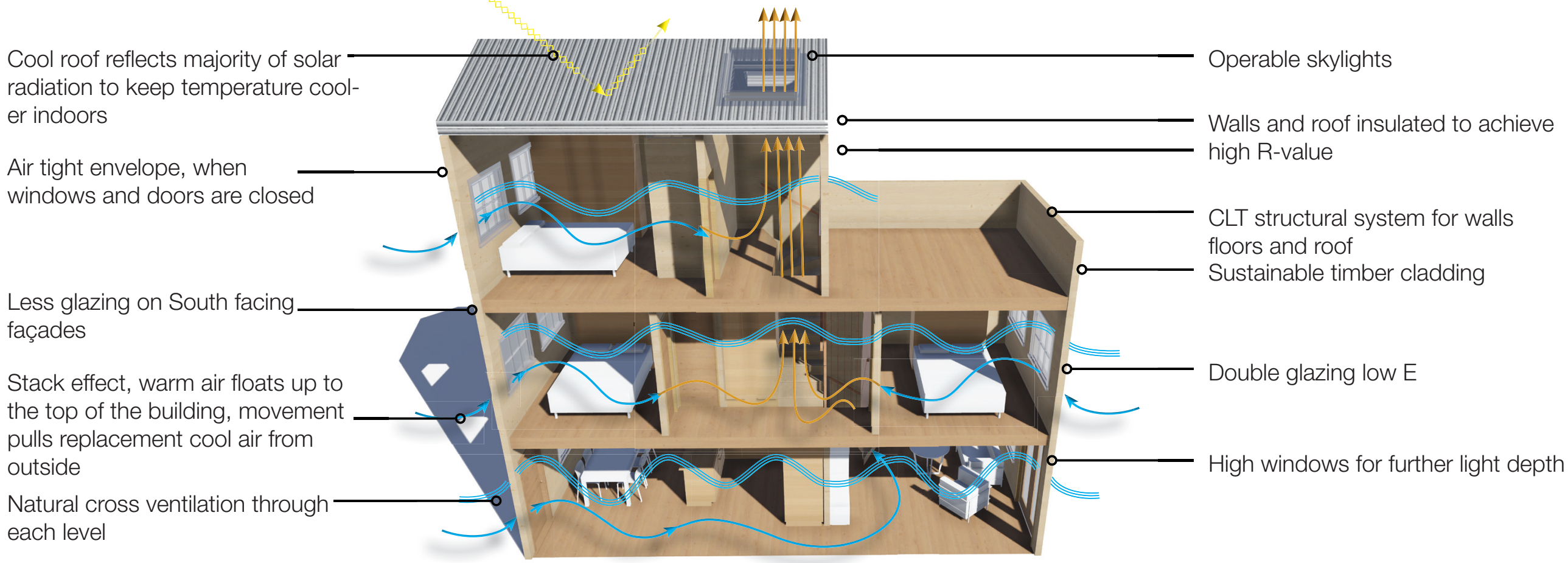




\section{Stage 2-4 Bedroom Unit 1:100@A4}

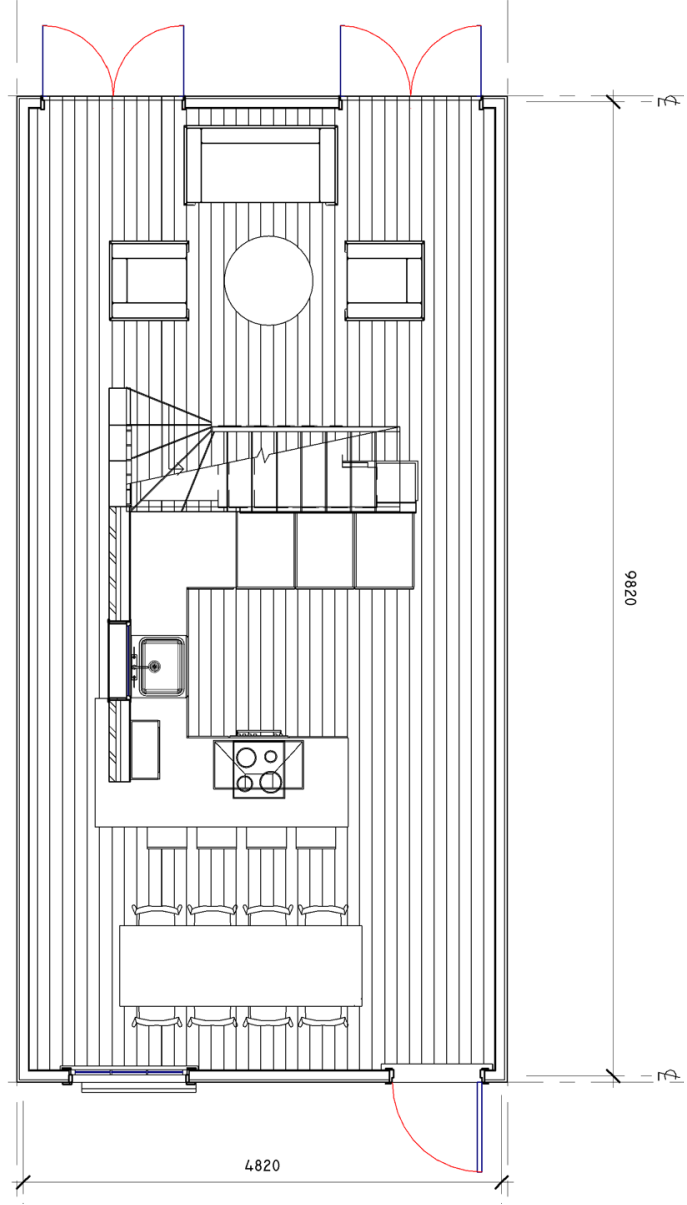

Figure 116: Stage 2, 4 bed ground floor plan.
$D$

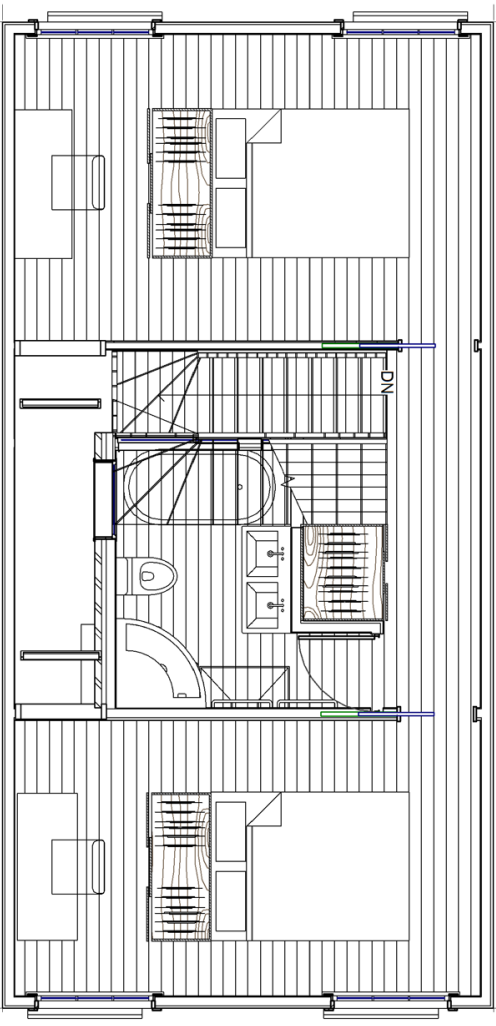

Figure 117: Stage 2, 4 bed first floor plan.
$>$

$\infty$
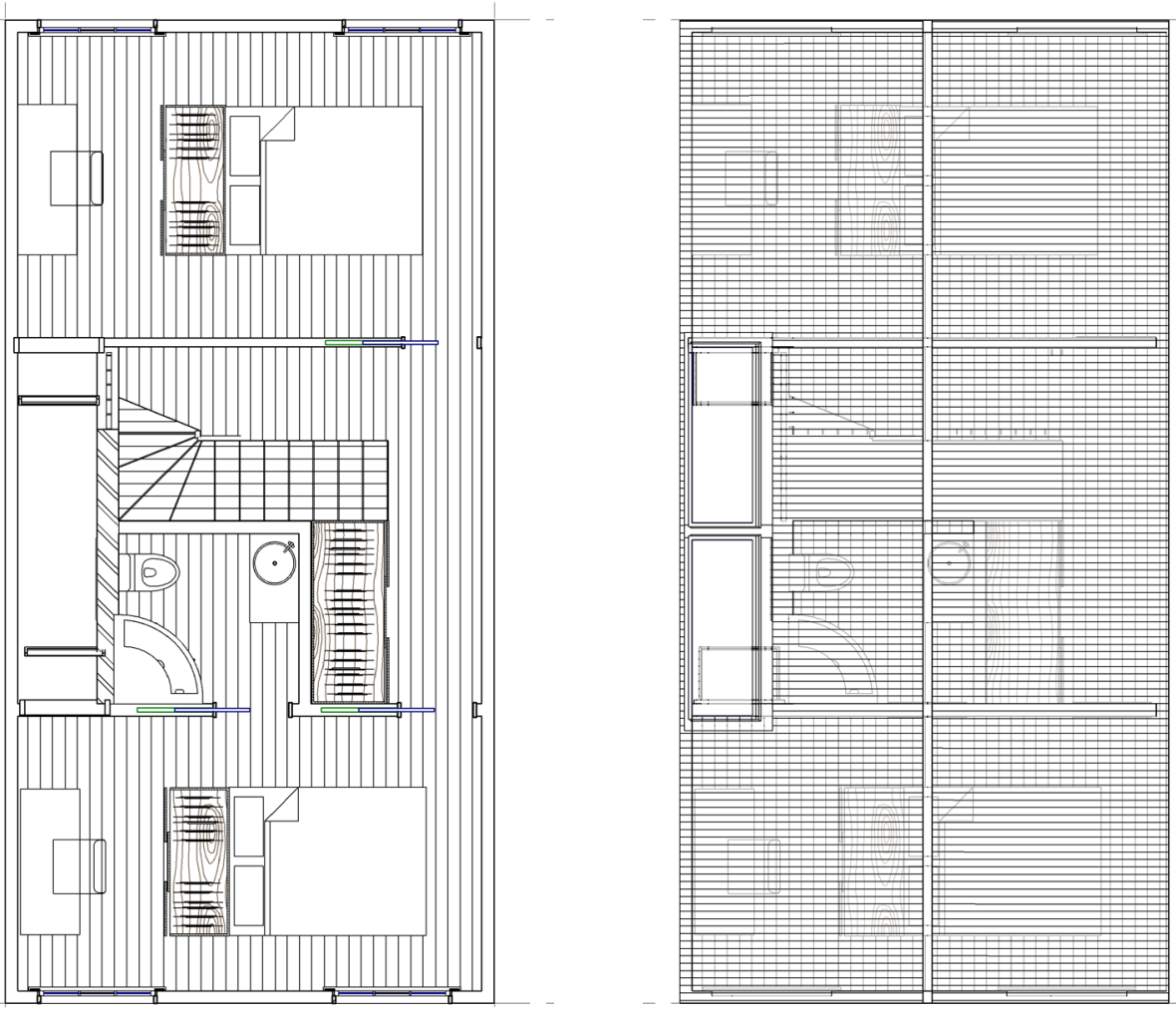

Figure 118: Stage 2, 4 bed second floor plan. Figure 119: Stage 2, 4 bed roof plan. 


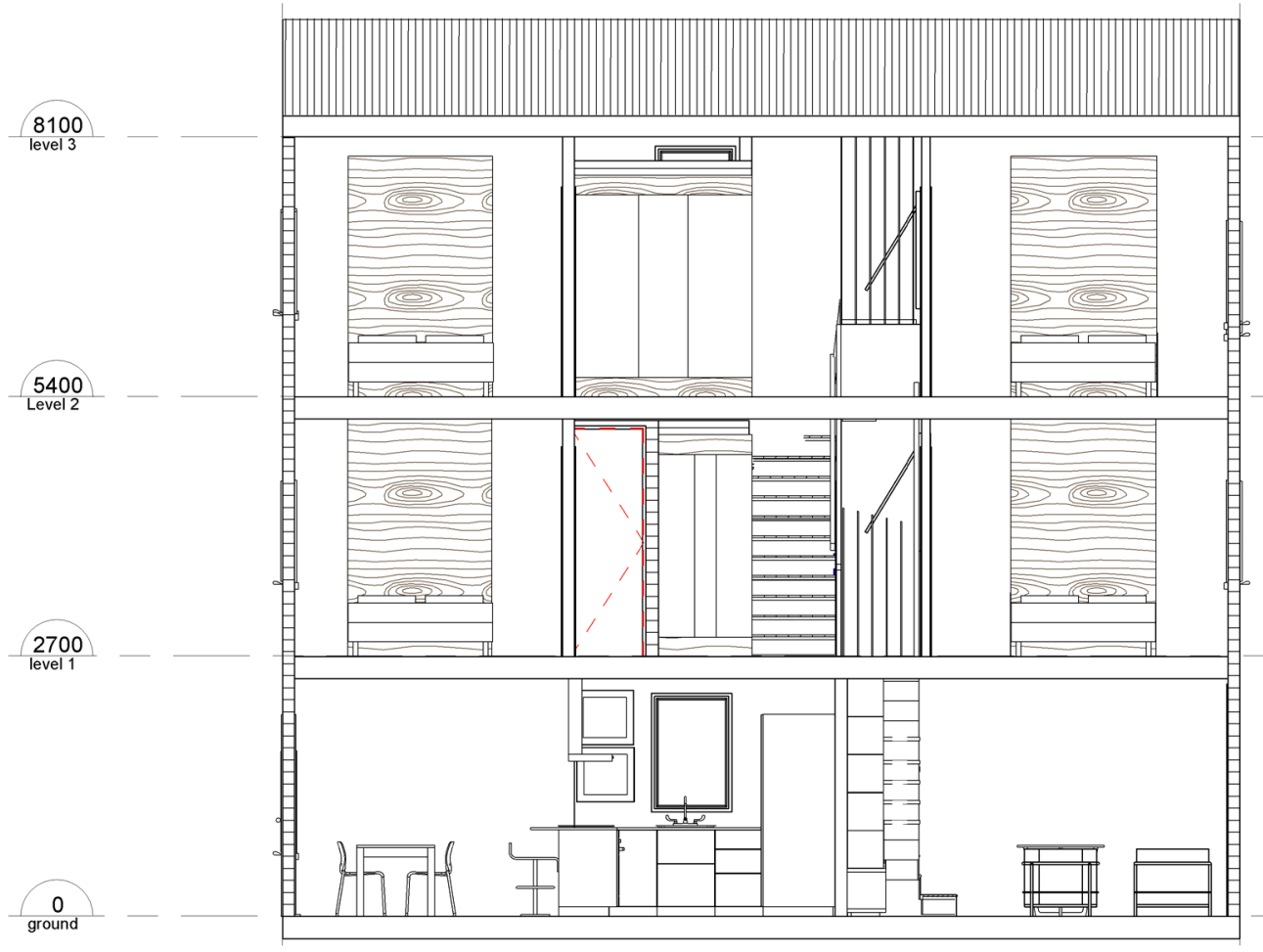

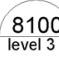

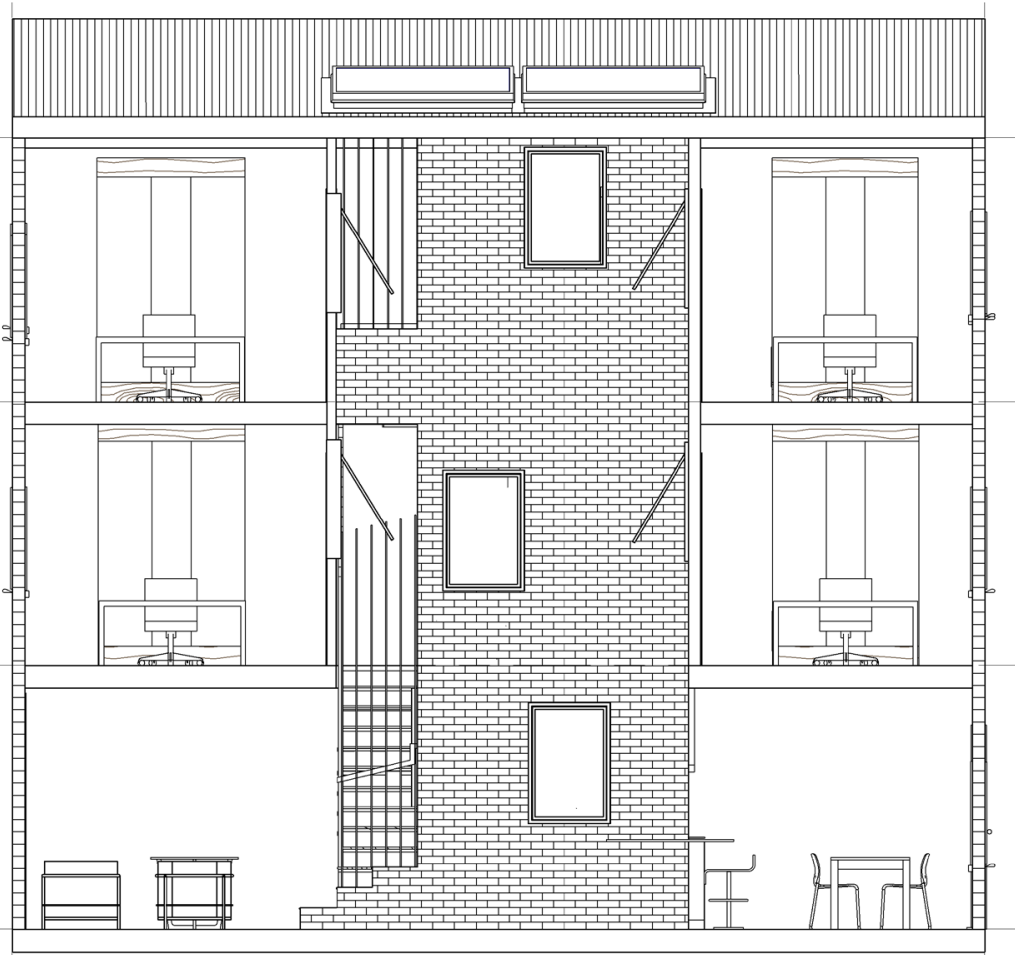

Figure 120: Stage 2, 4 bed sectional elevation through B.

Figure 121: Stage 2, 4 bed sectional elevation through A. 


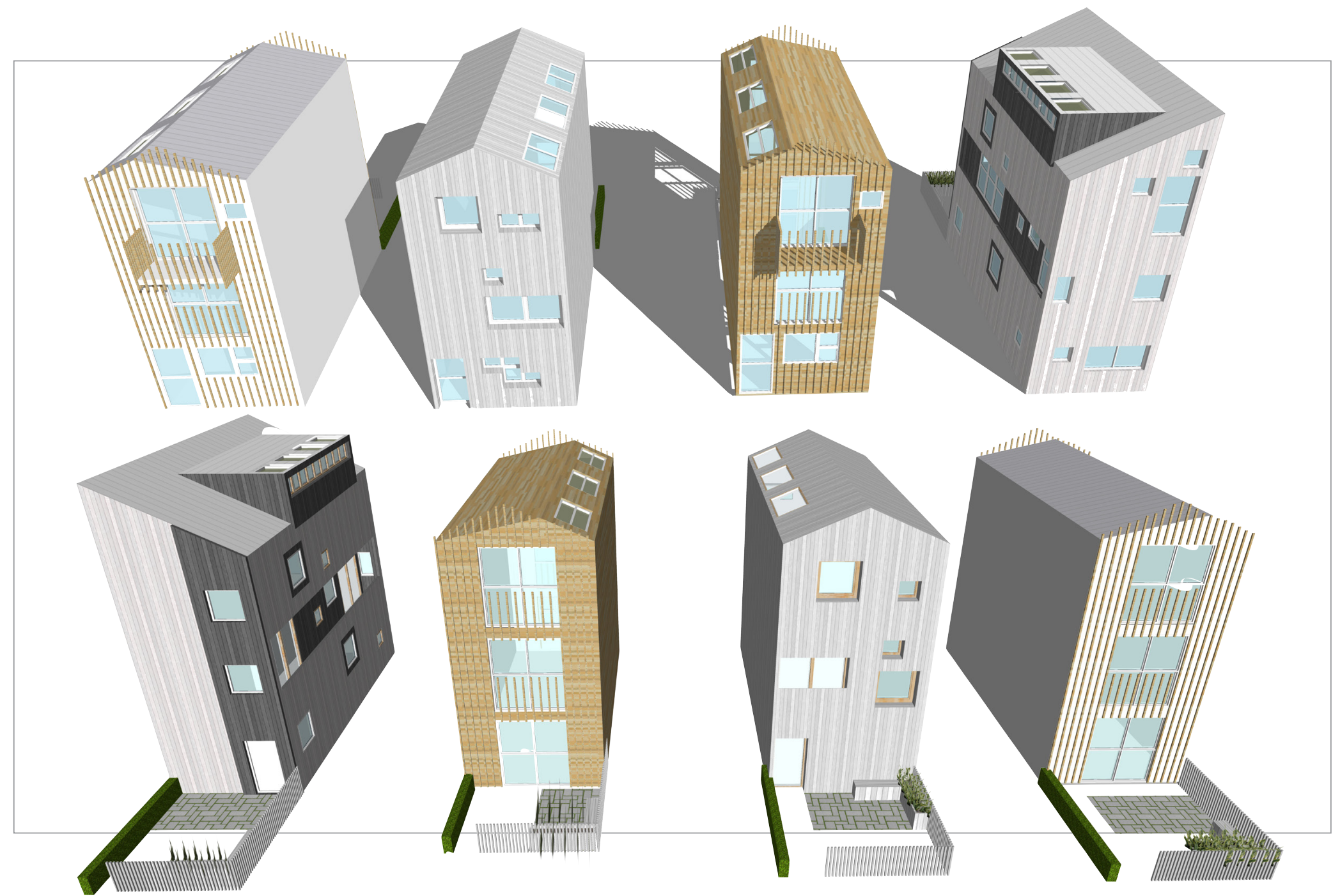

Figure 122: Stage 2, 4 bedroom typologies. 


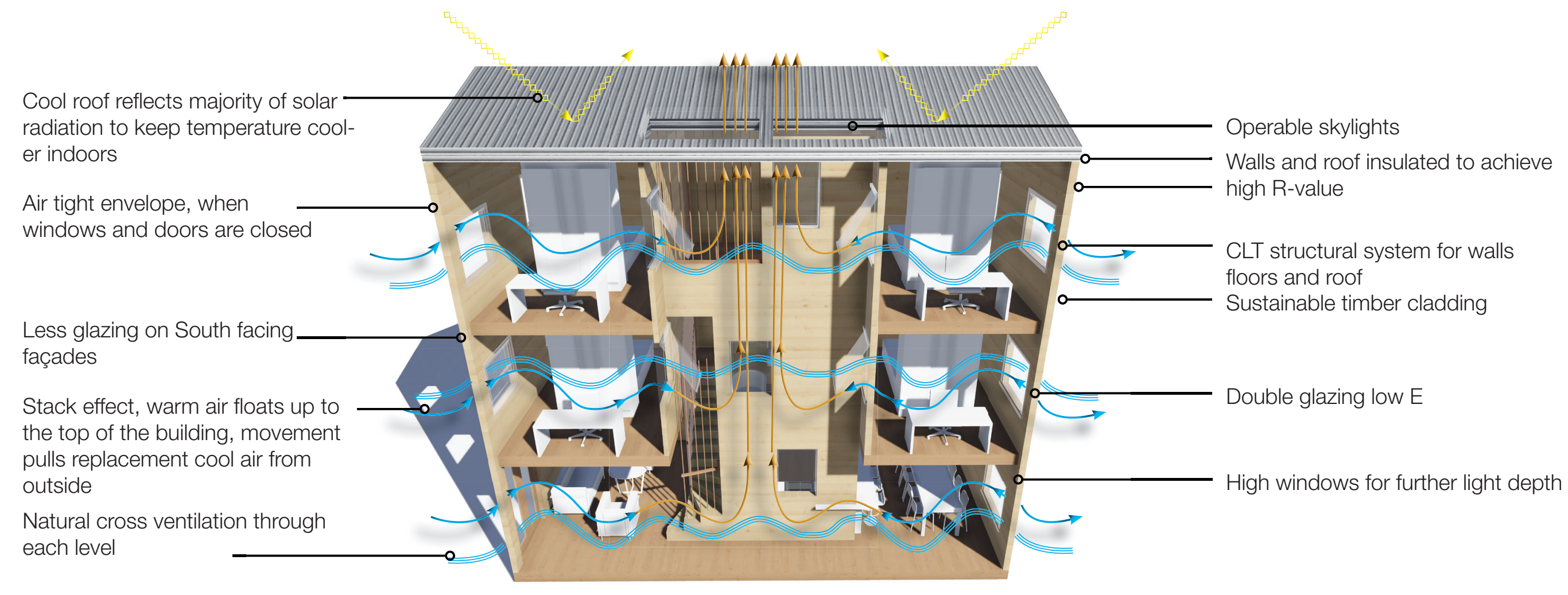




\section{Apartment Planning}

The articulation of the apartments was inspired by the Victorian and Edwardian architectural context. The Site Study character analysis was refined down to simplistic principles that could be used to govern the design. These themes included a play between positive and negative; extrusion and protrusion. A modern façade interpretation was explored, incorporating stained glass, trellises and bay windows, as well as a cut-out gable form also displayed a green roof system behind (see Figures 125-127 and 137). However, more research into green roof systems found that their expense would make them unfeasible for a project of this scale and budget. With extensive open areas already provided in the development, green roof space was deemed excessive. Additionally, green roof systems are less sustainable than first thought, as their weatherproofing and tray materials are plastic, and their weight means that additional structural support must be incorporated into the entire building (International Green Roof Association, 2017).

Internal planning for the apartment units was also developed at this stage. The shape of the main apartment building was constrained by the site. A first concept tried an ' $L$ '-shaped building, designed with one north-facing length and one west-facing length (see Figure 128). This was intended to maximise the sun, however it meant that each unit only received light from one side. For passive heating / cooling, ventilation and overall comfort, it was important that sun was prioritised. An interlocking two-storey unit configuration was attempted so that each unit received sun from two sides, but this led to issues with the circulation of the overall building and access to the units (see Figure 124).

A second solution was developed with 'L'-shaped units that interlocked. This configuration maximised the external wall area and the amount of sun in each unit (see Figures 129-133) (see Appendix B and C for additional building development figures). To maximise the land use, a corner unit was also created that moulded to the leftover negative spaces (see Figure 132).

This new planning solution meant a second external articulation had to be developed (see Figures 134-136). It was decided that the cladding options and windows would mimic those of the townhouses to help blend the large apartment buildings into the overall scheme. The form of the main apartment building was complex enough that extra features were unnecessary. However, the design of apartment blocks 2 and 3 explores stealth density, using a façade to conceal the actual amount of units behind (see Figures 138-141). The townhouse-shaped forms act as panels that could be prefabricated, and then alternated across the façade. 


\section{Apartment Building 1 Development}

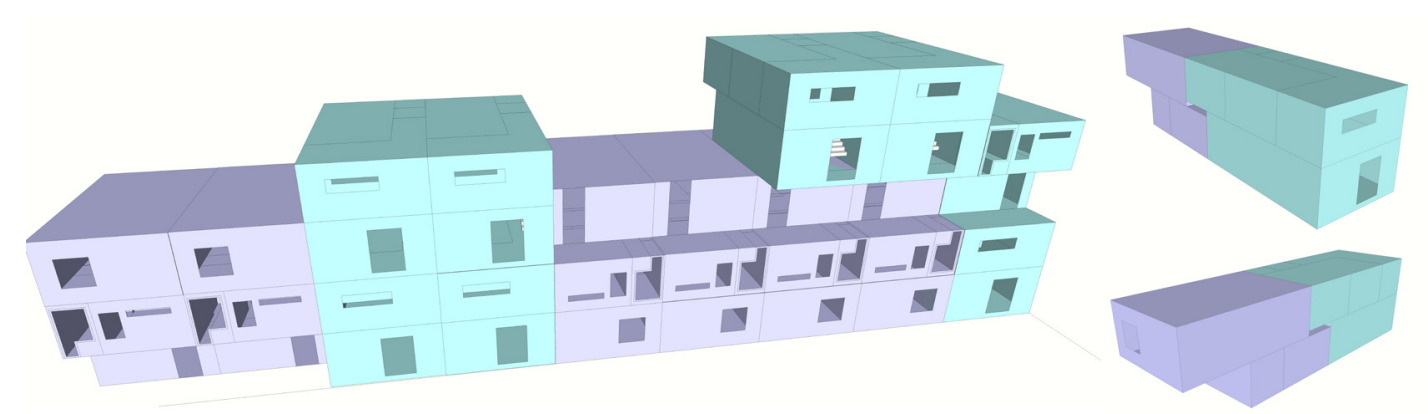

Figure 124: Failed attempt to interlock units vertically.

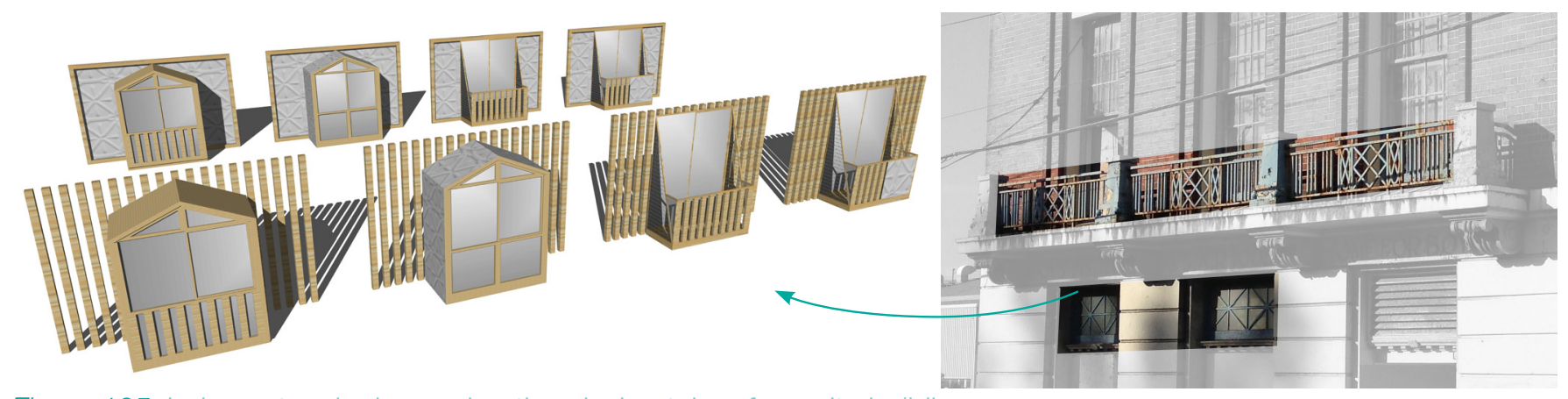

Figure 125: balcony typologies exploration design taken from site building.
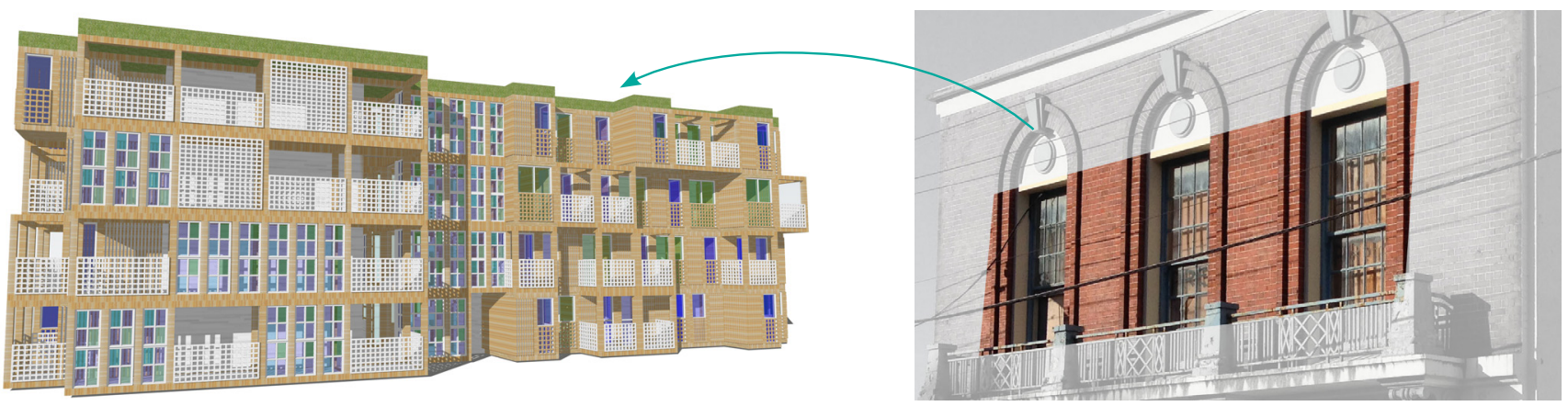

Figure 126: Stain glass and trellis external articulation. 

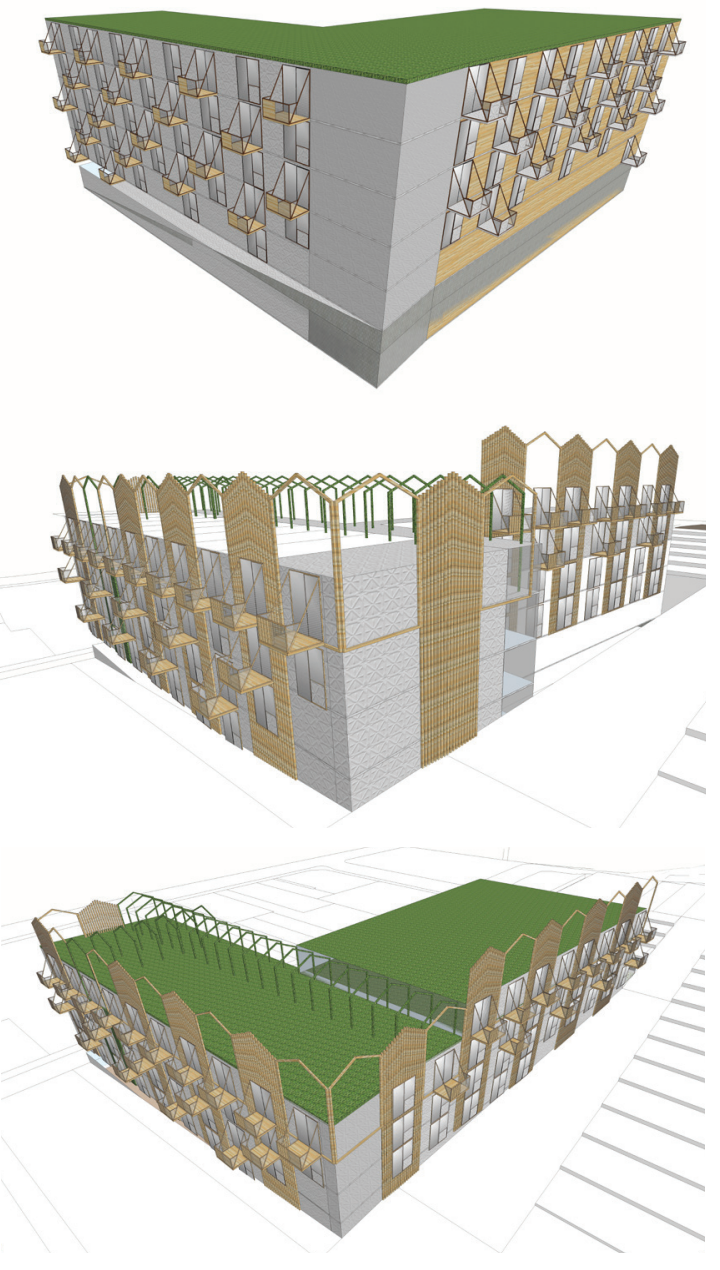

Figure 127: Large apartment development.

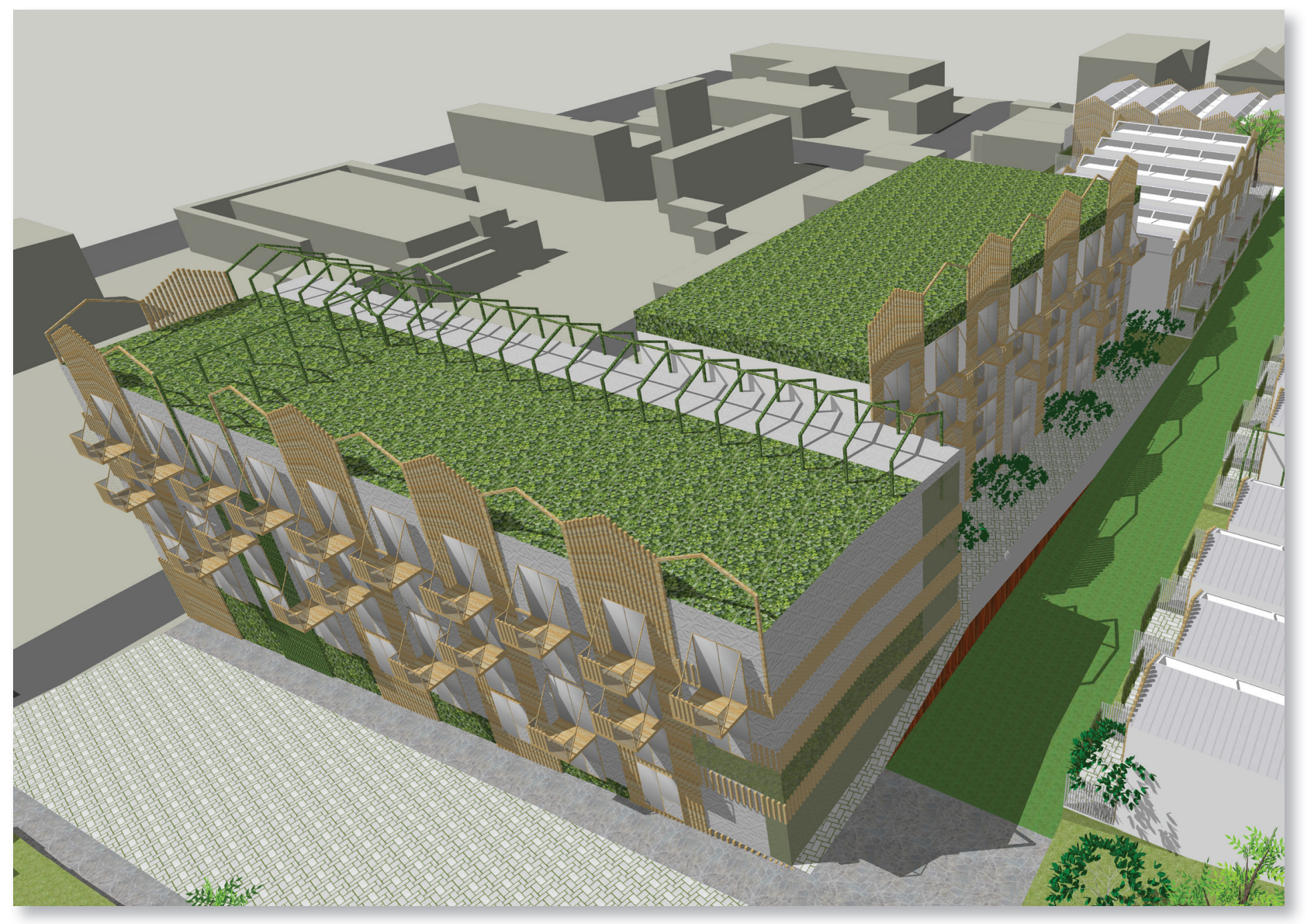



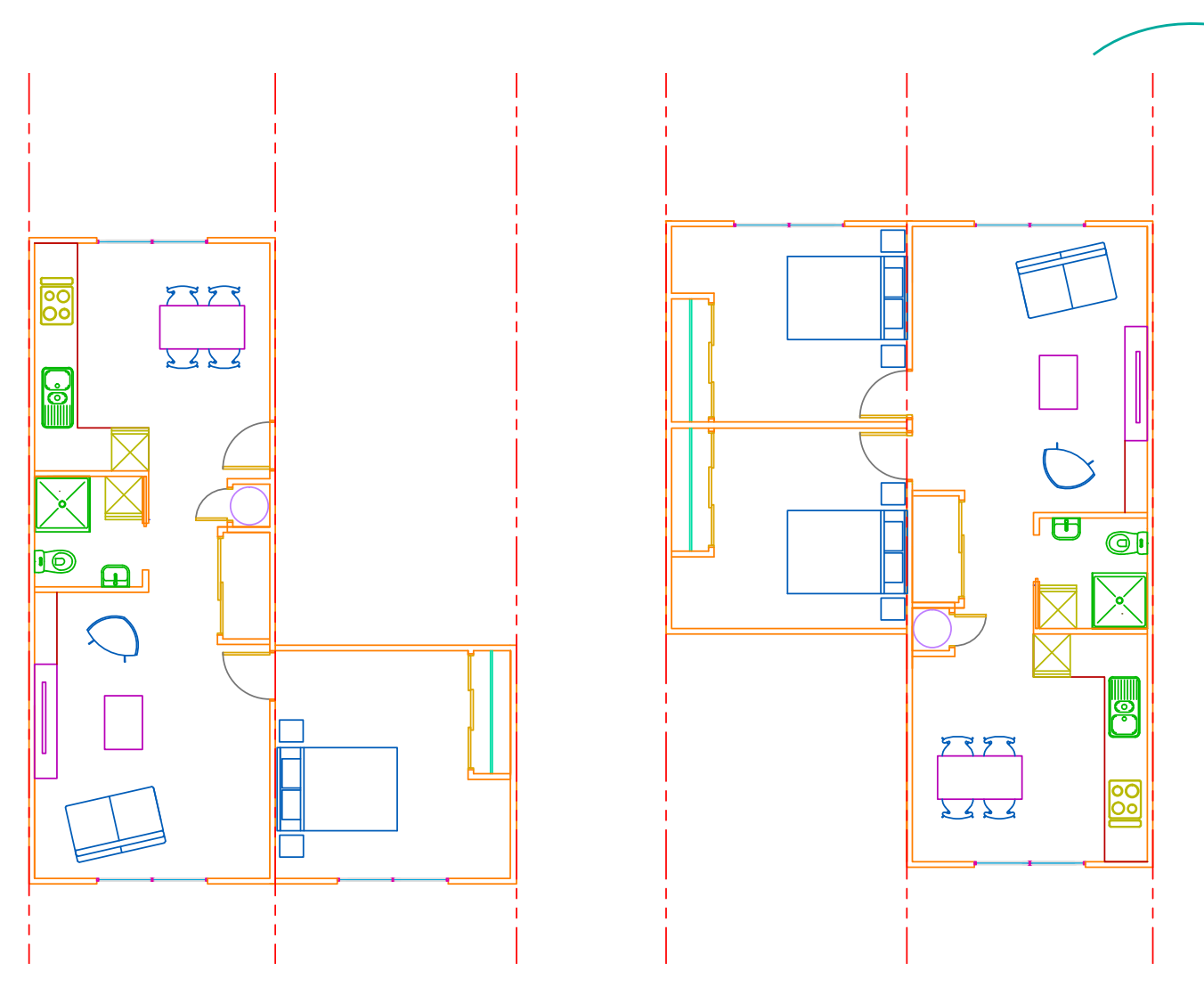

Figure 128: Apartment exploration. not to scale.

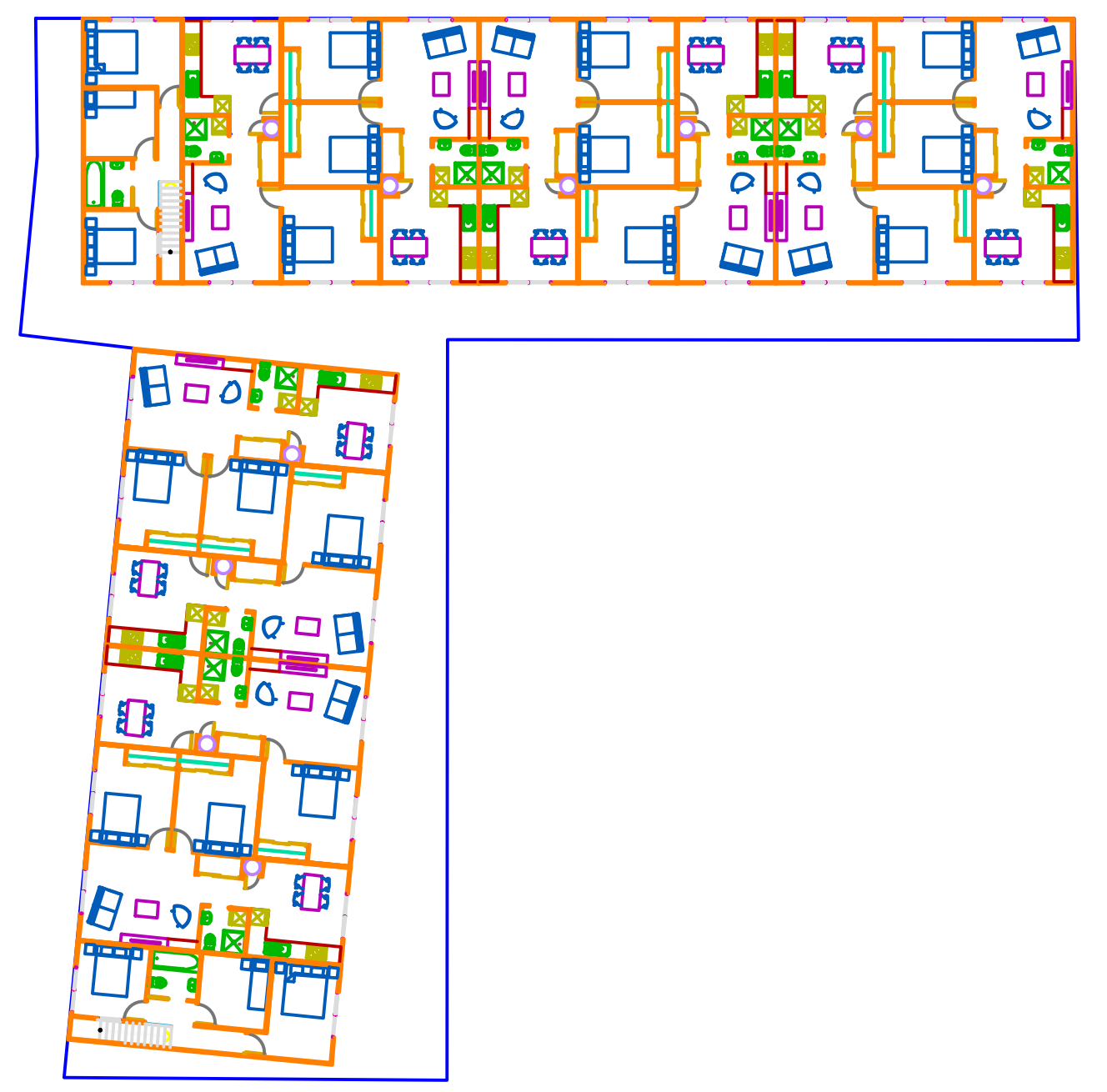




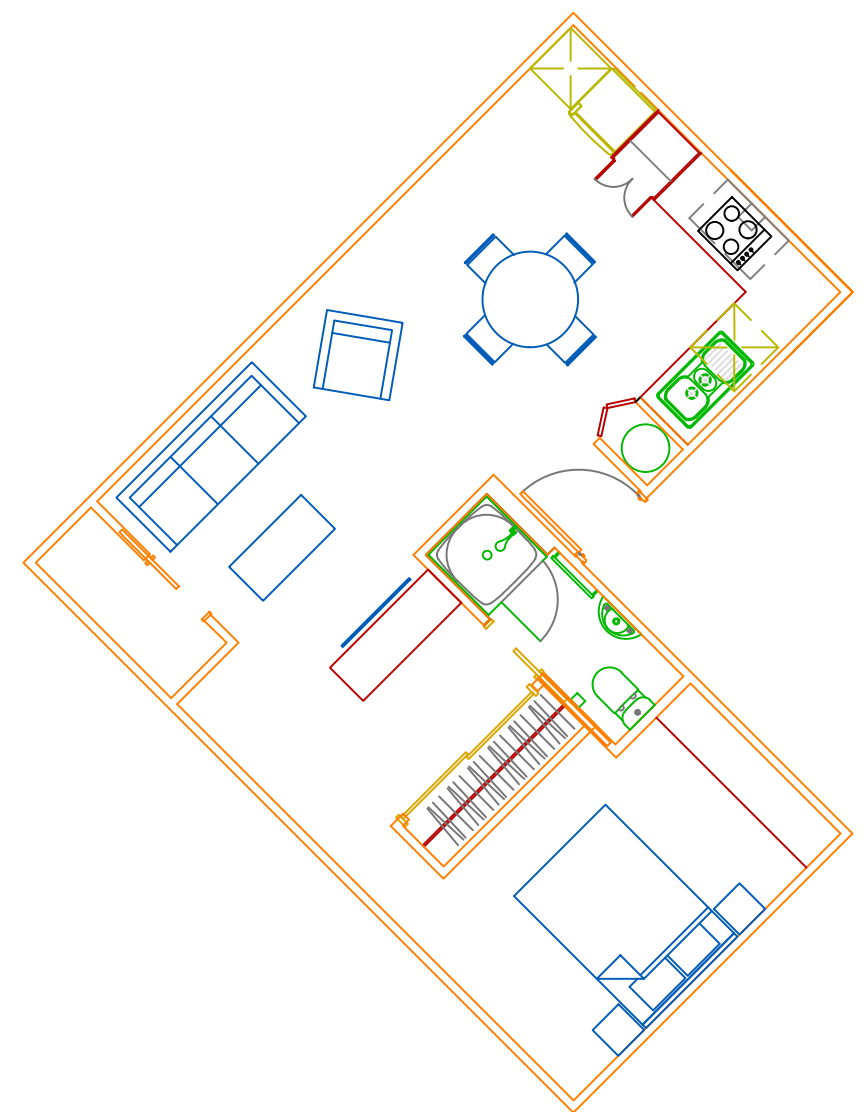

Figure 129: 1 bed apartment type 1(50m2).1:100@A4.

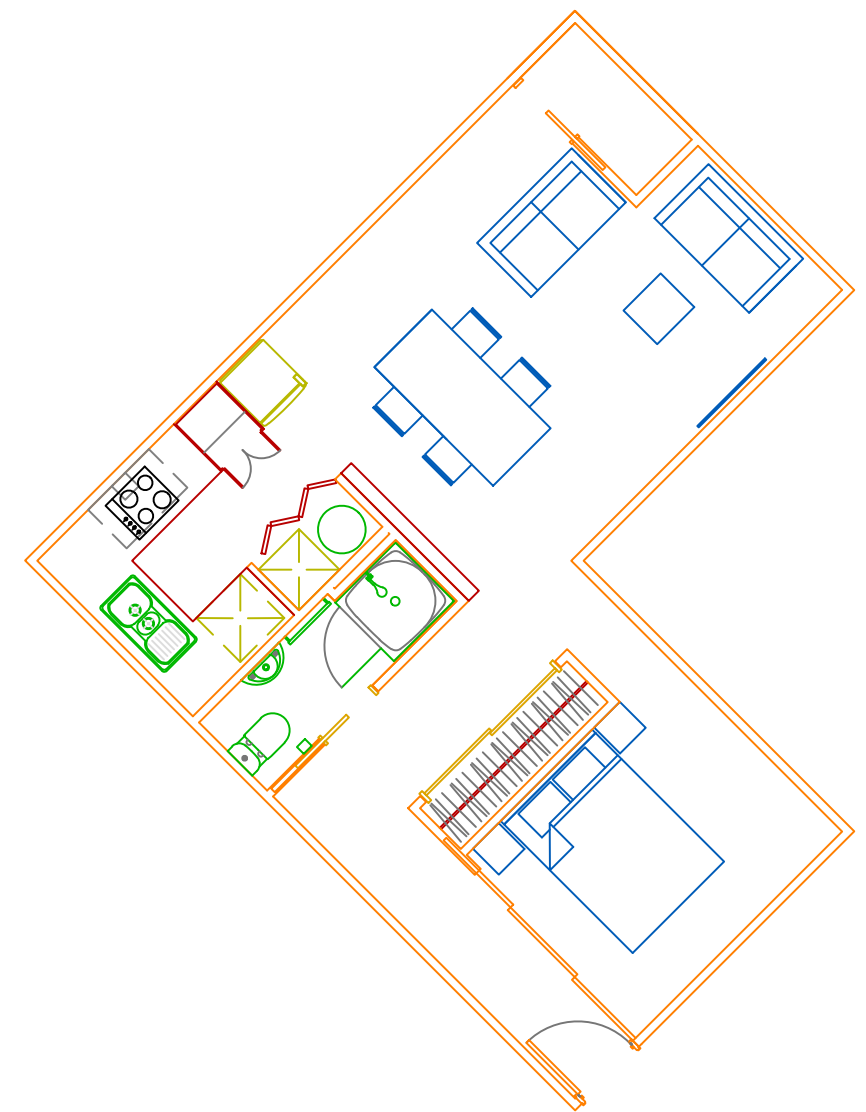

Figure 130: 1 bed apartment type 2 (50m2). 1:100@A4. 


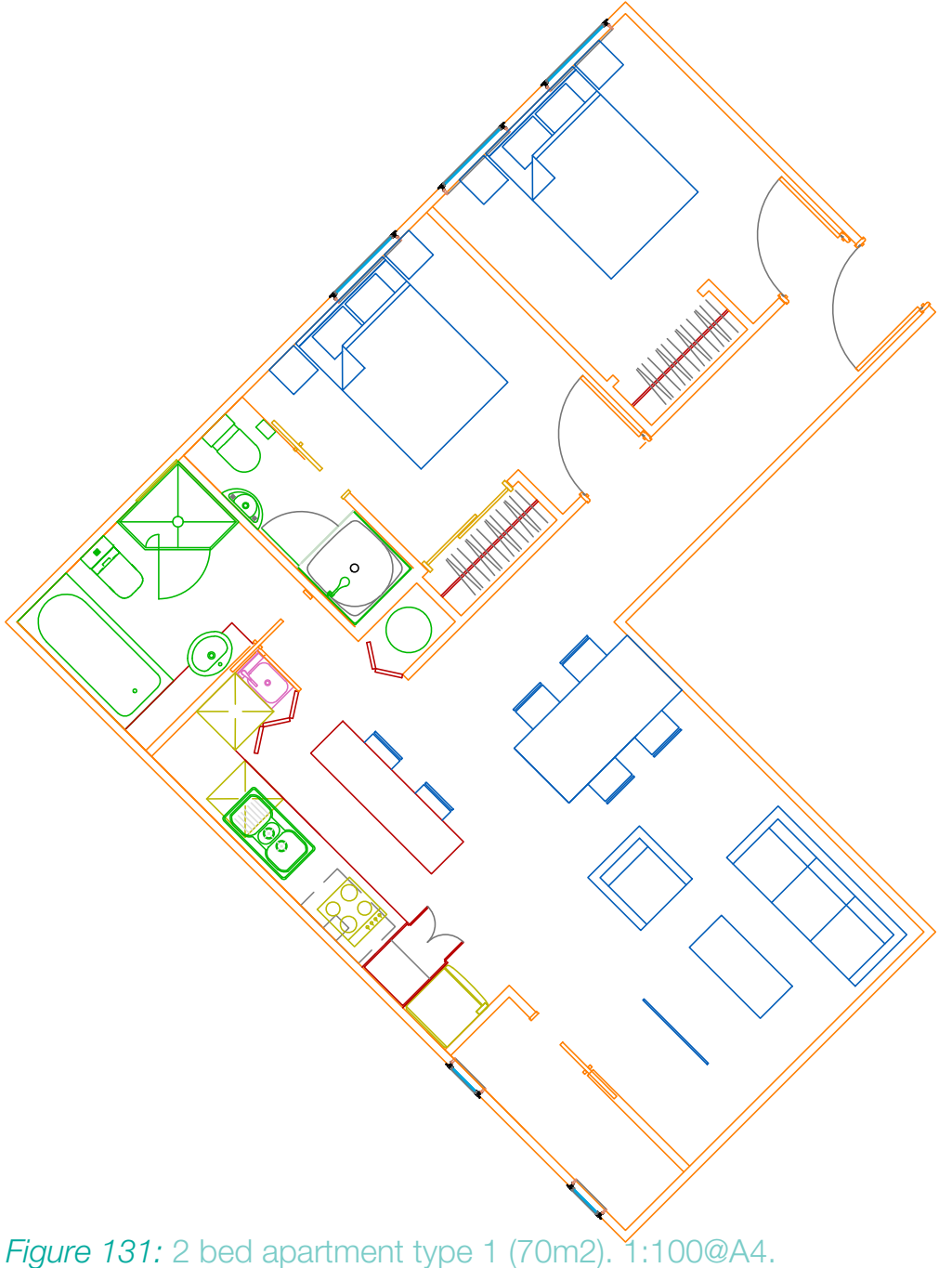

Figure 131: 2 bed apartment type 1 (70m2). 1:100@A4.

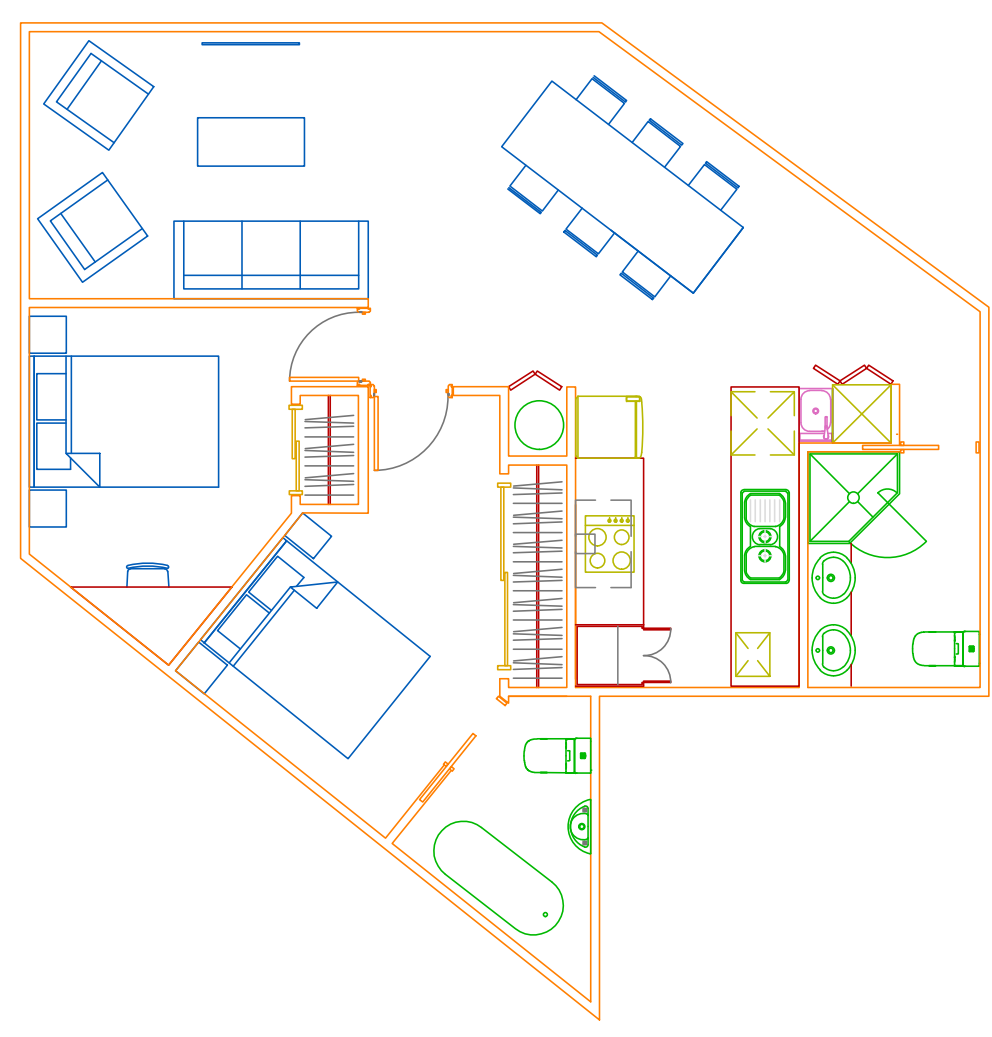

Figure 132: 2 bed corner apartment type 2 (70m2). 1:100@A4. 


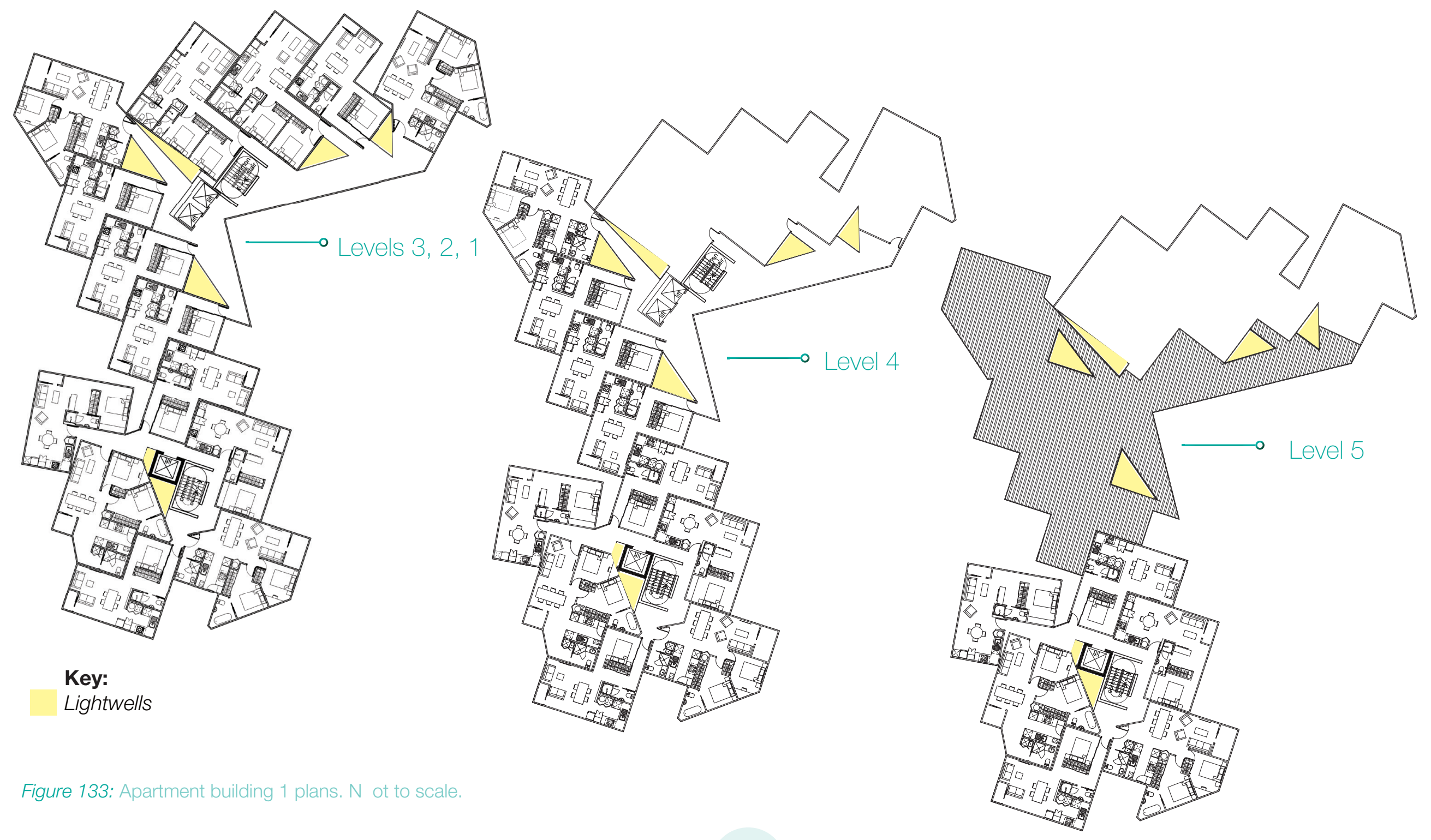



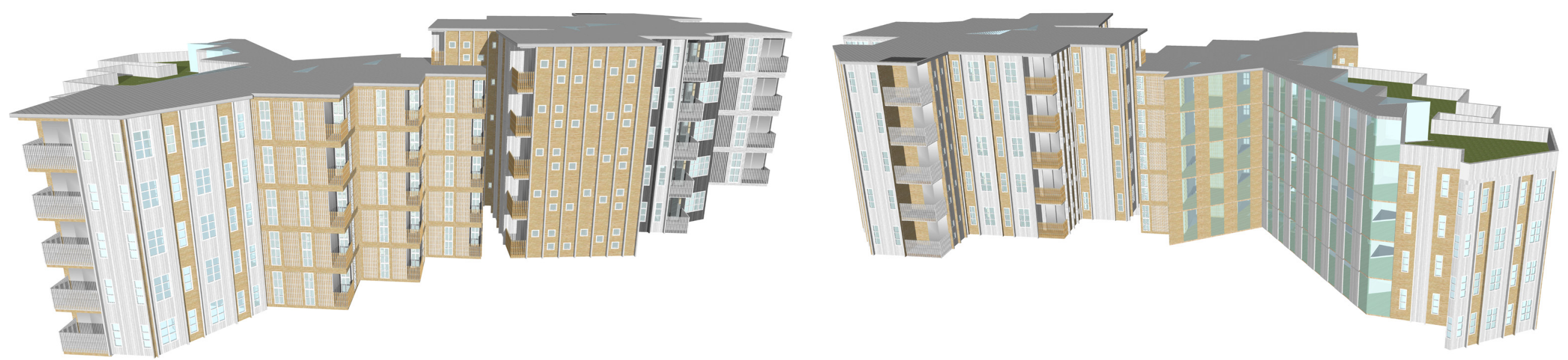

Figure 134: Roof and facade gradation with land topography.

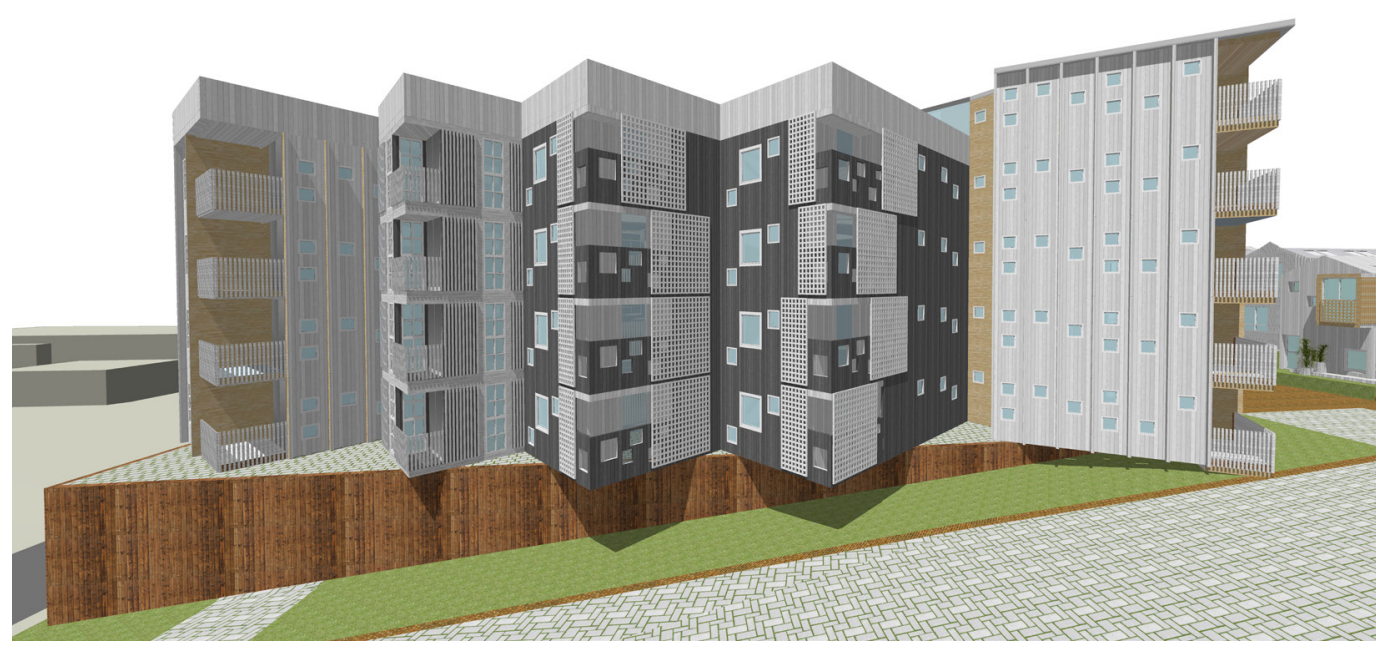

Figure 135: Public facing North Eastern façades.

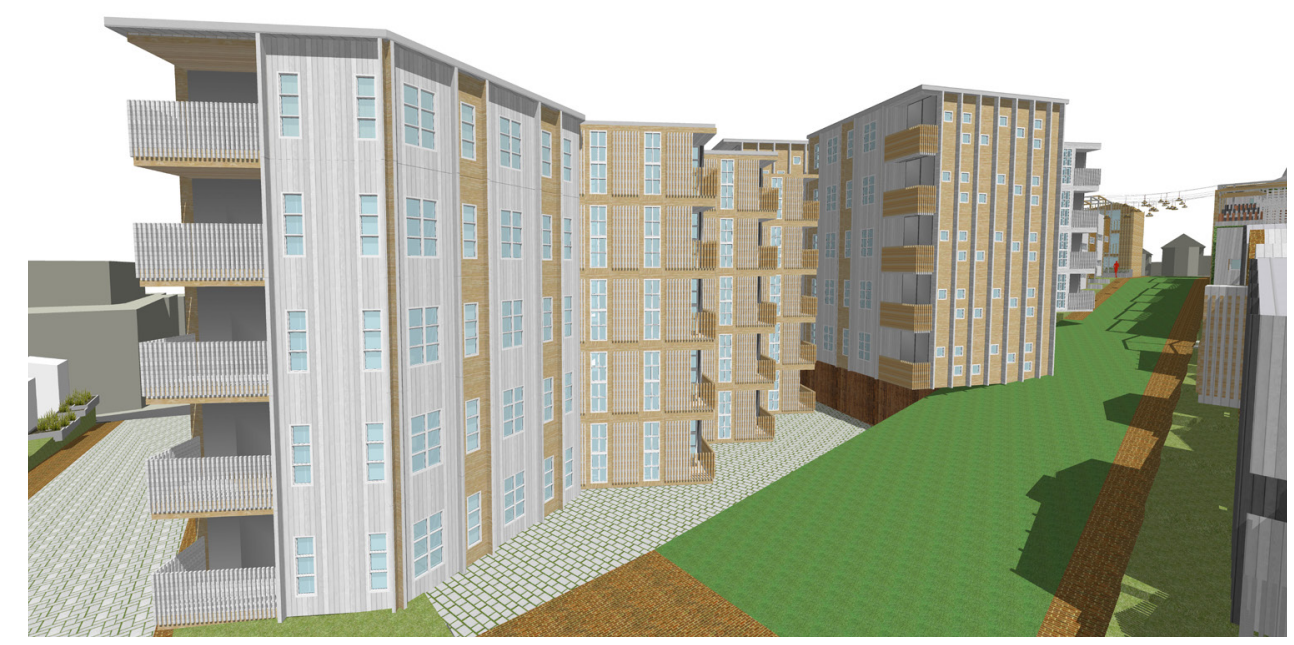

Figure 136: Public facade North Western façades. 
Apartment Buildings 2 and 3 Development
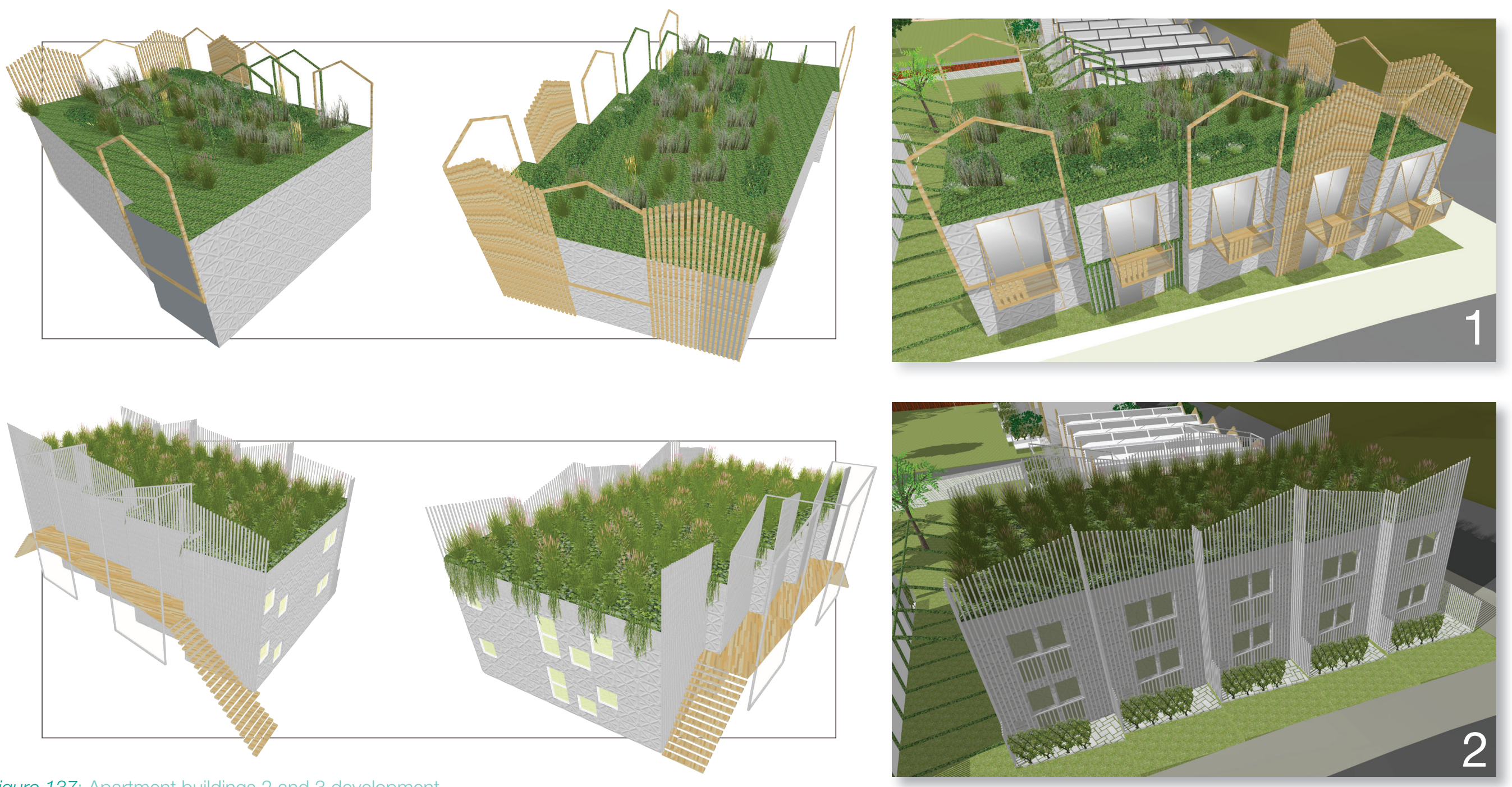

Figure 137: Apartment buildings 2 and 3 development. 

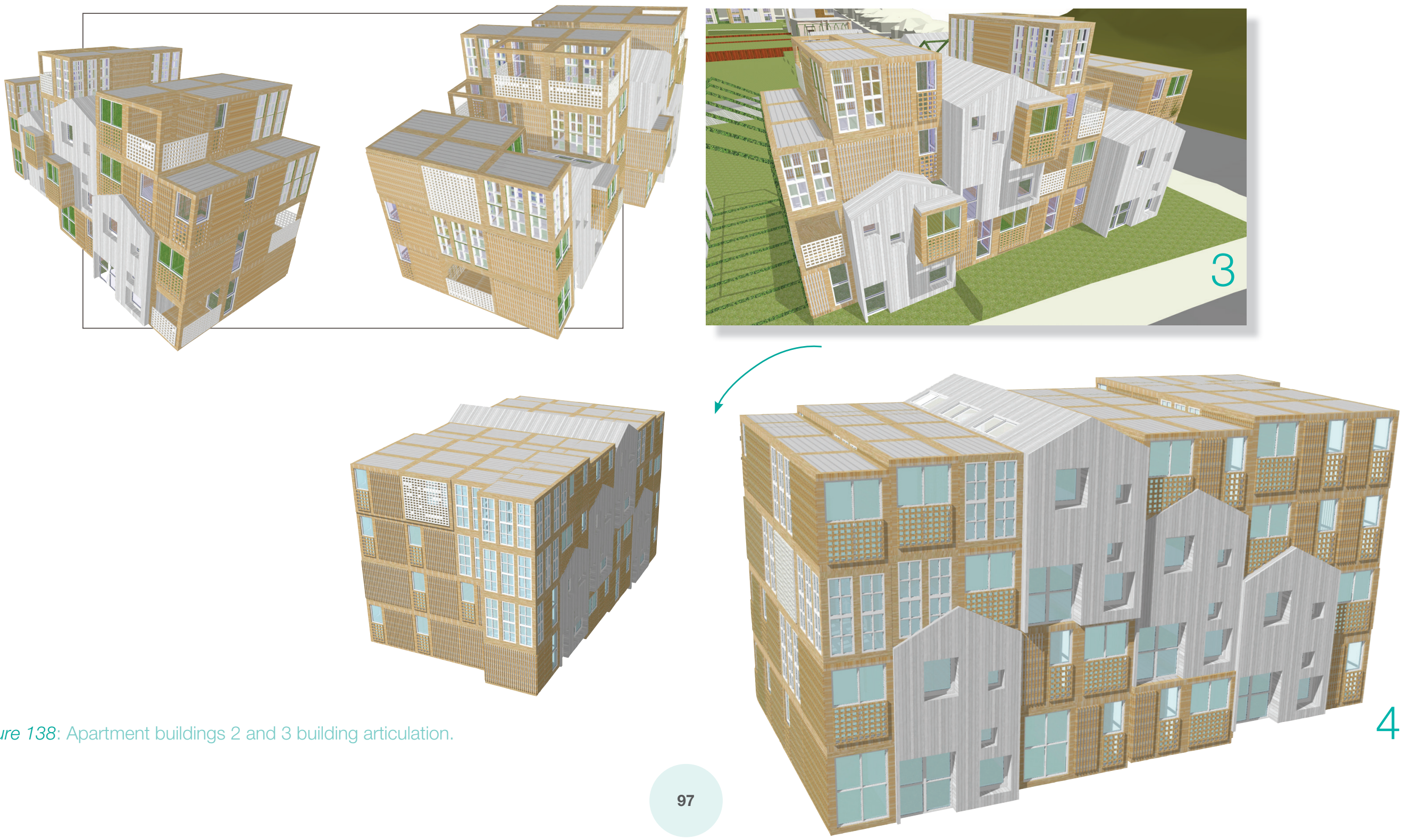

Figure 138: Apartment buildings 2 and 3 building articulation. 


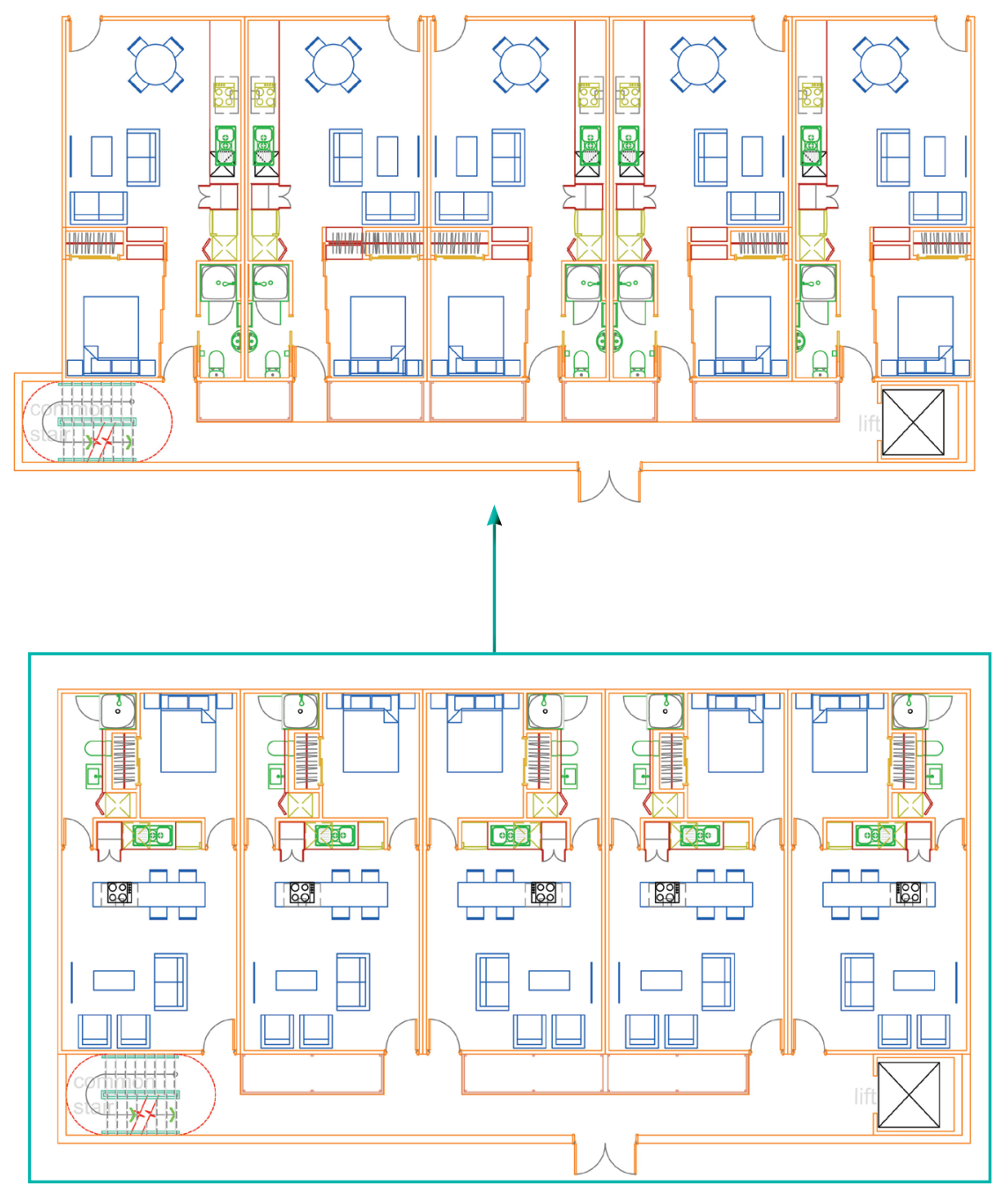

Figure 139: Apartment buildings 2 and 3, building plans development.

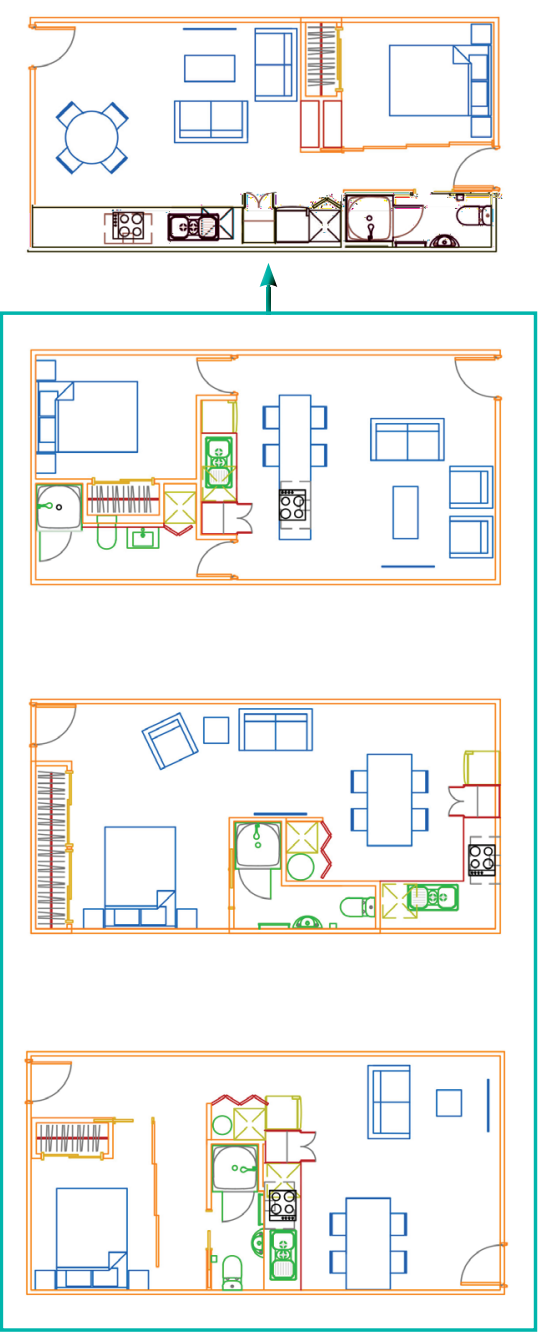

Figure 140: Apartment buildings 2 and 3, unit plans development. 


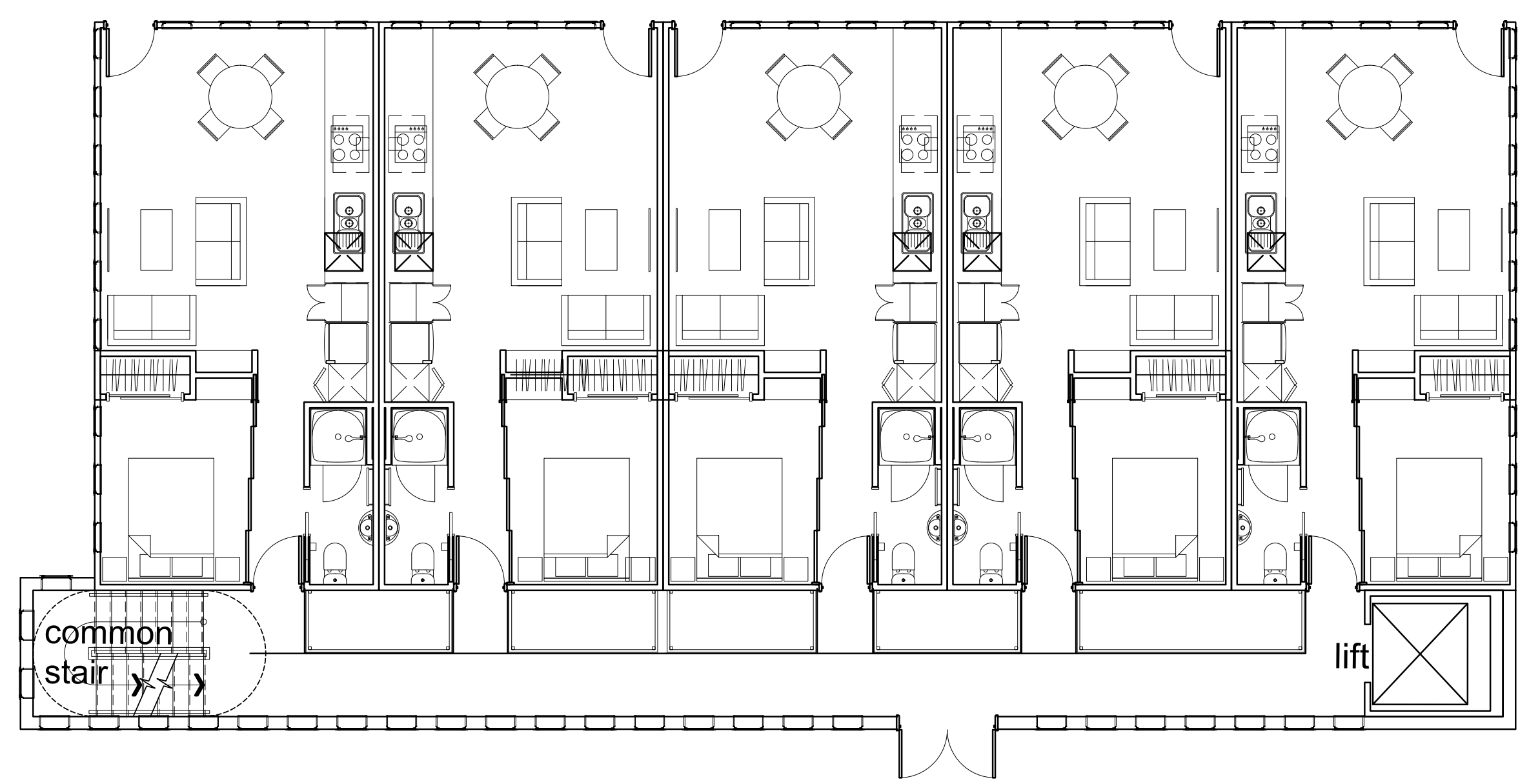




\section{Landscaping}

Once the site plan was finalised, landscaping options began to be considered (see figures 142-143). The outdoor amenities aimed to enhance the sustainable focus of the project. For example, paving was minimised where possible and a permeable paving was used. Concepts for filtration reed ponds were also explored (see Appendix $D$ for landscape concept development figures).

Pedestrian routes from the street started at pergolas that paralleled the shape of the MDH units. These 'green gates' aimed to welcome residents into the site, and acted as a frame for the green space beyond. Features such as a children's playground were incorporated to create a sense of community and attract families.

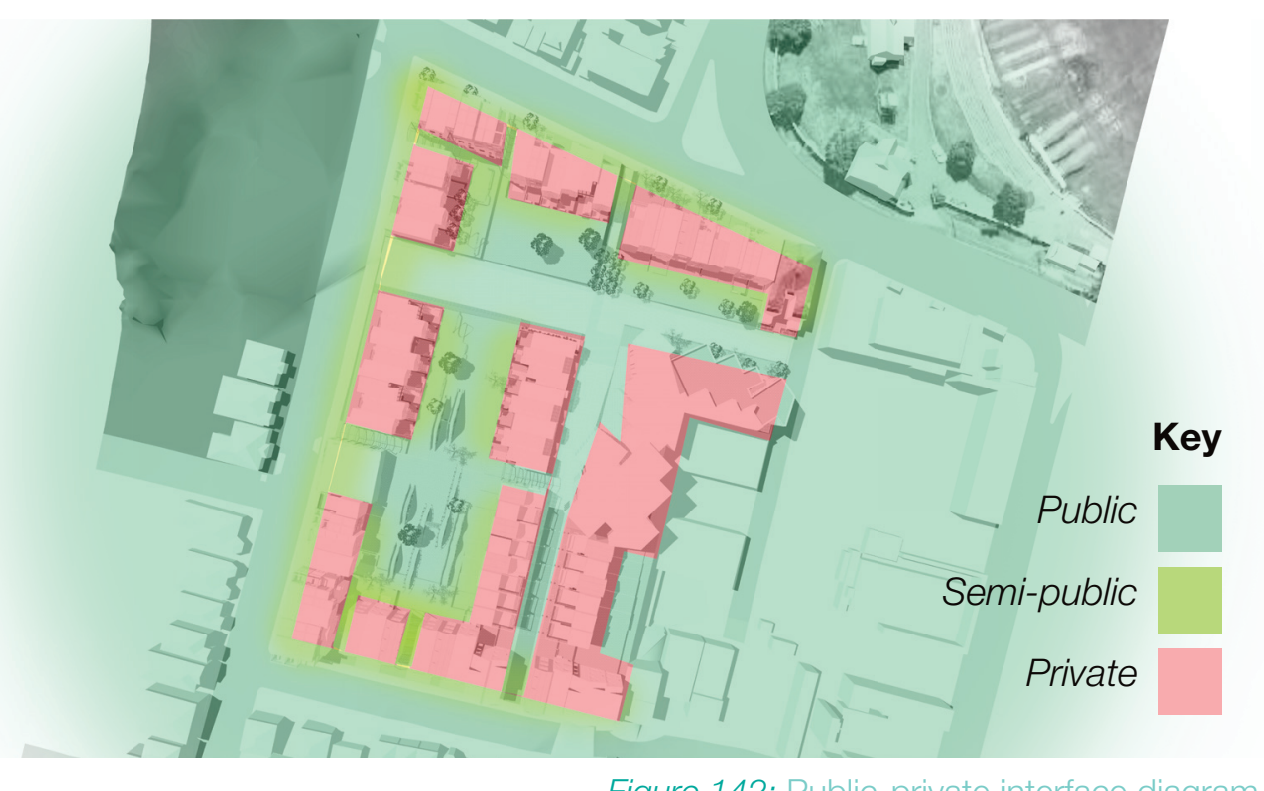

Figure 142: Public-private interface diagram 


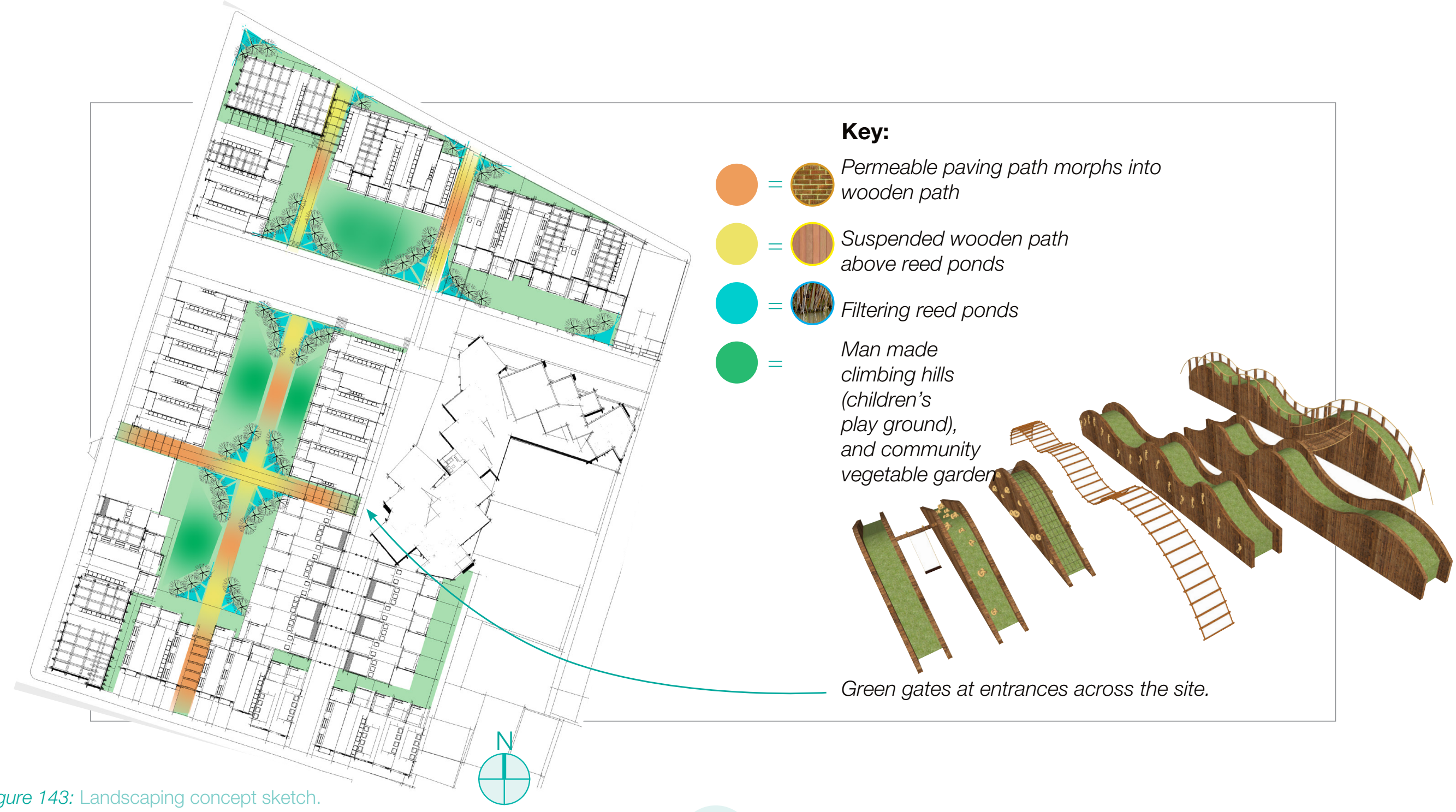


Stage 2-Site Figures
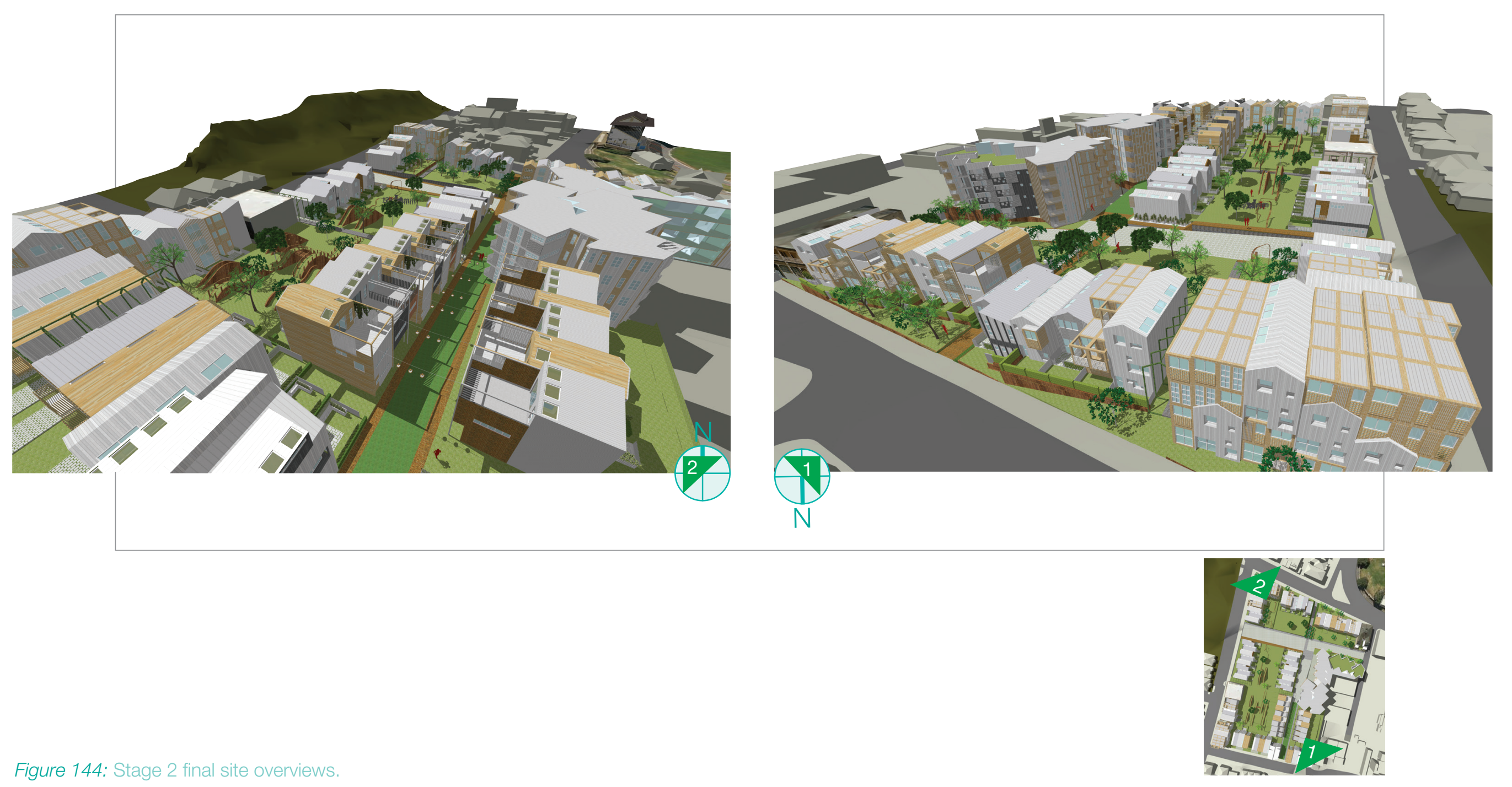

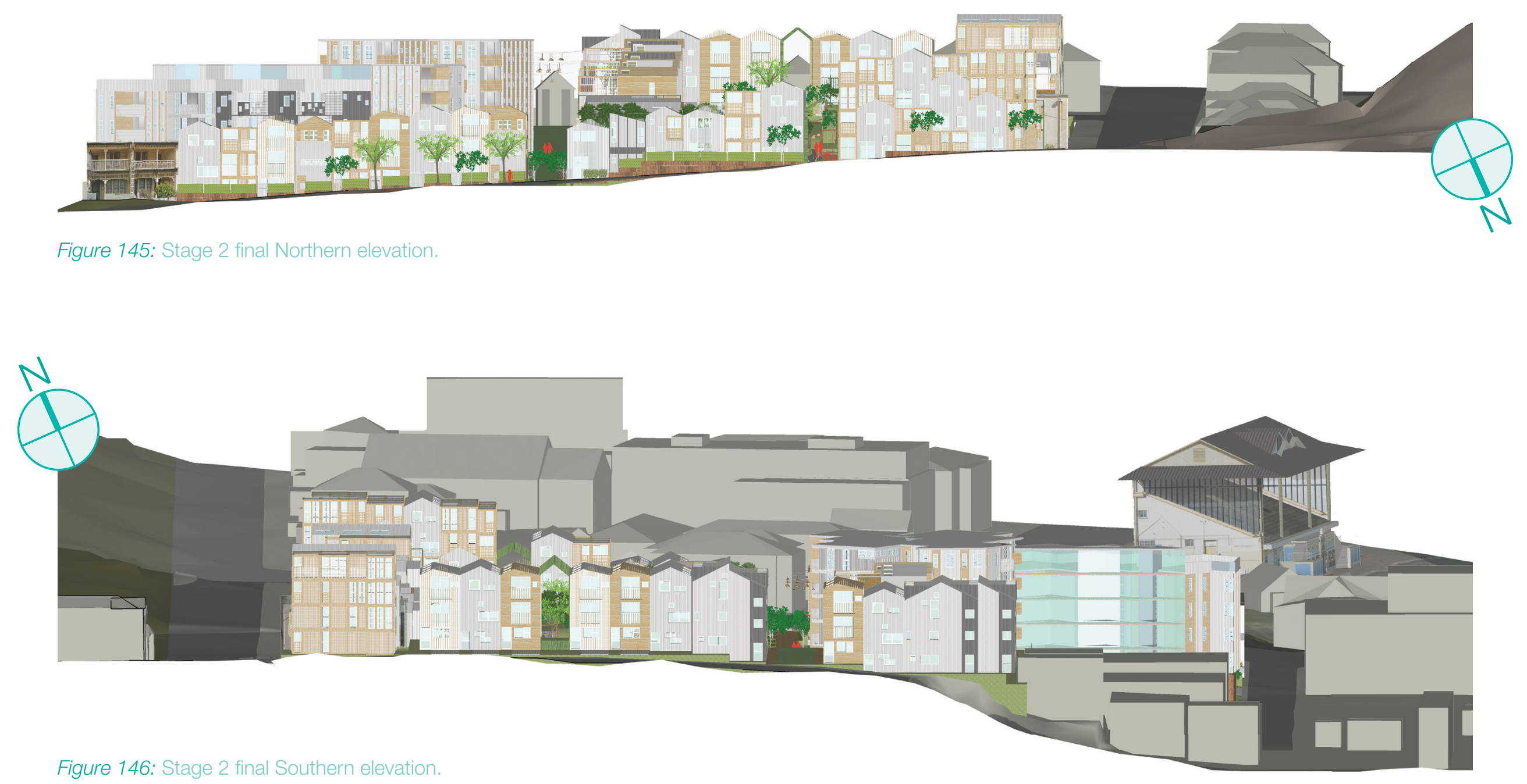


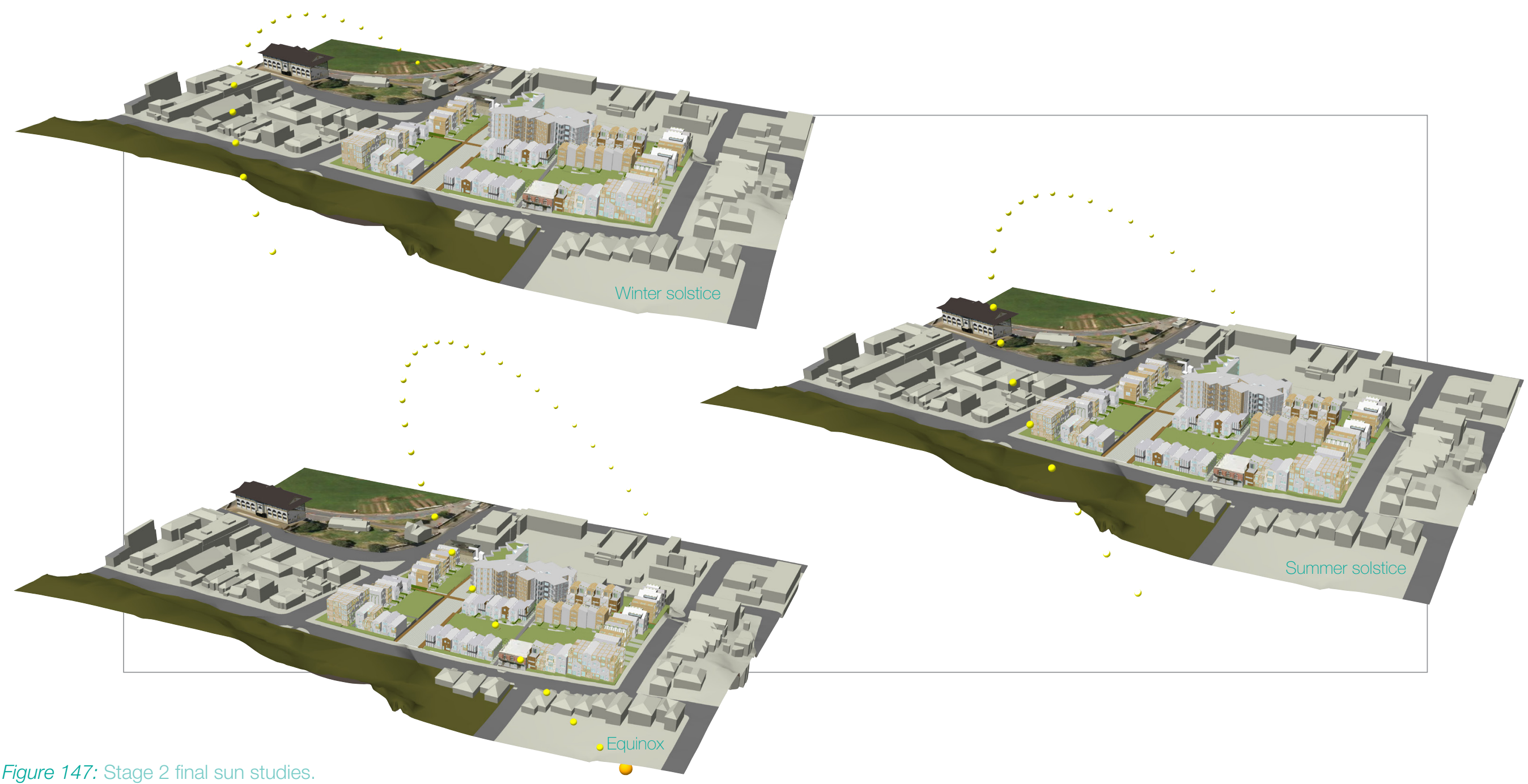




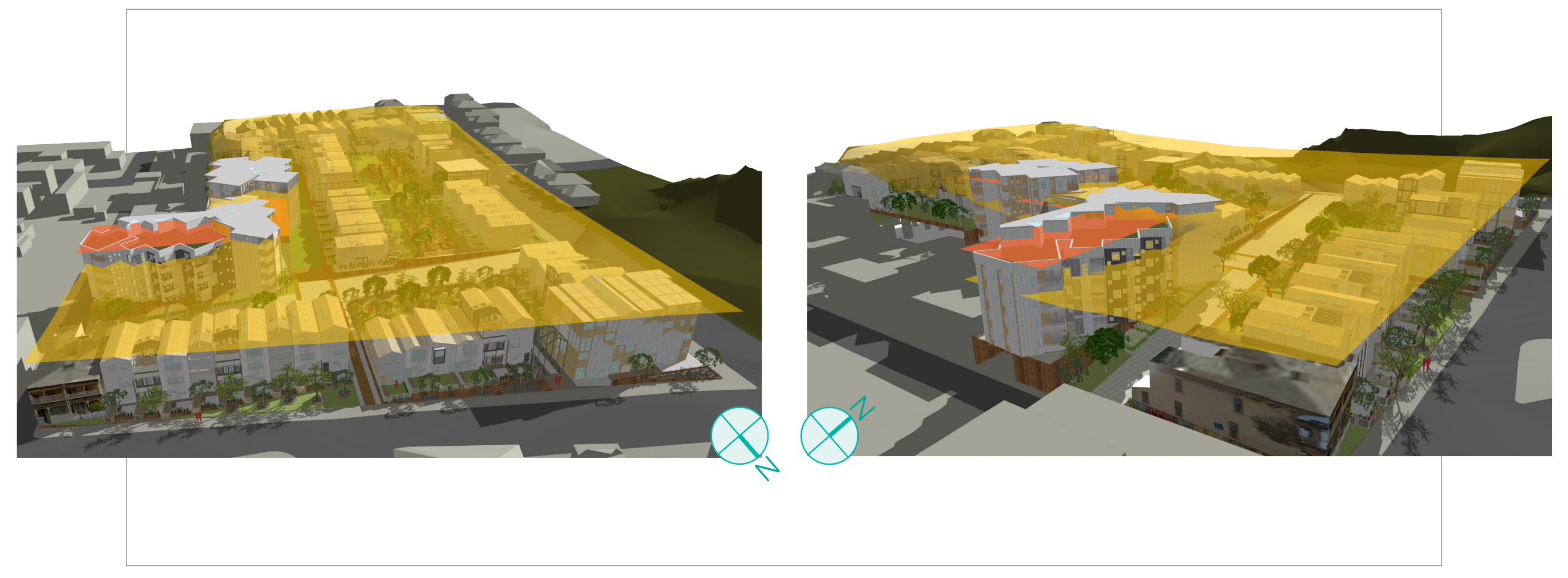

Figure 148: Stage $212 \mathrm{~m}$ height limit. Yellow: plane from existing ground level, orange: ground plane $12 \mathrm{~m}$ up when flattened. 


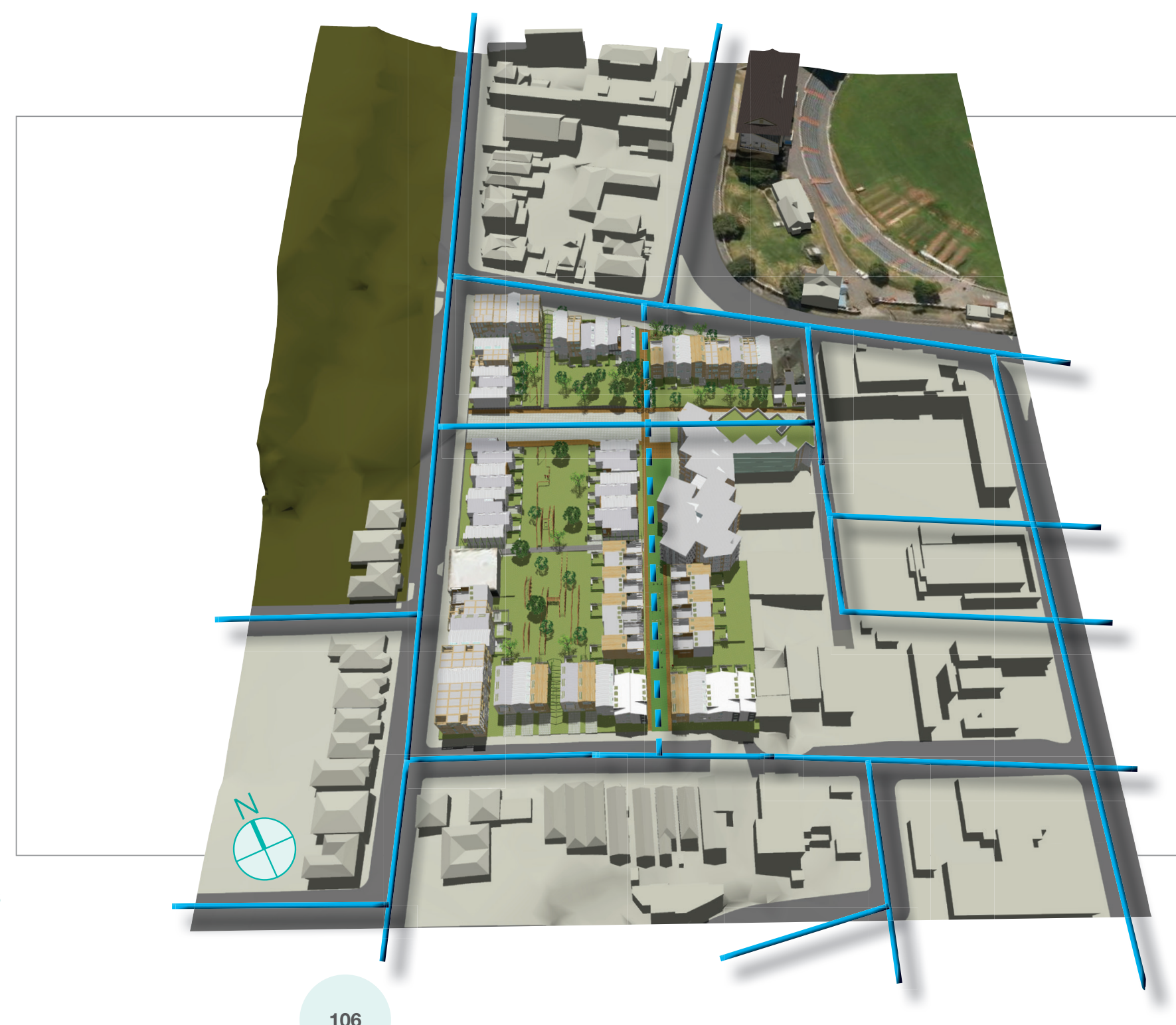




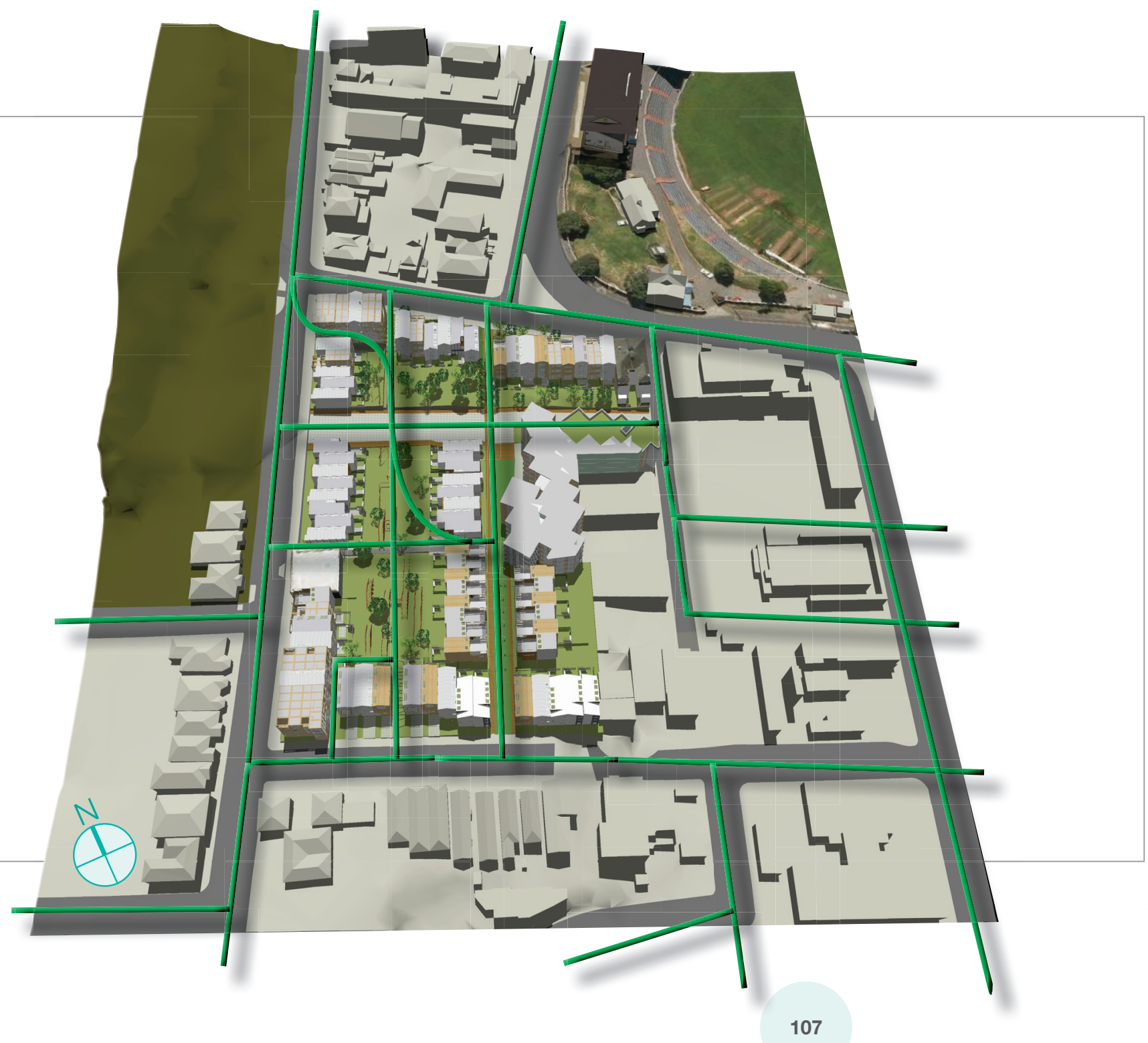

Figure 150: Stage 2 final pedestrian routes are unlimited through site. 


\section{Stage 2 - Feedback and Analysis}

\section{Developer Interview 2}

The Stage 2 plans and the updated feasibility study were shown to the developer in a second interview (Anonymous, personal communication, September 9, 2016) (see Tables 12 and 13). The MDH scheme and site coverage were considered appropriate. The developer also stated that the second feasibility study had considered all the necessary elements. After looking at the plans, he believed the costings were still underestimated.

More realistic figures were discussed, and the developer also outlined how much he would typically be prepared to pay for apartments. This allowed a third and final feasibility study to be calculated (see Appendix E for tables of average sale prices).

However, the developer pointed out that the many external walls and corners of the main apartment building would make it expensive to build, meaning it would fall outside of the budget he had given. The developer explained that he prefers near-square buildings that are material-efficient and quickly constructed. He also mentioned that more carparks would be necessary to avoid lost market value. 


\begin{tabular}{|c|c|c|c|c|c|c|c|c|c|}
\hline Type & $\mathrm{m} 2$ & Units & $\begin{array}{l}\text { Construction cost } \\
\text { per unit }\end{array}$ & $\begin{array}{l}\text { Other costs } \\
\text { per unit }\end{array}$ & GST $20 \%$ & $\begin{array}{l}\text { Total cost } \\
\text { per unit }\end{array}$ & $\begin{array}{l}\text { Total cost } \\
\text { per m2 }\end{array}$ & $\begin{array}{l}\text { Sale price } \\
\text { per unit }\end{array}$ & $\begin{array}{l}\text { Sale } \$ \\
\text { per m2 }\end{array}$ \\
\hline 2 bed MDH & 80 & 17 & $\$ 134,600$ & $\$ 100,000$ & $\$ 46,920$ & $\$ 281,520$ & $\$ 3,519$ & $\$ 479,000$ & $\$ 5,988$ \\
\hline 3 bed MDH & 104 & 30 & $\$ 175,000$ & $\$ 100,000$ & $\$ 55,000$ & $\$ 330,000$ & $\$ 3,173$ & $\$ 689,000$ & $\$ 6,625$ \\
\hline 4 bed MDH & 150 & 20 & $\$ 252,400$ & $\$ 100,000$ & $\$ 70,480$ & $\$ 422,880$ & $\$ 2,819$ & $\$ 746,000$ & $\$ 4,973$ \\
\hline 1 bed apt & 50 & 76 & $\$ 100,000$ & $\$ 50,000$ & $\$ 30,000$ & $\$ 180,000$ & $\$ 3,600$ & $\$ 260,000$ & $\$ 5,200$ \\
\hline 2 bed apt & 70 & 27 & $\$ 140,000$ & $\$ 50,000$ & $\$ 38,000$ & $\$ 228,000$ & $\$ 3,257$ & $\$ 397,000$ & $\$ 5,671$ \\
\hline
\end{tabular}

Table 12: Cost feasibility 3

\begin{tabular}{|l|l|}
\hline Total development cost & $\$ 43,124,949$ \\
\hline Total development sale price & $\$ 74,442,286$ \\
\hline Profit & $\$ 15,498,337$ \\
\hline Profit margin & $26 \%$ \\
\hline
\end{tabular}

Table 13: Cost feasibility 3 outcomes. 


\section{Architect Interview 2}

The architect was approached for a second time to comment on each of the plans. (Anonymous, personal communication, September 5, 2016)

\section{Two bedroom unit}

The architect suggested swapping the kitchen and living areas due to his understanding that residents would prefer a larger living room over a large kitchen and dining space (see Figure 151 and 152). This was not changed. Keeping the kitchen and upstairs bathroom services together was more energy efficient and lowered plumbing costs. Other comments were also made about the excessive use of skylights, which was addressed.

\section{Three bedroom unit}

It was pointed out that the second floor circulation space seemed excessive when the ensuite was too tight (see Figure 156). Rather than changing the circulation layout, which would have been difficult, a change in the size and swing of the shower door solved the issue.

\section{Four bedroom unit}

The architect disliked the triple height void as he perceived it to be "like a service way in a block of flats" (see Figure 153 and 154). This was rearranged to connect with the circulation route, greatly improving the feeling of the space.

\section{Apartment building 1}

Echoing the developer, the architect said the building was overly complex and would be extremely costly. Though the design intent was recognised, it was clear that the building would not be within the project's budget.

\section{Apartment buildings 2 and 3}

The planning of the circulation space was commended, however the architect believed the entrance to each apartment lacked a sense of threshold and privacy beyond (see Figure 155). This was solved with the addition of an enclosed setback to create a clear entrance.

\section{Outdoor Areas}

The architect suggested the units should be set back further from the road. This comment was valid and an increased setback allowed for front yard areas and a better distinction between public and private space. He also said the fencing around the backyards needed to be more private. 

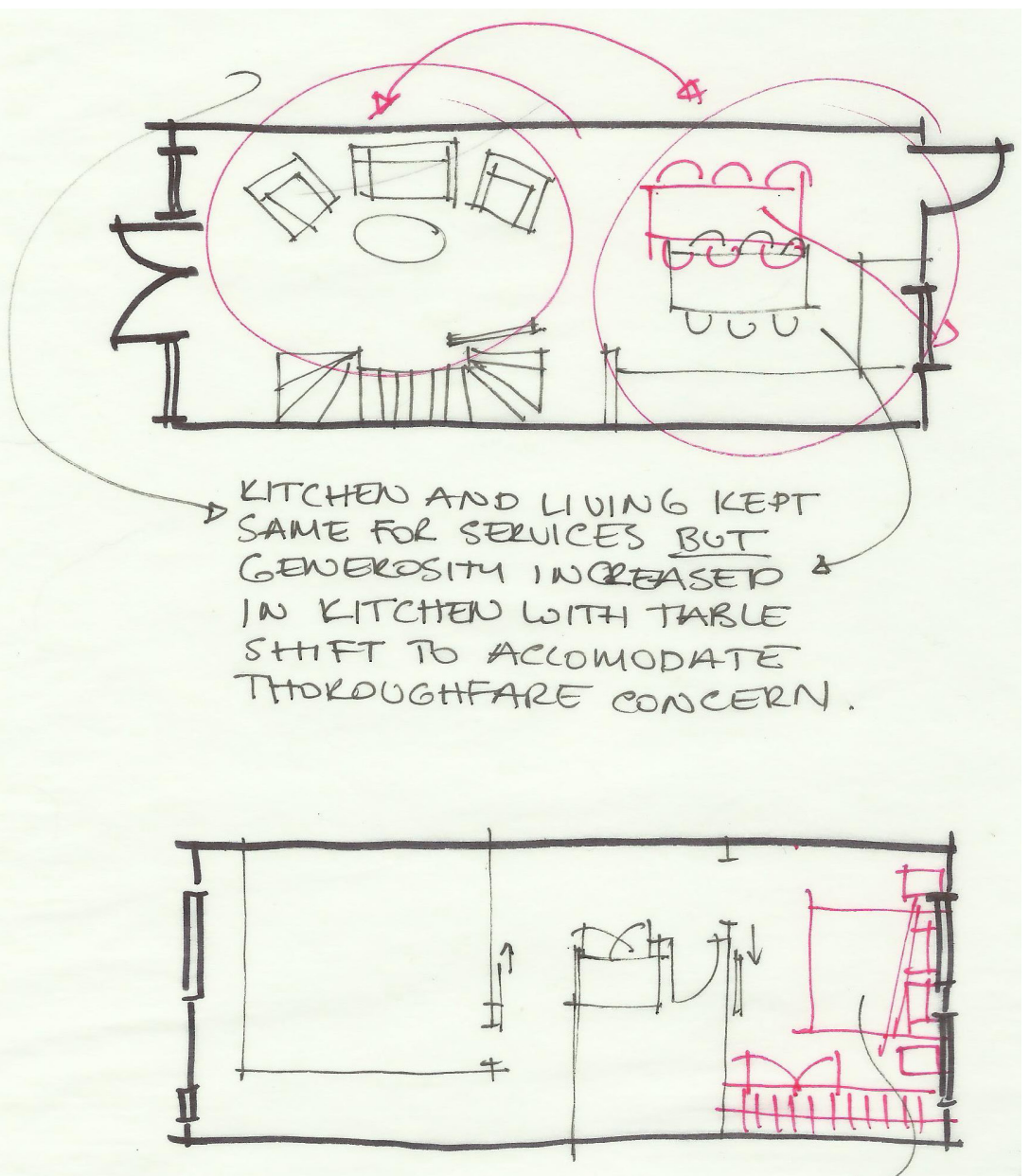

MORE CONVENTIDOे AL BEDROOM LAYOUT

Figure 151: 2 bedroom unit architect's issues with

designer's solutions.

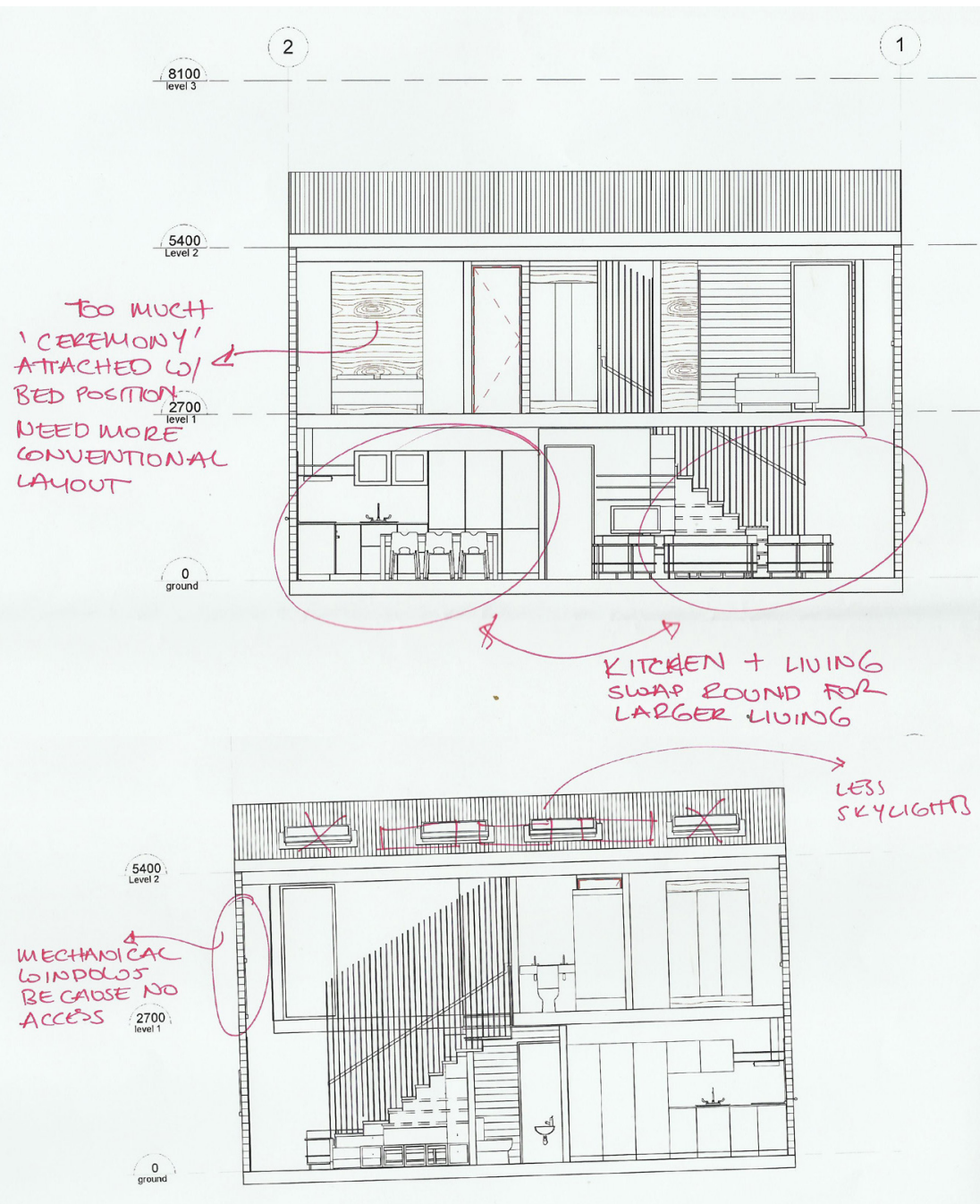

Figure 152: 2 bedroom unit architect's issues with

designer's solutions. 


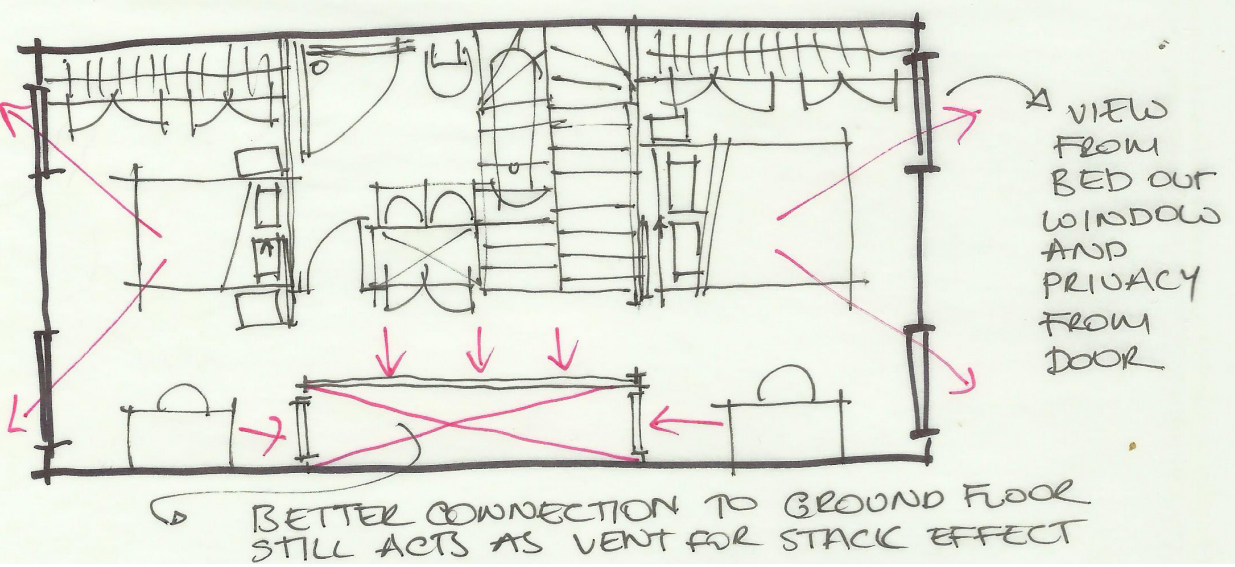

Figure 153: 4 bedroom unit architect's issues with

designer's solutions.

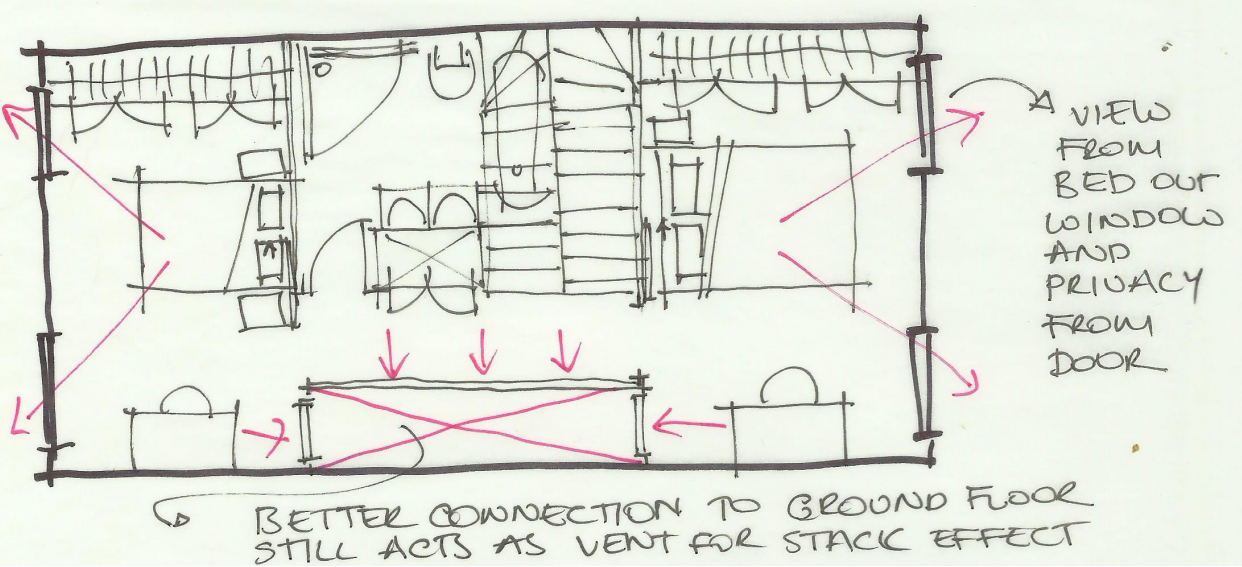

Figure 154: 4 bedroom unit architect's issues with

designer's solutions.

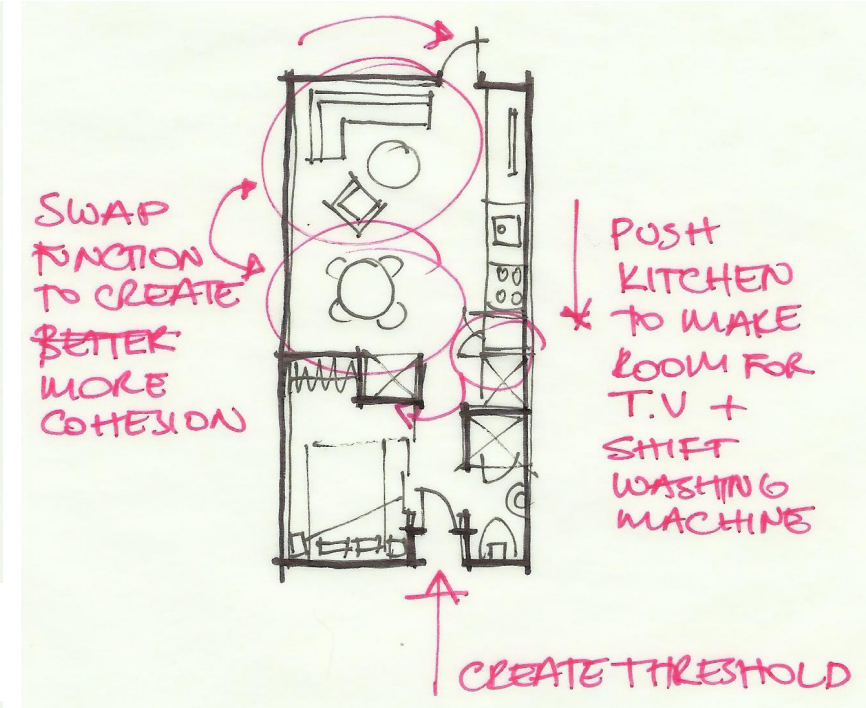

Figure 155: Apartment buildings 2 and 3 architect's

issues with designer's solutions.

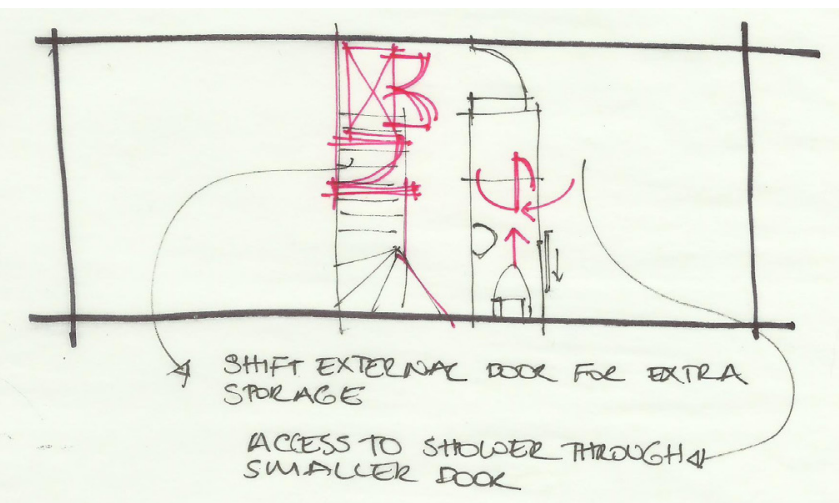

Figure 156: 3 bedroom unit architect's issues with designer's solutions. 


\section{Secondary Developer Interview}

Contact was finally made with a second development professional. Working across numerous property and infrastructure sectors as a strategic planner, this developer was qualified in answering questions around market demands and the value of sustainability (Anonymous, personal communication,

October 24, 2016).

The developer agreed with the concept of sustainable development, but recognised that it is often unfeasible. He explained, "in a market with rampant construction costs and a market that is still predicated on lowest price it is sometimes difficult to make it work." Like the primary developer, he is market driven. "If we produce a product the market does not want we fail. There are plenty of failed developers or persons with good intentions trying to be different."

Interestingly, this developer disagreed with the primary developer about the risks associated with sustainable materials, stating "where there is no real cost differential it is not a major issue.

These comments verify that when the cost difference between sustainable and traditional materials is small or non-existent, sustainability will become a priority. 


\section{Structural Engineer Feedback}

A consultation with a structural engineer provided further feedback about the designs at this stage (Anonymous, personal communication, October $27,2016)$. While the design for the townhouses was approved, the apartment buildings needed to be reassessed (see Figures 157-162). The consultant indicated that the scale of the buildings would require:

- Large concrete foundations

- Steel or concrete for the structural columns

- A percentage of solid wall in glazed circulation areas, to be fire safe

She also mentioned that certain awkward corners and angles would be difficult for builders.

The consultation made it clear that the size and design of the apartment buildings would require the use of unsustainable construction materials, and that the next stage of design would require a scope assessment.

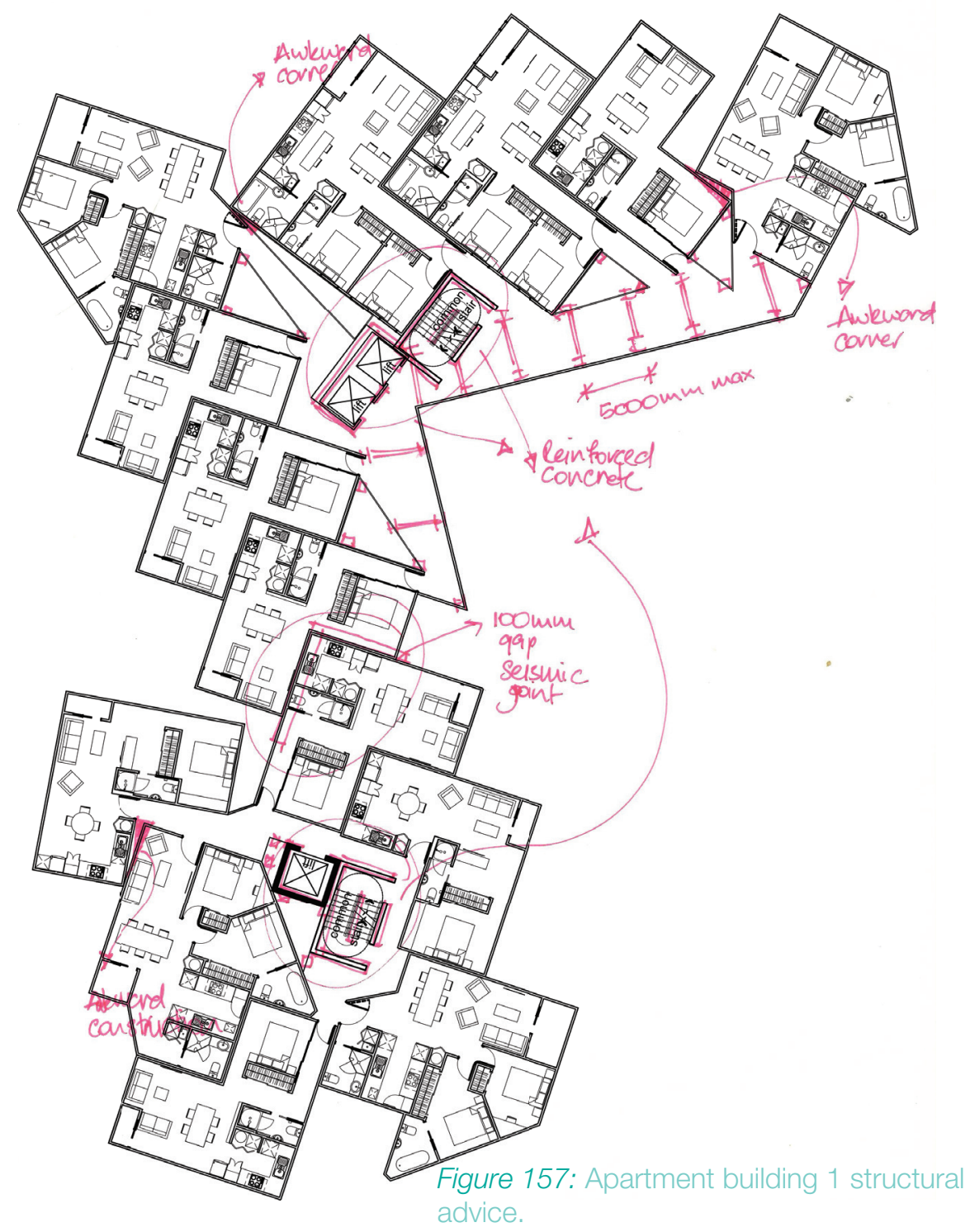




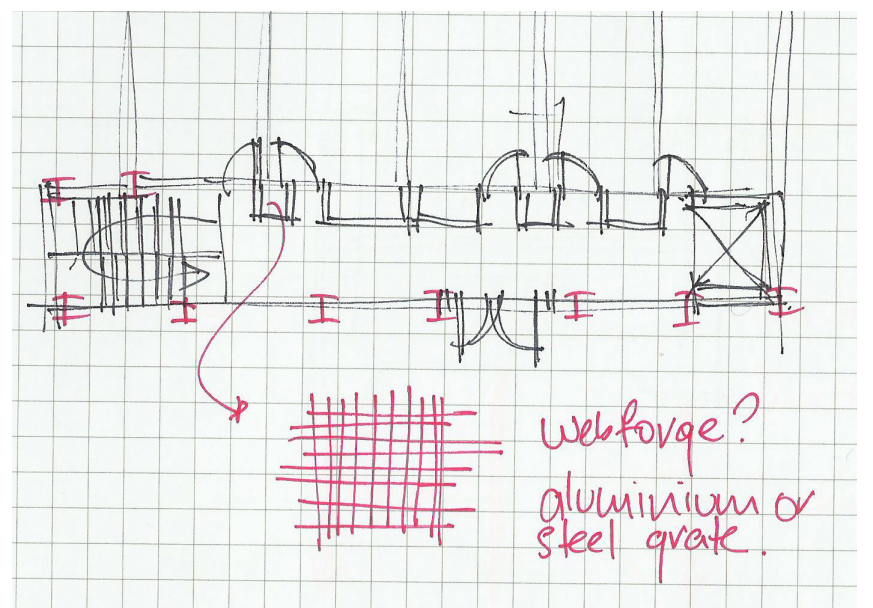

Figure 158: Apartment building 2 and 3

structural advice.

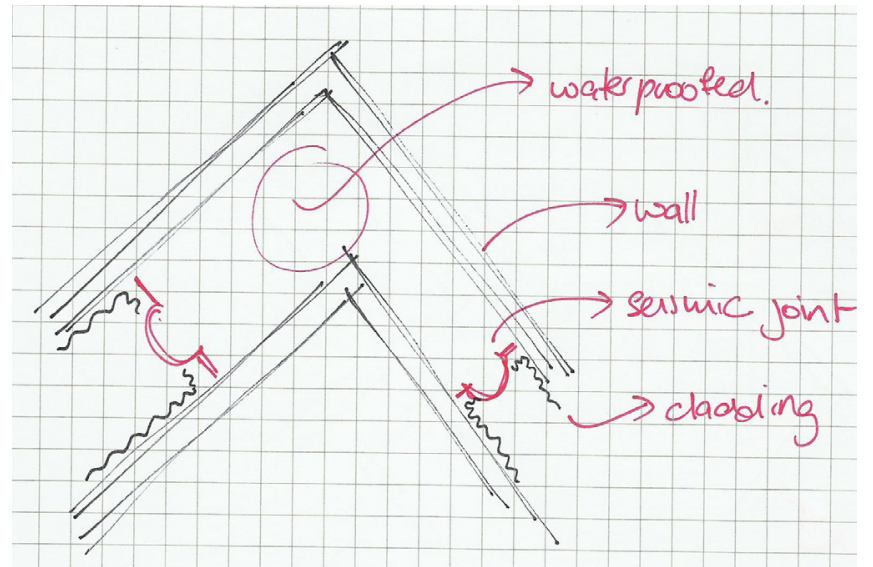

Figure 159: Seismic joint detail structural advice.

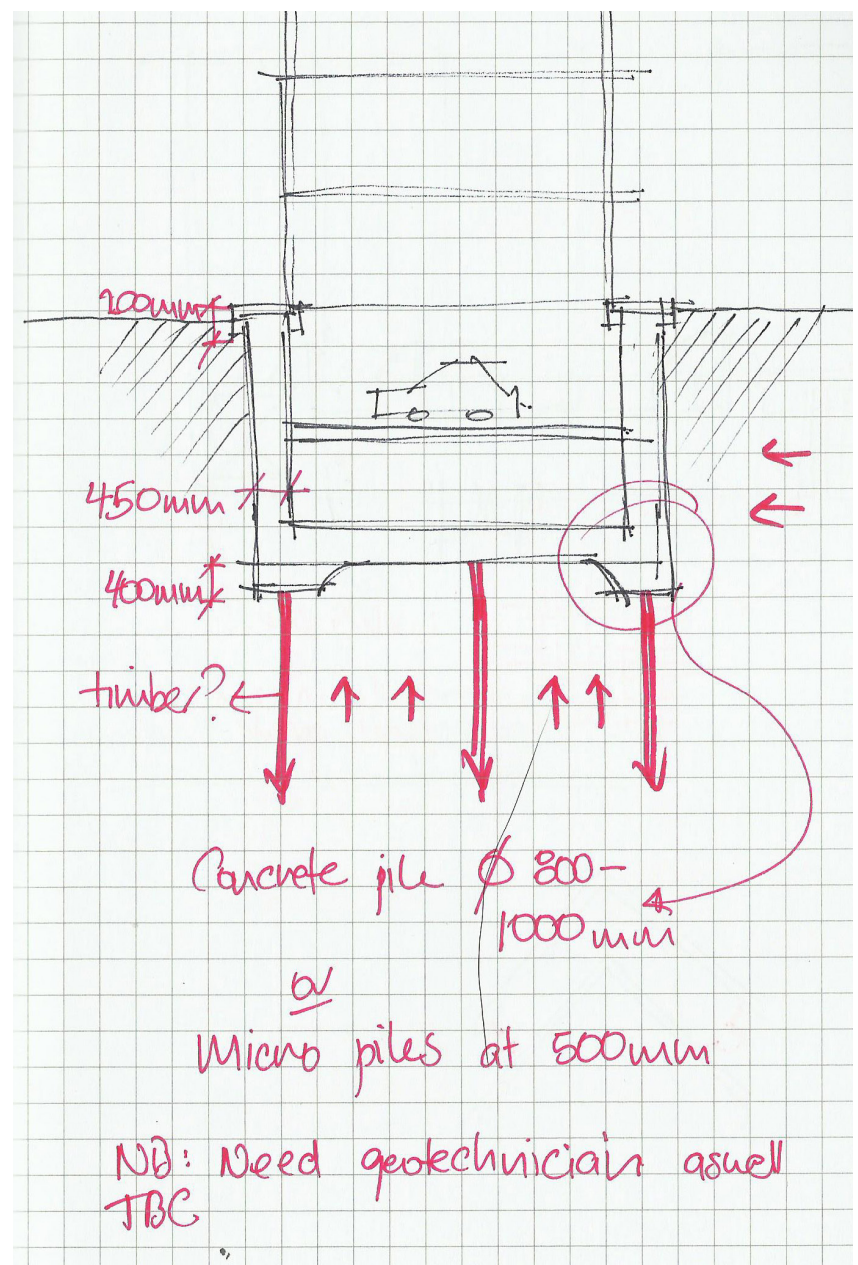

Figure 160: Apartment building 1 foundations structural advice.

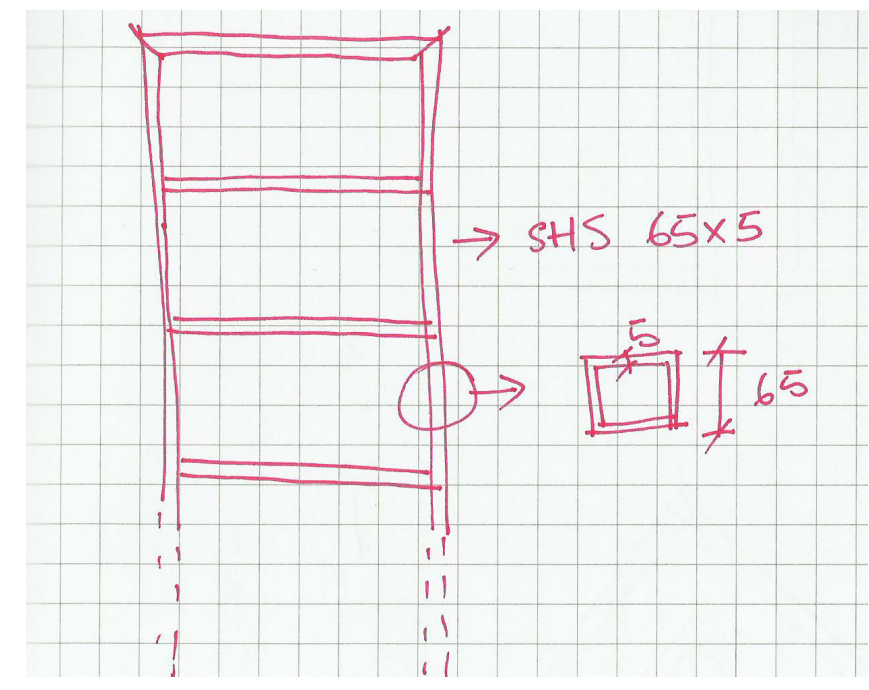

Figure 161: Apartment building 1 multi-storey steel detai structural advice.

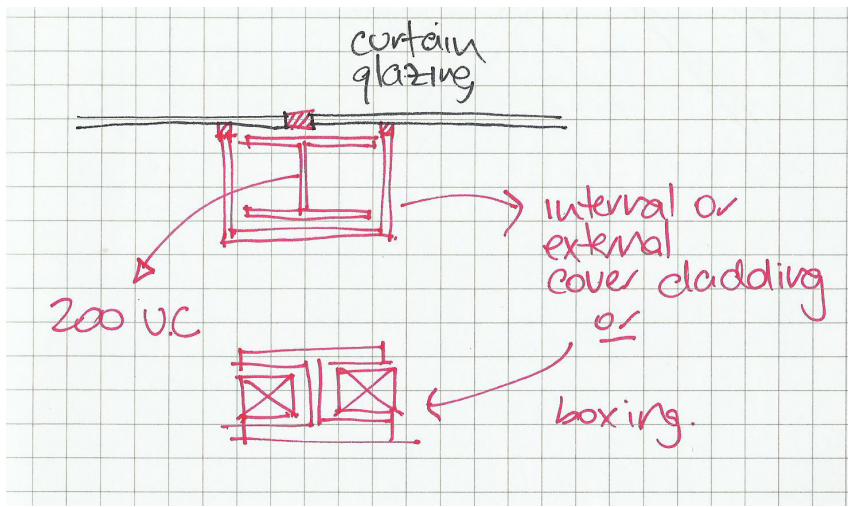

Figure 162: Apartment building 1 curtain glazing detail structural advice. 


\section{Design Review 2}

The second review by industry experts discussed a number of key issues.

- The minimal car parking within the development was not supported by the panel of reviewers, who believed that it would limit buyer interest. However, parking was not increased as a result. As discussed in the Site Study, market research showed that almost $40 \%$ of Mt Cook residents do not own a car. Additionally, the real estate agents had both reinforced that the high demand for housing in central Wellington means any unit will sell.

- A comment was made that demolishing the existing warehouses would be unsustainable. However, if the neglected warehouses were carefully deconstructed and recycled where possible, the land could be put to better use and the impression of the surrounding area would be improved.

- Suggestions were made to integrate architectural moments and quirky spaces, such as reading nooks and crannies, but these would increase the footprint and the cost.

- The reviewers felt that too many aesthetic styles were being used and that economies of scale would not be achieved. It was agreed that this should be scaled back to benefit the profitability of the project, while still maintaining some individuality between the units. 


\section{Stage 3- Design Process Scope Assessment}

Once all feedback had been reflected upon, the scope of the project was reassessed before beginning the final design stage. In this last stage, the focus was placed on refining the MDH units. It was decided the apartment buildings were outside the scope of the development and that they would not be continued with. For many reasons, it was clear the apartments would be impossible to construct affordably without sacrificing the sustainability principles that governed the project. Time constraints meant that those areas of the development needed to halt, with the final design stage instead directed towards clarifying a solution for the MDH units.

The cost analysis also needed to be consolidated in the next stage. The initial plan was to create a cost sheet for each individual unit typology, comparing traditional materials against the sustainable alternative. However, it was decided that multiple cost sheets would go beyond the scope of this thesis. Instead, pricing would be calculated for the 2-bedroom and 4-bedroom units, which represented the proportionally most and least expensive units to build. This would allow conclusions to be made regarding the entire development. 


\section{Final Design}

Style

In the final stage, the MDH unit planning, external articulation and the landscaping was refined, with a focus on developing the aesthetic character (see Figure 163-164). The units were designed to fit a common vernacular, which would result in a natural discourse amongst the terraced row. This vernacular also aimed to reflect the surrounding architectural context. It was felt that a pristine, modern development would be unsympathetic towards the culture and historical significance of the area (see Figures 166-217).

As such, a typical Edwardian or Victorian villa has been simplified and modernised, removing the fretwork and decoration to leave only the abstract bones of the villa's form. This merging of old and new responds to the natural evolution of the city.

\section{Structure}

CLT is specified for the structural framing of the units. As discussed in the Warrander Studio precedent, this system has many benefits both technologically and sustainably. Visually, the material colour lends a warmth to the interior, but it can be painted if the home-owner wishes.

While CLT construction drawings have not been produced for this project,

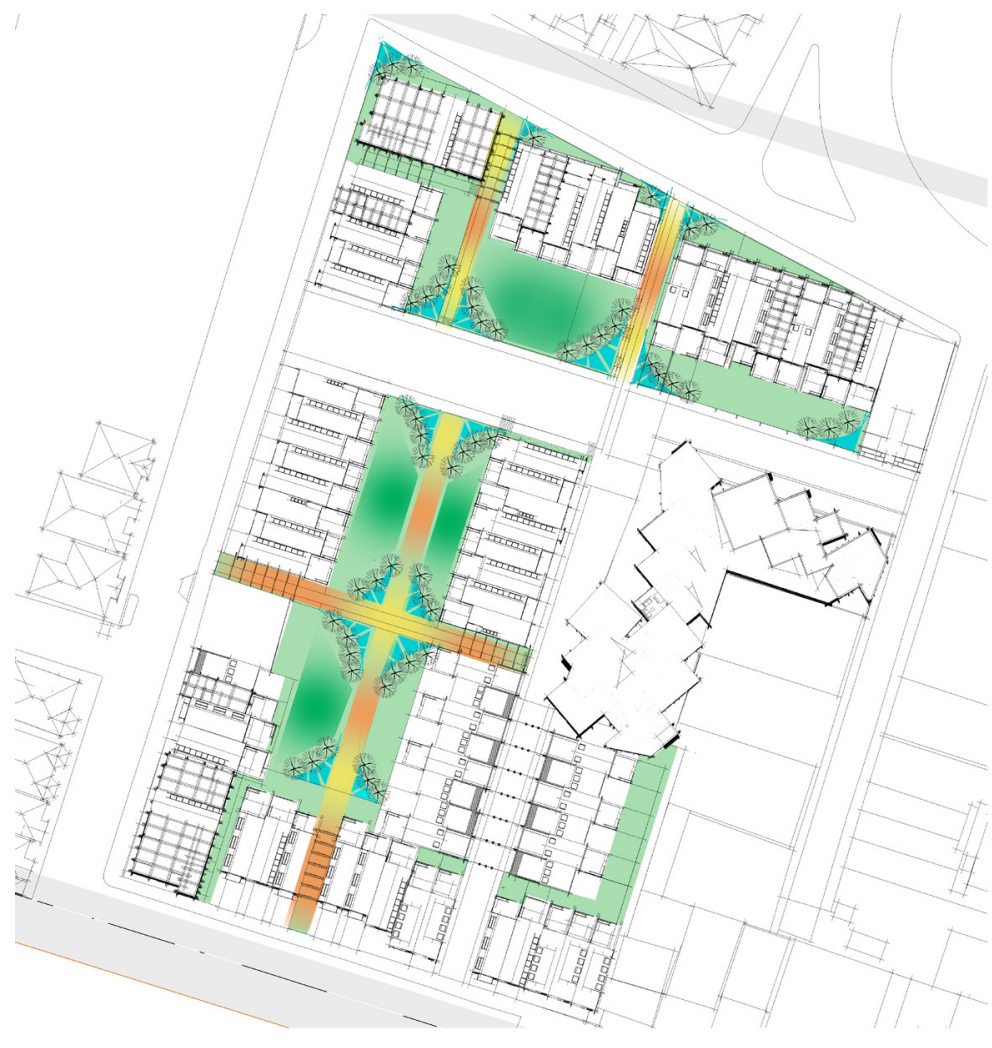

Figure 163: Landscape redistribution plan - post design review. 

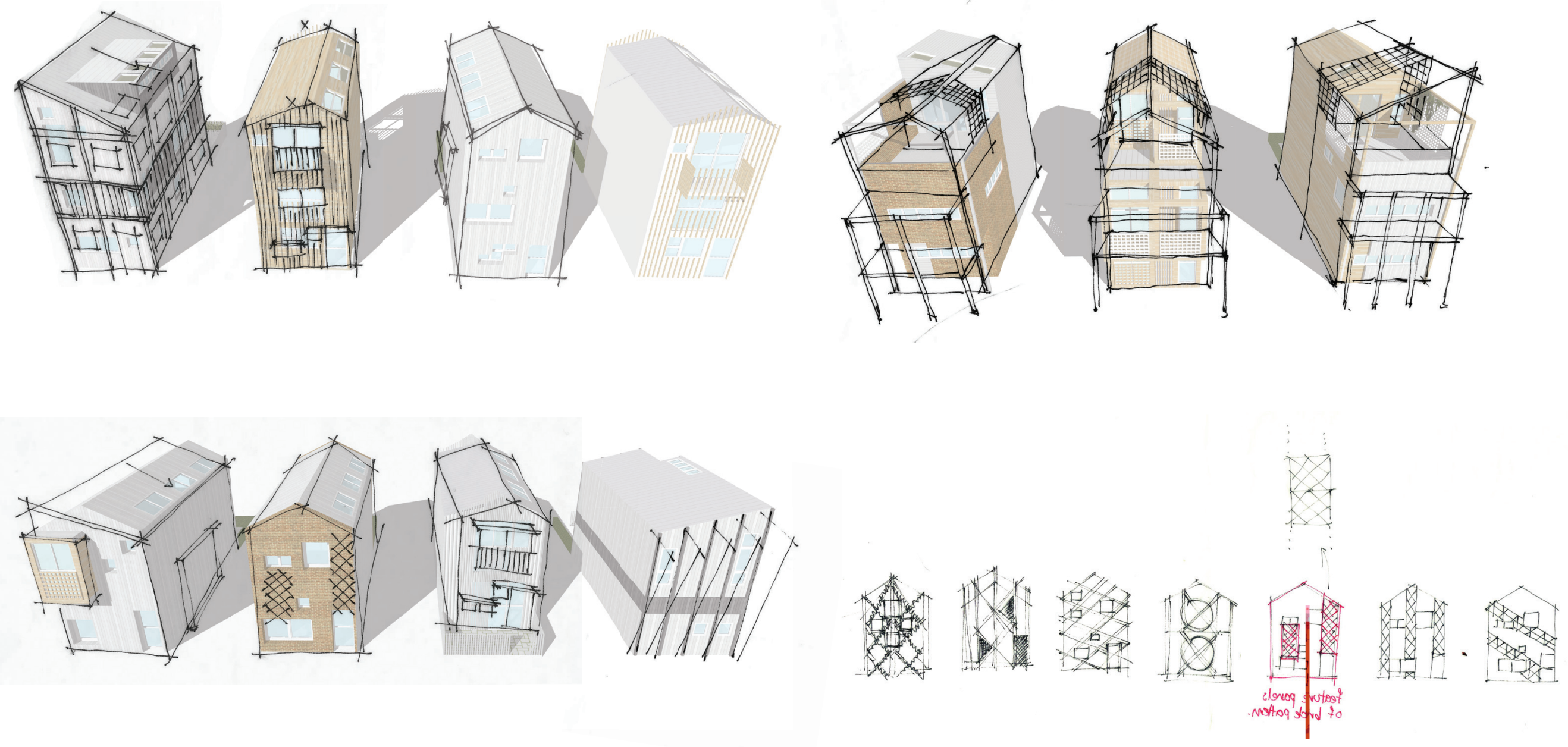

Figure 164: Design refinement for unit articulation. 
a detail drawing helps describe its application (see Figure 165).

Roof

As previously discussed, three roof pitches help to differentiate individual units and blend with the historical context. Across each block of houses, the roof valleys meet to create a dynamic overall form.

The colour of the roofs was ultimately determined by the wallaba shingle material that was chosen. Similar to macrocapa, wallaba is a hardwood that is resistant to insects, decay and moisture without needing to be treated. It will slowly silver over time to align with sustainable 'cool roof' principles.

\section{Cladding}

Weatherboard and brick cladding characterises Victorian and Edwardian villas. In this reinterpretation, macrocarpa board and batten, and wallaba shingles have been used in a similar way. The modern aesthetic is simplistic, but to reflect the past, some typologies have subtle patterns that reference the elaborate detailing of a historic villa.

Ideally, the cladding would be produced as prefabricated panels which would allow for economies of scale and faster construction.

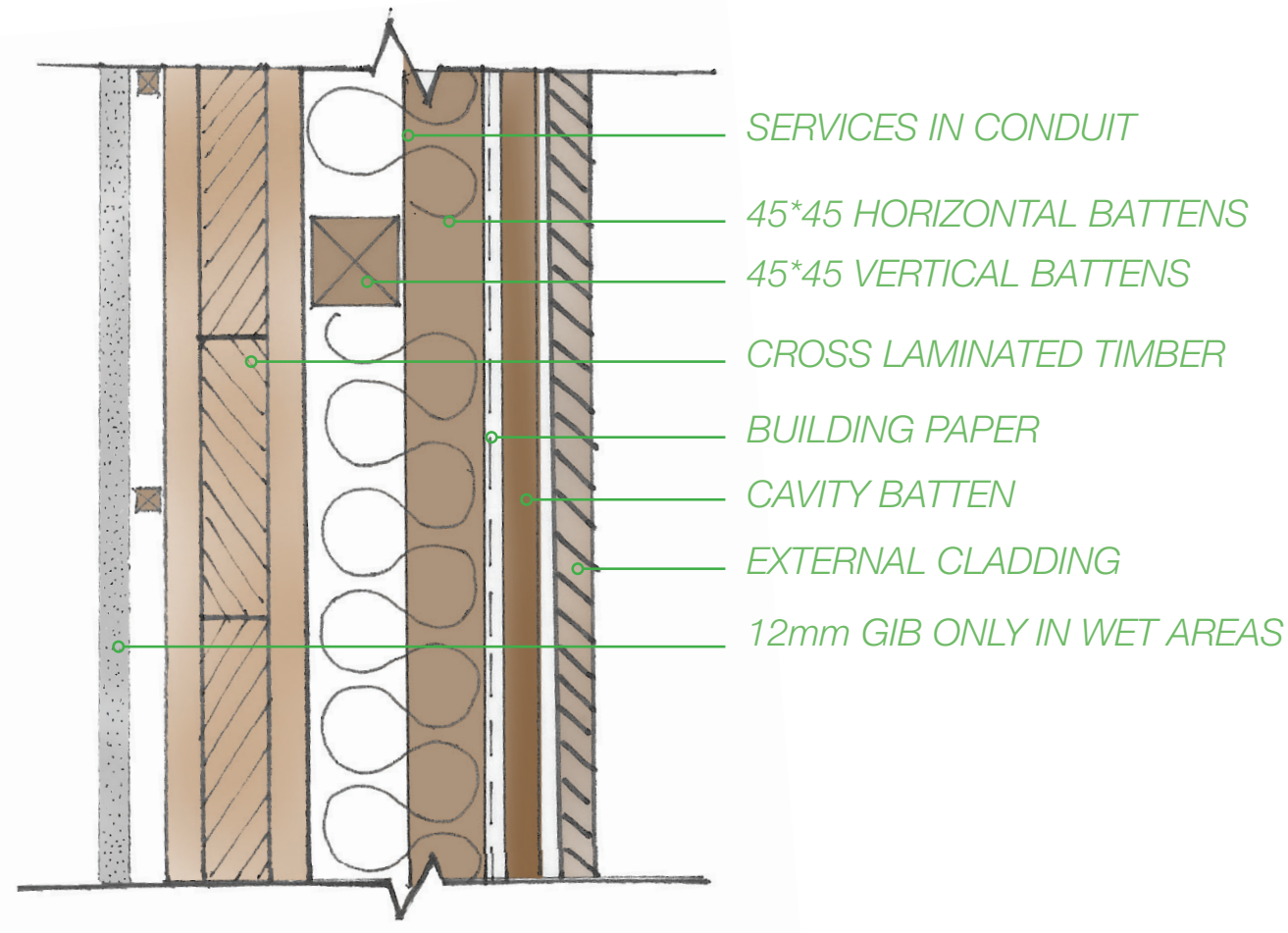

Figure 165: CLT typical wall detail. 


\section{Fenestrations}

The window placement in a villa is reasoned and significant, whether to create a view, balance a room, or display wealth and status. In the current design, views, sunlight and ventilation have been the most important considerations. Though it is common in modern architecture to glaze entire walls, views are here created through multiple smaller frames. This adds architectural interest and an element of privacy. Only three window variations have been used throughout the entire development, maximising economies of scale. Careful arrangement prevents them from looking uniform.

\section{Landscaping}

Landscaping has been designed for future development. While the developer may not be prepared to pay extra for well-articulated landscaping, it was worth creating a design that could potentially be funded by other means.

New features that were considered as concepts at this stage included (see Figure 198-209):

- A community hall in the historical buildings on the corner of Rugby and Belfast streets
- A community vegetable garden

- Native gardens

Reed ponds, conceptualised during Stage 1, were also fully articulated here. They are placed at intersections throughout the site, where they could act as a sustainable storm water management system and a purifier for water that could be used on gardens (Lismore City Council, 2005). 
Final Two Bedroom Units

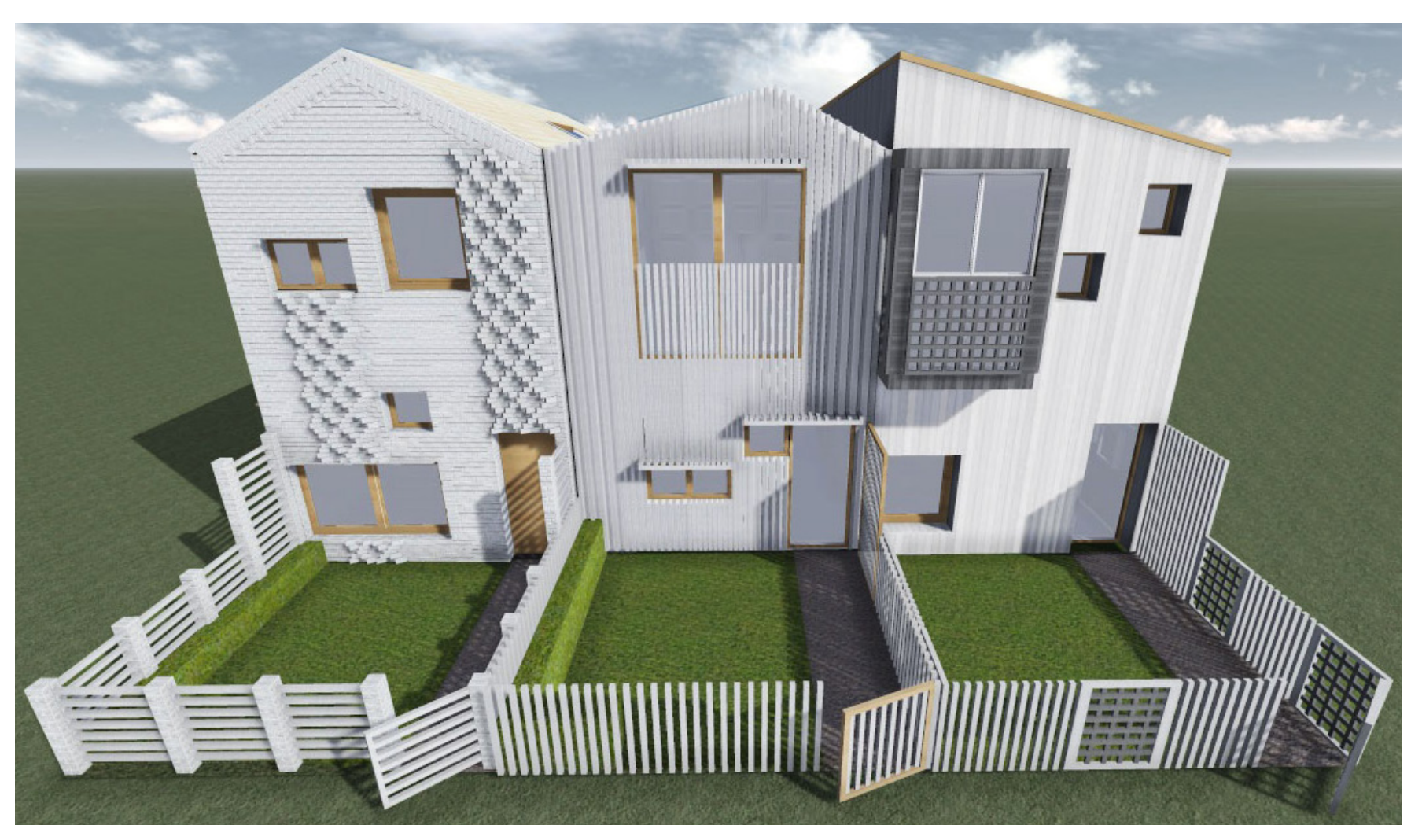

Figure 166: Final front façade articulation for 2 bedroom units.

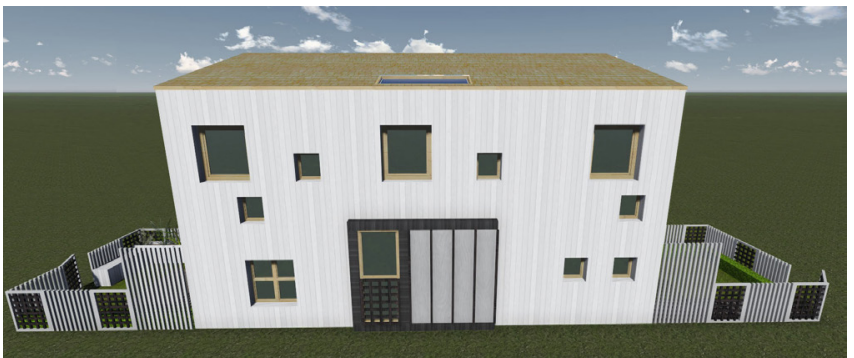

Figure 167: Final side facade articulation for type 3 2 bedroom unit. 


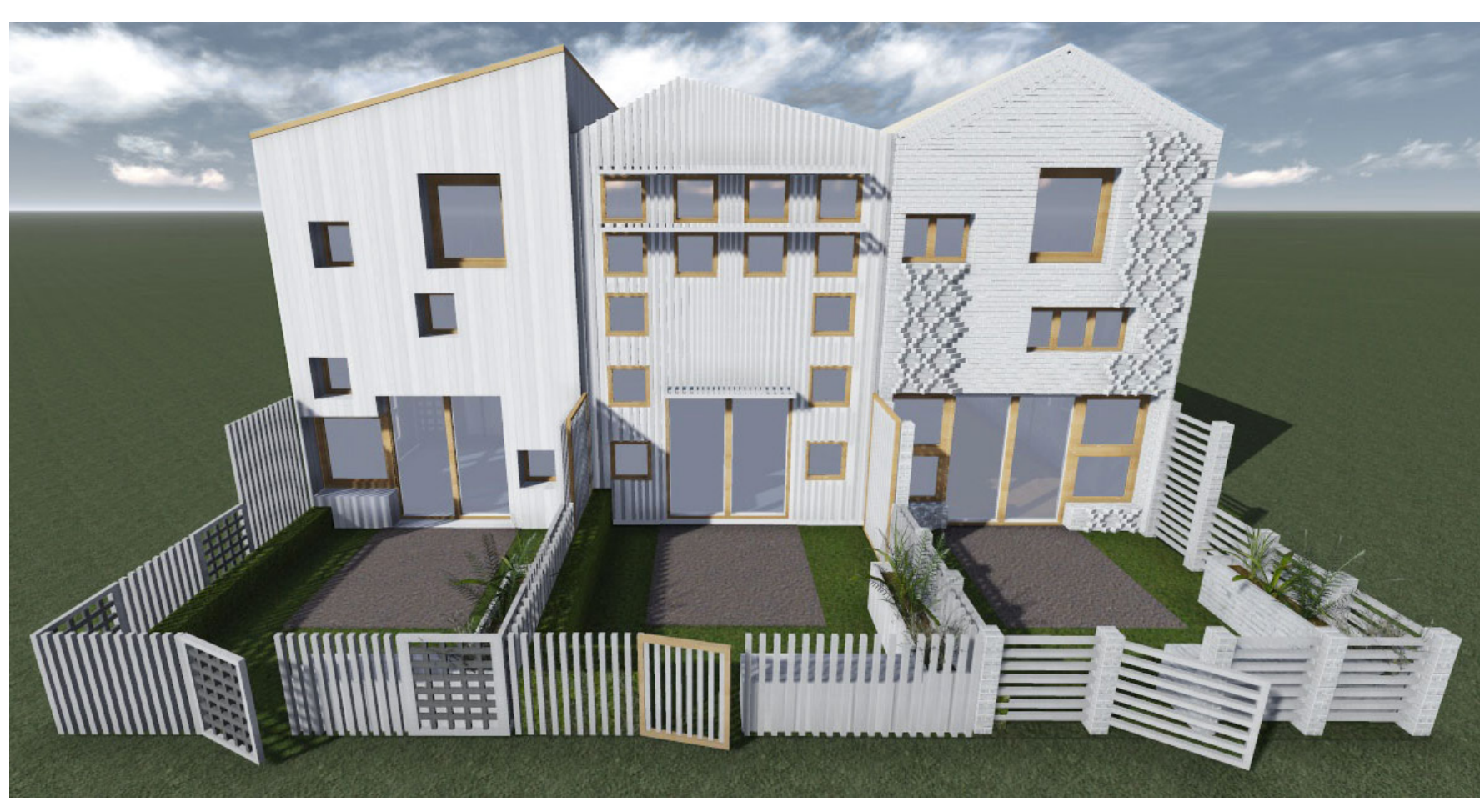

Figure 168: Final rear façade articulation for 2 bedroom units.

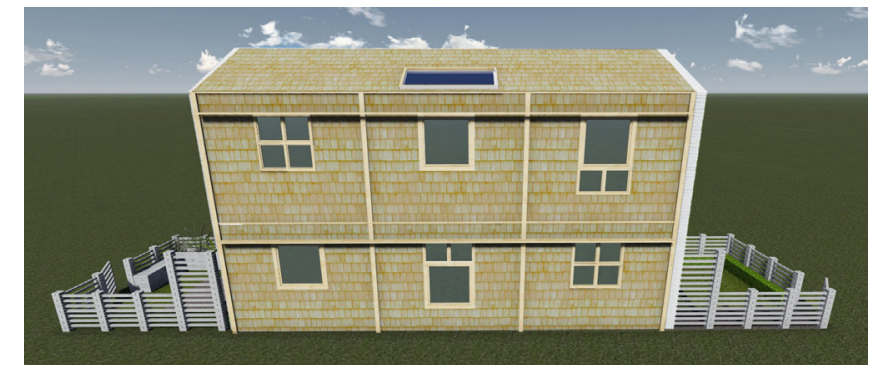

Figure 169: Final side facade articulation for type 1 2 bedroom unit. 


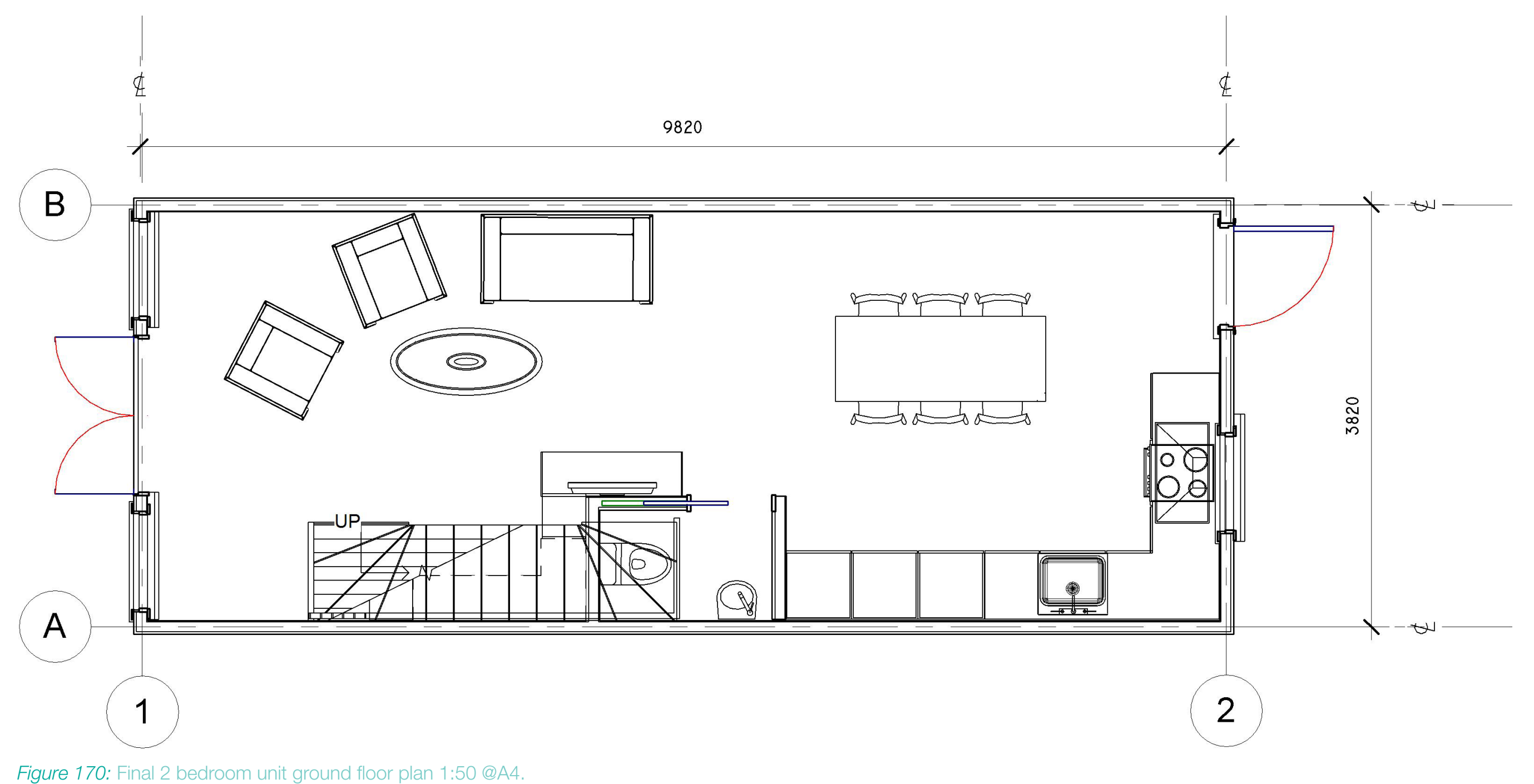

Figure 170: Final 2 bedroom unit ground floor plan 1:50@A4. 

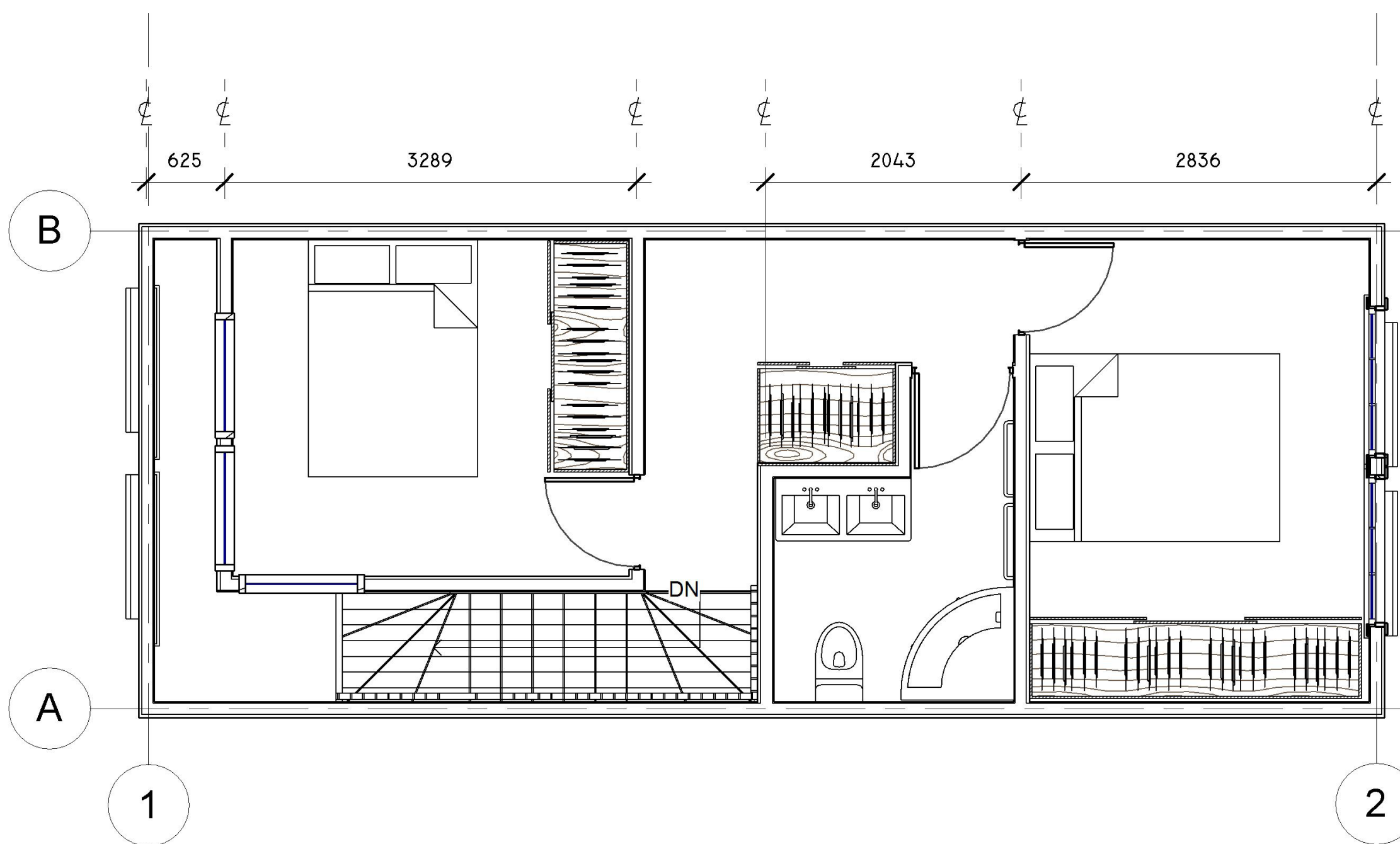

Figure 171: Final 2 bedroom unit first floor plan 1:50@A4. 


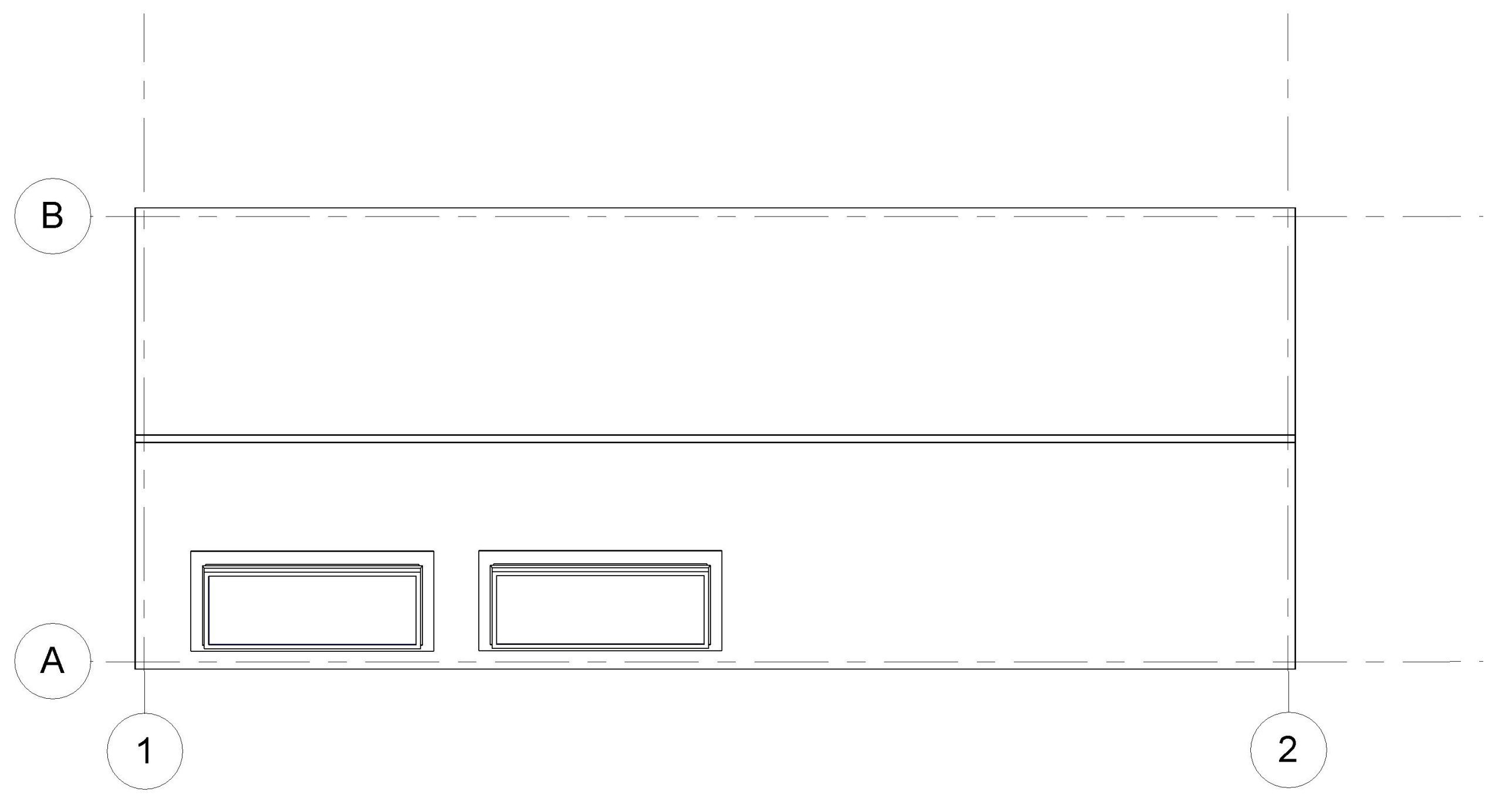

Figure 172: Final 2 bedroom unit roof plan 1:50 @A4. 
5400

Level 2

2700

level 1

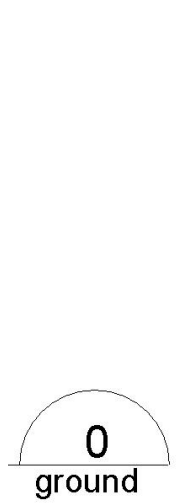

Figure 173: Final 2 bedroom unit sectional elevation A 1:50 @A4.
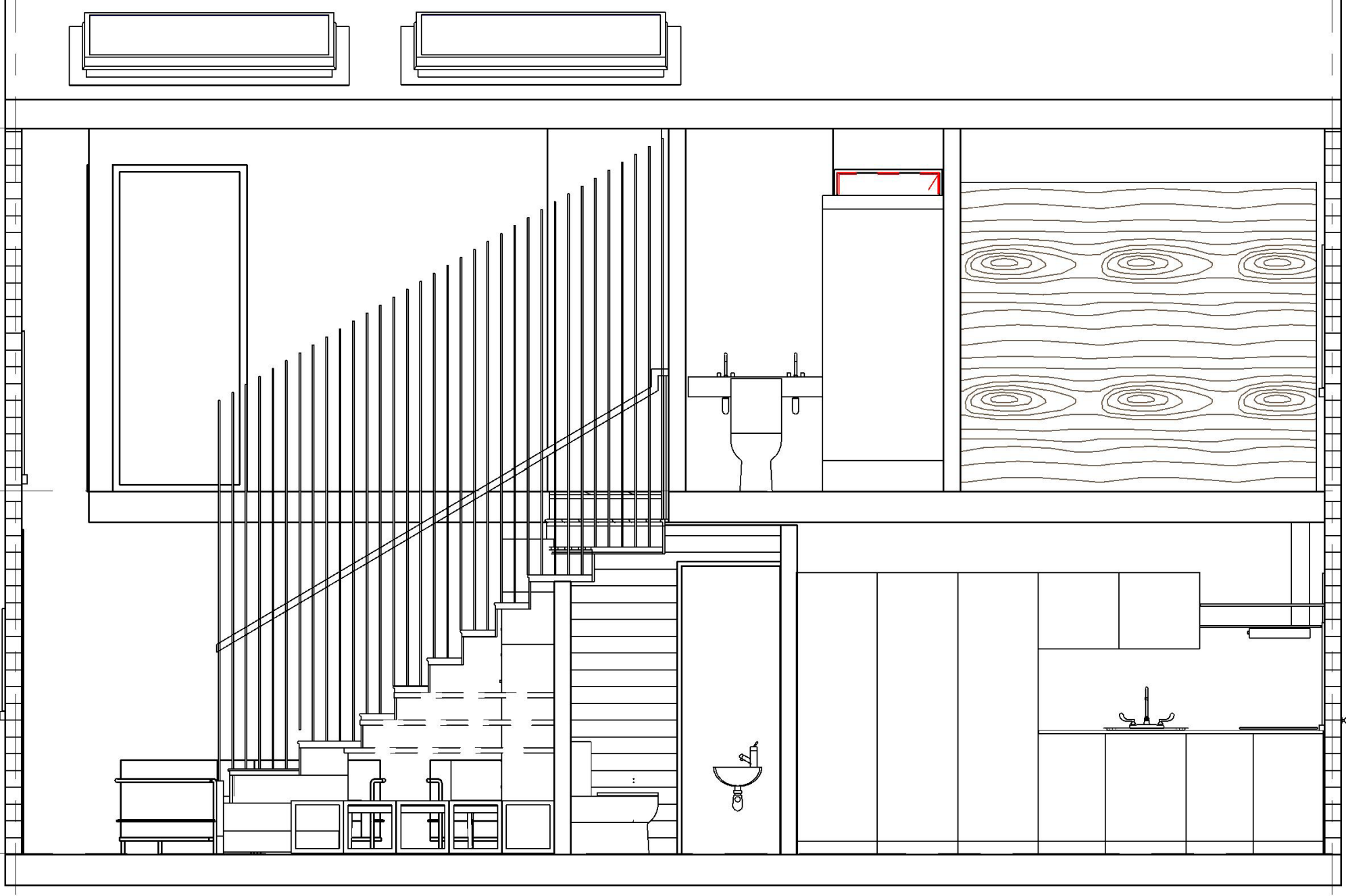


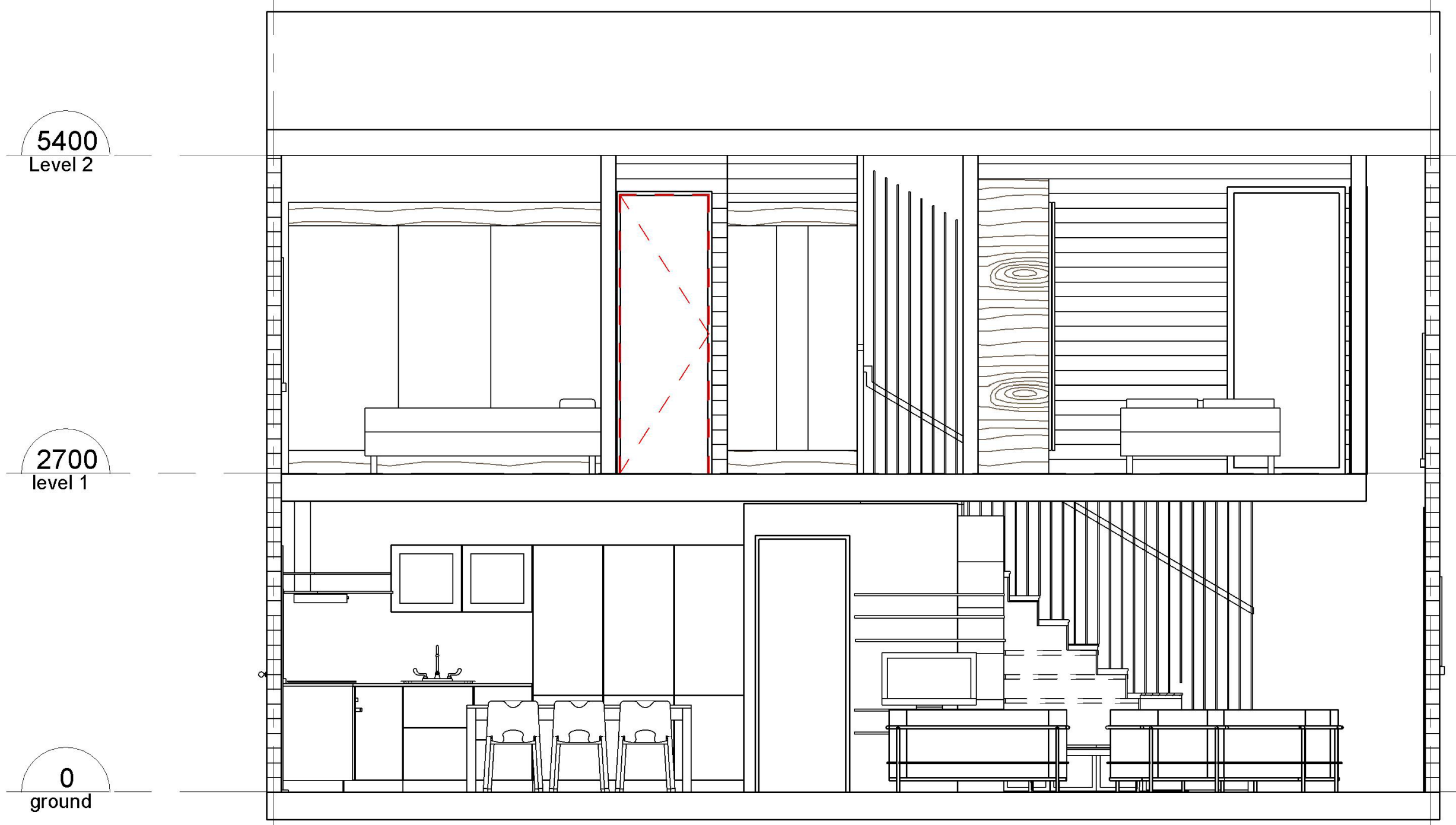

Figure 174: Final 2 bedroom unit sectional elevation B 1:50@A4. 
Final Three Bedroom Units
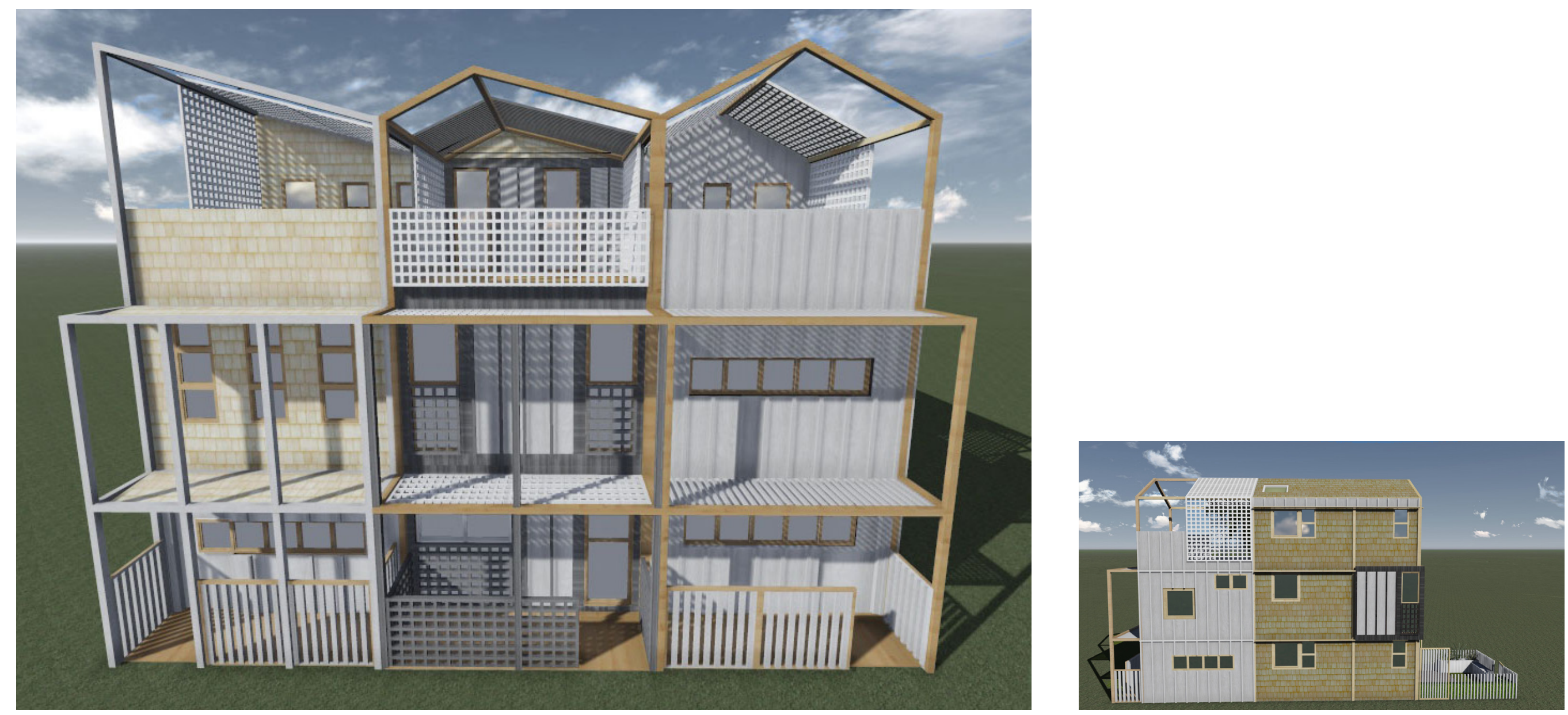


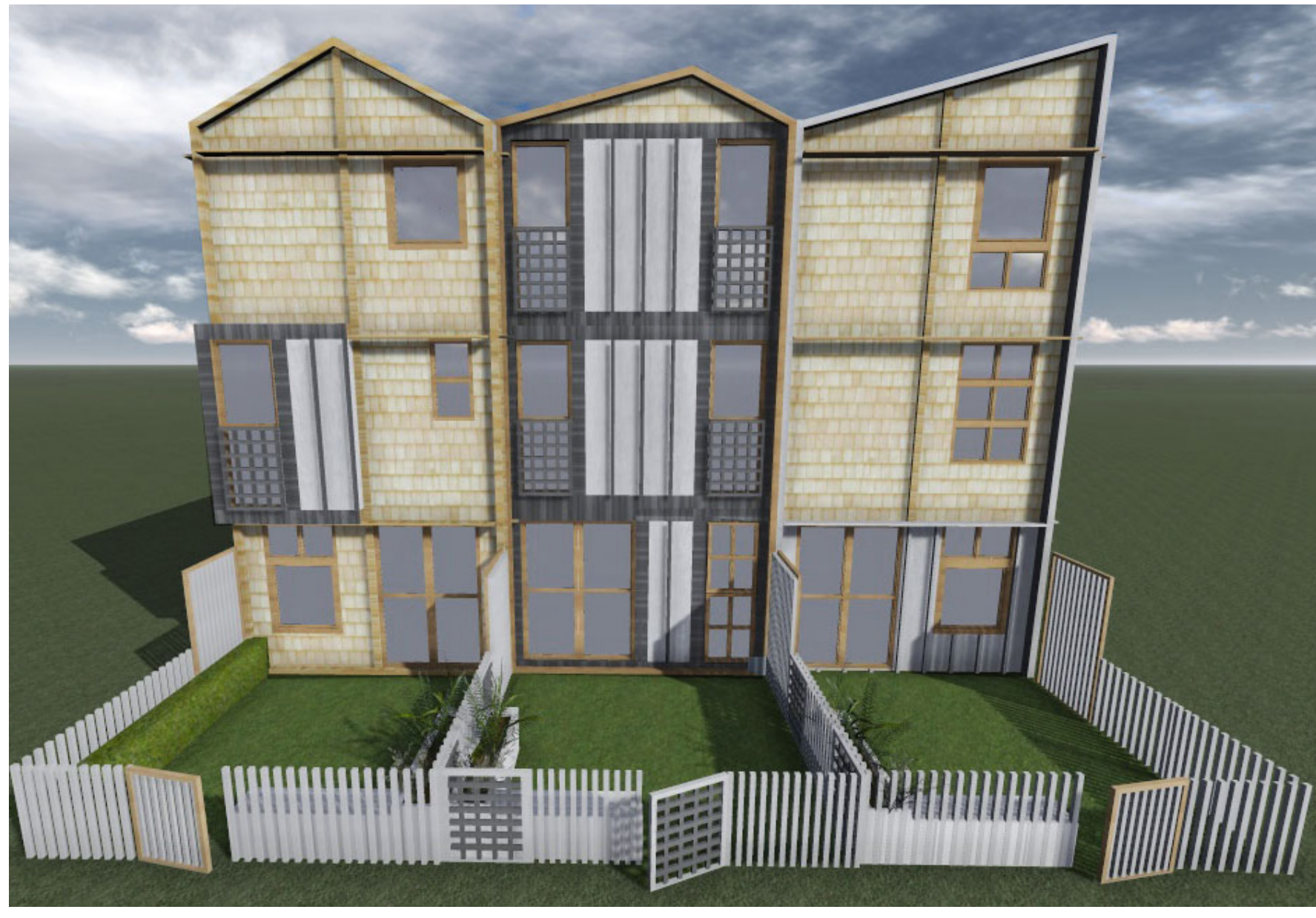

Figure 177: Final rear façade articulation for 3 bedroom units.

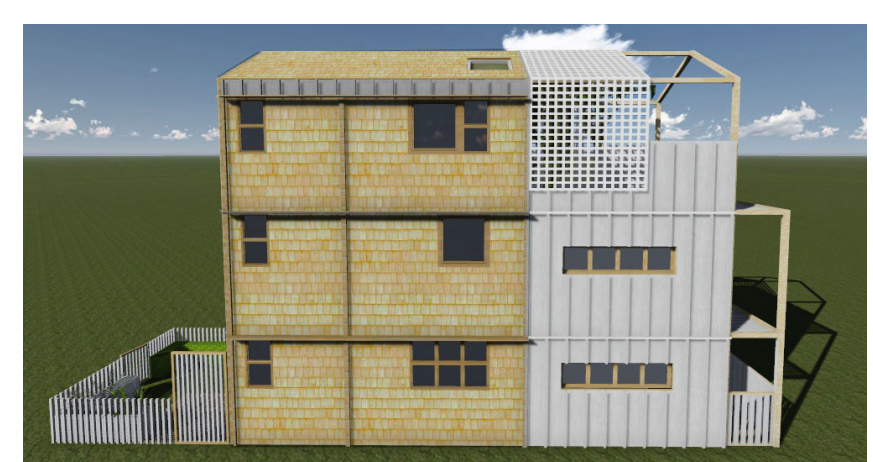

Figure 178: Final side facade articulation for type 13 bedroom unit.

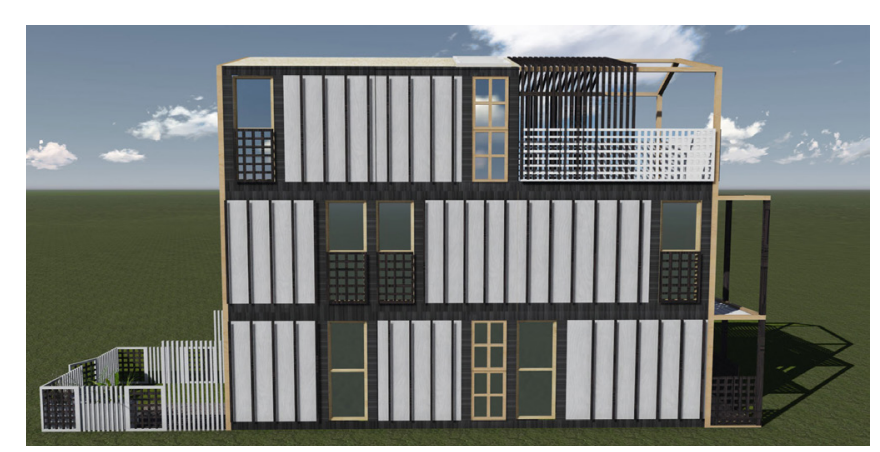

Figure 179: Final side facade articulation for type 2 3 bedroom unit. 


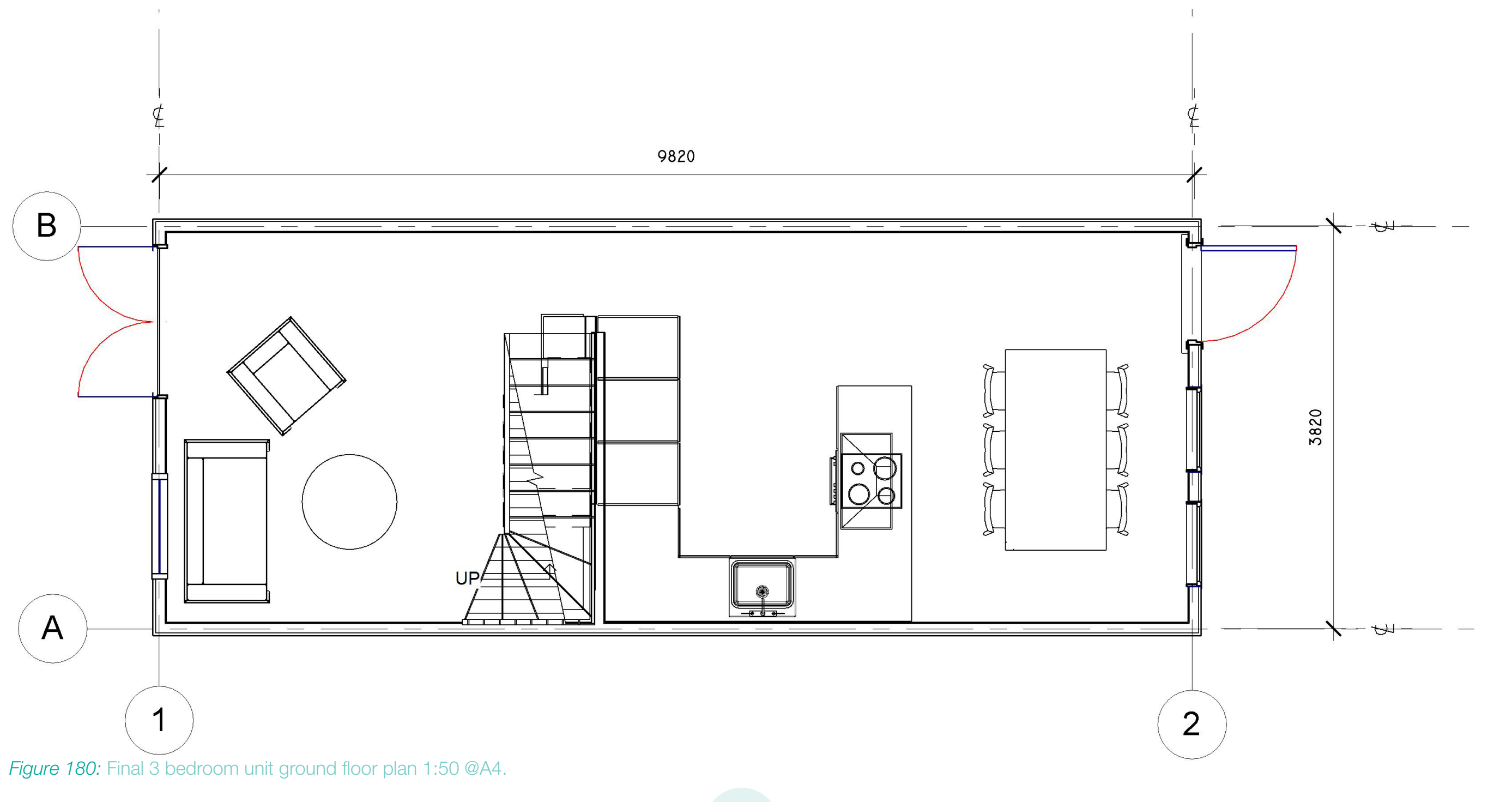




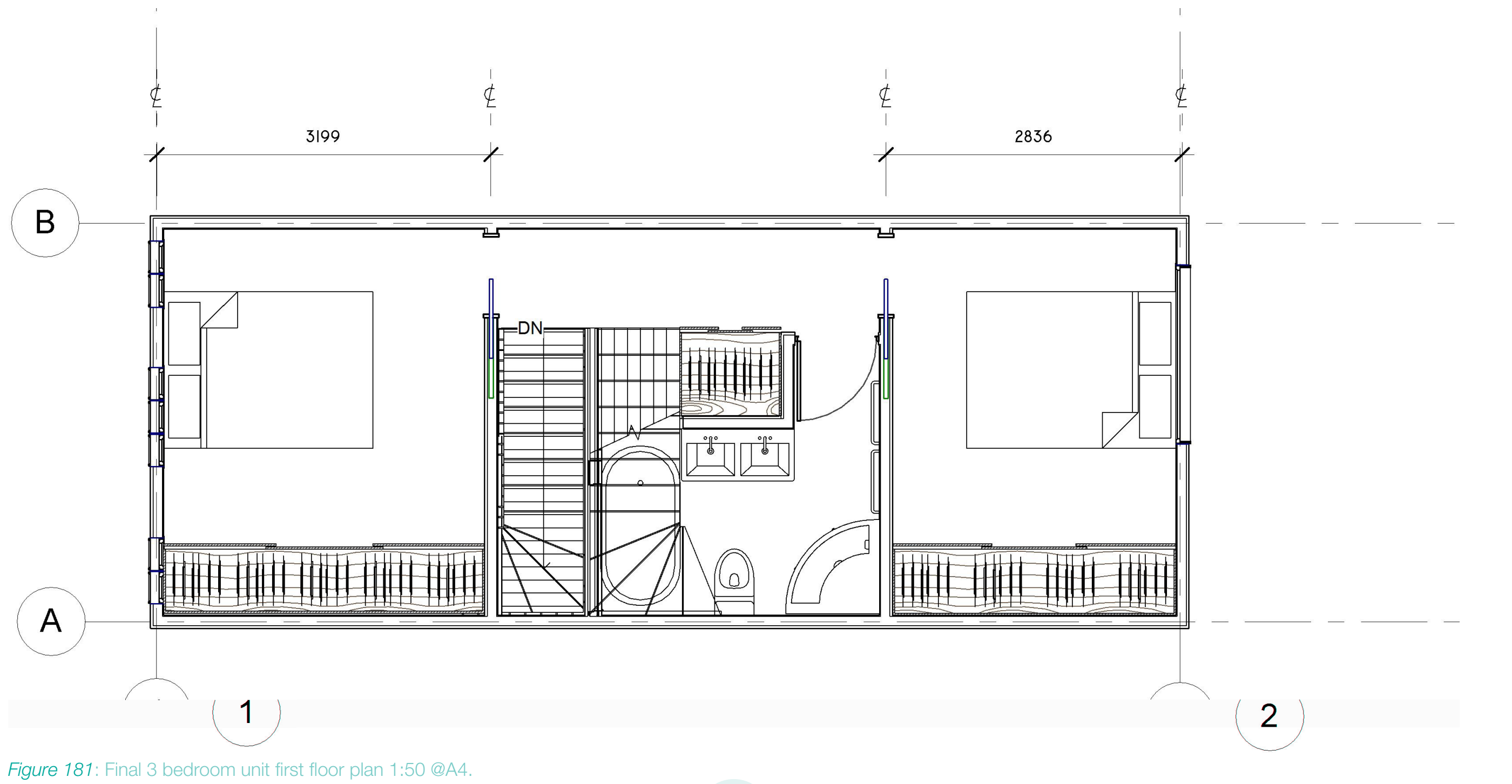




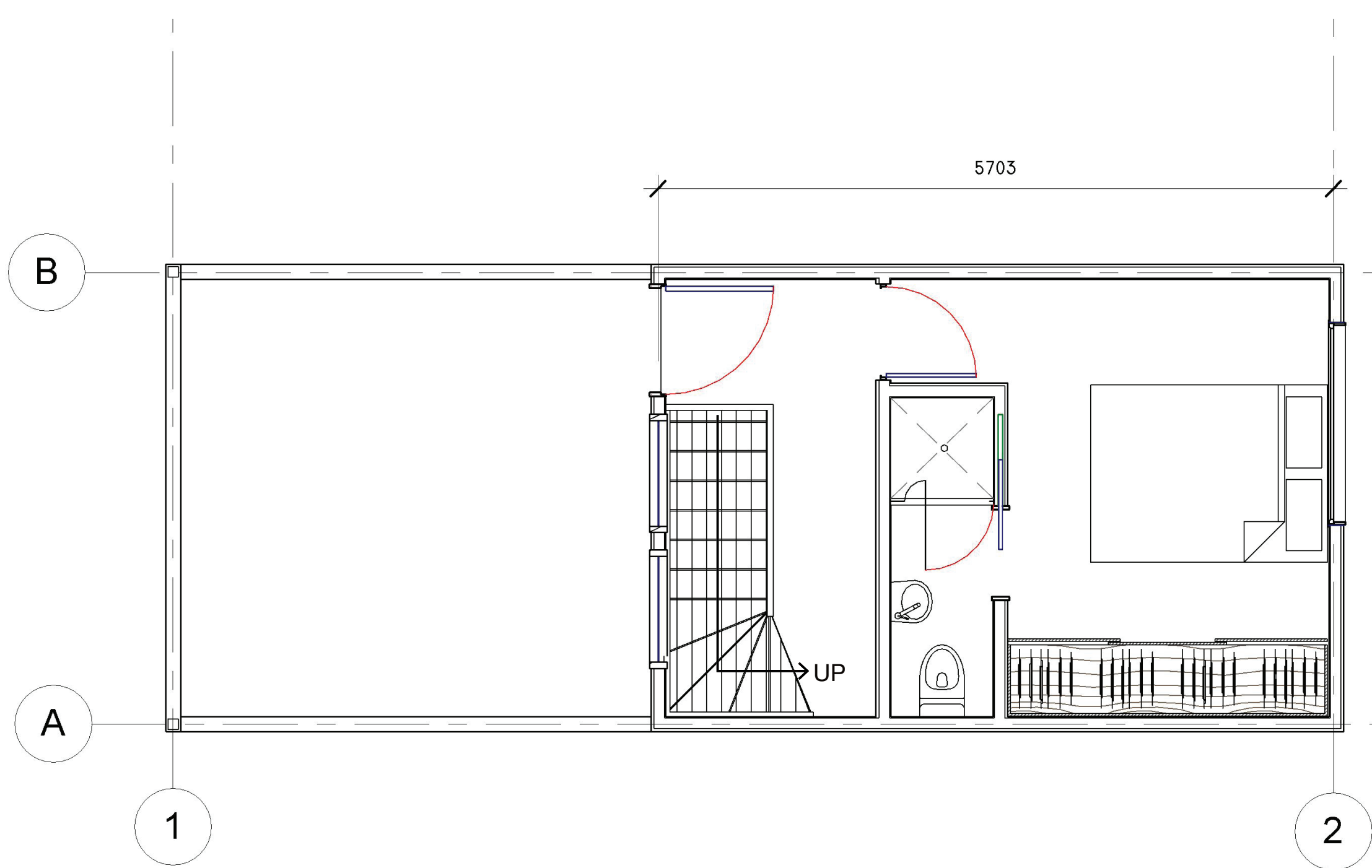

Figure 182: Final 3 bedroom unit second floor plan 1:50@A4. 


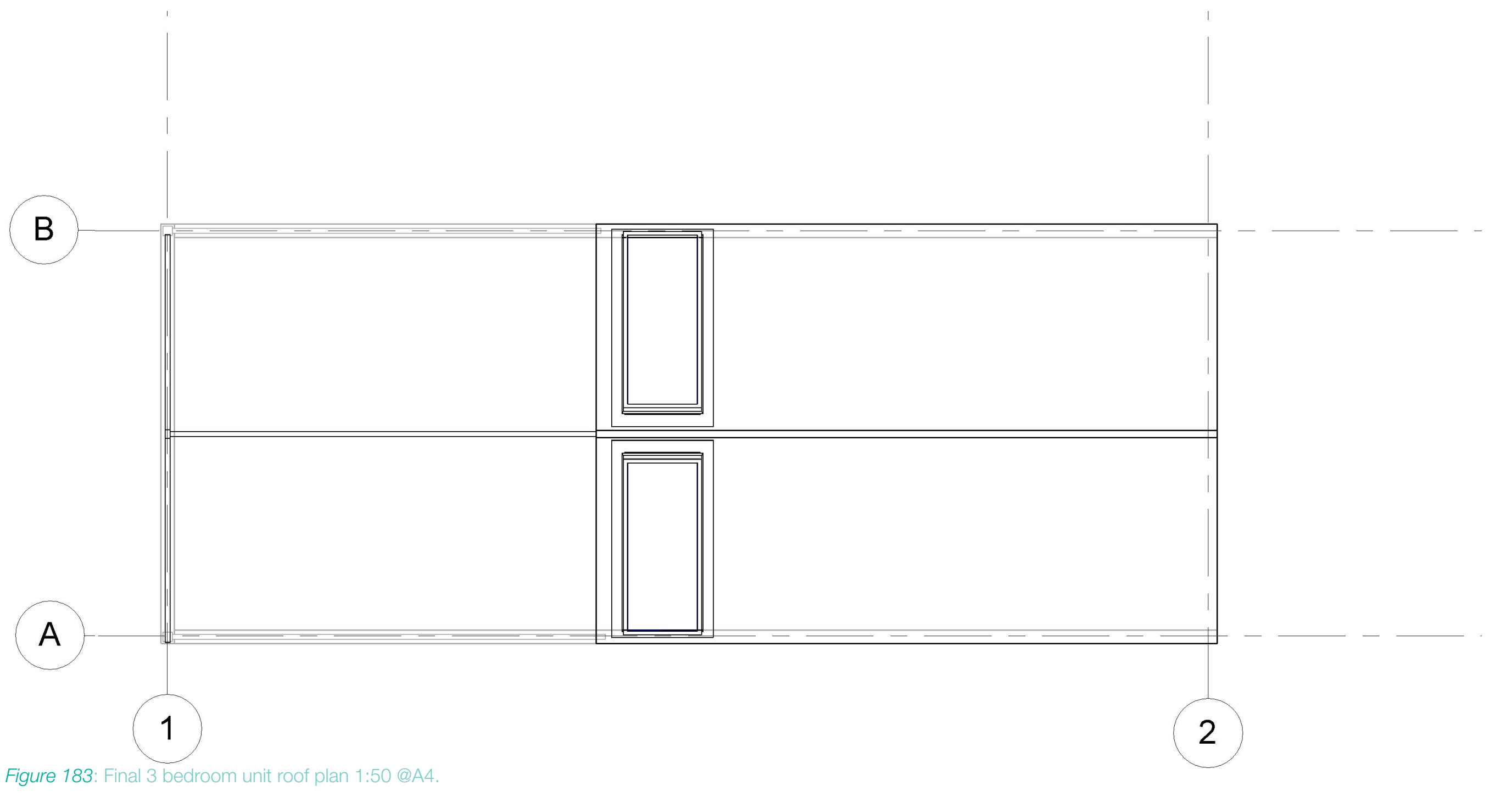




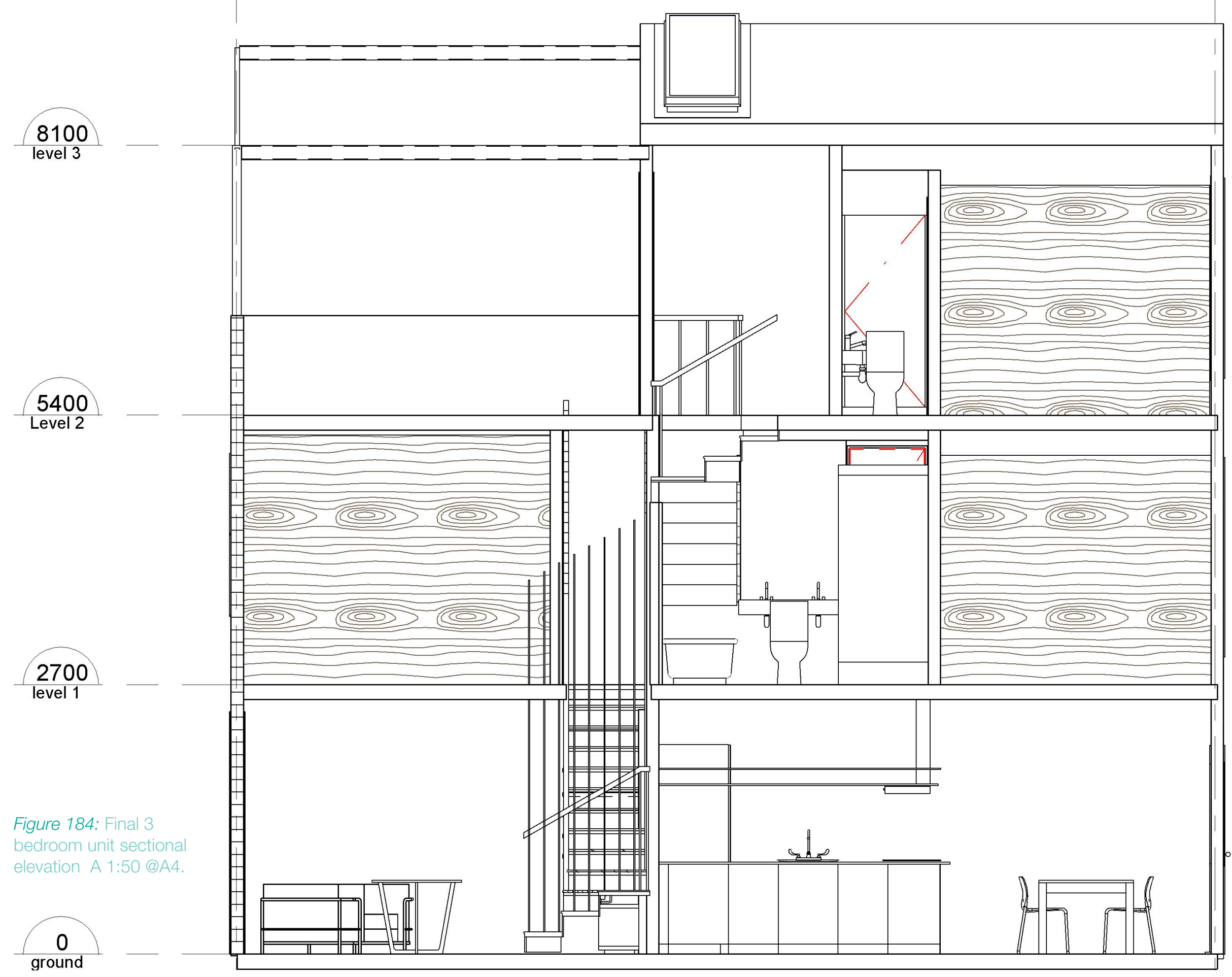




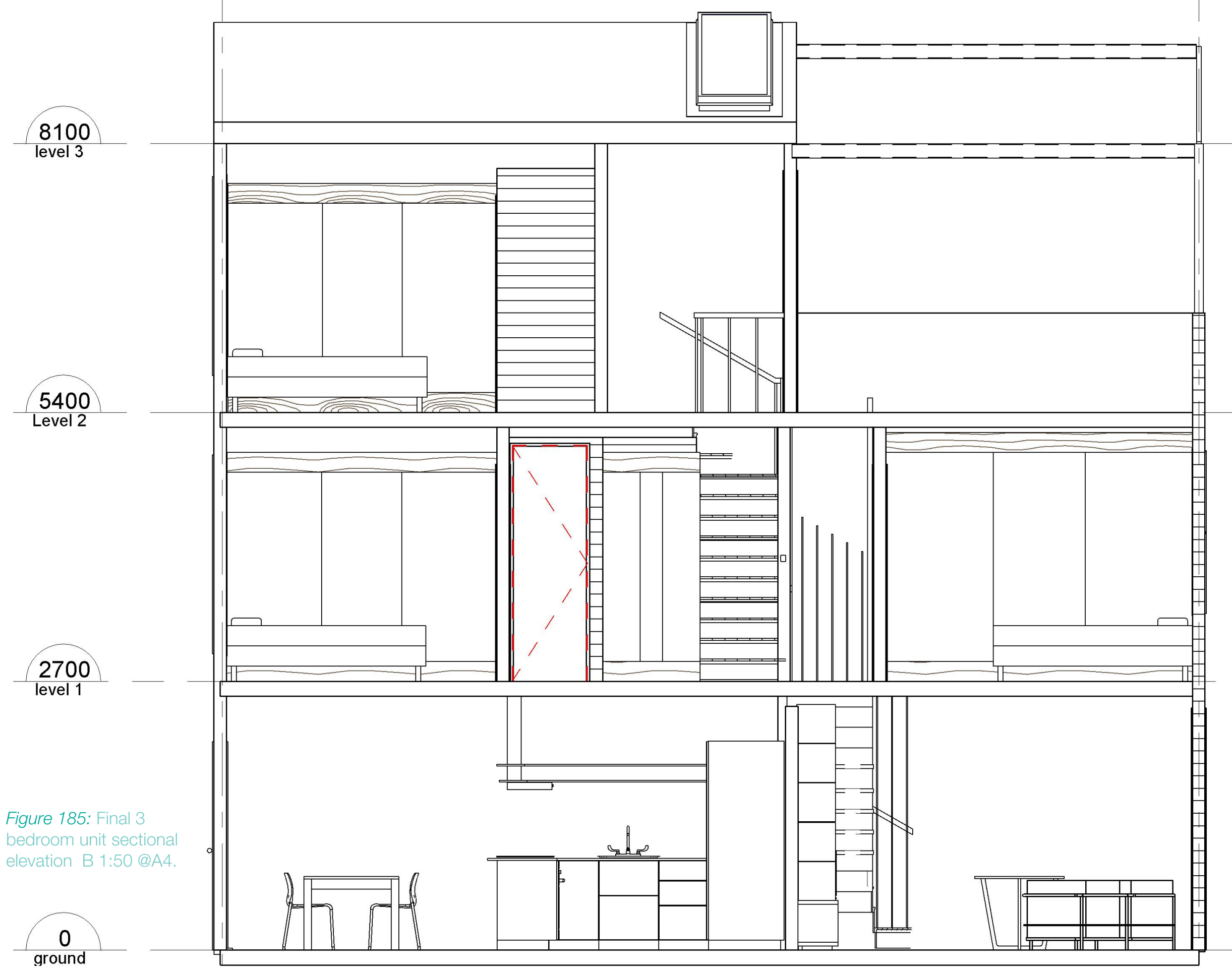


Final Four Bedroom Units

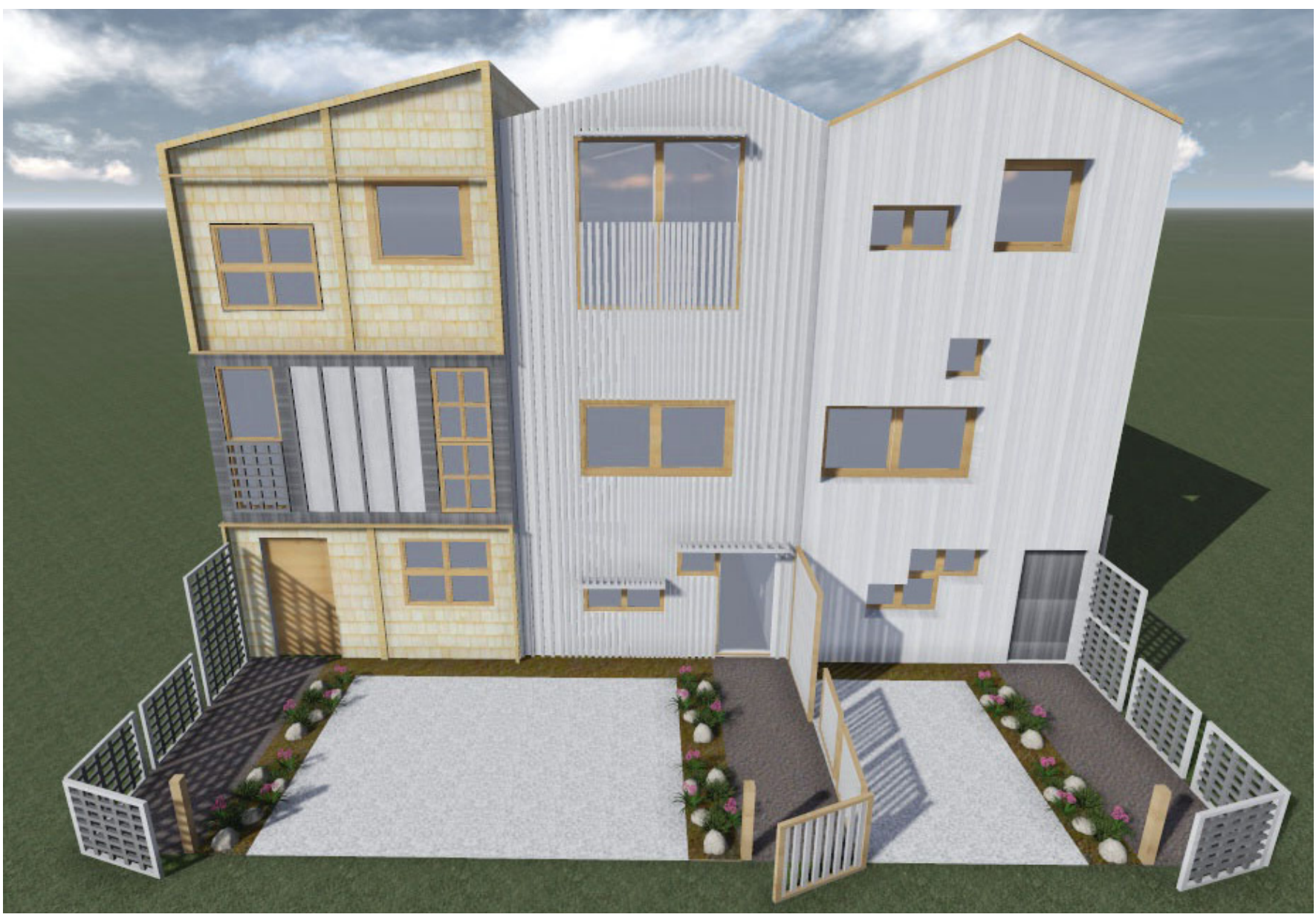

Figure 186: Final front façade articulation for 4 bedroom units

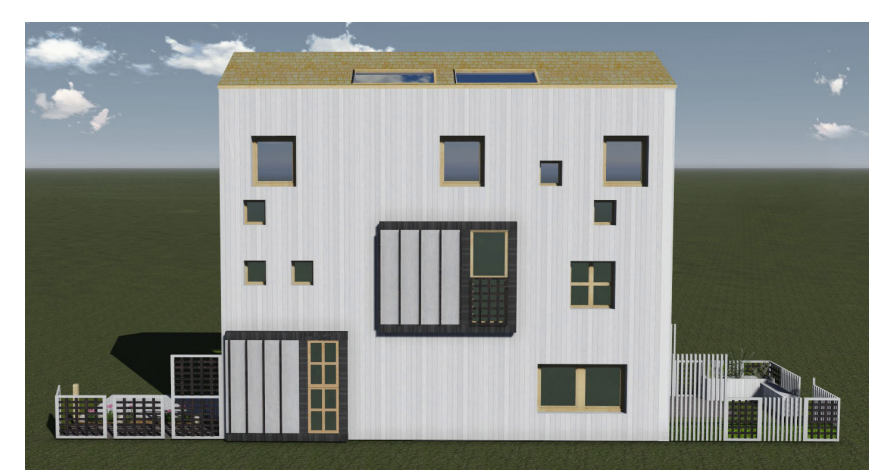

Figure 187: Final side facade articulation for type 3, 4 bedroom unit. 


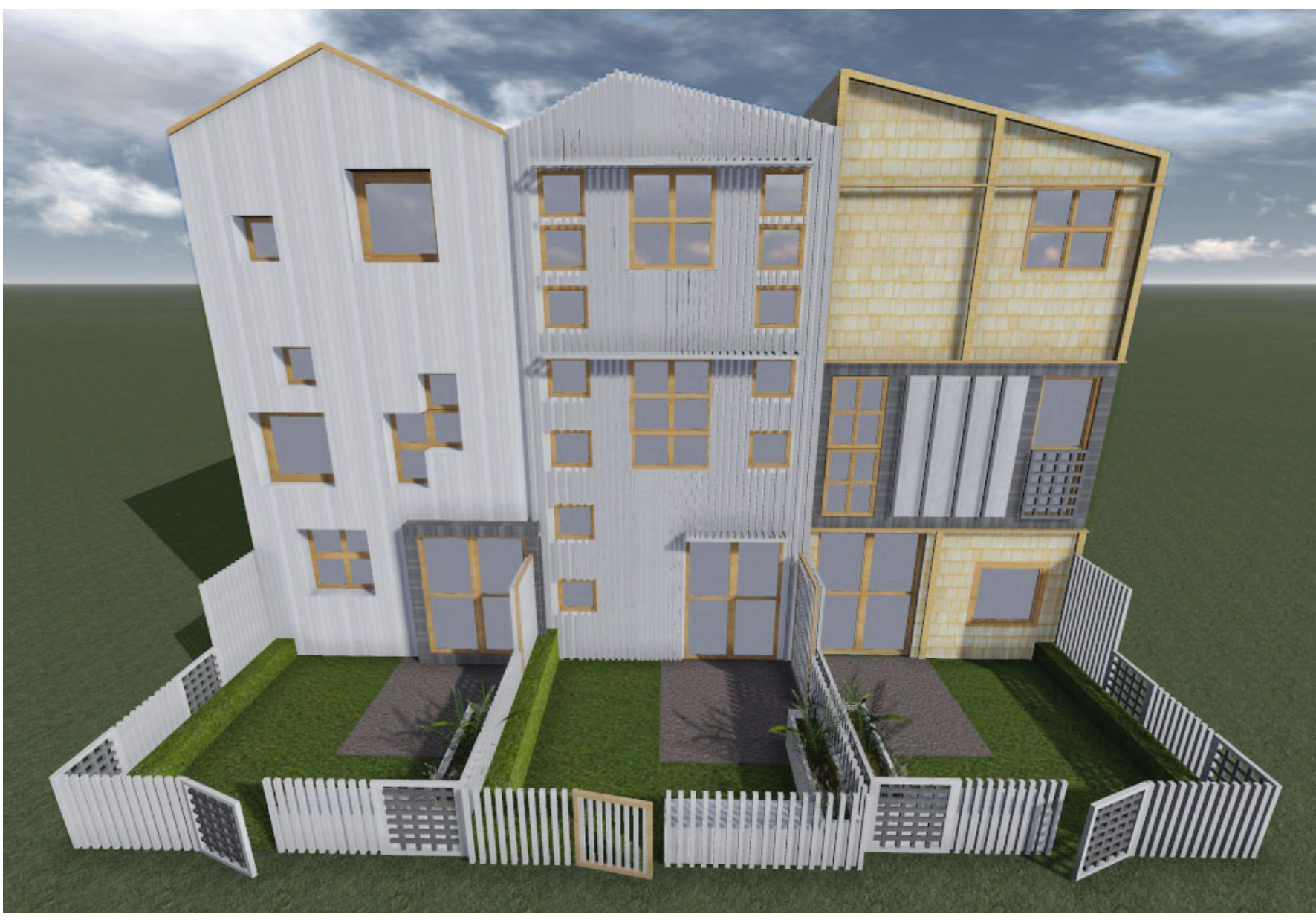

Figure 188: Final rear façade articulation for 4 bedroom units

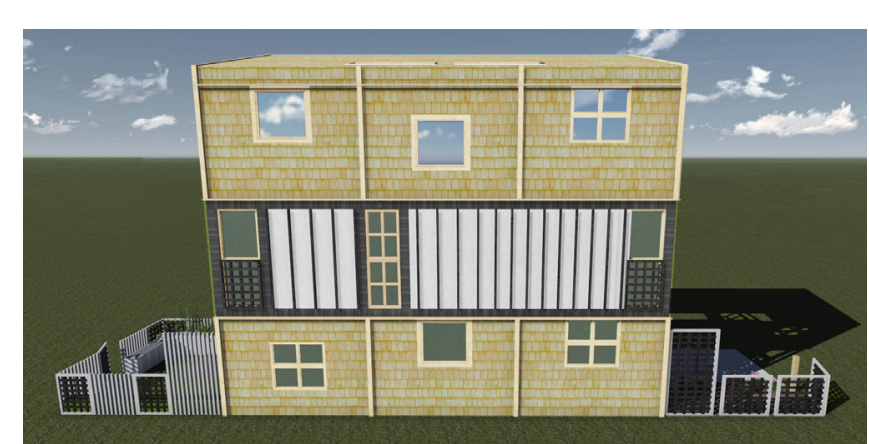

Figure 189: Final side facade articulation for type 3 4 bedroom unit. 


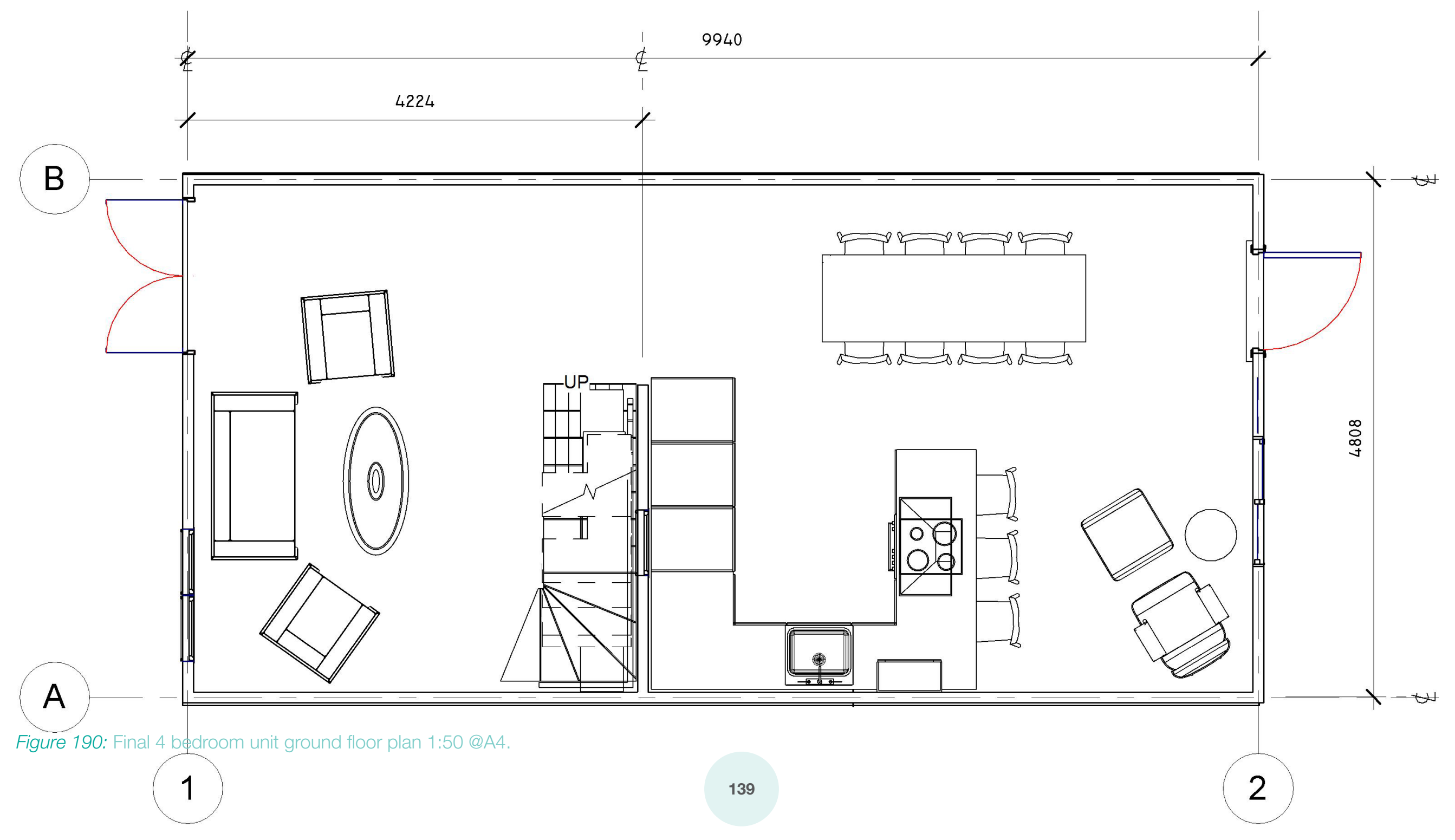




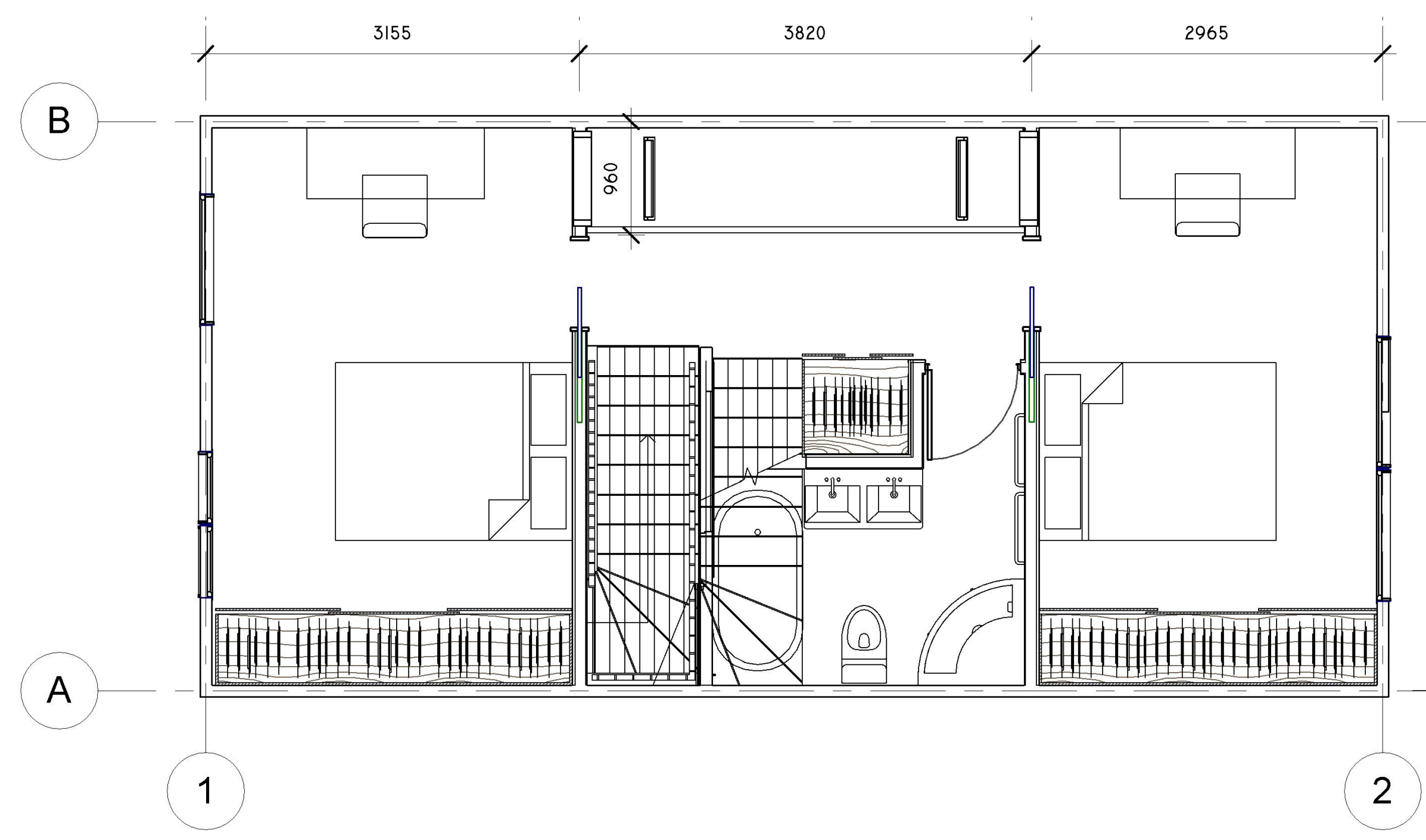

Figure 191: Final 4 bedroom unit first floor plan 1:50@A4. 


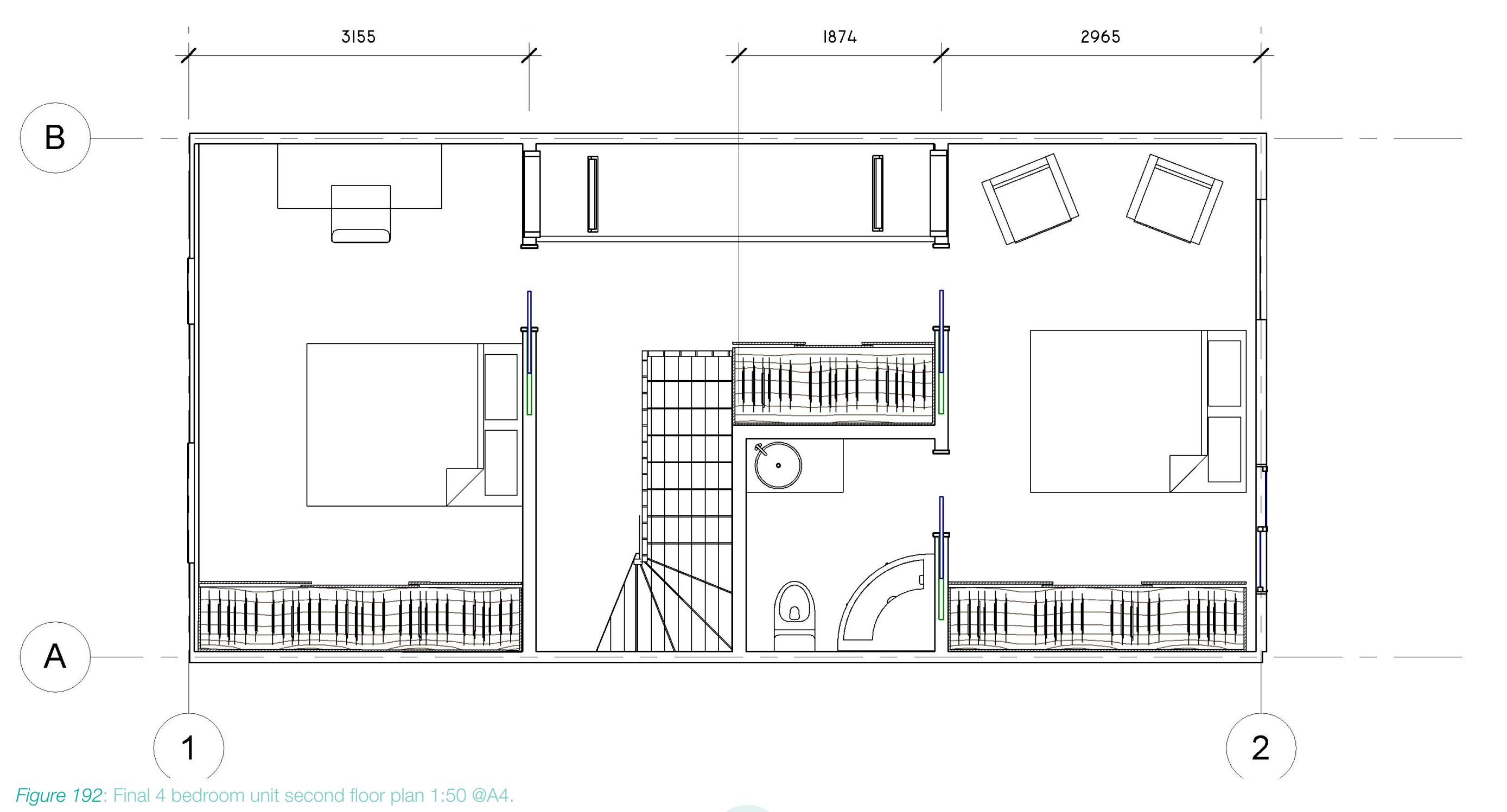




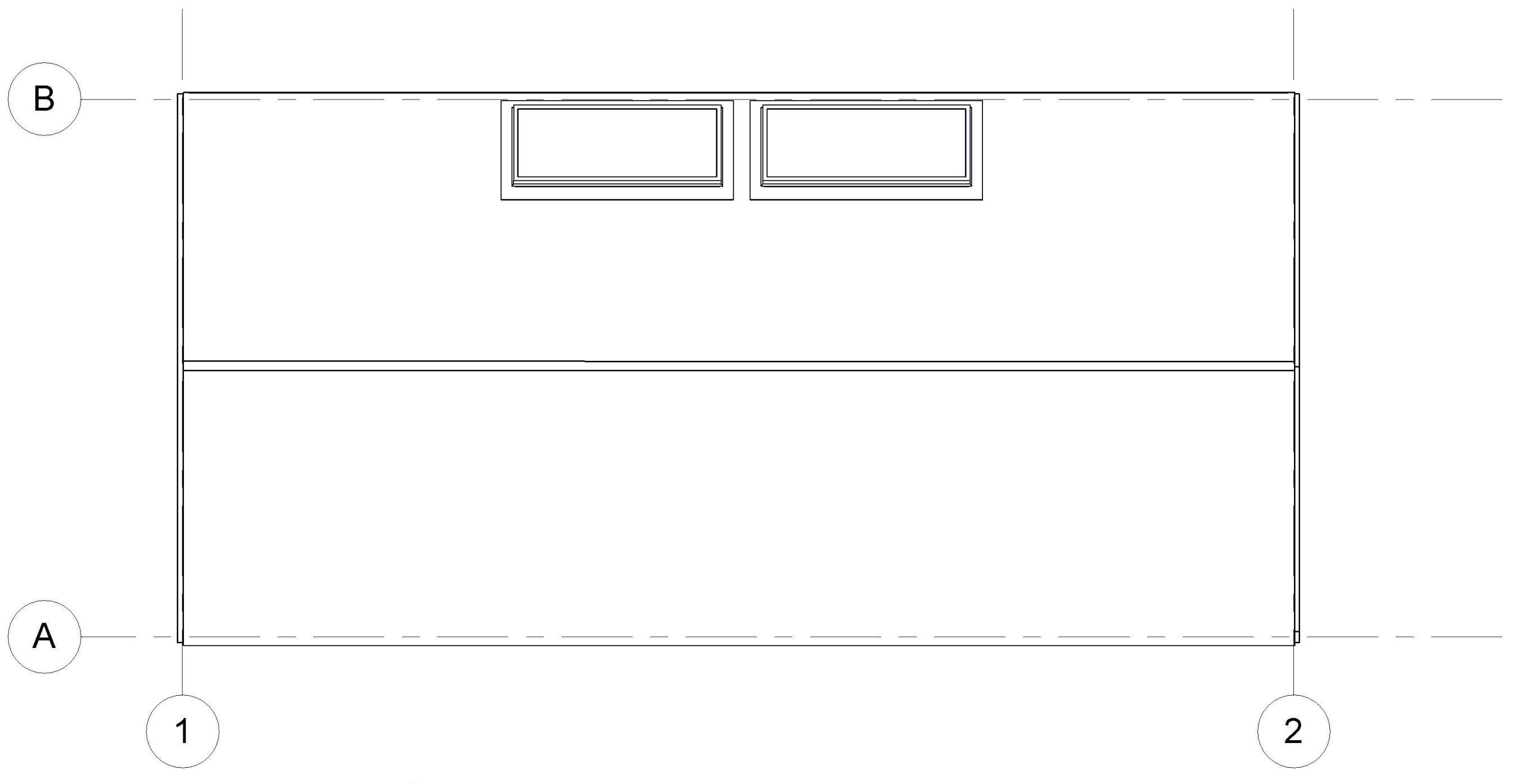

Figure 193: Final 4 bedroom unit roof plan 1:50 @A4. 


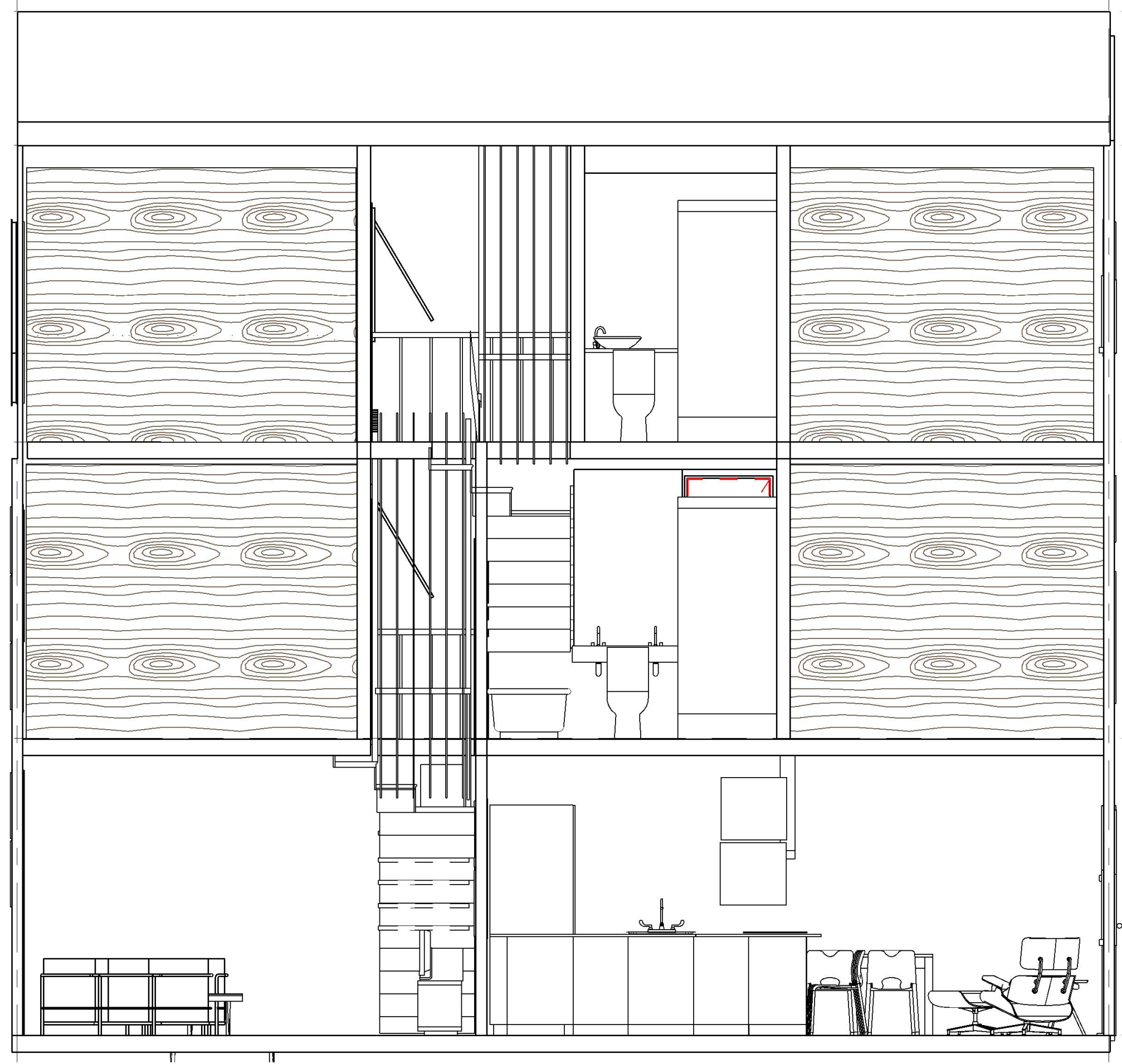

Figure 194: Final 4 bedroom unit sectional elevation A1:50@A4.

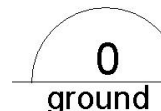



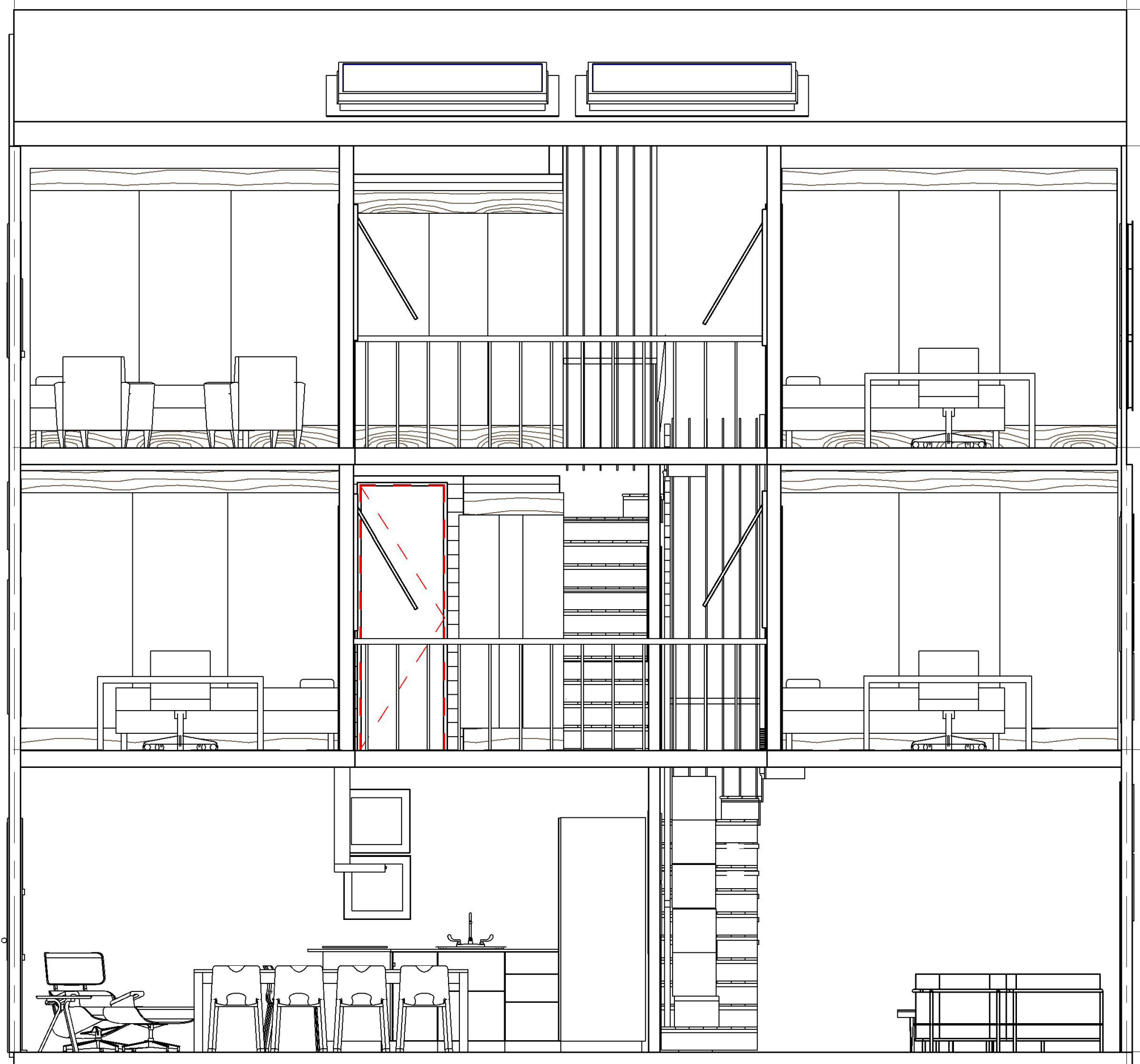

Figure 195: Final 4 bedroom unit sectional elevation B 1:50@A4

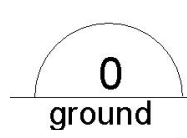


Final Site Figures

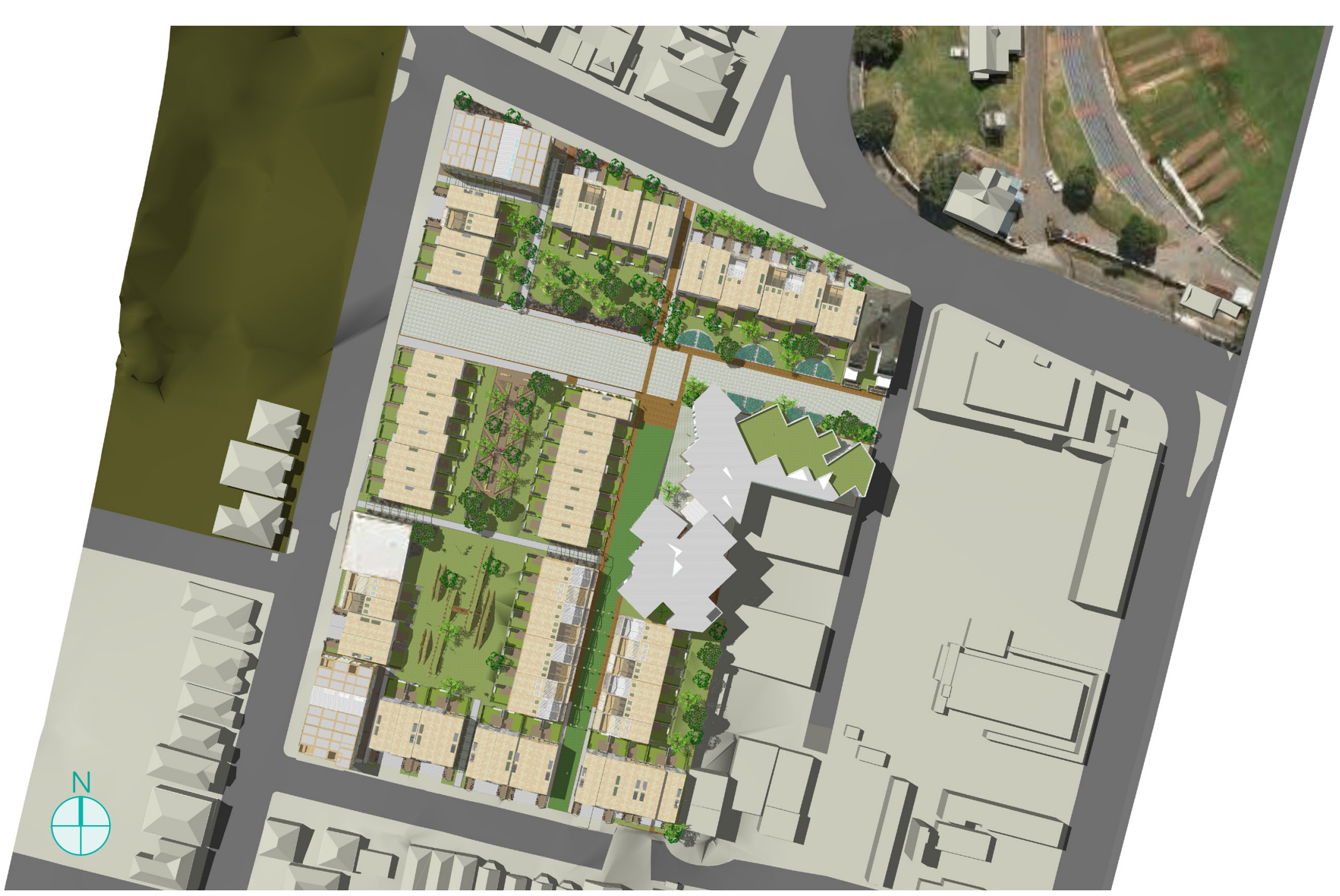



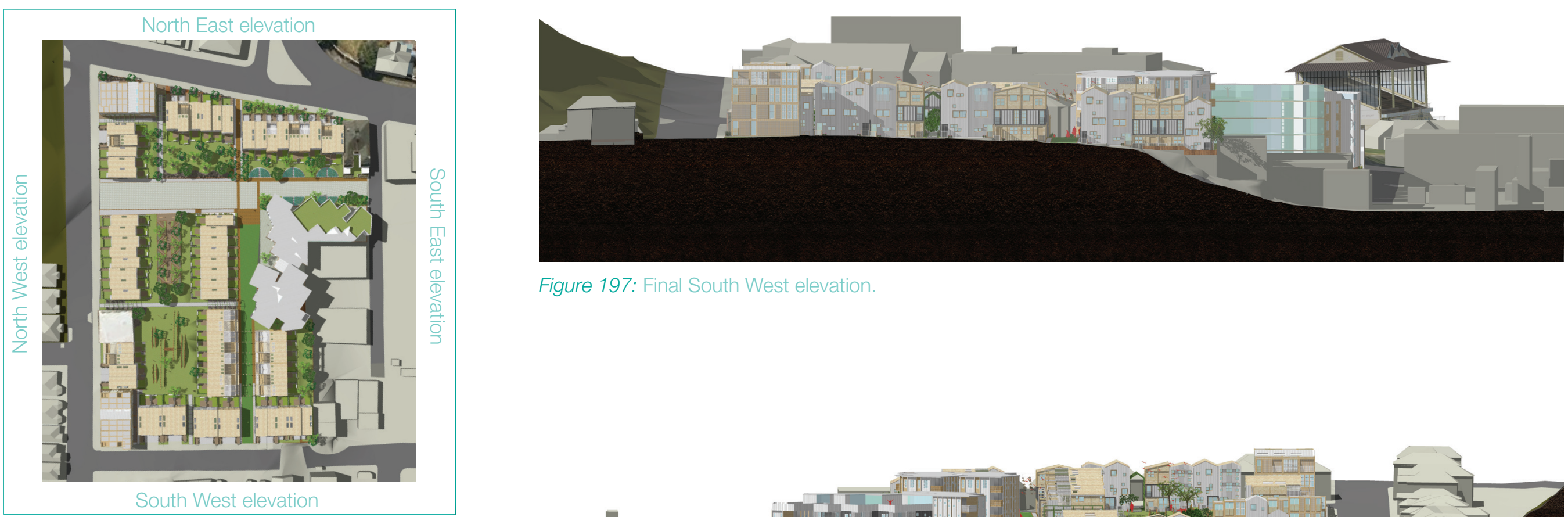

Figure 197: Final South West elevation.

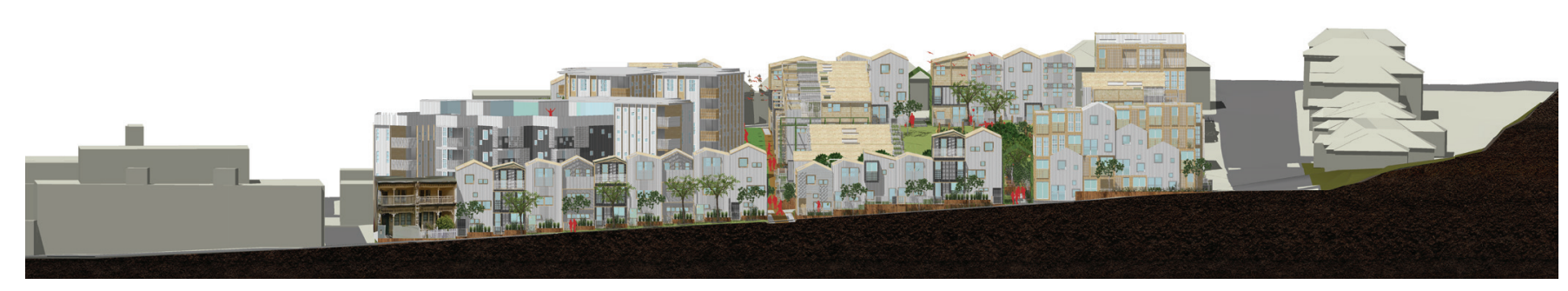

Figure 198: Final North East elevation. 


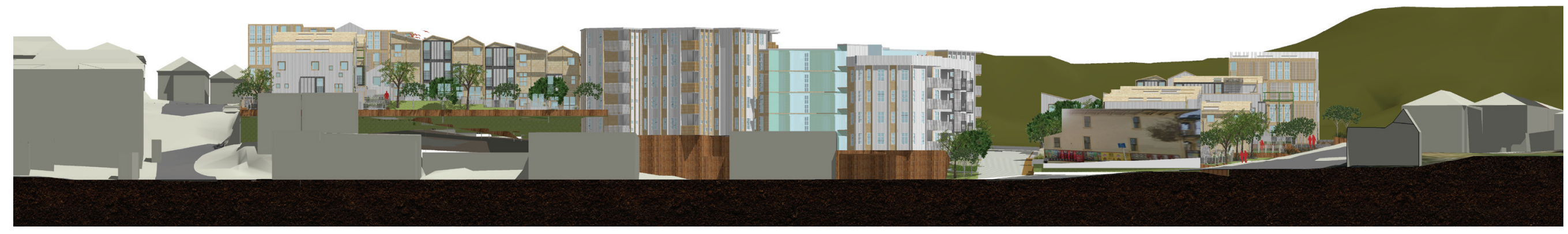

Figure 199: Final South East elevation.

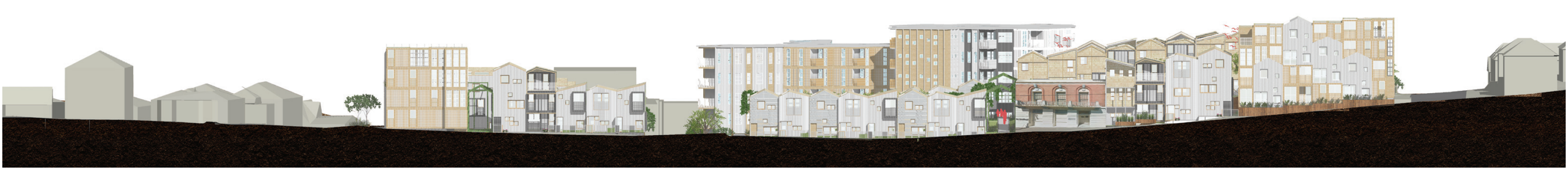

Figure 200: Final North West elevation. 


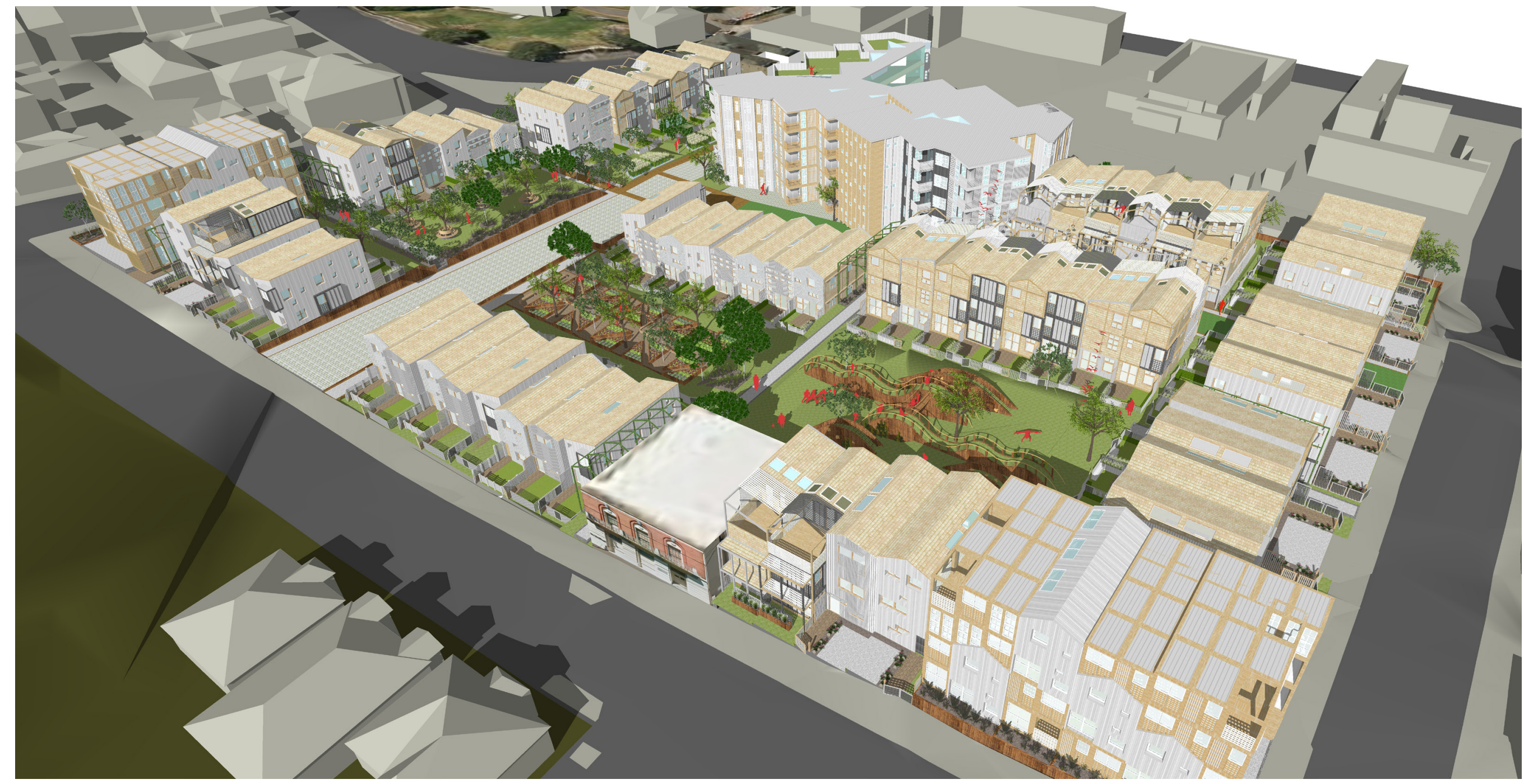

Figure 201: Final project South West aerial view. 


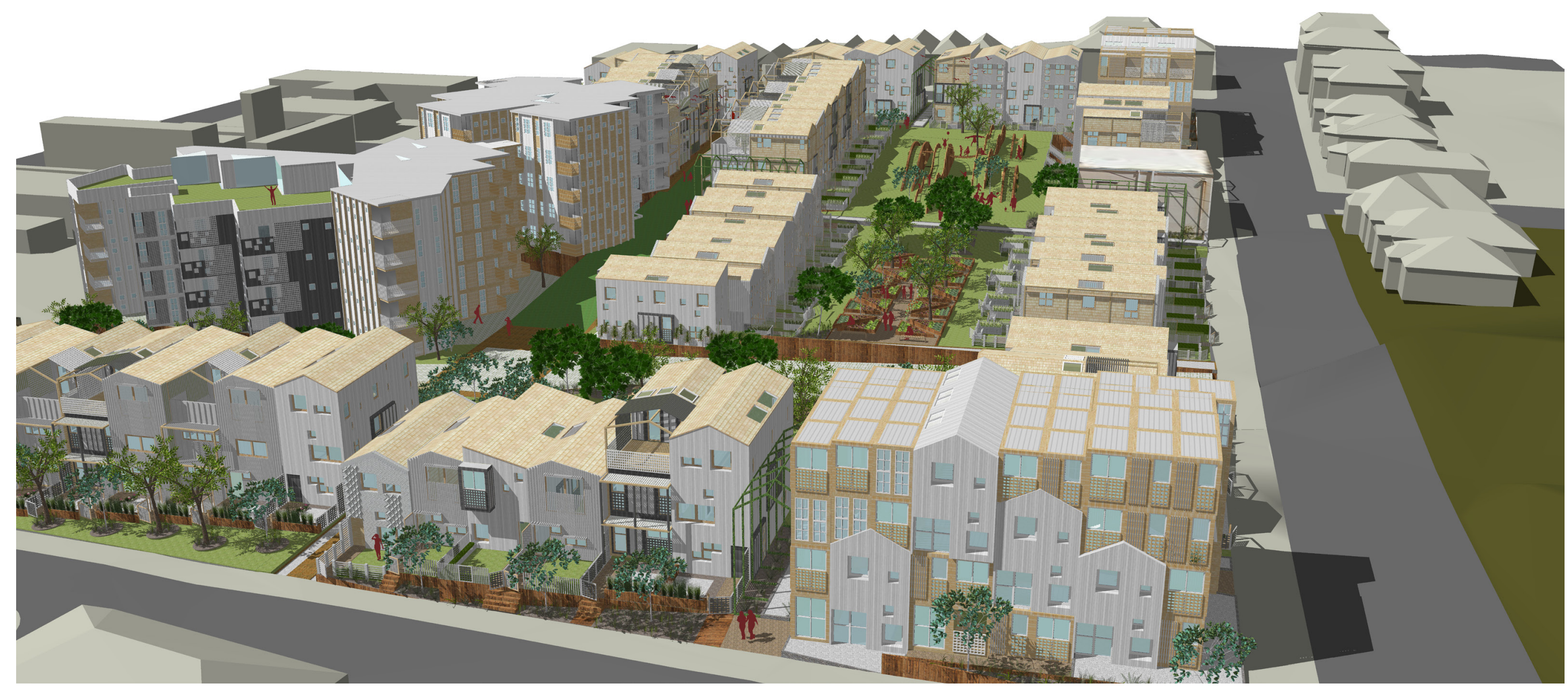

Figure 202: Final project North aerial view. 


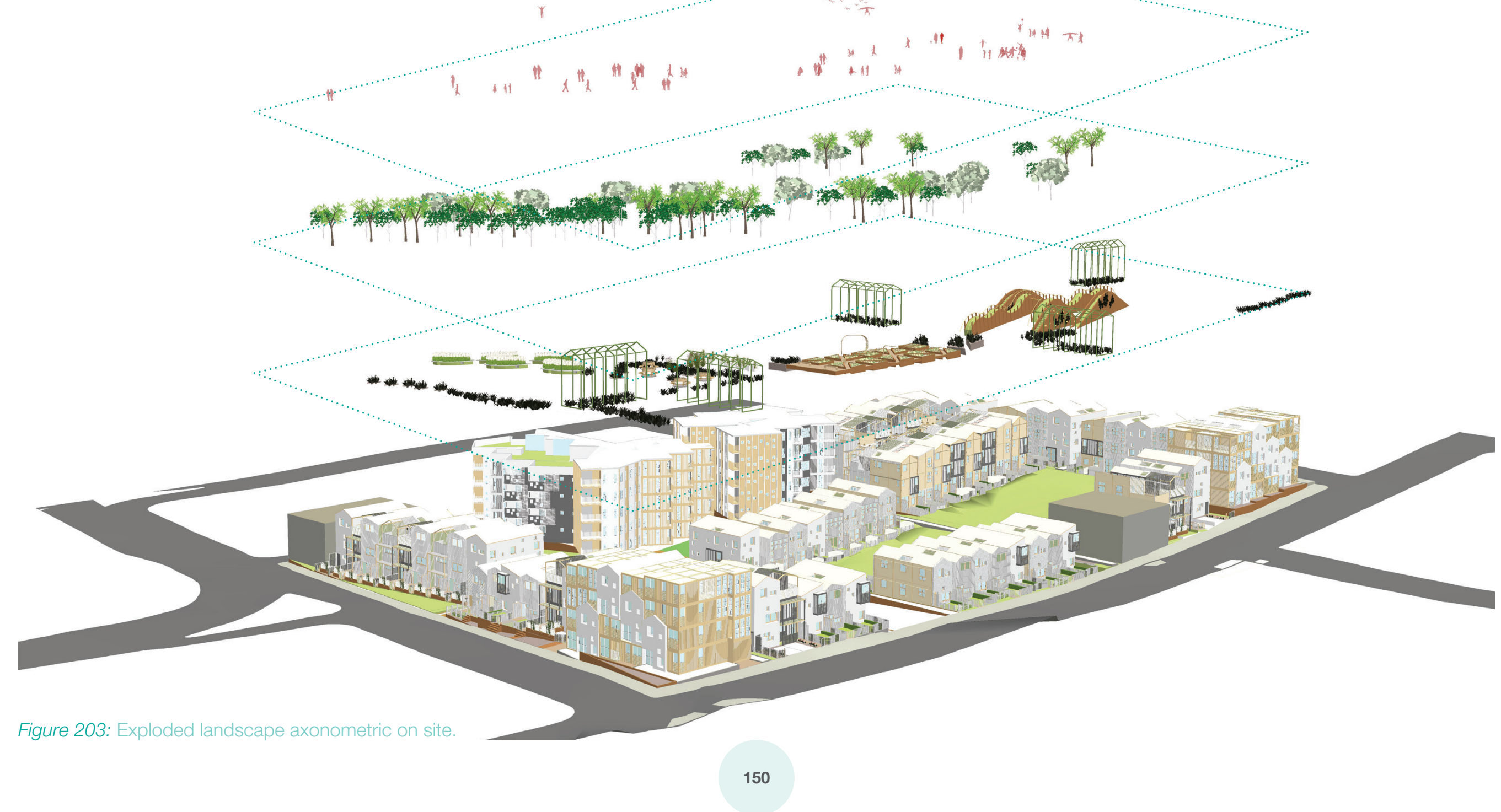




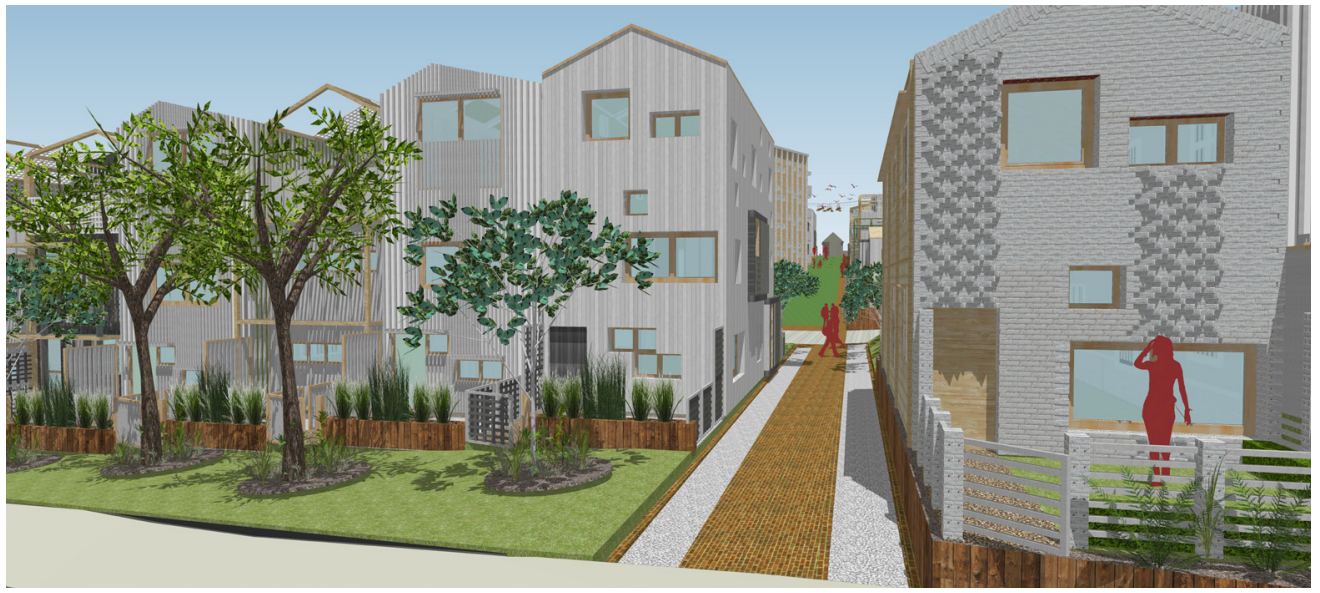

Figure 204: Secondary road entrance from rugby street.

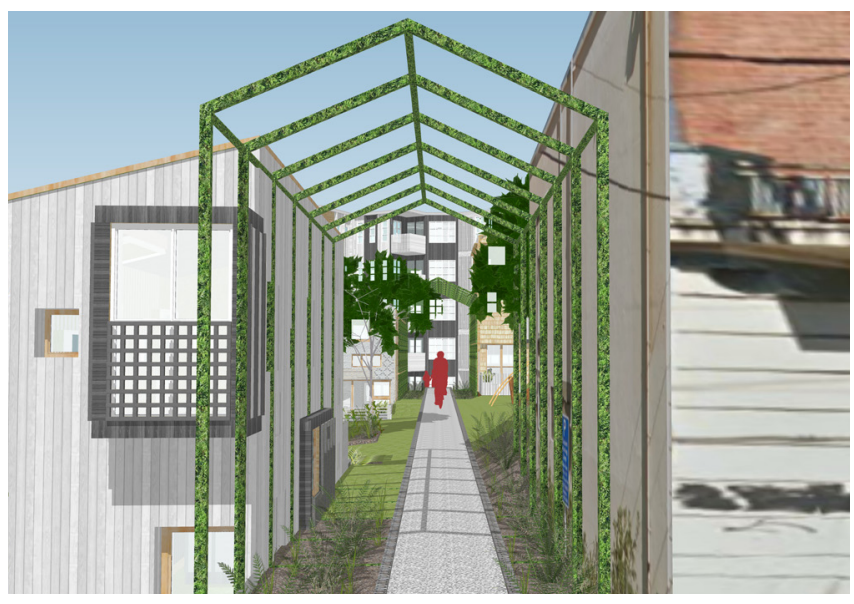

Figure 206: Three of the green gate entrances.

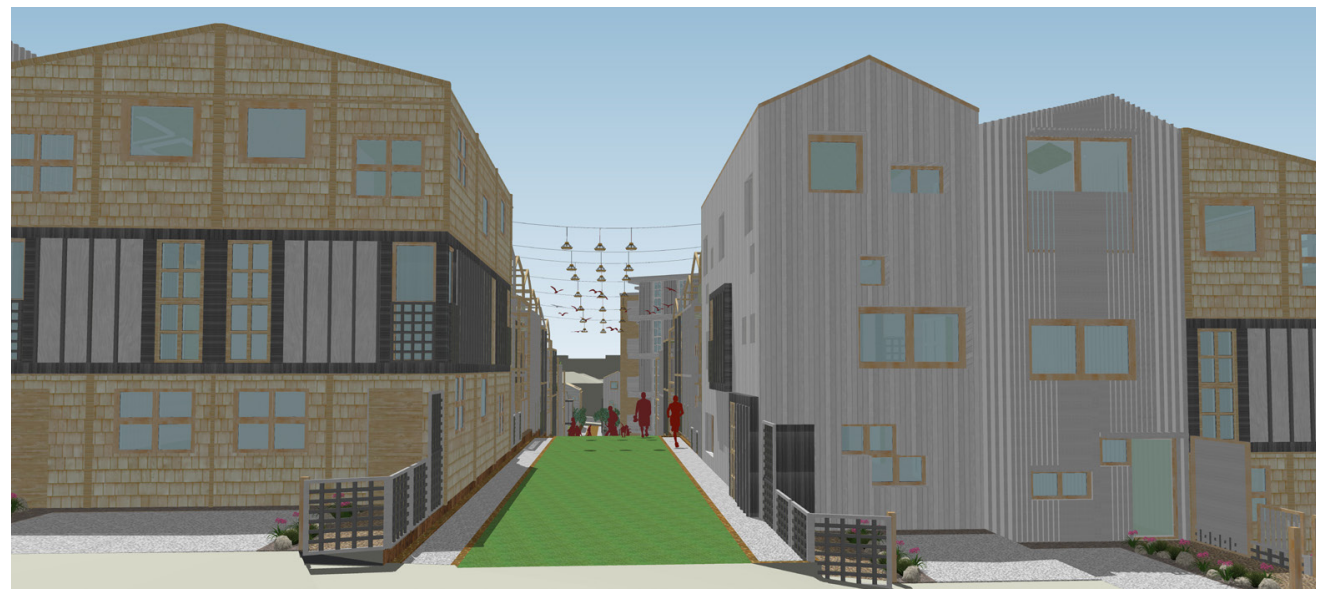

Figure 205: Secondary road entrance from Douglas street.

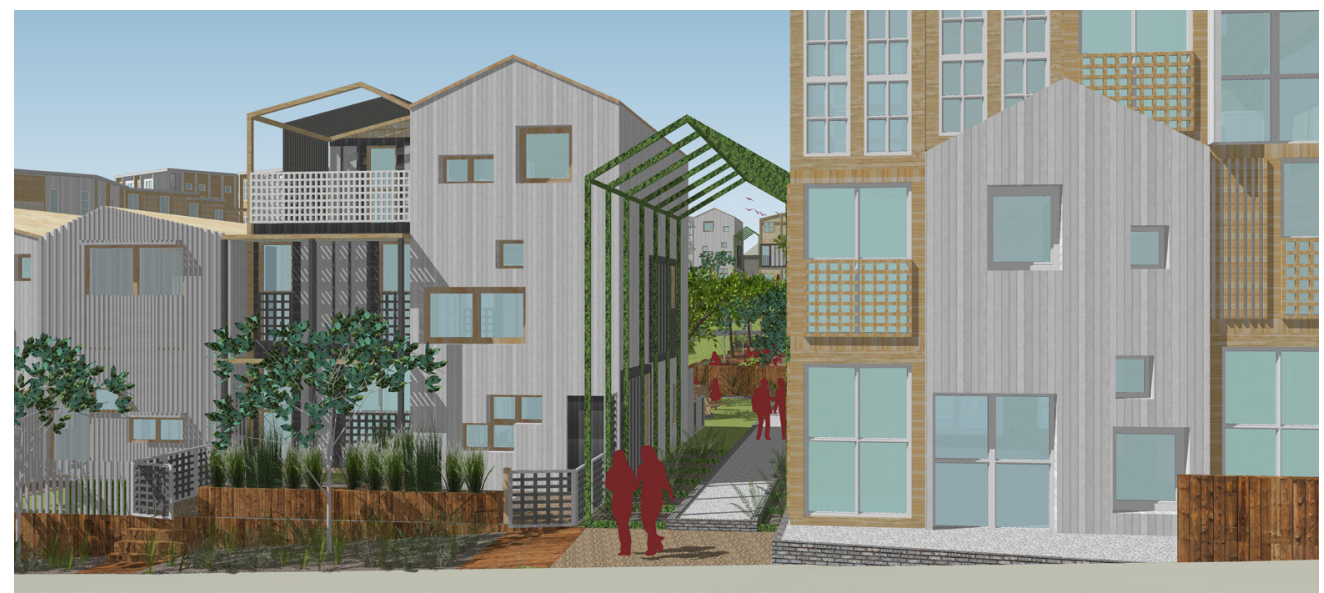




\section{Landscaping}
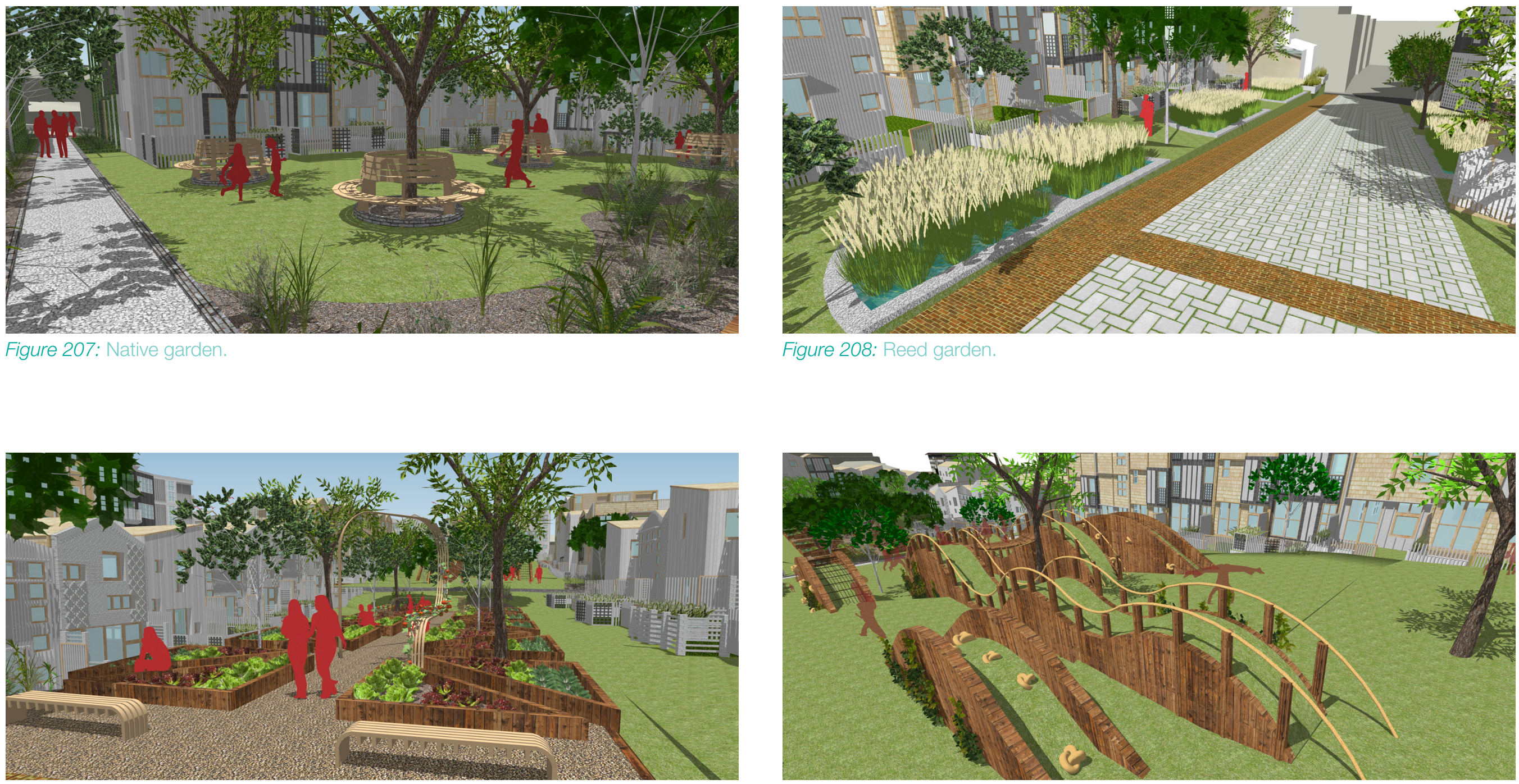

Figure 209: Community vegetable garden.

Figure 210: Children's garden 


\section{Site Montages}

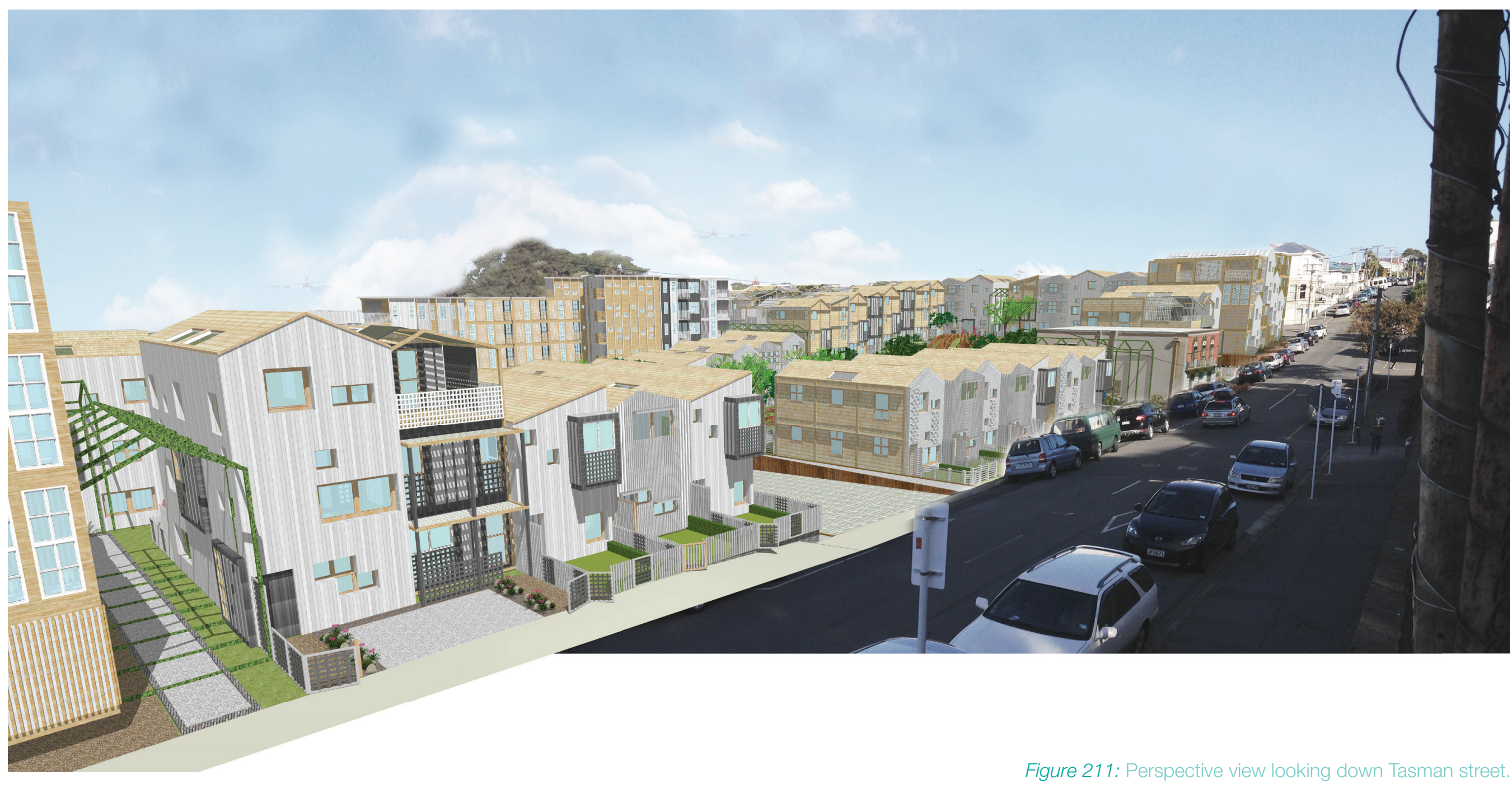



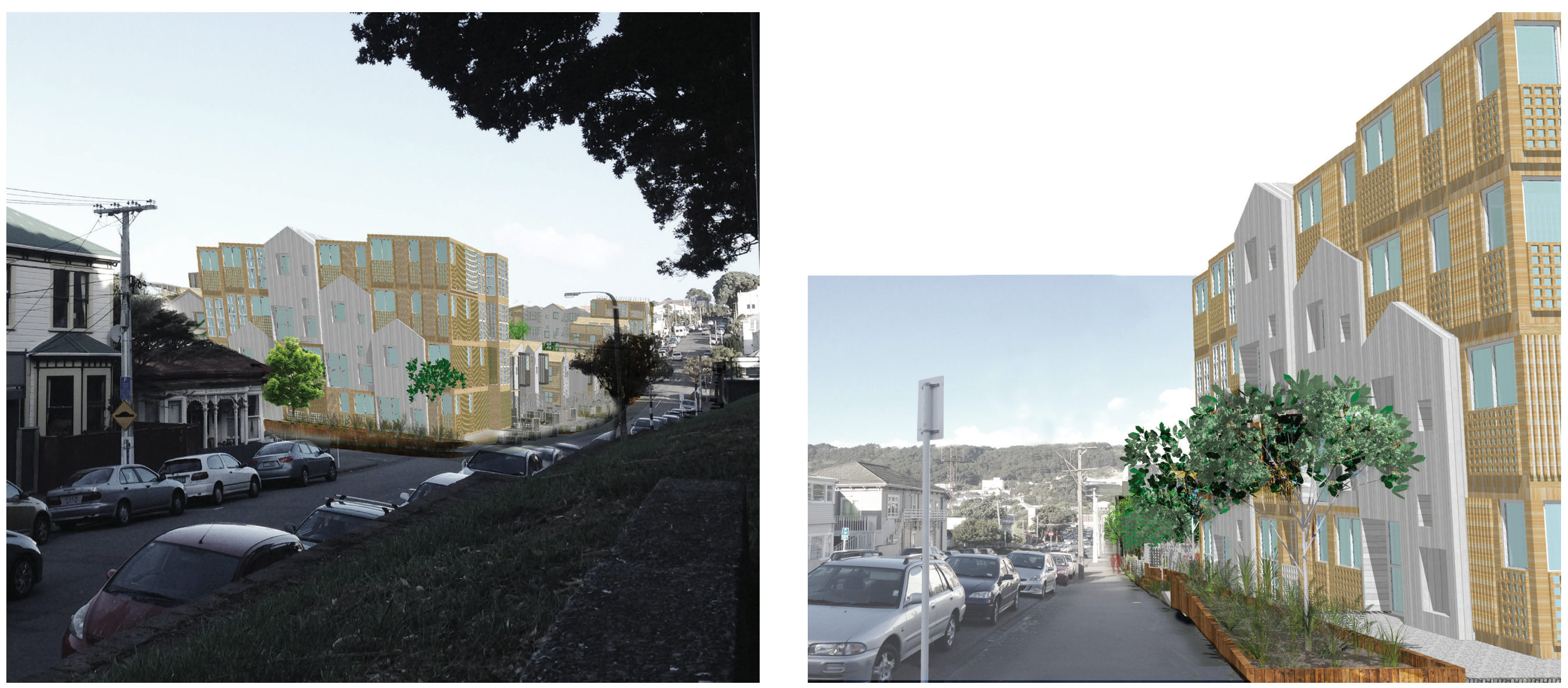


\section{Stage 3-Feedback and Analysis}

\section{Developer Interview 3}

A presentation of the final project was made to the developer, in the third and final interview (Anonymous, personal communication, January 19, 2017). The main topics discussed were as follows:

\section{Units design}

The developer felt the voids created for ventilation in the 2 and 3 bedroom typologies were not saleable as the average buyer would not see their value and would view them as a waste of potential floor area. He was also of the opinion that some components of the design are fashionable now but would not be in the future, for example the window shapes and sizes.

The developer did not believe the market would choose exposed CLT interiors over carpeted and painted units. However, it could be argued that the CLT provides a blank canvas which could be easily personalised by the buyer if they chose to do their own cosmetic work.

\section{Costing}

The developer suggested that because costings were done to a novice level there were likely to be issues and inaccuracies. While it is acknowledged that the costing analysis relies heavily on estimates, it still allows for overall cost comparisons to be made between the traditional and sustainable units. The developer also suggested that the site could be further intensified with units (see Figure 218), as the open spaces and landscaping were more generous and elaborate than he would be prepared to consider.

\section{Sustainability}

The developer recognises that there are currently no sustainable residential developments in Wellington, and that this provides a point of difference.

\section{$\mathrm{CLT}$}

The developer was interested in the prefabricated CLT system. However, he did not consider the small cost savings of this system to be enough to justify the risks associated with the product. He related these risks to the size of the one manufacturing company that produces the material, which is still in its start-up stages. Perceived risks included potential manufacturing delays; business bankruptcy; a lack of market competition, as there is only a single manufacturer in NZ; and a lack of control over the off-site construction process. He said he would require savings of $20 \%$ before he would consider using CLT.

While CLT is both sustainable and cost-effective, this was not enough to outweigh the developer's concern for risk. However, the perceived risks could be reduced over time, if the product becomes more commonly used and the manufacturing company expands. 


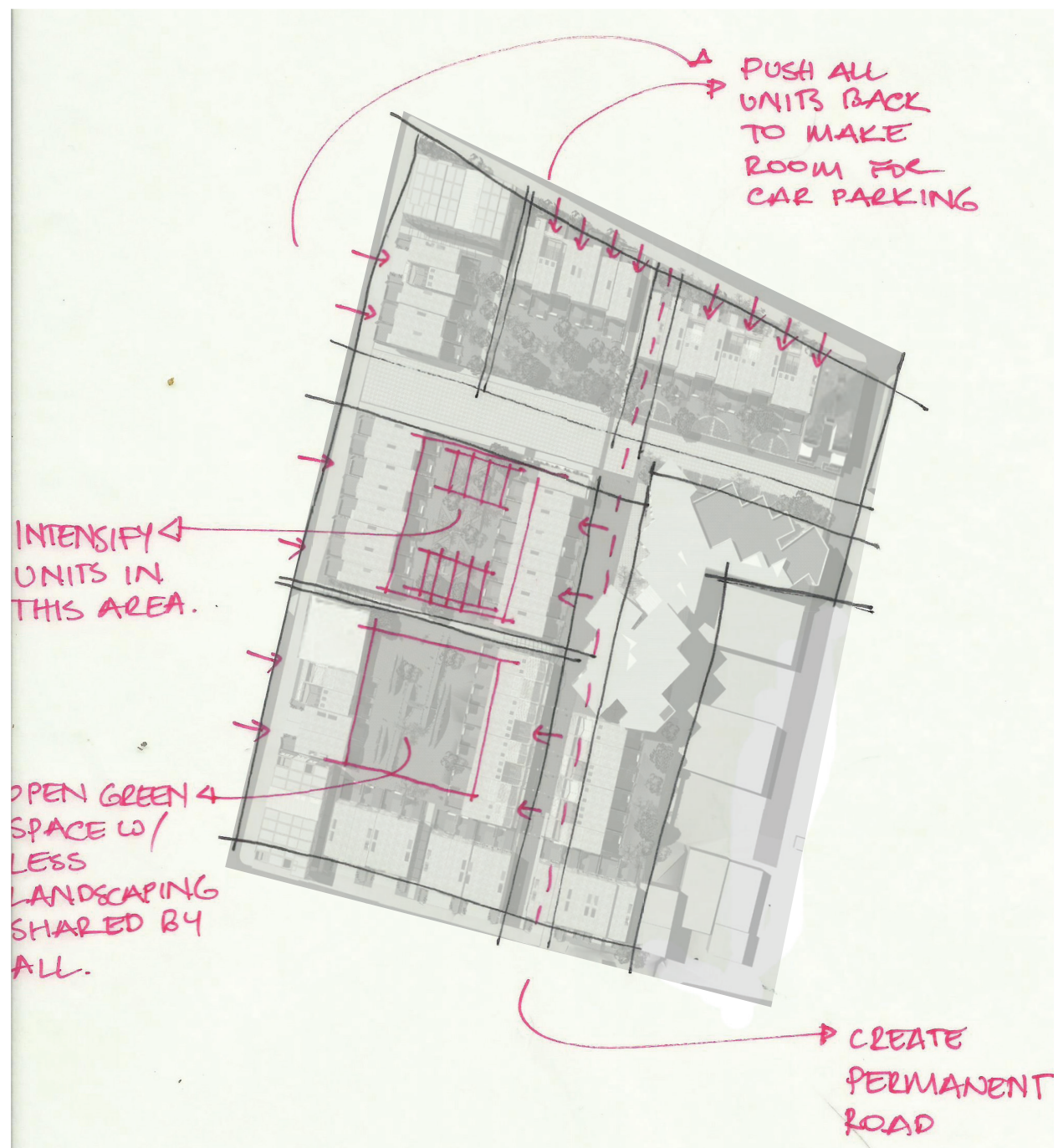

Figure 214: Developer's last comments on site. 


\section{Architect Interview 3}

A closing interview was held with the architect, to present the final design solution. (Anonymous, personal communication, January 24, 2017). The architect's main points of positive and negative feedback are outlined below.

- Positives

"I do buy into idea that you're not spreading your infrastructure all over the place by having to drive into the site." The architect liked the concept of carparking provided within the apartment buildings, on site but out of sight.

- "Having a majority of East West facing units allow for the most amount of sun". The architect approved of the unit position.

- The architect appreciated the diversity of the landscaping elements, stating that they had value in this type of development, and catered to the users.

- Of all the unit designs, the architect found the minimalistic vertical weatherboard typologies to be the most appealing, with the most "sophisticated design language". He felt that they would be the most popular in the current market.
- The architect reflected that the mixed housing was suited to the area and related to the style of the low residential housing in the area.

- Negative feedback:

The houses adjacent to the green gates brought up issues regarding privacy. The units located at the entrances of the site had the least amount of privacy, which might be an issue for buyers. "Dealing with potential privacy issues could be an issue, it is a bit public and not ideal even for high density living."

- The landscaping features did not include spaces for teenage activities. The architect thought that a site this large could include a concept that would appeal to an adolescent age group.

- The architect did not see value in the secondary emergency-only road. He suggested it become a permanent road.

- The Architect felt that some of the unit designs were too eclectic in their materials and composition, and not refined or elegant enough. 
The Residential Design Guide provided by the Wellington City Council provides a framework for design objectives (WCC, 2014). The considerations in the design guide help to ensure residential liveability and amenity. The guide has been used to assess the effectiveness of this project. It provides evidence of careful and considerate planning throughout the development.

\section{Assessing and complementing neighbourhood character}

The development meets the recommendations of the design guide regarding designing for the surrounding context. Visual consistency (1.2), native planting (1.4/1.5), neighbouring height restrictions (1.6), similar neighbourhood grain formation (1.7), and consistent frontages (1.9/1.10) are all achieved in this development. Other significant features including roof form (1.11), façade articulation (1.12), and material finishes (1.13) also compliment the surrounding context, but in a modern reinterpretation.

\section{Site planning}

The site was comprehensively planned around positive open shared spaces (2.1/2.2). Private outdoor spaces were also supplied for each unit (2.3). Maximising natural light was imperative to the sustainability concept of this development, so all units are positioned to receive as much sun as possible (2.5). Elimination of garages and carports prevents the street frontages

\section{Design Guide Assessment}

from looking monotonous (2.8/2.9), while some secure indoor carparking could still be provided if the apartment buildings went ahead (2.11). The site benefits from a road boundary on most sides which means amenity is maintained in the future (2.6). The Belfast street boundary is shared with commercial buildings but the topography presents a significant height difference, future proofing against intensification. The shared road within the development provides necessary access but does not intrude on dwelling privacy (2.10).

\section{Building design}

All typologies have formal internal planning that maximises the footprint (3.11), while incorporating modern functional living conditions and plenty of storage (3.12). Clear feature windows compliment the internal spaces providing a view and sunlight (3.3/3.9), but the size of the windows is restrained for privacy (3.14). All frontages positively address the street with clear dwelling entrances and windows (3.2/3.18). Even though the units are terraced, the different visual typologies give each unit a sense of address and individuality (3.19), and façades include interesting textural and visual features (3.7).

\section{Open space design}

Private open spaces are provided for every unit and function as an 
extension to the living areas (4.1/4.2) The shared open green spaces in the development are expansive, amenity-rich, and easily accessed from all units (4.5). Screening is designed between units (4.6/4.8), but fences are kept low to provide a clear view out (4.17). The circulation through the development is understandable and the primary spine is designed as an efficient pedestrian and cycle route (3.9). The planting throughout the development is native and enhances the site aesthetically (4.12). Hanging lantern lighting is provided on pedestrian routes into the site (4.14). 


\section{Sustainability Assessment}

Operational Energy

The thermal conductivity and insulation value (R-value) were recorded for the selected materials (where possible) during the Life Cycle Assessment (see Appendix $\mathrm{F}$ for full tables). This allowed a comparison to be made between the heat loss of the traditional versus sustainable units. The values were sourced from suppliers or from a construction calculator that provides R-values for commonly used materials in New Zealand (Design Navigator Limited, 2016) (see Appendix G for detailed tables R-value tables). These values were then entered into an official industry calculation tool to find the heat loss for each unit (BRANZ, 2009) (see Appendix H for calculation tables). The results showed that sustainable units were above and beyond industry minimums, and retained heat significantly more effectively than the traditional unit (see Tables 14 and 15).

\section{Embodied Energy}

Carbon footprint information was obtained from a comprehensive carbon and energy inventory (Circular Ecology limited, 2016). This showed a clear difference between the embodied energy of the sustainable and traditional units, particularly through the use of sustainable timbers. However, the table did not provide carbon values for material transportation, which would be high for both units. Unfortunately, New Zealand's geographic location and limited resources mean that this is often unavoidable.

\section{Toxicity}

As per information gathered during the Life Cycle Assessment, toxicity for the traditional materials was higher overall than for the sustainable options, mainly due to increased reliance on bonding and treatment chemicals during manufacturing processes. The sustainable materials were often more natural. For example, the timber cladding does not need to be treated and would biodegrade at the end of its life without leaching toxins into the environment. 


\section{Summary of calculation method heat loss}

\begin{tabular}{|l|r|r|r|}
\hline Element & Area $\left(\mathbf{m}^{\mathbf{2}}\right)$ & $\begin{array}{c}\text { Proposed building } \\
\text { heat loss }\left(\mathbf{W} /{ }^{\circ} \mathbf{C}\right)\end{array}$ & $\begin{array}{c}\text { Reference building } \\
\text { heat loss }\left(\mathbf{W} /{ }^{\circ} \mathbf{C}\right)\end{array}$ \\
\hline Roofs/ceilings & 47.4 & 16.0 & 17.2 \\
Walls & 362.2 & 173.8 & 191.8 \\
Floors & 50.0 & 37.0 & 38.5 \\
Vertical glazing & 50.7 & 211.3 & 479.0 \\
Skylights & 2.6 & 10.0 & - \\
Doors & 2.2 & 0.0 & - \\
\hline Total & & 448.1 & 726.5 \\
$\mathrm{~W} /{ }^{\circ} \mathrm{C}$
\end{tabular}

Glazing percentage: $12 \%$ Glazing <40\%: Yes

Minimum R-values OK: Yes

Issues to check:

PASS/FAIL

\section{PASS}

Table 14: Traditional unit summary BRANZ calculation method summary. Retrieved from http://www.branz.co.nz/calcmethod2009 Copyright 2011 BRANZ. Reprinted with permission.

\section{Summary of calculation method heat loss}

\begin{tabular}{|l|r|r|r|}
\hline Element & Area $\left(\mathbf{m}^{\mathbf{2}}\right)$ & $\begin{array}{c}\text { Proposed building } \\
\text { heat loss } \mathbf{( W / { } ^ { \circ } \mathbf { C } )}\end{array}$ & $\begin{array}{c}\text { Reference building } \\
\text { heat loss }\left(\mathbf{W} /{ }^{\circ} \mathbf{C}\right)\end{array}$ \\
\hline Roofs/ceilings & 47.4 & 10.1 & 17.2 \\
Walls & 362.2 & 124.2 & 191.8 \\
Floors & 50.0 & 20.0 & 38.5 \\
Vertical glazing & 50.3 & 139.7 & 478.5 \\
Skylights & 2.6 & 5.4 & - \\
Doors & 2.2 & 0.0 & - \\
\hline Total & & 299.5 & 726.0 \\
$\mathrm{~W}$
\end{tabular}

Glazing percentage: $12 \%$

Glazing <40\%: Yes

Minimum R-values OK: Yes

Issues to check: Some R-values appear to be very high. Check highlighted values.

PASS/FAIL

PASS

Table 15: Sustainable unit summary BRANZ calculation method summary. Retrieved from http://www. branz.co.nz/calcmethod2009 Copyright 2011 BRANZ. Reprinted with permission. 


\section{Unit Costing}

Materials were chosen based on the information collected through the Life Cycle Assessment. A quantity schedule was then created to compare their cost against a traditional build (see Appendix I for quantity tables, and Appendix $\mathrm{J}$ for cost breakdown tables). While there are nine possible plans - three typologies for each of the three unit sizes - only two plans were chosen for cost analysis. These were the 4-bedroom unit Type 1, and the 2-bedroom unit Type 2 (see Figures 219 and 220).

The values for each component were taken from a range of sources. In most cases, the traditional construction materials were costed using Rawlinsons 2013/14 edition (Rawlinsons Publications, 2013). Because the Rawlinsons pricing was out of date, inflation was applied at $19.78 \%$ since 2013 (SNZ, 2016). For the sustainable materials, prices were acquired through correspondence with the manufacturer, or from product websites.

Components were divided into three categories, which were calculated separately and then combined to find a total cost. These categories were horizontal building components, vertical building components, and internal components (such as sanitary plumbing, electrical services and drainage) (see Appendix $\mathrm{K}$ for detailed cost analysis).

As expected, the analysis found that the 2-bedroom unit options were more expensive to construct per square metre than the 4-bedroom units (see Table 16 and 17). This can mainly be attributed to the disproportionate area required for service rooms in a small house.

A comparison analysis between the traditional and sustainable unit options showed that the sustainable version of both units was more expensive by a small percentage. The sustainable 2-bedroom unit would cost an extra $\$ 172.53$ per square metre (7\%), while the 4-bedroom is an extra $\$ 220.24$ per square metre (9\%) (see Appendix I for detailed tables).

Although the sustainable unit is more expensive overall, a closer look at the cost breakdown shows that certain components were in fact cheaper than their traditional counterparts. The successfully substituted materials include:

- Timber piles at a cost saving of $\$ 137 / \mathrm{m} 2$, compared to concrete slab foundations.

- Wallaba and macrocarpa claddings at a saving of around $\$ 350 / \mathrm{m} 2$, compared to traditional brick veneer or fibre cement weatherboards.

Materials that had the greatest impact on the higher price of the sustainable build include: 
- Timber window framing, at around $\$ 225 / \mathrm{m} 2$ more per square metre than aluminium framing.

- CLT, which can be up to $\$ 230 / \mathrm{m} 2$ more expensive than traditional wall framing and $\$ 82 / \mathrm{m} 2$ more expensive than traditional flooring. However, this cost difference could be somewhat reduced if the CLT was left exposed, eliminating the need for wall and floor treatments (see Figure 217).
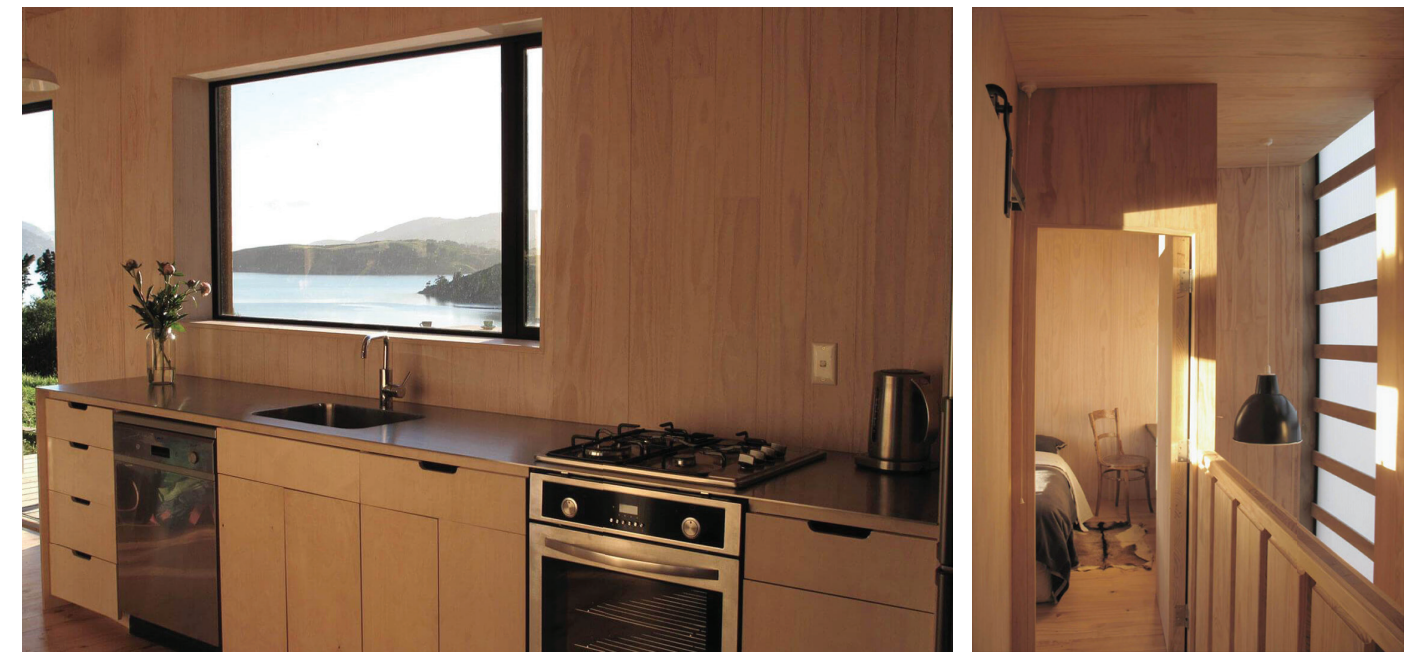

Figure 217: CLT finished interiors of Warrander Studio. From http://www. makersofarchitecture.co.nz/approach/ Copyright 2016 by Makers of Architecture. Reprinted with permission.

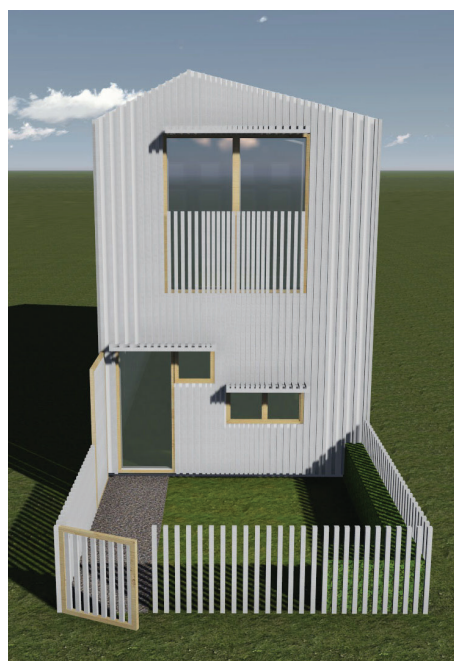

Figure 215: 2 bed unit used for cost comparison.

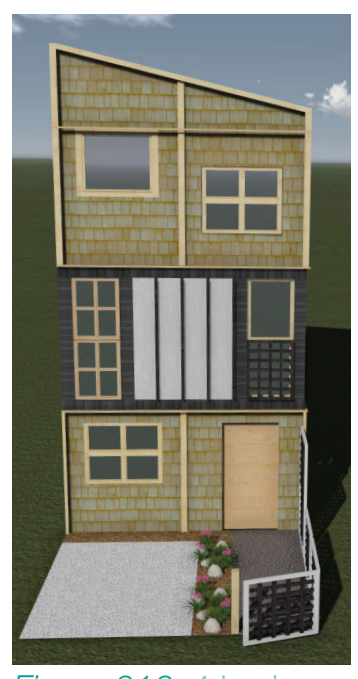

Figure 216: 4 bed unit used for cost comparison

\begin{tabular}{|l|l|l|l|l|}
\hline \multirow{2}{*}{$\begin{array}{c}\text { Total unit construction cost } \\
2\end{array}$} & Traditional & $\$ 188,237.11$ & Per $m 2$ & $\$ 2,352.96$ \\
\cline { 2 - 5 } & Sustainable & $\$ 202,039.34$ & Per m2 & $\$ 2,525.49$ \\
\cline { 2 - 5 } & $\begin{array}{l}\text { Percentage } \\
\text { difference }\end{array}$ & $7 \%$ & \\
\hline
\end{tabular}

Table 16: 2 bedroom unit build cost comprising sustainable and traditional materials.

\begin{tabular}{|c|l|l|l|l|}
\hline \multirow{2}{*}{$\begin{array}{c}\text { Total unit construction cost } \\
4\end{array}$ bedroom unit } & Traditional & $\$ 344,390.57$ & Per $m 2$ & $\$ 2,295.94$ \\
\cline { 2 - 5 } & Sustainable & $\$ 377,426.70$ & Per m2 & $\$ 2,516.18$ \\
\cline { 2 - 5 } & $\begin{array}{l}\text { Percentage } \\
\text { difference }\end{array}$ & $9 \%$ & \\
\hline
\end{tabular}

Table 17: 4 bedroom unit build cost comprising sustainable and traditional materials, 


\section{Development Costing}

To find the end cost of the development, final calculations were completed in the manner of the initial feasibility studies. These calculations used the actual unit costing (3-bedroom units were priced at an average of the 2-bedroom and 4-bedroom costs). Other costs were kept at the developer's initial estimates. He had made it clear in his last interview that the landscaping designs were beyond what he would ever consider, so final figures were kept at a standard option.

Because the apartment buildings were unsuccessful as a sustainable concept, they were also excluded from the final costings. Their allocated space was instead designated to 27 additional MDH units (see Table 18 and Figure 218).

Final figures showed that the development would be unlikely to earn a profit once probable hidden costs had emerged. As such, the project could not be completed by a private developer (see Table 19). A profitable development would require a higher density scheme, either with apartment complexes included or outdoor spaces reduced. As per Table 20, the latter option would not be possible within the current $35 \%$ site coverage regulations, nor would it offer comfortable living for residents.

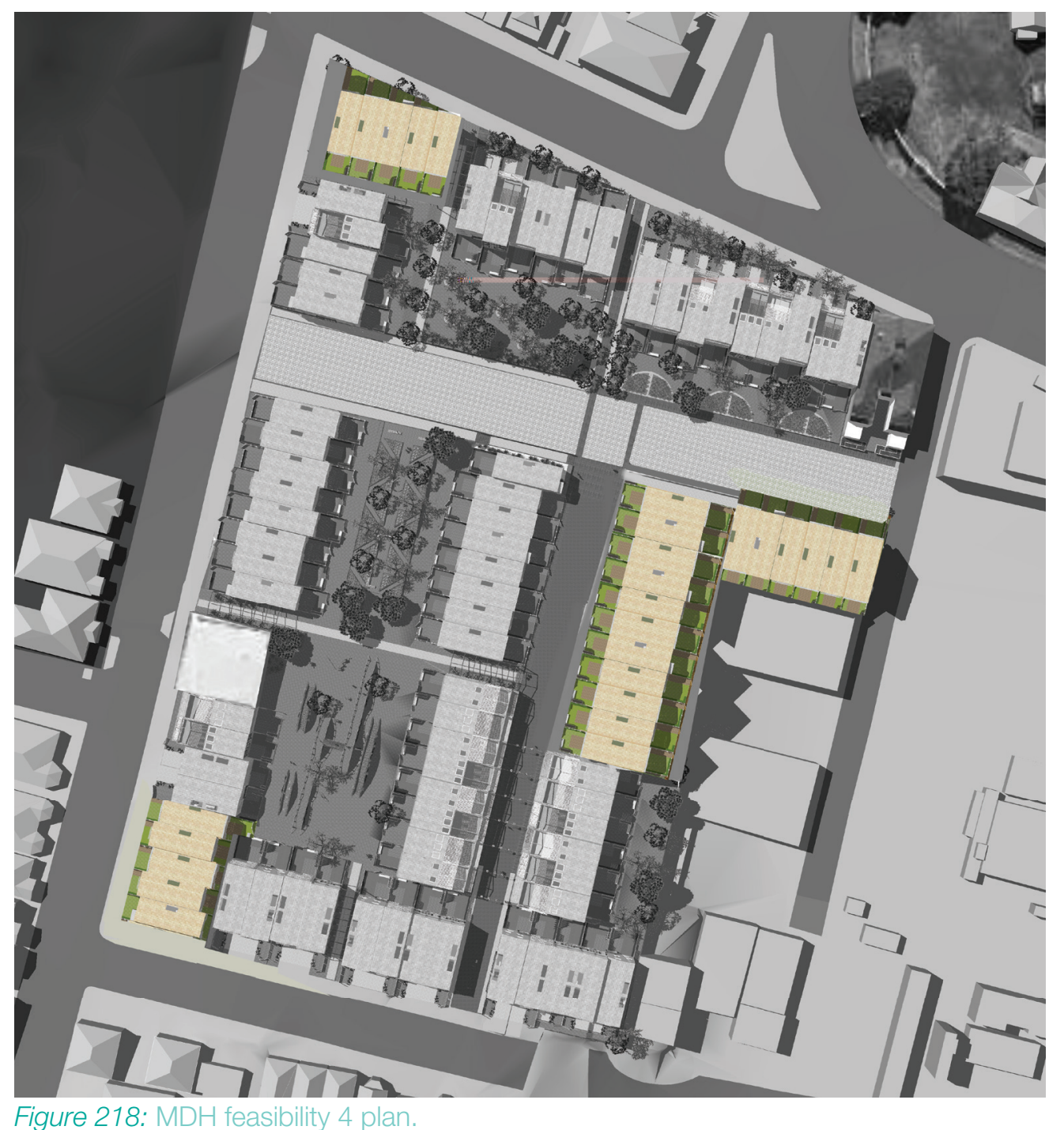




\begin{tabular}{|c|c|c|c|c|c|c|c|c|c|}
\hline Type & $\mathrm{m} 2$ & Units & $\begin{array}{l}\text { Construction cost } \\
\text { per unit }\end{array}$ & $\begin{array}{l}\text { Other costs } \\
\text { per unit }\end{array}$ & GST 20\% & $\begin{array}{l}\text { Total cost } \\
\text { per unit }\end{array}$ & $\begin{array}{l}\text { Total cost } \\
\text { per m2 }\end{array}$ & $\begin{array}{l}\text { Sale price } \\
\text { per unit }\end{array}$ & $\begin{array}{l}\text { Sale } \$ \\
\text { per m2 }\end{array}$ \\
\hline 2 bed MDH & 80 & 34 & $\$ 202,039$ & $\$ 100,000$ & $\$ 60,408$ & $\$ 362,447$ & $\$ 4,531$ & $\$ 479,000$ & $\$ 5,988$ \\
\hline 3 bed MDH & 104 & 40 & $\$ 289,733$ & $\$ 100,000$ & $\$ 77,947$ & $\$ 467,680$ & $\$ 4,497$ & $\$ 689,000$ & $\$ 6,625$ \\
\hline 4 bed MDH & 150 & 20 & $\$ 377,427$ & $\$ 100,000$ & $\$ 95,485$ & $\$ 572,912$ & $\$ 3,819$ & $\$ 746,000$ & $\$ 4,973$ \\
\hline
\end{tabular}

Table 18: Cost feasibility 4.

\begin{tabular}{|l|l|}
\hline Total development cost & $\$ \$ 42,488,631$ \\
\hline Total development sale price & $\$ 58,766,000$ \\
\hline Profit & $\$ 458,369$ \\
\hline Profit margin & $1 \%$ \\
\hline
\end{tabular}

Table 19: Cost feasibility 4 outcomes.

\begin{tabular}{|l|l|l|}
\hline $\begin{array}{l}\text { site coverage area } \\
(\mathrm{m} 2)\end{array}$ & $\mathrm{m} 2$ & units \\
\hline MDH @ 40m2 & 2960 & 74 \\
\hline MDH @ 50m2 & 1000 & 20 \\
\hline Historic buildings & 300 & 3 \\
\hline Total site coverage & 4260 \\
\hline Coverage percentage & $36 \%$ \\
\hline
\end{tabular}

Table 20: Feasibility 4 site coverage. 


\section{Stage 3 - Summary / Self-Reflection}

Overall, this project has demonstrated that it is possible to design a medium density housing solution which utilises a range of non-intrusive materials that provide significant sustainability benefits. It has also shown that a modern development can integrate into a historically significant area, and still have a sense of place, through design and social cohesion.

Some specific positive aspects of the final design include:

- Entry and accessibility are incorporated in a positive way. Pedestrian/ bike entrances are provided all around the site, and are made inviting through landscaping and lighting. Vehicle access is considered in terms of the surrounding streets.

- Division of the site creates connections and destinations.

- Unit separation, orientation and screening features provide privacy.

- Green space amenities increase the value of the units and foster community activities and a sense of place.

- Variety in typologies and building heights creates individuality and dynamism across the site.
- Site is appropriate for intensification and development, and is within walking distance of city centre amenities.

- Housing works with the topography of site to reduce the need for excavation work.

- Sunlight is maximised and prioritises the main living spaces.

- Council regulations such as height limits and site coverage are met.

- Three unit sizes are offered, to accommodate a diverse market.

- Unit plans use space as efficiently as possible.

- Internal layouts optimise orientation for direct connectivity to outdoor spaces.

- The development measures up well against the wellington council residential design guide. This suggests that amenity and liveability have been carefully considered.

- The development has been designed to initiate discourse between neighbours and create a community. 
Unfortunately, as well as being unprofitable within the current market, there were also some other negative aspects of the final design. These include:

- Living spaces are tight due to the small footprint.

- Significant excavation is required for vehicle access through the site.

- Accommodation for mobility-impaired residents is not provided.

- Some exterior articulation is complex and 'busy'.

- Landscaping and amenity costs are outside the feasibility of the initial budget and would also need ongoing maintenance.

- Lighting solutions have not been considered for the roadways.

- Balconies overlook each other.

- Architectural creativity has been somewhat limited by budget and size restrictions.

- Apartment housing was unable to be included within the sustainable principles. 


\section{Conclusions and Future Potential}

\section{Discussion}

This thesis explored the research question "How can design contribute to a sustainable medium density housing solution that is an affordable alternative for developers?". While the final solution failed to meet the affordability aspect of the question, it does show that a sustainable alternative is possible, if not yet profitable. The research found that a range of sustainable features can be easily and effectively incorporated into the medium density housing vernacular. These features include passive heating, cooling, and ventilation techniques, as well as material choices, construction processes, and outdoor amenities. The research is presented as a theoretical design solution. This helped to articulate the information to a variety of industry professionals, allowing them to visualise the real-world applications of the research.

As the project progressed and it became clearer that the affordability component of the research question was unachievable, a hierarchy of impact emerged that helped to explain why a fully sustainable development was not yet possible. At the lowest level of the hierarchy is the designer. A designer's scope for incorporating sustainable concepts into an architectural project is largely restricted by the brief and budget of the developer or client. While the architect can suggest sustainable options, and explain their benefits, all final decisions are at the discretion of the developer.
At the next level of the hierarchy is the developer. Presently, the sustainable product manufacturing industry has not yet matured enough to cater to large developments. Sustainable options are available, but manufacturers do not yet have the variety, competition or infrastructure to produce materials that a developer could viably consider. A developer is ultimately a businessperson, and is therefore restricted by their need to make a profit and avoid risk.

Both developers and the sustainable product industry are driven by the buyer market. Without a market demand for sustainable options, the industry will be unable to expand. A change in market attitudes and priorities would be required to create growth in the area, but a large-scale push towards sustainability is unlikely during the current housing crisis. While property prices are already exorbitant, any extra cost is unwelcome.

As such, the top tier of the hierarchy includes policy-implementing authorities, such as government and local councils. It should be the government's responsibility to manage the sustainability of the country. This includes:

- Controlling the housing crisis to bring down property prices. This may create leeway for sustainable practices to be implemented while they are 
still more expensive, so that they can become cheaper over time.

- Educating the public about environmental issues, so that the harmful effects of traditional construction products, processes and waste are better understood.

- Developing policies and regulations that enforce sustainable practices within the industry.

- Managing trade relations so that sustainable building materials can be imported inexpensively from overseas, where the market is larger and more diverse.

Subsidies for sustainable design might also be worth considering. The NZ 'Healthy Homes' programme, which offers subsidies for home insulation (Energy Efficiency and Conservation Authority [EECA], 2017), has proved successful. A similar scheme could be extended to other materials. 


\section{Limitations}

The scope and theoretical nature of this thesis limit its ability to consider all the factors that would be involved in an actual development. However, measures were taken to create the overall framework of a real-world project. These included:

- Undertaking feasibility studies and a cost analysis

- Interviewing industry experts

- Assessing the development against the WCC Design Guidelines, a materials Life Cycle Assessment, and BRANZ energy analysis.

In-depth discussion with a range of industry professionals was limited. The main developer, who acted as the hypothetical client for the project, was generous with his time. However, it is recognised that the project was driven largely by his opinions and motivations. It would have been helpful to have input from a range of developers, to ensure that a representative perspective was attained and that other market positions were considered. Unfortunately, of the many other Wellington developers who were contacted, only one responded.
The design itself was also limited in several ways. The project was inventive in terms of exterior articulation, site planning and landscaping, however internal planning was very much restricted. Site coverage regulations, as well as the market standards for MDH in New Zealand, meant that the unit footprints needed to be small. This did not allow for unique architectural moments to be designed within an entry-level budget. Additionally, material specifications were limited by NZ's geography. Fully 'cradle-to-cradle' products were impossible to find at a commercial scale, as most overseas suppliers do not export to NZ. A more moderate approach to sustainability principles was therefore required. 


\section{Future Questions}

This project lends itself to continued research into sustainable systems, materials, and construction processes. In particular, future investigation could tackle issues around the sustainable construction of apartment buildings that do not rely on steel and concrete.

Further research also needs to be directed towards establishing more comprehensive rating systems for sustainable products. Current rating systems are promoting 'green washing' (EnviroMedia Marketing, 2017) by allowing products to be marketed as sustainable despite only meeting one aspect of sustainability, or being 'less bad' than other products. While it was predicted that green washing would be seen during the research, it was in fact more prevalent than imagined. Words like 'eco' and 'green' are everywhere, despite only a small percentage of products being genuinely sustainable. 


\section{End Notes}

This research has found that sustainable change is not the responsibility of a single stakeholder. It requires a collaborative effort.

It is the responsibility of government to increase public education in schools and through the media, to drive the change in attitude that may potentially lead to a change in market desires.

It is the responsibility of developers and buyers to consider their impact on the environment, potentially compromising some of their focus on profit in order to prioritise their social conscience.

Finally, it is the duty of architectural designers to continually seek out and highlight more sustainable options, and bring them to the forefront of the construction conversation.

The question is not whether we can afford to build sustainably for the future but whether we can afford not to. 
American Institute of Architects. (n.d.). E+ // 226-232 Highland Street Townhouses. Retrieved October 20, 2016, from http://www.aiatopten. org/node/433

Auckland City Council. (n.d.). New Streets in Newtown: Redevelopment of stylish and affordable apartments. Retrieved from http://content. aucklanddesignmanual.co.nz/ADM\%20lmages/Carousel/004\%20 Housing\%20Case\%20Studies/004\%2017\%20Regent\%20Park/ Case\%20study_Apartments_Regent\%20Park.pdf

Bierre, S., Howden-Chapman, P., \& Early, L. (2013). Homes people can afford: How to improve housing in New Zealand. Wellington, NZ: Steele Roberts Aotearoa.

Boffa Miskell Limited. (2012, January). Medium-density Housing Case Study. Retrieved from Ministry for the Environment: http://www.mfe.govt.nz/ sites/default/files/medium-density-housing-case-study-wellington.pdf

BRANZ. (2009). NZS 4218:2009 Calculation Method Tool. Retrieved from http://www.branz.co.nz/calcmethod2009.

Braungart, M., \& McDonough, W. (2009). Cradle to Cradle remaking the way we make things. London, UK: Vintage.
Chiras, D. D. (2004). The new ecological home: A complete guide to green building options. White River Junction, USA: Chelsea Green Publishing Company.

Circular Ecology Limited. (2016). Embodied energy and carbon database. Retrieved from http://www.circularecology.com/embodied-energyand-carbon-footprint-database.html\#.WKu39FV95hE

Cool Roof Rating Council. (n.d.). Cool roofing information for home and building owners. Retrieved http://coolroofs.org/resources/homebuilding-owners

Creswell, W. J. (1994). Research Design: Qualitative and Quantitative Approaches. CA, USA: Sage Publications.

Crouch, C., \& Pearce, J. (2012). Doing research in design. London, UK: Berg Publishers.

Design Navigator Limited. (2016). Construction R-value Calculator. Retrieved from https://www.designnavigator.co.nz/CRC.php

Dresner, S. (2008). The principles of sustainability. London, UK: Earthscan. 
Dixon, J., \& Dupuis, A. (2003). Urban intensification in Auckland, New Zealand: A challenge for new urbanism. Housing Studies, 18(3), 353368. http://dx.doi.org/10.1080/02673030304239

EnvioMedia Social Marketing. (2017). What is greenwashing? Retrieved from ttp://greenwashingindex.com/about-greenwashing/

Evident. (n.d.). Cladding. Retrieved from http://zeroenergyhouse.co.nz/ cladding/

Farooq, A. (2012, April 5). Borneo Sporenburg Analysis. Retrieved from https://issuu.com/aysha_farooq/docs/borneo_sporenburg_brochure

Friedman, A. (2012.) Fundamentals of Sustainable Dwellings. Washington, USA: Island Press.

Gibson, Anne. (2015, September 14). Wellington house prices drop. NZherald. Retrieved from http://www.nzherald.co.nz/business/news/ article.cfm?c_id=3\&objectid=11512776

Gray Partners Limited. (2014, August). Commercial Drivers for MediumDensity Residential Development in Selected Wellington Suburbs. Retrieved from http://wellington.govt.nz/ /media/your-council/ projects/files/housing-choice-supply/medium-density-housing/ commerical-drivers-mdra-development.pdf?la=en
Higgins, M. (2010). Urban design and the planning system in Aotearoa-New Zealand: Disjuncture or convergence? Urban Design International, 15(1), 1-21. http://dx.doi.org/10.1057/udi.2009.16

Hobsonville Land Company Limited. (n.d.). Living sustainably. Retrieved from http://www.hobsonvillepoint.co.nz/vision/living-sustainably

Hobsonville Land Company Limited. (2016). Point Life. Retrieved from http:// www.hobsonvillepoint.co.nz/downloads/point-life-05.pdf

Hobsonville Land Company Limited. (2017, January). For Sale. Retrieved from http://www.hobsonvillepoint.co.nz/for-sale

Hulse, P. (2015, September 24). Addressing Auckland's housing crisis. NZHerald. Retrieved from http://www.nzherald.co.nz/nz/news/article. cfm?c_id=1\&objectid $=11518360$

International Green Roof Association. (2017). Construction Engineering. Retrieved from http://www.igra-world.com/engineering/construction_ engineering.php

International Organization for Standardization. (2006). Environmental management : Life cycle assessment ; requirements and guidelines. (1st ed., International Organization for Standardization. International standard ; ISO 14044: 2006). Geneva, CH: ISO. 
Intuitive Technology and Bio-Architecture-TIBÁ. (n.d.). Projects. Retrieved May 4, 2016 from http://www.tibarose.com/ing/projetosmocambique.php

Jackman, A. (2014, March 27). Supermarket land still vacant. The Wellingtonian. Retreived from http://www.nzherald.co.nz/business/ news/article.cfm?c_id=3\&objectid $=11512776$

Judd, B., Gamble, J. (1993). Designed for Urban Living : Recent MediumDensity Group Housing in Australia. Red Hill, Australia: Royal Australian Institute of Architects.

Kemmis, S., \& McTaggart, R. (2003). Participatory Action Research (second ed.). CA, USA: Sage Publications.

Lewin, K. (1946). Action research and minority problems. Journal of Social Issues, 2(4), 34-36. http://dx.doi.org/10.1111/j.1540-4560.1946. tb02295.x

Litten, C. (2016, June). Exploring MDH Challenges. BRANZ, 154, 46.

Lismore City Council. (2005, May). The Use of Reed Beds for the Treatment of Sewage \& Wastewater from Domestic Households. Retrieved from https://www.lismore.nsw.gov.au/page.asp?f=RES-PEY-54-48-10
Makers of Architecture. (n.d.). Warrander studio. Retrieved from http://www. makersofarchitecture.co.nz/warrander-studio/

Meisel, A. (2010). Leed Materials: A Resource Guide to Green Building. New York, USA: Princeton Architectural Press.

Page, I. (2016, June). Growth in MDH. BRANZ, 154, 48.

Pearce, D., Markandya, A., \& Barbier, E. B. (1989). Blueprint for a Green Economy. London, U.K: Earthscan.

PropertyNZ Limited. (2017). Properties. Retrieved from https://homes.co.nz/ app/homes.

Rawlinsons Publications. (2013). Rawlinsons New Zealand Construction Handbook. Lower Hutt, NZ: PrintLink Limited.

Silestone. (n.d.). Eco Line Colour Series. Retrieved from http://nz.silestone. com/eco-line-series/

Stewart, P. (2016, June). Finding a happy medium. BRANZ, 154, 44-45.

Statistics New Zealand. (n.d.). Wellington City community profile Mount Cook. Retrieved from http://profile.idnz.co.nz/wellington/carownership?WeblD=300 
Statistics New Zealand. (2011). Capital goods price index, percentage increase. Retrieved from http://stats.govt.nz/browse_for_stats/ economic_indicators/prices_indexes/BusinessPricelndexes_

HOTPJun16qtr/Commentary.aspx\#title4

Statistics New Zealand. (2016). Business Price Indexes: June 2016 quarter. Retrieved from http://stats.govt.nz/browse_for_stats/economic_ indicators/prices_indexes/BusinessPricelndexes_HOTPJun16qtr/ Commentary.aspx\#title4

Terra Lana Products Limited. (2017). The wool advantage. Retrieved from http://www.terralana.co.nz/advantages.html

Turner, D., Hewitt, J., Wagner, C,. Su, B., Davies, D. (2004). Best Practice in Medium Density Housing Design: Housing New Zealand Corporation. Retrieved from http://www.hnzc.co.nz/assets/Uploads/best-practicein-medium-density-housing.pdf

Tutt, P., \& Adler, D. (1979). New Metric Handbook. London, UK: Architectural Press.
Vallance, S., Perkins, H. C., \& Dixon, J. E. (2011). What is social sustainability? A clarification of concepts. Geoforum, 42(3), 342-348. Retrieved from http://www.sciencedirect.com/science/article/pii/ S0016718511000042

Van Baaren, E. (2013, April) Paint it white to combat global warming. Green Ideas. 3. Retrieved from: http://www.greenideas.co.nz/how-to/ building-and-renovation/paint-it-white-to-combat-global-warming

Van Lengen, J. (2008). The barefoot architect: $A$ handbook for green building. Bolinas, CA, USA: Shelter Publications.

Wellington City Council. (n.d.). Appendix 4: Southern Inner Residential Areas. Retrieved from http://wellington.govt.nz/ /media/your-council/ plans-policies-and-bylaws/district-plan/changes/active-changesvariations/files/change72-v2-appendix4.pdf?la=en

Wellington City Council. (2012a). Colourful New Townhouses Win Top Paint Award. Retrieved from http://wellington.govt.nz/your-council/ news/2012/08/colourful-new-townhouses-win-top-paint-award

Wellington City Council. (2012b). Chapter 5. Residential Area Rules. Retrieved from http://wellington.govt.nz/ /media/your-council/planspolicies-and-bylaws/district-plan/volume01/files/v1chap05pt1.pdf 
Wellington City Council. (2014, November 19). Residential Design Guide.

Retrieved from http://wellington.govt.nz/ /media/your-council/

plans-policies-and-bylaws/district-plan/volume02/files/v2residential.

pdf?la=en

Wellington City Council. (2017). Webmap. Retrieved from http://wellington. govt.nz/webmap/wccmap.html

World Commission on Environment and Development. (1987). Our Common Future. New York, USA: Oxford University Press.

XLam. (n.d.). XLam Cross Laminated Timber Panels. Retrieved from http:// www.xlam.co.nz/xlam-clt.html 


\section{List of tables}

Table 1: Altair project details.

Table 2: Altair costing details.

Table 3: Car ownership 2013 in Mount Cook.

Table 4: Occupation of employment 2013 in Mount Cook.

Table 5: Household size 2013 in Mount Cook.

Table 6: Number of bedrooms per occupied dwelling 2013 in Mount Cook.

Table 7: Household types 2013 in Mount Cook.

Table 8: Section lots included in project.

Table 9: Cost feasibility 1.

Table 10: Additional section lots included in project.

Table 11: Cost feasibility 2.

Table 12: Cost feasibility 3.

Table 13: Cost feasibility 3 outcomes.

Table 14: Traditional unit summary BRANZ calculation method summary.

Table 15: Sustainable unit summary BRANZ calculation method summary.

Table 16: 2 bedroom unit build cost comprising sustainable and traditional materials.

Table 17: 4 bedroom unit build cost comprising sustainable and traditional materials

Table 18: Cost feasibility 4.

Table 19: Cost feasibility 4 outcomes.

Table 20: Feasibility 4 site coverage.

Table E: RV averages for feasibility study.

Table F1: Traditional unit R-values BRANZ calculation method summary.

Table F2: Sustainable unit R-values BRANZ calculation method summary.

Table G1: 4 bedroom quantities.

Table G2: 3 bedroom quantities.

Table G3: 2 bedroom quantities.

Table H1: Site cost breakdown.

Table H2: Frame and wall cost breakdown.

Table H3: Exterior walls and exterior finishes cost breakdown.

Table H4: Windows and exterior doors cost breakdown. 
Table H5: Roof cost breakdown.

Table H6: Interior finishes cost breakdown.

Table H7: Interior services cost breakdown.

Table H8: Exterior work and sundries cost breakdown.

Table 11: 2 bedroom horizontal building components.

Table I2: 2 bedroom vertical building components, and internal components.

Table 13: 3 bedroom horizontal building components.

Table 14: 4 bedroom vertical building components, and internal components.

Table J1: Sustainable internal wall R-Value.

Table J2: Traditional internal wall R-Value.

Table J3: Traditional flooring R-Value.

Table J4: Sustainable end wall plywood R-Value.

Table J5: Traditional end wall R-Value.

Table J6: Sustainable end wall weatherboard R-Value.

Table K1: External walls, and exterior finishes LCA.

Table K2: External walls, and exterior finishes LCA.
Table K3: Roof LCA.

Table K4: Roof LCA.

Table K5: Windows and doors LCA.

Table K6: Substructure and internal finishes LCA.

Table K7: Frames and walls LCA.

Table K8: Frames and walls LCA. 


\section{List of Figures}

Figure 1: Action research diagram showing it's application to this thesis

Figure 2: Visual representation of the cradle to cradle cycles.

Figure 3: Photos of the Altair, showing exterior articulation.

Figure 4: Photos of the Altair, showing shared open space.

Figure 5: Photos of the Altair,showing context.

Figure 6: Regent park Internal site photo.

Figure 7 : Contextual site photos Regent St.

Figure 8: Hobsonville point development plan.

Figure 9: Site showing Northern axis.

Figure 10: Existing site view from Rugby St.

Figure 11: Existing site view from Tasman St.

Figure 12: Existing site with $12 \mathrm{~m}$ height limit.

Figure 13: Sun paths at three times of the year.

Figure 14: September equinox 7am.

Figure 15: March equinox $7 \mathrm{am}$.

Figure 16 June winter solstice 8am.

Figure 17: December summer solstice 7am.
Figure 18: September equinox 6pm.

Figure 19: March equinox 7:10pm.

Figure 20: June winter solstice 4:30pm.

Figure 21: December summer solstice 8:30pm.

Figure 22: Existing site view points.

Figure 23: Current pedestrian routes through site.

Figure 24: Potential pedestrian routes through site.

Figure 25: Existing vehicular routes through site.

Figure 26: Potential vehicular routes through site.

Figure 27: Contextual photos of character houses.

Figure 28: On site houses.

Figure 29: Old boy's institute.

Figure 30: Contextual site sketches.

Figure 31: Conceptual design sketches for style direction.

Figure 32: Initial 2D sketch unit planning.

Figure 33: Initial 3D sketch unit planning.

Figure 34: Initial 3D unit massing ground floors. 
Figure 35: Initial 3D unit massing first floors.

Figure 36: Initial 3D unit massing second floors.

Figure 37: Initial 3D exterior articulation.

Figure 38: Potential figure ground study on site.

Figure 39: Apartment, town-house, open space distribution.

Figure 40: Axis through site.

Figure 41: Movement through site.

Figure 42: Potential vehicular access.

Figure 43: Overlay of figures 34-38.

Figure 44: Site massing option 1.

Figure 45: Sussex street option 1.

Figure 46: Tasman street option 1.

Figure 47: Site massing option 2.

Figure 48: Sussex street option 2.

Figure 49: Tasman street option 2.

Figure 50: Site grain option 1.

Figure 51: Site grain option 2.
Figure 52: Surrounding suburban grain.

Figure 53: Routes through site option 1.

Figure 54: Routes through site option 2.

Figure 55: Visual permeability though site option 1.

Figure 56: Visual permeability though site option 2.

Figure 57: Facilities option 1.

Figure 58: Facilities option 2.

Figure 59: Unit orientation option 1.

Figure 60: Unit orientation option 2.

Figure 61: Lots on site.

Figure 62: Building lots on site.

Figure 63: Photo showing many construction workers working at once.

Figure 64: Weatherboard cladding primed before applied.

Figure 65: Cavity battens to meet regulations.

Figure 66: Framing with steel tension bracing.

Figure 67: 'Posistrut' beam system provides service space.

Figure 68: En-suite addition by owner, with pocket door. 
Figure 69: 'Bradford gold' insulation.

Figure 70: Prefabricated Plywood stairs.

Figure 71: Expansion foam seals windows and doors.

Figure 72: Street elevation of final development.

Figure 73: Alternating roofline.

Figure 74: Shared driveway.

Figure 75: Alternating articulation.

Figure 76: Shared green space.

Figure 77: Detail of cladding.

Figure 78: Typologies along the canal on Amsterdam Borneo island.

Figure 79: Individual architecture on the Amsterdam Borneo island.

Figure 80: Artistic render of project.

Figure 81: CLT panels placed on site.

Figure 82: Cassette system.

Figure 83: Macrocarpa cladding at time of construction.

Figure 84: Macrocarpa cladding after less than a year after construction.

Figure 85: Site massing option 3.
Figure 86: Tasman street option 3.

Figure 87: Sussex street option 3.

Figure 88: Access through site option 3.

Figure 89: Routes through site option 3.

Figure 90: Site grain option 3.

Figure 91: Facilities site option 3.

Figure 92: Unit orientation site option 3.

Figure 93: Cool roof design exploration.

Figure 94: 2 bedroom unit.

Figure 95: 3 bedroom unit plan.

Figure 96: 4 bedroom unit. plan not to scale.

Figure 97: Unit plan exploration.

Figure 98: 2 bedroom units exterior articulation development.

Figure 99: 3 bedroom units exterior articulation development.

Figure 100: 4 bedroom units exterior articulation development.

Figure 101: Stage 2, 2 bed ground floor plan.

Figure 102: Stage 2, 2 bed first floor plan. 
Figure 103: Stage 2, 2 bed roof plan.

Figure 104: Stage 2, 2 bed sectional elevation through B.

Figure 105: Stage 2, 2 bed sectional elevation through A.

Figure 106: Stage 2, 2 bedroom typologies.

Figure 107: Stage 2, 2 bed sustainable concepts.

Figure 108: Stage 2, 3 bed ground floor plan.

Figure 109: Stage 2, 3 bed first floor plan.

Figure 110: Stage 2, 3 bed second floor plan.

Figure 111: Stage 2, 3 bed roof plan.

Figure 112: Stage 2, 3 bed sectional elevation through B.

Figure 113: Stage 2, 3 bed sectional elevation through A.

Figure 114: Stage 2, 3 bedroom typologies.

Figure 115: Stage 2, 2 bed sustainable concepts.

Figure 116: Stage 2, 4 bed ground floor plan.

Figure 117: Stage 2, 4 bed first floor plan.

Figure 118: Stage 2, 4 bed second floor plan.

Figure 119: Stage 2, 4 bed roof plan.
Figure 120: Stage 2, 4 bed sectional elevation through B.

Figure 121: Stage 2, 4 bed sectional elevation through A.

Figure 122: Stage 2, 4 bedroom typologies.

Figure 123: Stage 2, 4 bed sustainable concepts.

Figure 124: Failed attempt to interlock units vertically.

Figure 125: balcony typologies exploration design taken from site building.

Figure 126: Stain glass and trellis external articulation.

Figure 127: Large apartment development.

Figure 128: Apartment exploration.

Figure 129: 1 bed apartment type 1 (50m2).

Figure 130: 1 bed apartment type 2 (50m2).

Figure 131: 2 bed apartment type 1 (70m2).

Figure 132: 2 bed corner apartment type 2 (70m2).

Figure 133: Apartment building 1 plans.

Figure 134: Roof and façade gradation with land topography.

Figure 135: Public facing North Eastern façades.

Figure 136: Public façade North Western façades 
Figure 137: Apartment buildings 2 and 3 development.

Figure 138: Apartment buildings 2 and 3 building articulation.

Figure 139: Apartment buildings 2 and 3, building plans development.

Figure 140: Apartment buildings 2 and 3, unit plans development.

Figure 141: Levels 1-5 plan for apartment buildings 2 and 3 1:100@A4.

Figure 142: Public-private interface diagram.

Figure 143: Landscaping concept sketch.

Figure 144: Stage 2 final site overviews.

Figure 145: Stage 2 final Northern elevation.

Figure 146: Stage 2 final Southern elevation.

Figure 147: Stage 2 final sun studies.

Figure 148: Stage $212 \mathrm{~m}$ height limit.

Figure 149: Stage 2 final vehicular routes.

Figure 150: Stage 2 final pedestrian routes are unlimited through site.

Figure 151: 2 bedroom unit architect's issues with designer's solutions.

Figure 152: 2 bedroom unit architect's issues with designer's solutions.

Figure 153: 4 bedroom unit architect's issues with designer's solutions.
Figure 154: 4 bedroom unit architect's issues with designer's solutions.

Figure 155: Apartment buildings 2 and 3 architect's issues with designer's solutions.

Figure 156: 3 bedroom unit architect's issues with designer's solutions.

Figure 157: Apartment building 1 structural advice.

Figure 158: Apartment building 2 and 3 structural advice.

Figure 159: Seismic joint detail structural advice.

Figure 160: Apartment building 1 foundations structural advice.

Figure 161: Apartment building 1 multi-storey steel detail structural advice.

Figure 162: Apartment building 1 curtain glazing detail structural advice.

Figure 163: Landscape redistribution plan - post design review.

Figure 164: Design refinement for unit articulation.

Figure 165: CLT typical wall detail .

Figure 166: Final front façade articulation for 2 bedroom units.

Figure 167: Final side façade articulation for type 3, 2 bedroom unit.

Figure 168: Final rear façade articulation for 2 bedroom units.

Figure 169: Final side façade articulation for type 1, 2 bedroom unit. 
Figure 170: Final 2 bedroom unit ground floor plan 1:50@A4.

Figure 171: Final 2 bedroom unit first floor plan 1:50 @A4.

Figure 172: Final 2 bedroom unit roof plan 1:50@A4.

Figure 173: Final 2 bedroom unit sectional elevation A 1:50 @A4.

Figure 174: Final 2 bedroom unit sectional elevation B 1:50 @A4.

Figure 175: Final front façade articulation for 3 bedroom units.

Figure 176: Final side facade articulation for type 3, 3 bedroom unit.

Figure 177: Final rear façade articulation for 3 bedroom units.

Figure 178: Final side facade articulation for type 13 bedroom unit.

Figure 179: Final side facade articulation for type 23 bedroom unit.

Figure 180: Final 3 bedroom unit ground floor plan 1:50@A4.

Figure 181: Final 3 bedroom unit first floor plan 1:50 @A4.

Figure 182: Final 3 bedroom unit second floor plan 1:50@A4.

Figure 183: Final 3 bedroom unit roof plan 1:50 @A4.

Figure 184: Final 3 bedroom unit sectional elevation A 1:50 @A4.

Figure 185: Final 3 bedroom unit sectional elevation B 1:50 @A4.

Figure 186: Final front façade articulation for 4 bedroom units
Figure 187: Final side façade articulation for type 3, 4 bedroom unit.

Figure 188: Final rear façade articulation for 4 bedroom units.

Figure 189: Final side façade articulation for type 3, 4 bedroom unit.

Figure 190: Final 4 bedroom unit ground floor plan 1:50 @A4.

Figure 191: Final 4 bedroom unit first floor plan 1:50 @A4.

Figure 192: Final 4 bedroom unit second floor plan 1:50@A4.

Figure 193: Final 4 bedroom unit roof plan 1:50 @A4.

Figure 194: Final 4 bedroom unit sectional elevation A 1:50 @A4.

Figure 195: Final 4 bedroom unit sectional elevation B 1:50 @A4

Figure 196: Final plan of site.

Figure 197: Final South West elevation.

Figure 198: Final North East elevation.

Figure 199: Final South East elevation.

Figure 200: Final North West elevation.

Figure 201: Final project South West aerial view.

Figure 202: Final project North aerial view.

Figure 203: Exploded landscape axonometric on site. 
Figure 204: Secondary road entrance from rugby street.

Figure 205: Secondary road entrance from Douglas street.

Figure 206: Three of the green gate entrances.

Figure 207: Native garden.

Figure 208: Reed garden.

Figure 209: Community vegetable garden.

Figure 210: Children's garden.

Figure 211: Perspective view looking down Tasman street.

Figure 212: Perspective view looking down Tasman street.

Figure 213: Perspective view looking down Rugby street.

Figure 214: Developer's last comments on site.

Figure 215: 2 bed unit used for cost comparison.

Figure 216: 4 bed unit used for cost comparison.

Figure 217: CLT finished interiors of Warrander Studio.

Figure 218: MDH feasibility 4 plan

Figure A2: Development of de-constructed villa ideas.

Figure B1: Development of bedrooms in $\mathrm{MDH}$ units
Figure B2: Development of apartment building 1.

Figure B3: Development of apartment building 1 unit planning.

Figure C1: Development of apartment building 1.

Figure C2: Development of lane-way.

Figure D1: Development of landscape paving.

Figure D2: Development of landscape concepts. 


\section{List of Appendices}

Appendix A: Hand drawn unit development and concepts.

Appendix B: CAD drawn unit exploration.

Appendix C: Apartment and unit development process images.

Appendix D: Landscape concept planning.

Appendix E: Average RV for MDH in Wellington.

Appendix F: Life cycle analysis.

Appendix G: Design Navigator R-value tables

Appendix H: BRANZ Calculation method work sheets.

Appendix I: All unit typology window and wall quantities.

Appendix J: Cost analysis material breakdown.

Appendix K: 2 bedroom and 4 bedroom unit cost analysis. 
Appendix A: Hand drawn unit development and concepts.
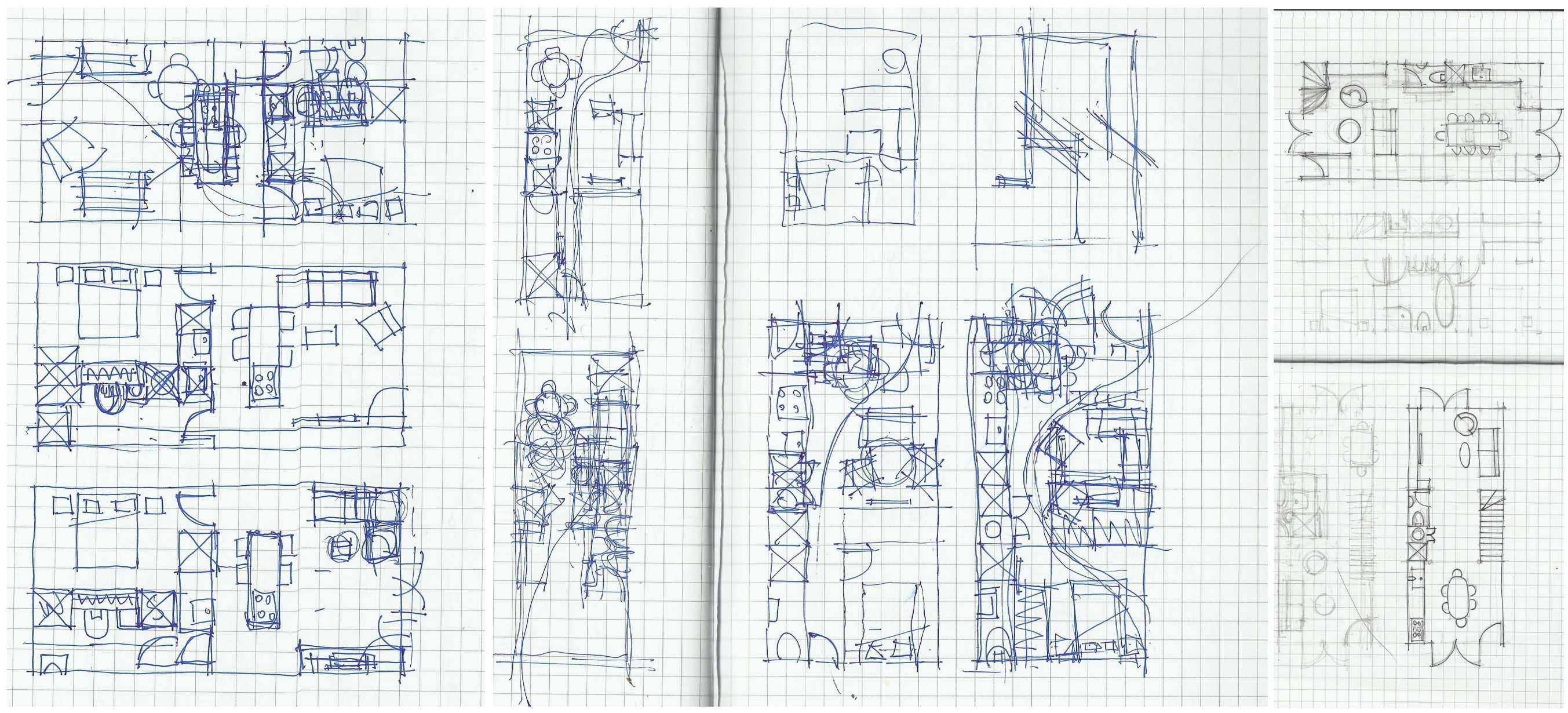

Figure A1: Development of circulation spaces through units. 


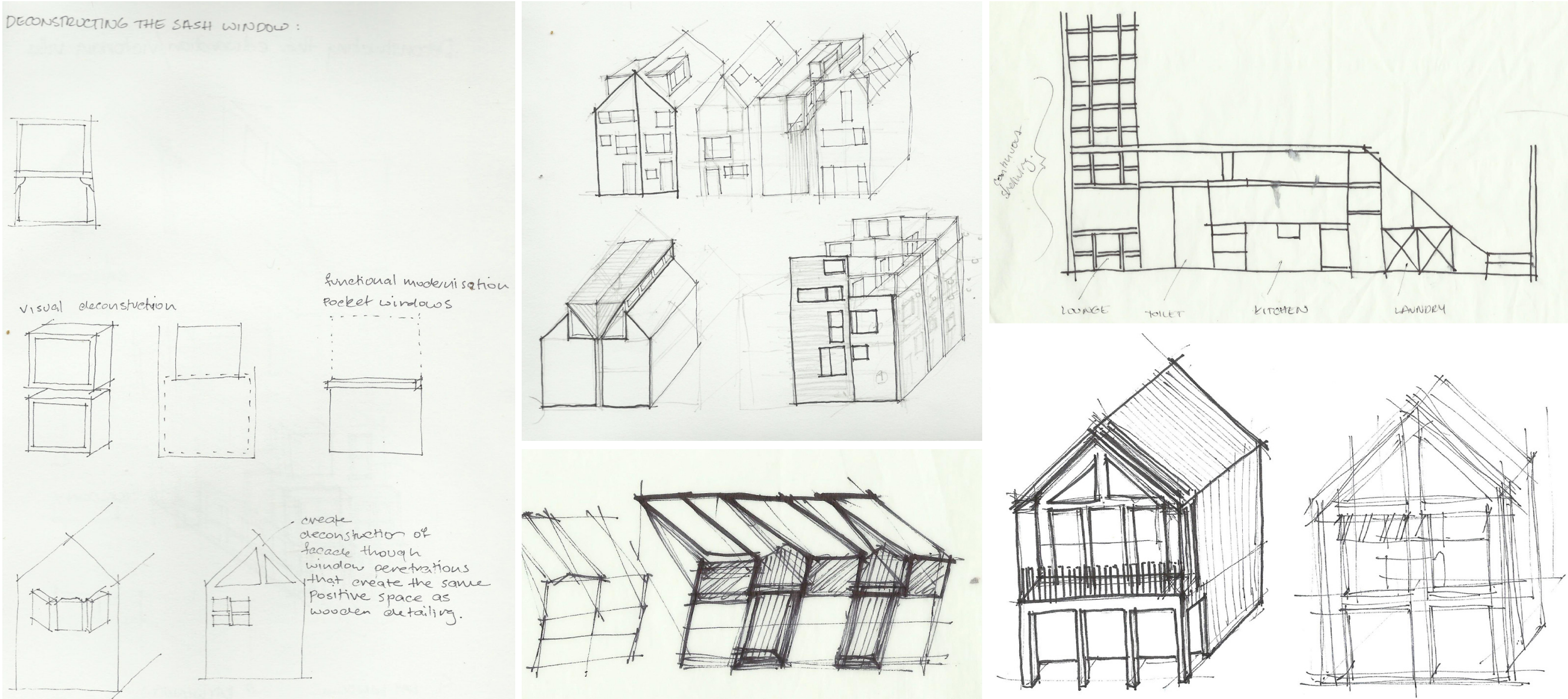

Figure A2: Development of de-constructed villa ideas. 
Appendix B: CAD drawn unit exploration.
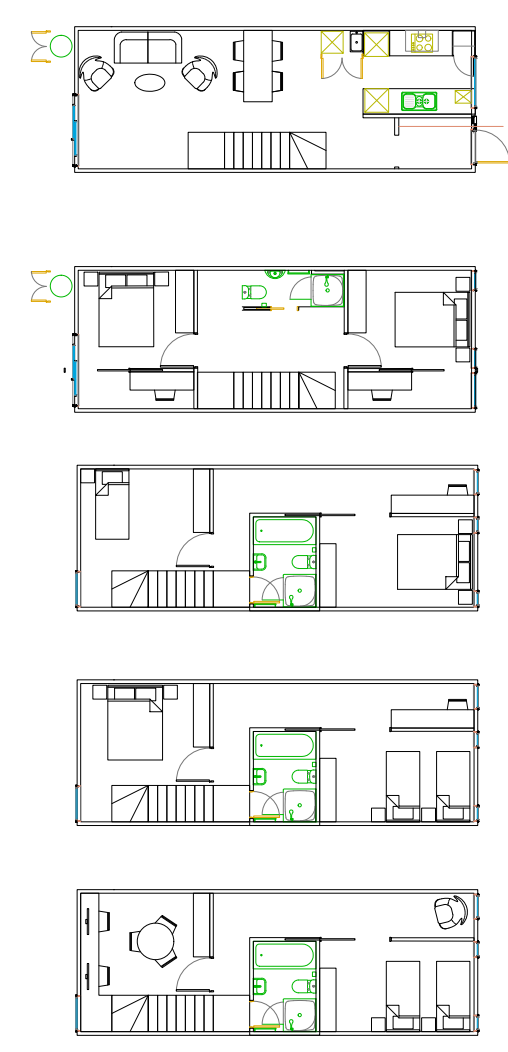

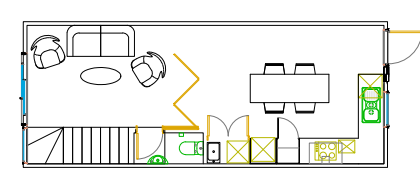

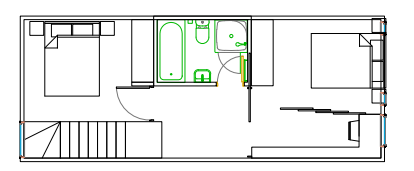

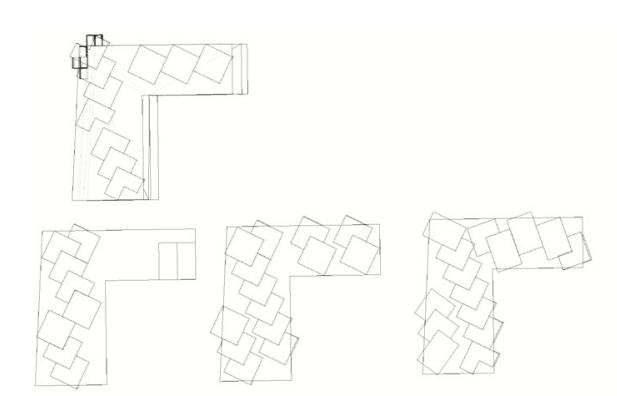
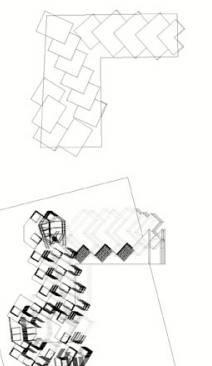

apartment building 1.
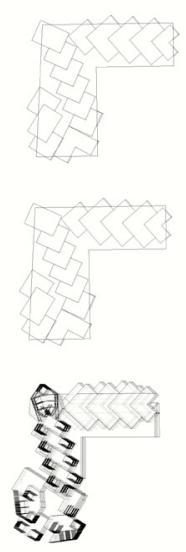


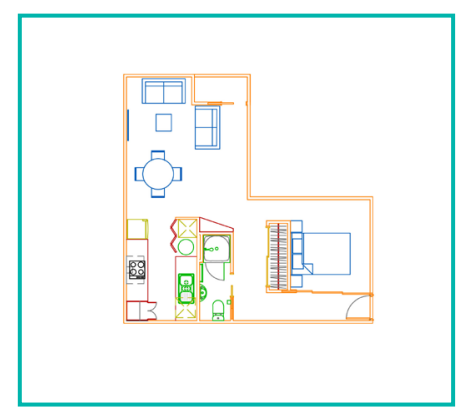

! bed apartment
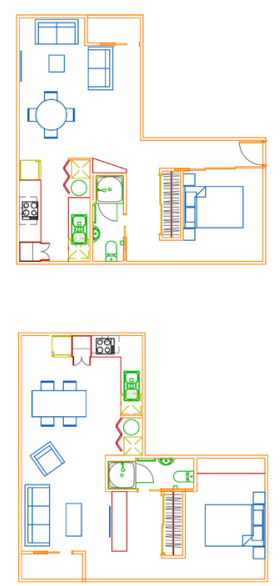

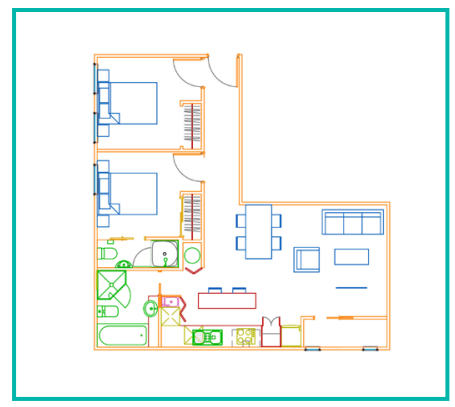

2 bed apartment
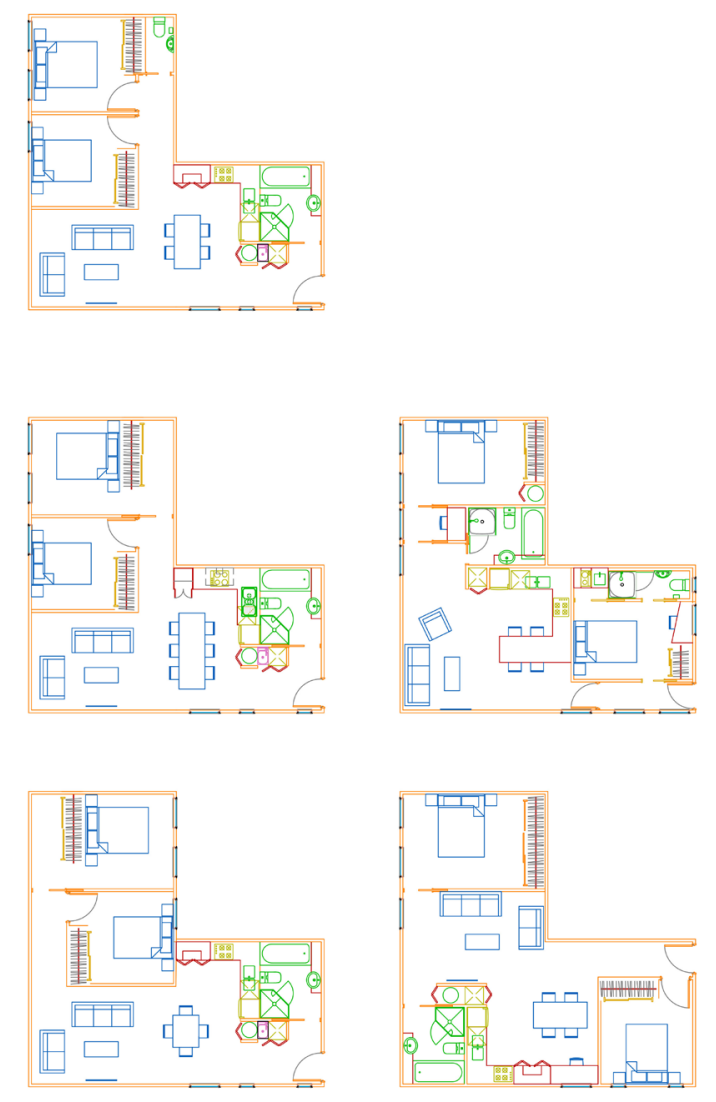
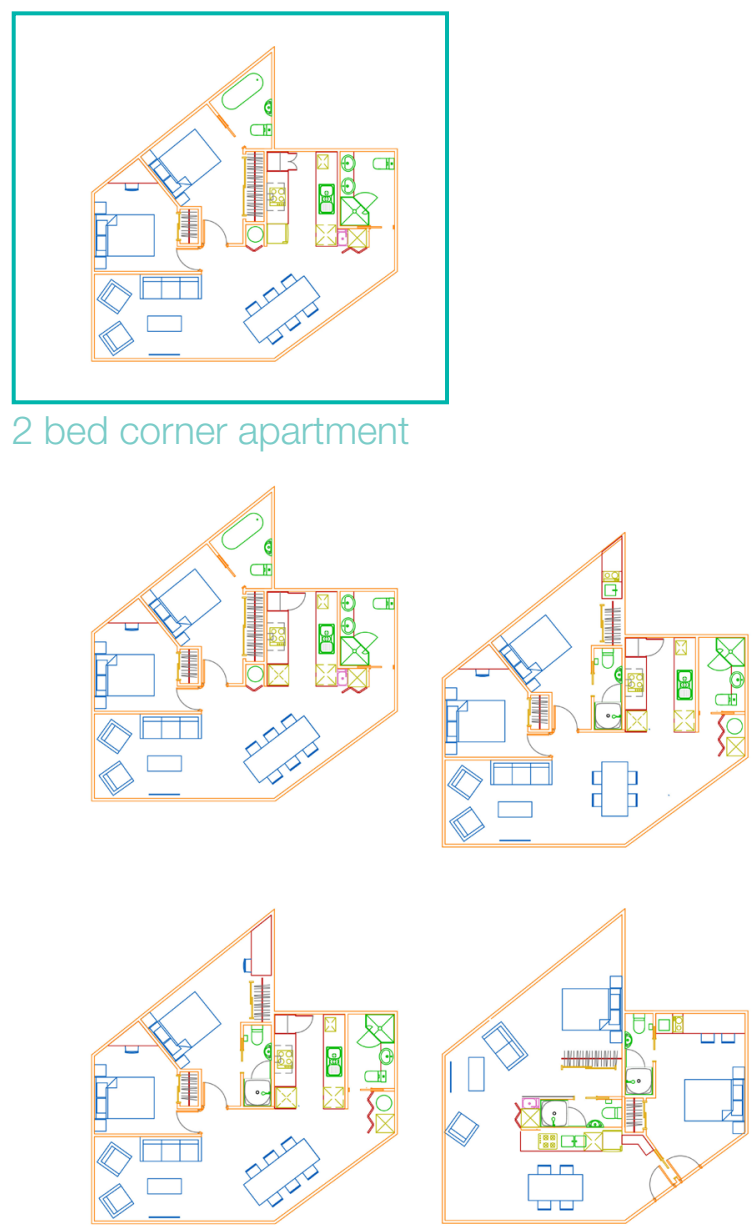

Figure B3: Development of apartment building 1 unit planning. 
Appendix C: Apartment and unit development process images.
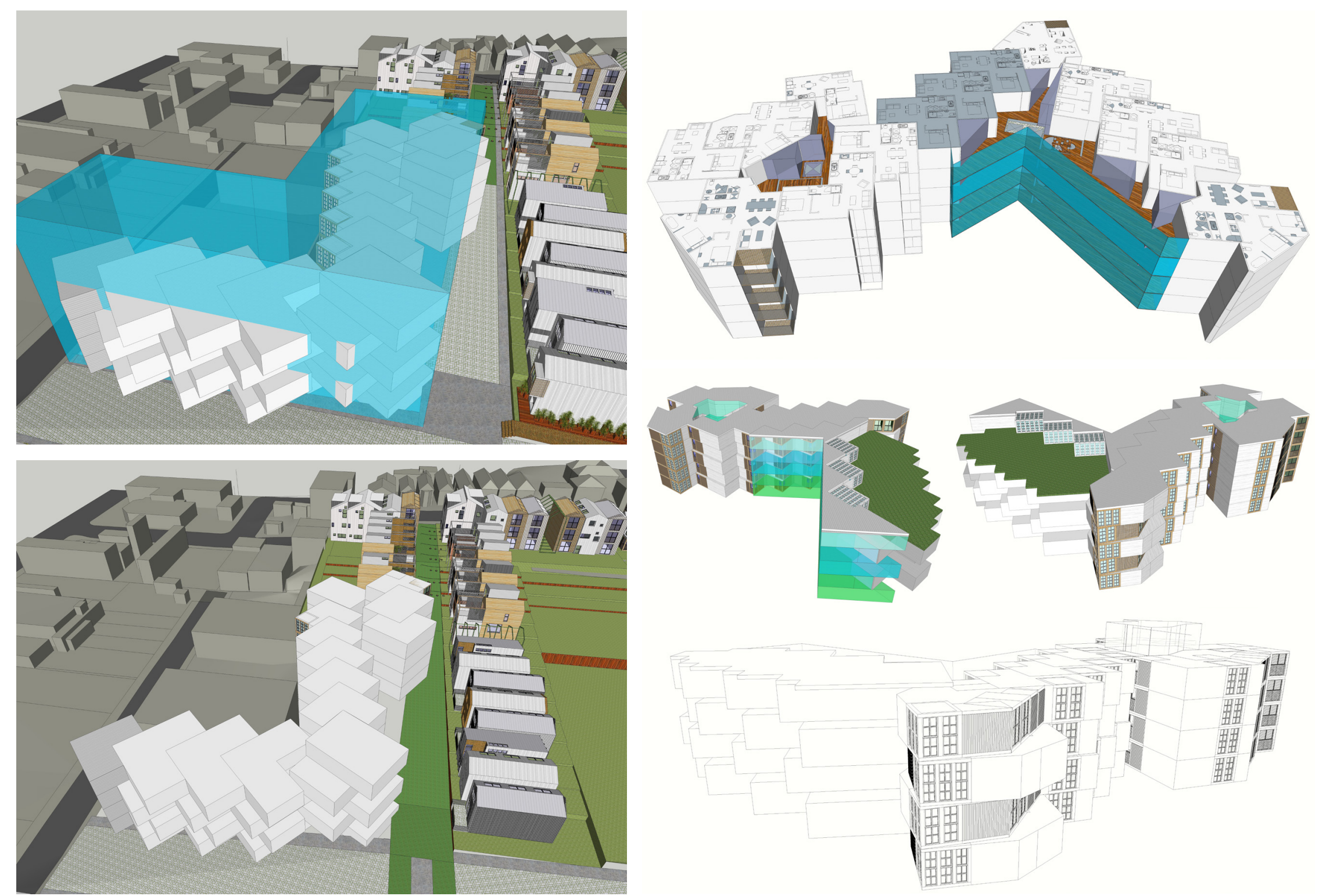

Figure C1: Development of apartment building 1 


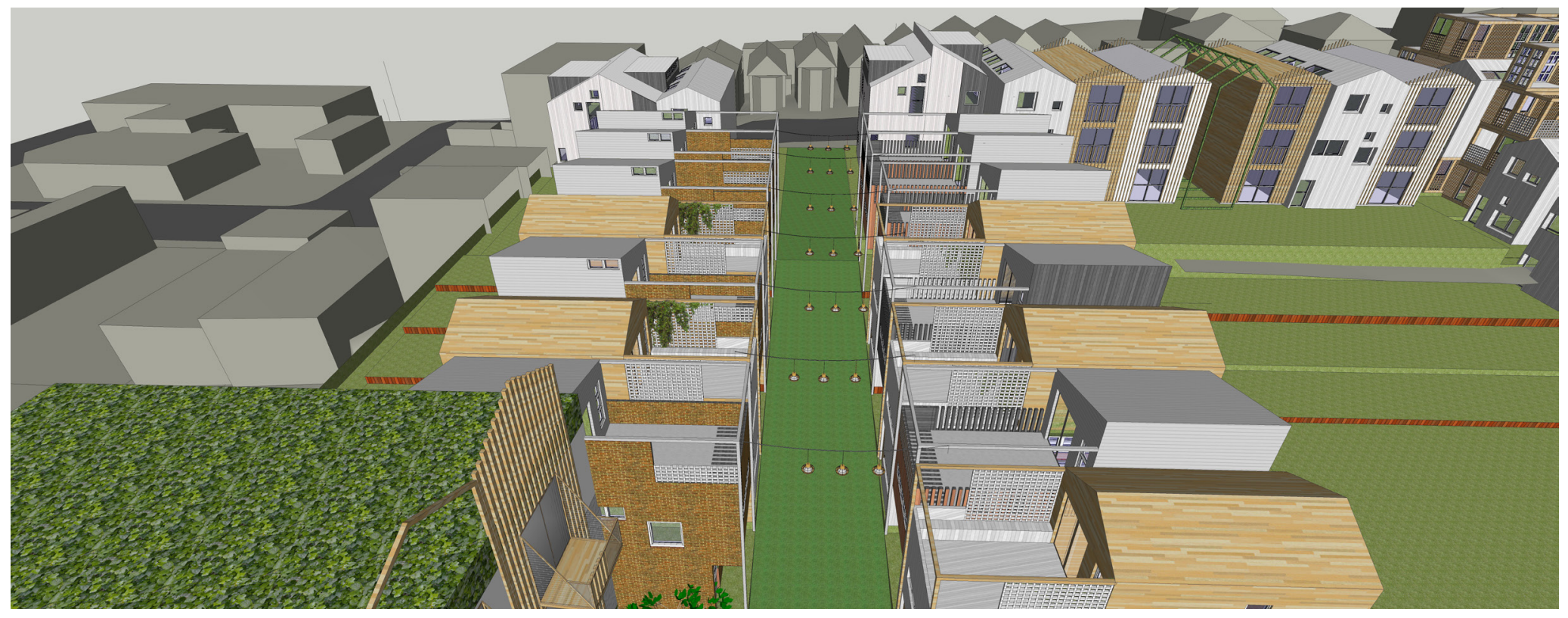

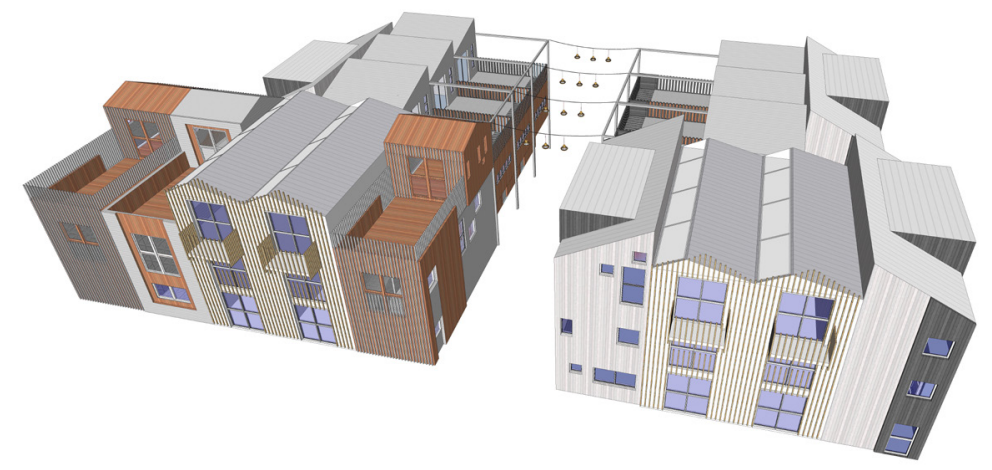

Figure C2: Development of lane-way.

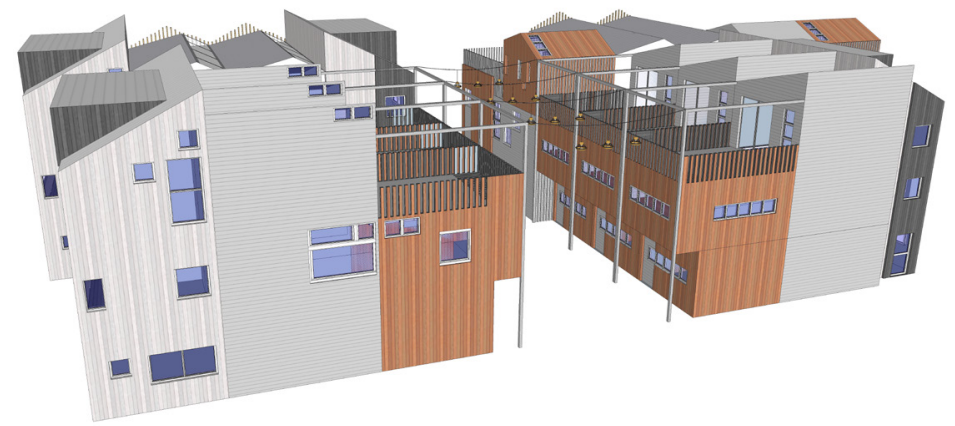


Appendix D: Landscape concept planning.
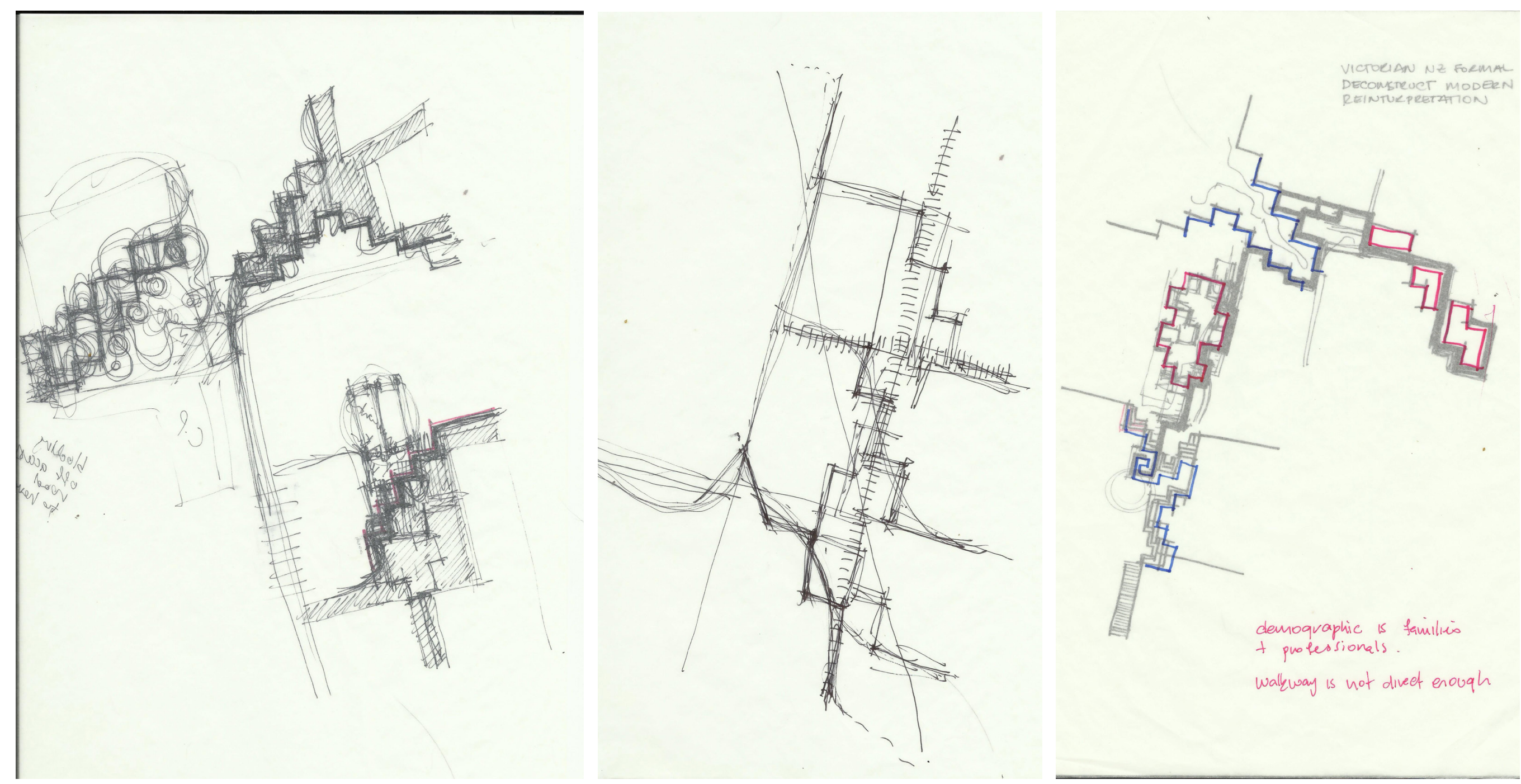

Figure D1: Development of landscape paving. 

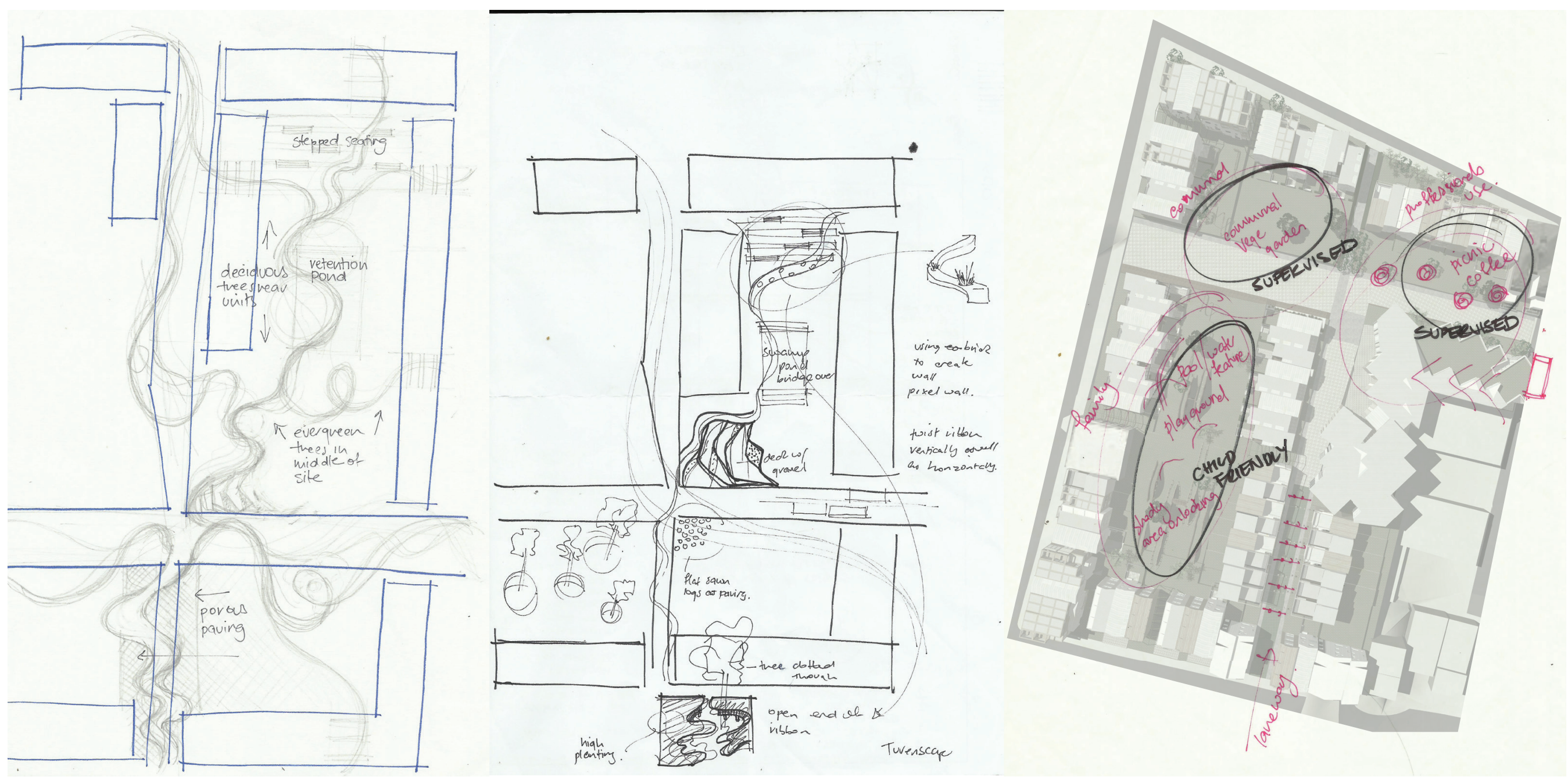

Figure D2: Development of landscape concepts. 
Appendix E: Average RV for MDH in Wellington.

\begin{tabular}{|c|c|c|c|c|c|}
\hline Street number & \multicolumn{2}{|l|}{ Street } & Bed & RV & Average RV \\
\hline $58 / 120$ & Rintoul st & Newtown & 3 & 675,000 & \multirow{3}{*}{666.667} \\
\hline $70 / 120$ & Rintoul st & Newtown & 3 & 670,000 & \\
\hline $51 / 120$ & Rintoul st & Newtown & 3 & 655,000 & \\
\hline $6 / 88$ & Brougham st & Mt Vic & 3 & 640,000 & \multirow{3}{*}{660,000} \\
\hline $3 / 88$ & Brougham st & Mt Vic & 3 & 710,000 & \\
\hline $10 / 88$ & Brougham st & Mt Vic & 3 & 630,000 & \\
\hline $17 / 26$ & Wright st & Mt Cook & 3 & 760,000 & \multirow{3}{*}{785,000} \\
\hline $3 / 26$ & Wright st & Mt Cook & 3 & 825,000 & \\
\hline $9 / 26$ & Wright st & Mt Cook & 3 & 770,000 & \\
\hline & & & & & 703,889 \\
\hline $30 / 31$ & Princess tce & Newtown & 2 & 525,000 & \multirow{3}{*}{477,476} \\
\hline $33 / 31$ & Princess tce & Newtown & 2 & 468,430 & \\
\hline $34 / 31$ & Princess tce & Newtown & 2 & 439,000 & \\
\hline $1 / 20$ & Thompson st & Mt Cook & 2 & 525,000 & \multirow{3}{*}{496,667} \\
\hline $2 / 20$ & Thompson st & Mt Cook & 2 & 480,000 & \\
\hline $5 / 20$ & Thompson st & Mt Cook & 2 & 485,000 & \\
\hline $1 / 24$ & Hanson st & Mt Cook & 2 & 510,000 & \multirow{3}{*}{535,333} \\
\hline $8 / 24$ & Hanson st & Mt Cook & 2 & 576,000 & \\
\hline $10 / 24$ & Hanson st & Mt Cook & 2 & 520,000 & \\
\hline & & & & & 494,158 \\
\hline $10 / 15$ & Roxburgh st & Mt Vic & 4 & 840,000 & \multirow{3}{*}{840,000} \\
\hline $12 / 15$ & Roxburgh st & Mt Vic & 4 & 840,000 & \\
\hline $11 / 15$ & Roxburgh st & Mt Vic & 4 & 840,000 & \\
\hline $1 / 45$ & Bidwill st & Mt Cook & 4 & 660,000 & \multirow{3}{*}{650,000} \\
\hline $2 / 45$ & Bidwill st & Mt Cook & 4 & 630,000 & \\
\hline $3 / 45$ & Bidwill st & Mt Cook & 4 & 660,000 & \\
\hline $3 / 77$ & Abel smith st & Te Aro & 4 & 795,000 & \multirow{3}{*}{785,000} \\
\hline $10 / 77$ & Abel smith st & Te Aro & 4 & 805,000 & \\
\hline \multirow[t]{2}{*}{$1 / 77$} & Abel smith st & Te Aro & 4 & 755,000 & \\
\hline & & & & & 761,000 \\
\hline
\end{tabular}

Table E: RV averages for feasibility study. Retrieved from https://homes.co.nz/app/

homes/cluster/cluster_-41d29575x174d77221 Copright 2017 PropertyNZ Ltd. 


\section{Appendix F: Life cycle analysis LCA.}

\begin{tabular}{|c|c|c|c|c|c|c|}
\hline \multicolumn{2}{|c|}{ Cost comparison on specific building components } & \multicolumn{2}{|c|}{ environmental impact (operational energy) $=+$ or -} & \multicolumn{3}{|c|}{ Co2 footprint (kg Co2 e) } \\
\hline Type & Building component & thermal conductivity $(\mathrm{W} / \mathrm{mK})$ & insulation value $R$-value $(\mathrm{m} 2 \mathrm{~K} / \mathrm{W})$ & Embodied energy-MJ/Ks & Embodied Carbon- $\mathrm{kgCO} / \mathrm{k}$ & transportation \\
\hline \multicolumn{7}{|l|}{ Exterior walls, exterior finish } \\
\hline \multicolumn{7}{|l|}{ traditional } \\
\hline & brick veneer cladding $33 \%$ & & R0.11 (inspectapedia) & Clay brick 3 [ICE Chart] & Clay brick 0.23 [ICE Chart] & NZ made \\
\hline \multicolumn{7}{|l|}{ sustainable } \\
\hline \multirow[t]{2}{*}{ timber shingles $67 \%$ Unit type 2} & radiata pine & $\begin{array}{l}0.12 \mathrm{~W} / \mathrm{m} 2 \\
\text { (http://www.nzwood.co.nz/wp- } \\
\text { content/uploads/2013/06/rvalue.pdf) }\end{array}$ & R0.94 (inspectapedia) & sawn softwood (virgin) 7.4 [ICE chart & $\begin{array}{l}\text { sawn softwood (virgin) } 0.58 \text { [ICE } \\
\text { Chart] }\end{array}$ & NZ made \\
\hline & wallaba & & R0.94 (inspectapedia) & $\begin{array}{l}\text { sawn hardwood (virgin) } 10.40 \text { [ICE } \\
\text { chart] }\end{array}$ & $\begin{array}{l}\text { sawn hardwood (virgin) } 0.86 \text { [ICE } \\
\text { chart] }\end{array}$ & $\begin{array}{l}\text { guyaana south america shipping } \\
\text { direct to NZ, truck to site }\end{array}$ \\
\hline $\begin{array}{l}\text { plywood board and battern type } 2 \\
33 \% \text { and } 333 \%\end{array}$ & macrocarpa & & R1.4 (inspectapedia) & plywood (virgin) 15 [ICE chart] & plywood (virgin) 1.07 [ICE chart] & NZ made forested plantation \\
\hline \multirow{3}{*}{$\begin{array}{l}\text { vertical shiplap weather boards } \\
100 \% \text { Unit type } 1\end{array}$} & macrocarpa & n/a & R0.81 (inspectapedia) & sawn softwood (virgin) 7.4 [ICE chart & $\begin{array}{l}\text { sawn softwood (virgin) } 0.58 \text { [ICE } \\
\text { Chart] }\end{array}$ & $\begin{array}{l}\text { forested plantation source, or farm } \\
\text { shelterbelts. }\end{array}$ \\
\hline & Tundra & n/a & R0.2 (ABODO email) & sawn softwood (virgin) 7.4 [ICE chart & $\begin{array}{l}\text { sawn softwood (virgin) } 0.58 \text { [ICE } \\
\text { Chart] }\end{array}$ & NZ Plantatior \\
\hline & Valcun + & $0.099 \mathrm{~W} / \mathrm{mK}$ & R1.35 (http://abodo.co.nz/wp & th sawn softwood (virgin) 7.4 [ICE chart: & $\begin{array}{l}\text { sawn softwood (virgin) } 0.58 \text { [ICE } \\
\text { Chart] }\end{array}$ & $\begin{array}{l}\text { Thermal modification is achieved } \\
\text { simply by using steam and high } \\
\text { temperatures } \\
\text { in excess of } 200 \text { degrees celsius }\end{array}$ \\
\hline
\end{tabular}

Table K1: External walls, and exterior finishes LCA. 


\begin{tabular}{|c|c|c|c|c|c|}
\hline \multicolumn{2}{|c|}{ Cost comparison on specific building components } & \multicolumn{2}{|c|}{ Toxicity } & \multicolumn{2}{|c|}{ Recyclability } \\
\hline Type & Building component & bonding methor & weather treatment/durability & biodegradability or recyclablı & life expectancy \\
\hline \multirow{2}{*}{\multicolumn{6}{|c|}{$\begin{array}{l}\text { Exterior walls, exterior finish } \\
\text { traditional }\end{array}$}} \\
\hline & & & & & \\
\hline & weatherboards $67 \%$ & cured by high presure autoclavin & $\begin{array}{l}\text { Portland cement, ground sand, } \\
\text { cellulose fibre and water. } \\
\text { (http://www.jameshardie.co.nz/asset } \\
\text { s/Upload/Linea-Weatherboard-cavity } \\
\text { fixed-447-amended-Mar16.pdf }\end{array}$ & & \\
\hline & brick veneer cladding $33 \%$ & kiln fired & & $100 \%$ recyclable & \\
\hline \multicolumn{6}{|l|}{ sustainable } \\
\hline \multirow[t]{2}{*}{ timber shingles $67 \%$ Unit type 2} & radiata pine & $\begin{array}{l}\text { Kiln dried / Alkaline Copper } \\
\text { Quaternary solution under pressure }\end{array}$ & m2 & $100 \%$ biodegradeable & 15 years minimum requirements (Ema \\
\hline & wallaba & $\begin{array}{l}\text { natrurally resisant to moisture, } \\
\text { insects and decay }\end{array}$ & & 100\% biodegradeablt & 15 years minimum requirements (Ema \\
\hline $\begin{array}{l}\text { plywood board and battern type } 2 \\
33 \% \text { and } 333 \%\end{array}$ & macrocarpa & natrurally resisant to moisture, insects & $\mathrm{H} 3 \quad 0.95 \mathrm{~m} 2$ & 101.00 & \\
\hline \multirow{3}{*}{$\begin{array}{l}\text { vertical shiplap weather boards } \\
100 \% \text { Unit type } 1\end{array}$} & macrocarpa & $n / a$ & Macrocarpa heartwood durability is es & http://www.cypress-sawmill.co.nz/macrocarp & 20-30 years (http://www.nzwood.co.n: \\
\hline & Tundra & n/a & waterborne or otherapproved ropriet & $100 \%$ biodegradeable & 25 years \\
\hline & Valcun + & polyurethane adhesive- VOC, solvent & naturally durable or natural oil (Tung $\mathrm{r}$ & $100 \%$ biodegradeable & 30 years \\
\hline
\end{tabular}

Table K2: External walls, and exterior finishes LCA. 


\begin{tabular}{|c|c|c|c|c|c|c|}
\hline \multicolumn{2}{|c|}{ Cost comparison on specific building components } & \multicolumn{2}{|c|}{ environmental impact (operational energy) $=+$ or -} & \multicolumn{3}{|c|}{ Co2 footprint (kg Co2 e) } \\
\hline Type & Building component & thermal conductivity $(\mathrm{W} / \mathrm{mK})$ & insulation value $R$-value ( $\mathrm{m} 2 \mathrm{~K} / \mathrm{W}$ ) & Embodied energy-MJ/Kc & Embodied Carbon- $\mathrm{kgCO} / \mathrm{k}$ & transportation \\
\hline \multicolumn{7}{|c|}{ 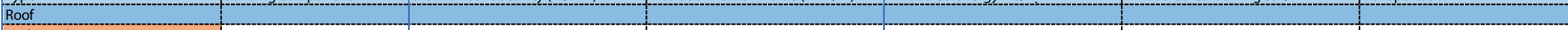 } \\
\hline \multicolumn{7}{|l|}{ traditional } \\
\hline & Sheet roofing & & R0.12 (designnavigator) & steel (virgin) 32.80 [ICE chart] & steel (virgin) 2.58 [ICE chart] & international \\
\hline & eaves \& gutters & & $0.4 \mathrm{~m}$ & zinc (virgin) 72.00 [ICE chart] & zinc (virgin) 3.90 [ICE chart] & international \\
\hline & downpipes & & $0.41 \mathrm{~m}$ & zinc (virgin) 72.00 [ICE chart] & zinc (virgin) 3.90 [ICE chart] & international \\
\hline \multicolumn{7}{|l|}{ Sustainable } \\
\hline \multirow[t]{4}{*}{ timber shingles } & radiata pine shingles & & R0.94 (inspectapedia) & sawn softwood (virgin) 7.4 [ICE chart & $\begin{array}{l}\text { sawn softwood (virgin) } 0.58 \text { [ICE } \\
\text { Chart] }\end{array}$ & NZ made \\
\hline & wallaba shingles & n/a & R0.94 (inspectapedia) & $\begin{array}{l}\text { sawn hardwood (virgin) } 10.40 \text { [ICE } \\
\text { chart] } 108.61\end{array}$ & $\begin{array}{l}\text { sawn hardwood (virgin) } 0.86 \text { [ICE } \\
\text { chart] }\end{array}$ & $\begin{array}{l}\text { guyaana south america shipping } \\
\text { direct to NZ, truck to site }\end{array}$ \\
\hline & eaves \& gutters & & $0.54 \mathrm{~m}$ & copper (recycled) 16.5 [ICE Chart] & copper (recycled) 0.80 [ICE Chart] & international \\
\hline & downpipes & & $0.4 \mathrm{~m}$ & copper (recycled) 16.5 [ICE Chart] & copper (recycled) 0.80 [ICE Chart] & international \\
\hline
\end{tabular}




\begin{tabular}{|c|c|c|c|c|c|}
\hline \multicolumn{2}{|c|}{ Cost comparison on specific building components } & \multicolumn{2}{|c|}{ Toxicity } & \multicolumn{2}{|c|}{ Recyclability } \\
\hline Type & Building component & bonding methor & weather treatment/durability & biodegradability or recyclabli & life expectancy \\
\hline \multicolumn{6}{|c|}{ 10-1 } \\
\hline \multicolumn{6}{|l|}{ traditional } \\
\hline & Sheet roofing & & $\begin{array}{l}\text { coated coated with a } 45 \% \text { zinc, } \\
55 \% \text { aluminium alloy } \\
\text { (http://www.colorsteel.co.nz/produc } \\
\text { ts/colorsteel-endura/) }\end{array}$ & 107.34 & \\
\hline & eaves \& gutters & $n / r$ & $\mathrm{n} / \mathrm{r}$ & 93.82 & \\
\hline & downpipes & $n / r$ & $\mathrm{n} / \mathrm{r} \quad 0.41 \mathrm{~m}$ & 168.96 & \\
\hline Sustainable & & & & & \\
\hline \multirow[t]{4}{*}{ timber shingles } & radiata pine shingles & N/A & $\begin{array}{l}\text { Kiln dried / Alkaline Copper } \\
\text { Quaternary solution under pressure }\end{array}$ & $100 \%$ biodegradeable & $\begin{array}{l}15 \text { years minimum requirements } \\
\text { (Email from sales rep) }\end{array}$ \\
\hline & wallaba shingles & N/A & $\begin{array}{l}\text { natrurally resisant to moisture, } \\
\text { insects and decay }\end{array}$ & $100 \%$ biodegradeable & $\begin{array}{l}15 \text { years minimum requirements } \\
\text { (Email from sales rep) }\end{array}$ \\
\hline & eaves \& gutters & $n / r$ & $\mathrm{n} / \mathrm{r} \quad 0.54 \mathrm{~m}$ & 112.00 & \\
\hline & downpipes & $n / r$ & $0.4 \mathrm{~m}$ & 132.00 & \\
\hline
\end{tabular}




\begin{tabular}{|c|c|c|c|c|c|}
\hline \multicolumn{2}{|c|}{ Cost comparison on specific building components } & \multicolumn{2}{|c|}{ environmental impact (operational energy) $=+$ or -} & \multicolumn{2}{|r|}{ Co2 footprint (kg Co2 e) } \\
\hline Type & Building component & thermal conductivity $(\mathrm{W} / \mathrm{mK})$ & insulation value R-value (m2K/W) & Embodied energy-MJ/Kg & Embodied Carbon- $\mathrm{kgCO} / \mathrm{kg}$ \\
\hline \multicolumn{6}{|l|}{ Windows and Exterior Doors } \\
\hline & aluminium double glazed & n/a & $\begin{array}{l}\text { Ro.25 } \\
\text { http://www.level.org.nz/passive- } \\
\text { design/glazing-and-glazing- } \\
\text { units/glazing-options-for-temperature. } \\
\text { control/) } \\
560.00\end{array}$ & $\begin{array}{l}\text { aluminium framed } 5470 \mathrm{MJ} \text { per } \\
\text { window [ICE chart] }\end{array}$ & aluminium framed 279 [ICE chart] \\
\hline \multicolumn{6}{|l|}{ sustainable } \\
\hline & timber and recycled aluminium composite double glazed & & $\begin{array}{l}\text { Ro.30 } \\
\text { http://www.level.org.nz/passive- } \\
\text { design/glazing-and-glazing- } \\
\text { units/glazing-options-for-temperature. } \\
\text { control/) }\end{array}$ & $\begin{array}{l}\text { aluminium- clad timber framed } 950- \\
1460 \text { MJ per window [IICE chart] }\end{array}$ & $\begin{array}{l}\text { aluminium- clad timber framed } 48-75 \\
\text { [ICE chart] }\end{array}$ \\
\hline & timber double glazied & $n / a$ & $\begin{array}{l}\text { Ro.34 } \\
\text { (http://www.level.org.nz/passive- } \\
\text { design/glazing-and-glazing- } \\
\text { units/glazing-options-for-temperature. } \\
\text { control/) } \quad 785.00\end{array}$ & $\begin{array}{l}\text { timber framed } 230-490 \mathrm{MJ} \text { per } \\
\text { window [ICE chart] }\end{array}$ & timber framed 12-25 [ICE chart] \\
\hline
\end{tabular}


environmental impact (operational energy) $=+$ or

thermal conductivity $(\mathrm{W} / \mathrm{mK}) \quad$ insulation value R-value (m2K/W)

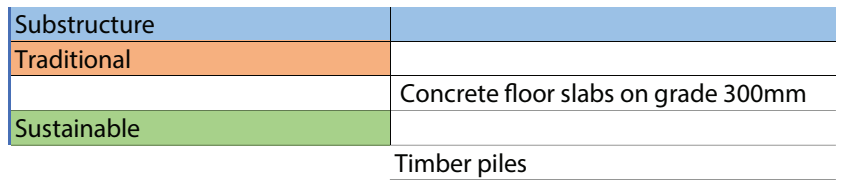

Timber piles

\begin{tabular}{|l|l|}
\hline interior finishes & \\
\hline traditional & \\
\hline \multirow{2}{*}{ floor finishes } & bedroom floor finishes \\
\hline & living floor finishes \\
\hline \multirow{2}{*}{ wall finishes } & pathroom floor finishes \\
\hline & intertenancy weall finishes \\
\hline & bathroom and kitchen wall finishes \\
\hline ceiling finishes \\
\hline sustainable & fitting and fixtures \\
\hline \multirow{2}{*}{ floor finishes } & \\
\hline \multirow{5}{*}{ wall finishes } & bedroom floor finishes \\
\hline & living flor finishes \\
\hline & bathroom floor finishes \\
\hline & partition wall finishes \\
\hline & intertenancy wall finishes \\
\hline & \\
\hline & bathroom and kitchen wall finishes \\
\hline & ceiling finishes \\
\hline & fitting and fixtures \\
\hline &
\end{tabular}

Table K6: Substructure and internal finishes LCA.

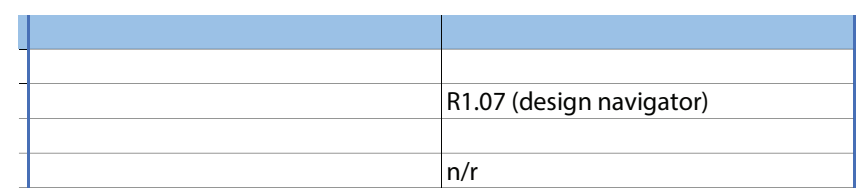

environmental impact (operational energy) $=+$ or

\begin{tabular}{|l|l|}
\hline thermal conductivity (W/ mK) & insulation value R-value (m2K/W) \\
\hline \hline & \\
\hline & \\
\hline & R0.06 (XLAM) \\
\hline & R0.06 (XLAM) \\
\hline & R0.06 (XLAM) \\
\hline & $R 0.06$ (XLAM) \\
\hline & \\
\hline & $R 0.06$ (XLAM) \\
\hline & $R 0.06$ (XLAM) \\
\hline & \\
\hline & $R 0.06$ (XLAM) \\
\hline & \\
\hline & \\
\hline & \\
\hline & \\
\hline & \\
\hline
\end{tabular}




\begin{tabular}{|c|c|c|c|c|c|c|}
\hline \multicolumn{2}{|c|}{ Cost comparison on specific building components } & \multicolumn{2}{|c|}{ environmental impact (operational energy) $=+$ or -} & \multicolumn{3}{|c|}{ Co2 footprint (kg Co2 e) } \\
\hline Type & Building component & thermal conductivity $(\mathrm{W} / \mathrm{mK})$ & insulation value R-value ( $\mathrm{m} 2 \mathrm{~K} / \mathrm{W}$ ) & Embodied energy-MJ/Kc & Embodied Carbon- $\mathrm{kgC0} / \mathrm{k}$ & transportation \\
\hline \multicolumn{7}{|l|}{ Frame and walls } \\
\hline \multicolumn{7}{|l|}{ traditional } \\
\hline \multirow{3}{*}{ framing } & timber wall framing & $\begin{array}{l}0.120 \mathrm{~W} / \mathrm{mK} \\
\text { (http://www.xlam.co.nz/technical.ht } \\
\mathrm{ml} \text { ) }\end{array}$ & R0.75 (design navigator) & timber (virgin) 10 [ICE chart] & timber (virgin) 0.71 [ICE chart] & NZ made \\
\hline & timber floor framing & $\begin{array}{l}0.120 \mathrm{~W} / \mathrm{mK} \\
\text { (http://www.xlam.co.nz/technical.ht } \\
\mathrm{ml} \text { ) }\end{array}$ & R0.75 (design navigator) & timber (virgin) 10 [ICE chart] & timber (virgin) 0.71 [ICE chart] & NZ made \\
\hline & timber ceiling framing & $\begin{array}{l}0.120 \mathrm{~W} / \mathrm{mK} \\
\text { (http://www.xlam.co.nz/technical.ht } \\
\mathrm{ml} \text { ) }\end{array}$ & R0.75 (design navigator) & timber (virgin) 10 [ICE chart]]. & timber (virgin) 0.71 [ICE chart] & \\
\hline \multirow{2}{*}{ insulation } & ceiling glass wool insulation & & R2.4 (ceiling) PINK BATTS & fiberglass (virgin) 28.00 [ICE Chart & fiberglass (virgin) 1.35 [ICE Chart] & NZ made \\
\hline & wall glass wool insulation & & R2.4 (wall) PINK BATTS & fiberglass (virgin) 28.00 [ICE Chart & fiberglass (virgin) 1.35 [ICE Chart] & NZ made \\
\hline \multicolumn{7}{|l|}{ Sustainable } \\
\hline & CLT panels & $\begin{array}{l}0.120 \mathrm{~W} / \mathrm{mK} \\
\text { (http://www.xlam.co.nz/technical.ht } \\
\mathrm{ml})\end{array}$ & $75-R 0.625 / 105-R 0.875 / 175-R 1.46$ & $\begin{array}{l}\text { (Using LVL for comaprison purposes) } \\
9.5 \text { [CE Chart] }\end{array}$ & $\begin{array}{l}\text { (Using LVL for comaprison purposes) } \\
0.63 \text { [IEE Chart] }\end{array}$ & $\begin{array}{l}\text { sustainably forested in NZ and } \\
\text { Australia, logging, cross cutting, finge } \\
\text { jointing, planning, layering and gluin } \\
\text { panel pressing, CNC machine cut by } \\
\text { truck from Nelson }\end{array}$ \\
\hline \multirow{3}{*}{ insulation } & wall sheeps wool insulation & & R2.4 (Green Sheep) & wool (recycled) 20.9 [ICE chart] & N/A & NZ made \\
\hline & ceiling sheeps wool insulation & & R3.2 (Green Sheep) & wool (recycled) 20.9 [ICE chart] & N/A & NZ made \\
\hline & underfloor sheeps wool insulation & & R2.0 (Green Sheep) & wool (recycled) 20.9 [ICE chart] & $\mathrm{N} / \mathrm{A}$ & NZ made \\
\hline
\end{tabular}




\begin{tabular}{|c|c|c|c|c|c|}
\hline \multicolumn{2}{|c|}{ Cost comparison on specific building components } & \multicolumn{2}{|c|}{ Toxicity } & \multicolumn{2}{|c|}{ Recyclability } \\
\hline Type & Building component & bonding method & weather treatment/durability & biodegradability or recyclable & life expectancy \\
\hline \multicolumn{6}{|l|}{ Frame and walls } \\
\hline traditional & & & & & \\
\hline \multirow{3}{*}{ framing } & timber wall framing & & $0.73 \mathrm{~m} 2$ & 119.27 & \\
\hline & timber floor framing & & & & \\
\hline & timber ceiling framing & & & & \\
\hline \multirow[t]{2}{*}{ insulation } & ceiling glass wool insulation & & & & \\
\hline & wall glass wool insulation & & & & \\
\hline \multicolumn{6}{|l|}{ Sustainable } \\
\hline & CLT panels & $\begin{array}{l}\text { glued together using Purbond HS } \\
\text { Polyurethane adhesive (see declare } \\
\text { label) }\end{array}$ & $\begin{array}{l}\text { H1.2 (Boric Acid, monothanolamine, } \\
\text { isothiazollnone derivative) (see } \\
\text { declare label) }\end{array}$ & $\begin{array}{l}\text { Salvageable/reuseable in its entirety } 100 \% \\
\text { recyclable(see declare label) }\end{array}$ & 50 years (see declare label) \\
\hline \multirow{3}{*}{ insulation } & wall sheeps wool insulation & $20 \%$ polyester for heat bonding & natural dureable and weatherproof & $100 \%$ recyclable & the building life \\
\hline & ceiling sheeps wool insulation & $20 \%$ polyester for heat bonding & natural dureable and weatherproof & $100 \%$ recyclable & the building life \\
\hline & underfloor sheeps wool insulation & $20 \%$ polyester for heat bonding & natural dureable and weatherproof & $100 \%$ recyclable & the building life \\
\hline
\end{tabular}




\section{Appendix G: Design Navigator R-value tables}

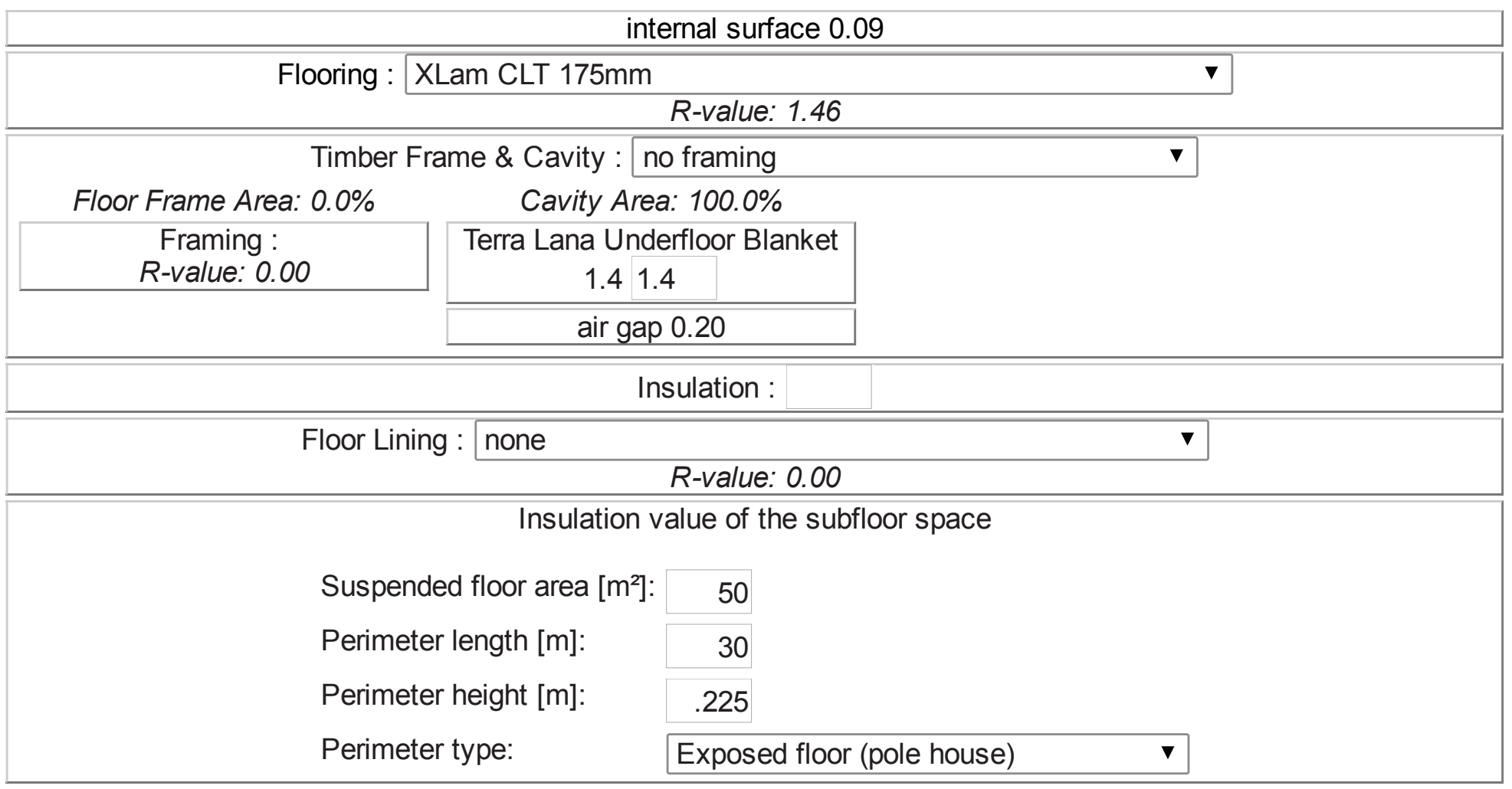

Current NZS4218/H1 Schedule minimum R-value Targets (non-solid contruction)

\begin{tabular}{|lccc|}
\hline & Zone 1 & Zone 2 & Zone 3 \\
Roof & $\mathrm{R}-2.9$ & $\mathrm{R}-2.9$ & $\mathrm{R}-3.3$ \\
Wall & $\mathrm{R}-1.9$ & $\mathrm{R}-1.9$ & $\mathrm{R}-2.0$ \\
Floor & $\mathrm{R}-1.3$ & $\mathrm{R}-1.3$ & $\mathrm{R}-1.3$ \\
Glazing (vertical) & $\mathrm{R}-0.26$ & $\mathrm{R}-0.26$ & $\mathrm{R}-0.26$ \\
Glazing (skylights) & $\mathrm{R}-0.26$ & $\mathrm{R}-0.26$ & $\mathrm{R}-0.31$ \\
\hline
\end{tabular}

Table J1: Sustainable internal wall R-Value. Adapted from from https://www.

designnavigator.co.nz/CRC.php Copyright 2016 by Design Navigator Limited. 
internal surface 0.09

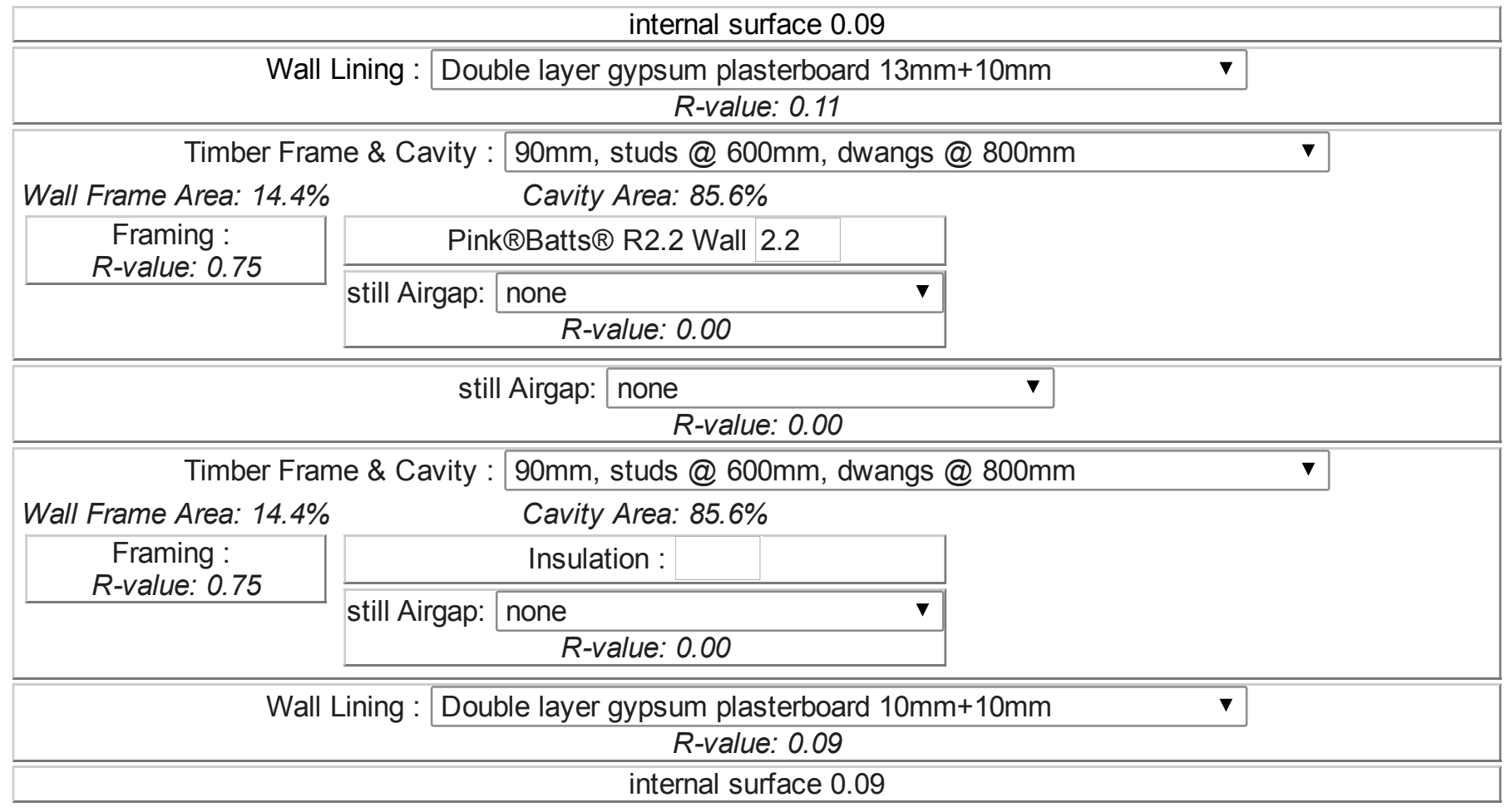

Current NZS4218/H1 Schedule minimum R-value Targets (non-solid contruction)

\begin{tabular}{|lccc|}
\hline & Zone 1 & Zone 2 & Zone 3 \\
Roof & $\mathrm{R}-2.9$ & $\mathrm{R}-2.9$ & $\mathrm{R}-3.3$ \\
Wall & $\mathrm{R}-1.9$ & $\mathrm{R}-1.9$ & $\mathrm{R}-2.0$ \\
Gloor & $\mathrm{R}-1.3$ & $\mathrm{R}-1.3$ & $\mathrm{R}-1.3$ \\
Glazing (vertical) & $\mathrm{R}-0.26$ & $\mathrm{R}-0.26$ & $\mathrm{R}-0.26$ \\
\hline
\end{tabular}

Table J2: Traditional internal wall R-Value. Adapted from https://www.

designnavigator.co.nz/CRC.php Copyright 2016 by Design Navigator Limited. 
Type: Floor: Slab floor $\mathbf{v}$

Slab floor

\begin{tabular}{|c|c|c|c|c|c|}
\hline \multicolumn{6}{|c|}{ internal surface 0.09} \\
\hline \multirow{2}{*}{\multicolumn{6}{|c|}{ Flooring : $\frac{50-100 \mathrm{~mm} \text { Concrete Topping Screed }}{R \text {-value: } 0.04}$}} \\
\hline & & & & & \\
\hline \multicolumn{6}{|c|}{ Slab Insulation } \\
\hline Slab floor area $\left[\mathrm{m}^{2}\right]$ : & 50 & & & & \\
\hline Perimeter length [m]: & 30 & & & & \\
\hline External wall thickness [mm]: & $90 \quad i$ & & & & \\
\hline Soil conductivity $\left[\mathrm{W} / \mathrm{m}^{\circ} \mathrm{C}\right]$ & $1.2 i$ & & & & \\
\hline Underslab insulation: & none & $\nabla$ & Insulation & & $i$ \\
\hline Piles Footings: & Number: & & Penetration Diameter: & & \\
\hline Slab edge insulation: & Internal $\mathbf{v}$ & & Snugfloor R1.6 & 1.6 & i \\
\hline
\end{tabular}

Current NZS4218/H1 Schedule minimum R-value Targets (non-solid contruction)

\begin{tabular}{|lccc|}
\hline & Zone 1 & Zone 2 & Zone 3 \\
Roof & $\mathrm{R}-2.9$ & $\mathrm{R}-2.9$ & $\mathrm{R}-3.3$ \\
Wall & $\mathrm{R}-1.9$ & $\mathrm{R}-1.9$ & $\mathrm{R}-2.0$ \\
Floor & $\mathrm{R}-1.3$ & $\mathrm{R}-1.3$ & $\mathrm{R}-1.3$ \\
Glazing (vertical) & $\mathrm{R}-0.26$ & $\mathrm{R}-0.26$ & $\mathrm{R}-0.26$ \\
Glazing (skylights) & $\mathrm{R}-0.26$ & $\mathrm{R}-0.26$ & $\mathrm{R}-0.31$ \\
\hline
\end{tabular}

Table J3: Traditional flooring R-Value. Adapted from from https://www.

designnavigator.co.nz/CRC.php Copyright 2016 by Design Navigator Limited. 
Type: Wall: Solid timber wall with external insulation Solid timber wall with external insulation

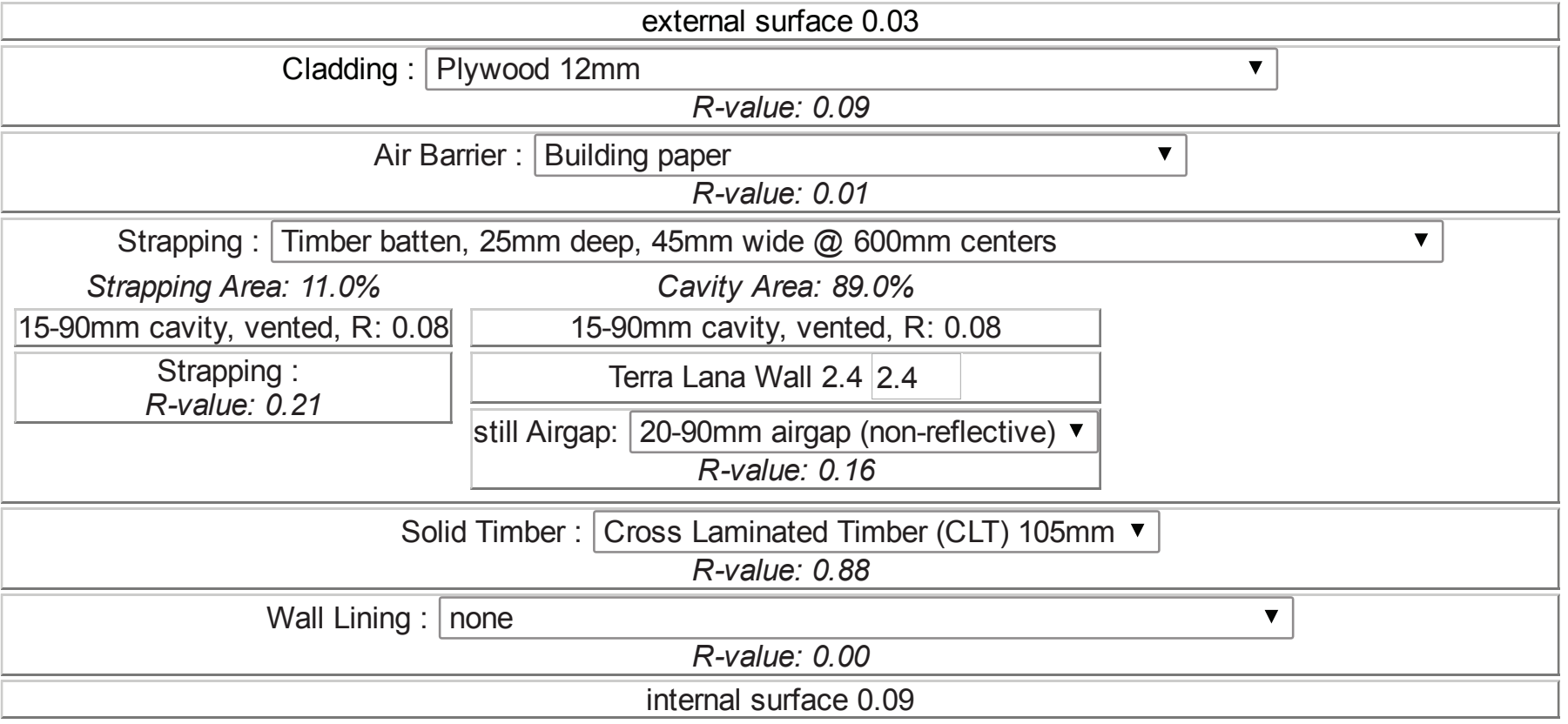

Current NZS4218/H1 Schedule minimum R-value Targets (non-solid contruction)

\begin{tabular}{|lccc|}
\hline & Zone 1 & Zone 2 & Zone 3 \\
Roof & $\mathrm{R}-2.9$ & $\mathrm{R}-2.9$ & $\mathrm{R}-3.3$ \\
Wall & $\mathrm{R}-1.9$ & $\mathrm{R}-1.9$ & $\mathrm{R}-2.0$ \\
Floor & $\mathrm{R}-1.3$ & $\mathrm{R}-1.3$ & $\mathrm{R}-1.3$ \\
Glazing (vertical) & $\mathrm{R}-0.26$ & $\mathrm{R}-0.26$ & $\mathrm{R}-0.26$ \\
Glazing (skylights) & $\mathrm{R}-0.26$ & $\mathrm{R}-0.26$ & $\mathrm{R}-0.31$ \\
\hline
\end{tabular}

Table J4: Sustainable end wall plywood R-Value. Adapted from from https://www. designnavigator.co.nz/CRC. php Copyright 2016 by Design Navigator Limited. 
Type: Wall: Timber frame with vented cavity timber frame with vented cavity

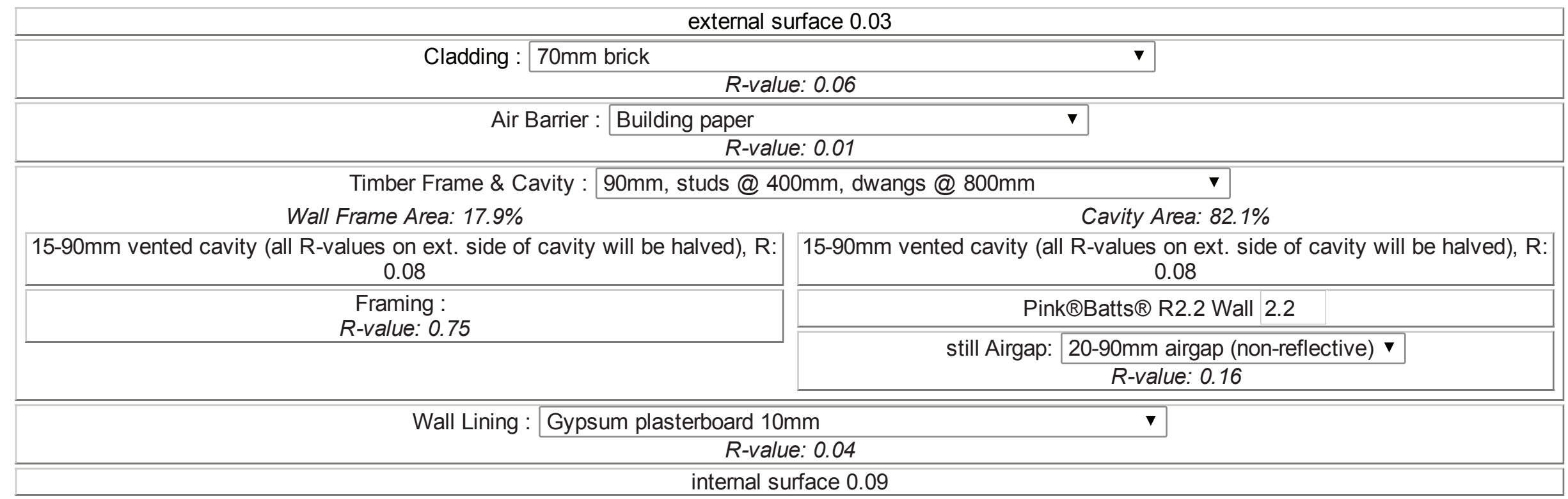

Current NZS4218/H1 Schedule minimum R-value Targets (non-solid contruction)

\begin{tabular}{|lccc|}
\hline & Zone 1 & Zone 2 & Zone 3 \\
Roof & $\mathrm{R}-2.9$ & $\mathrm{R}-2.9$ & $\mathrm{R}-3.3$ \\
Wall & $\mathrm{R}-1.9$ & $\mathrm{R}-1.9$ & $\mathrm{R}-2.0$ \\
Floor & $\mathrm{R}-1.3$ & $\mathrm{R}-1.3$ & $\mathrm{R}-1.3$ \\
Glazing (vertical) & $\mathrm{R}-0.26$ & $\mathrm{R}-0.26$ & $\mathrm{R}-0.26$ \\
Glazing (skylights) & $\mathrm{R}-0.26$ & $\mathrm{R}-0.26$ & $\mathrm{R}-0.31$ \\
\hline
\end{tabular}

Table J5: Traditional end wall R-Value. Adapted from https://www. 
Type: Wall: Solid timber wall with external insulation

Solid timber wall with external insulation

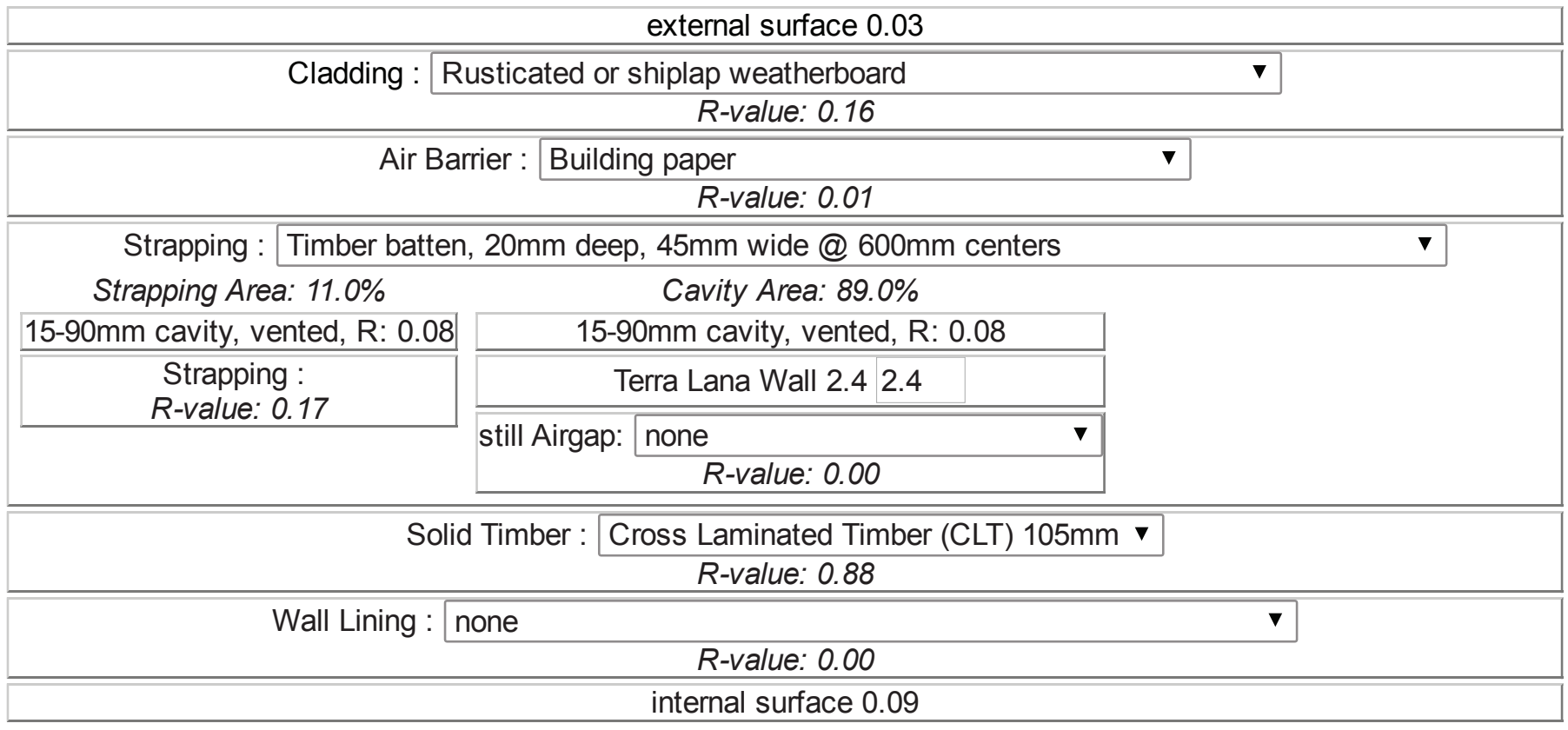

Current NZS4218/H1 Schedule minimum R-value Targets (non-solid contruction)

\begin{tabular}{|lccc|}
\hline & Zone 1 & Zone 2 & Zone 3 \\
Roof & $\mathrm{R}-2.9$ & $\mathrm{R}-2.9$ & $\mathrm{R}-3.3$ \\
Wall & $\mathrm{R}-1.9$ & $\mathrm{R}-1.9$ & $\mathrm{R}-2.0$ \\
Floor & $\mathrm{R}-1.3$ & $\mathrm{R}-1.3$ & $\mathrm{R}-1.3$ \\
Glazing (vertical) & $\mathrm{R}-0.26$ & $\mathrm{R}-0.26$ & $\mathrm{R}-0.26$ \\
Glazing (skylights) & $\mathrm{R}-0.26$ & $\mathrm{R}-0.26$ & $\mathrm{R}-0.31$ \\
\hline
\end{tabular}


Appendix H: BRANZ Calculation method work sheets.
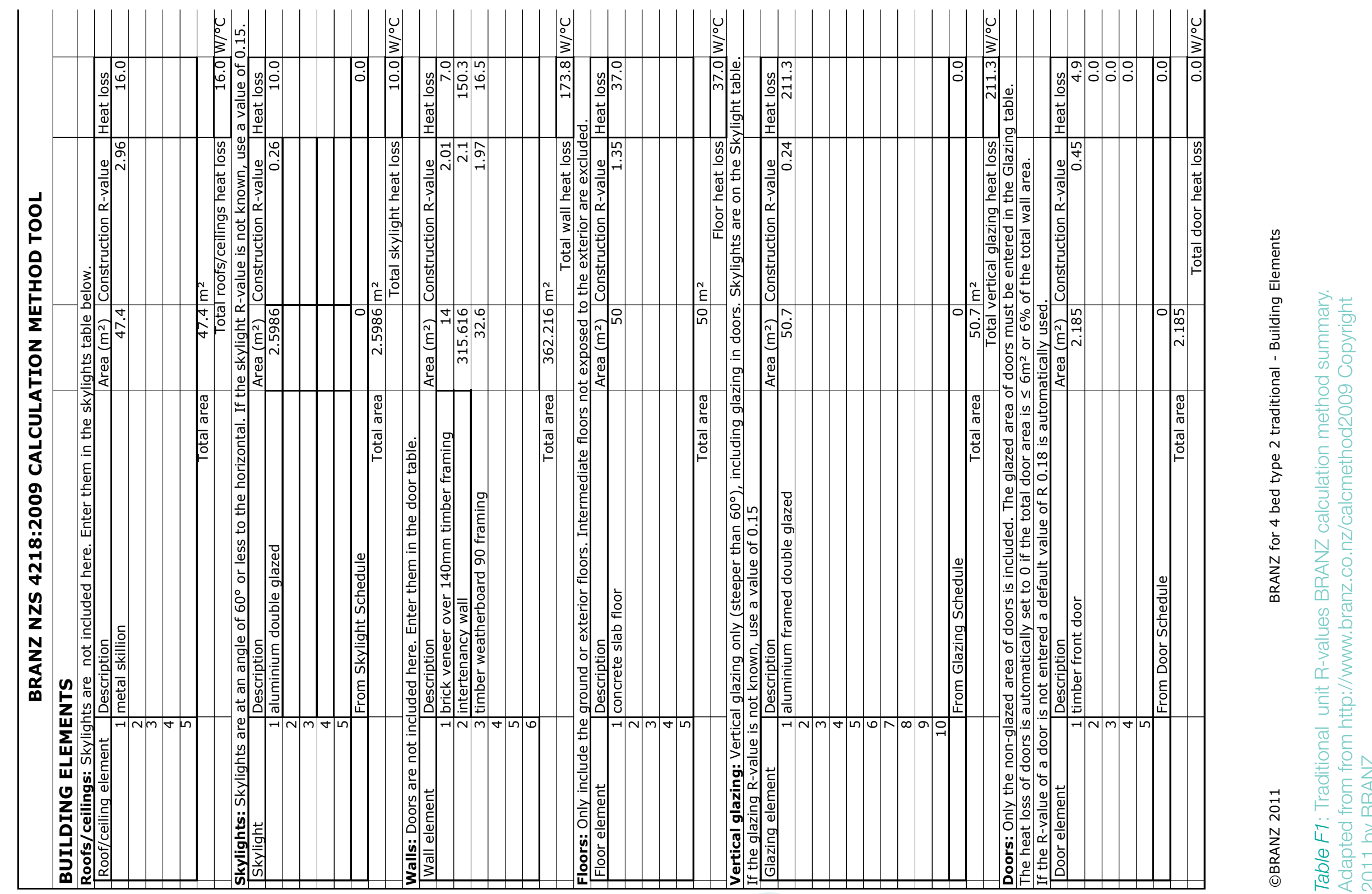

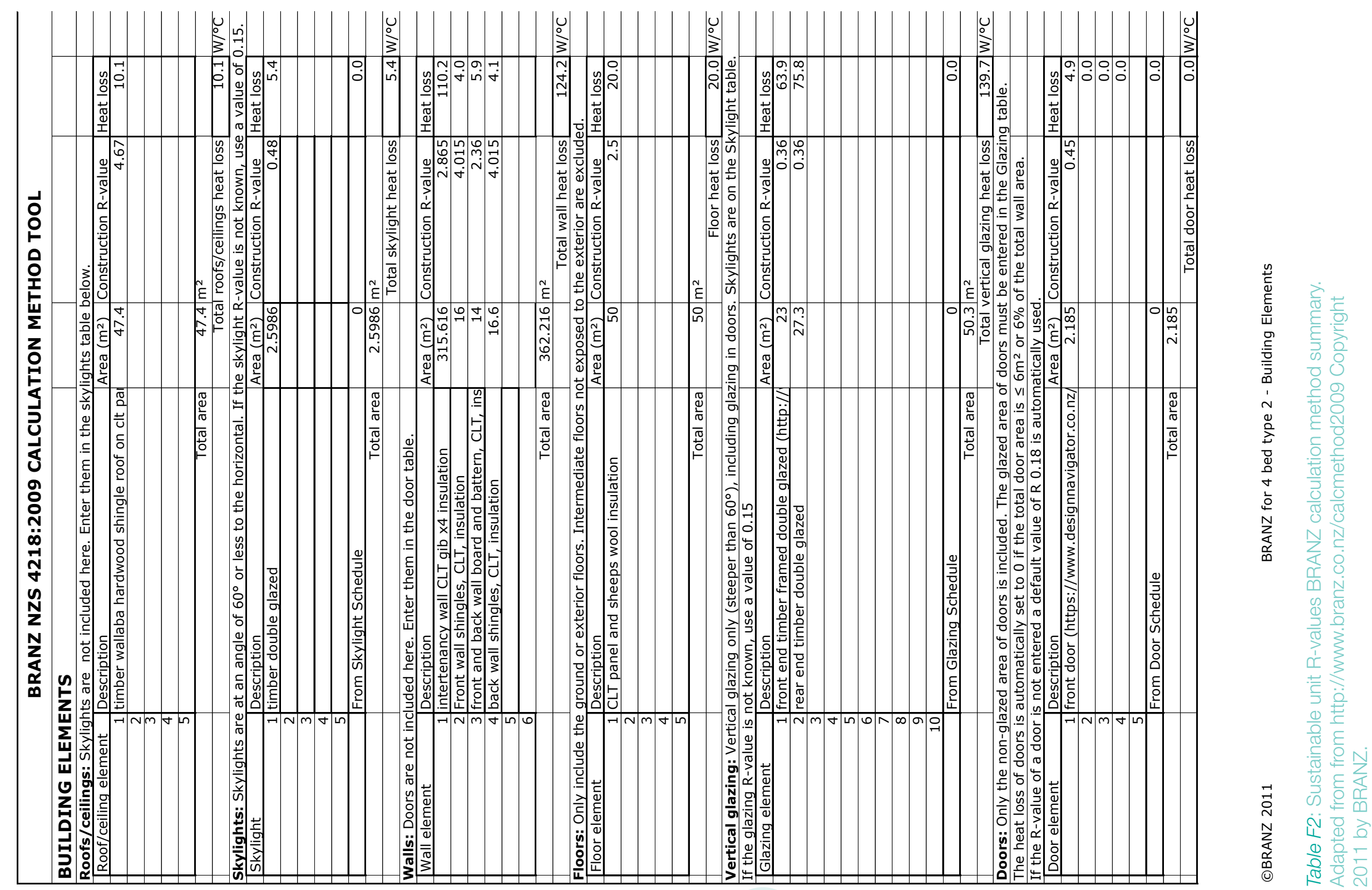
Appendix I: All unit typology window and wall quantities.

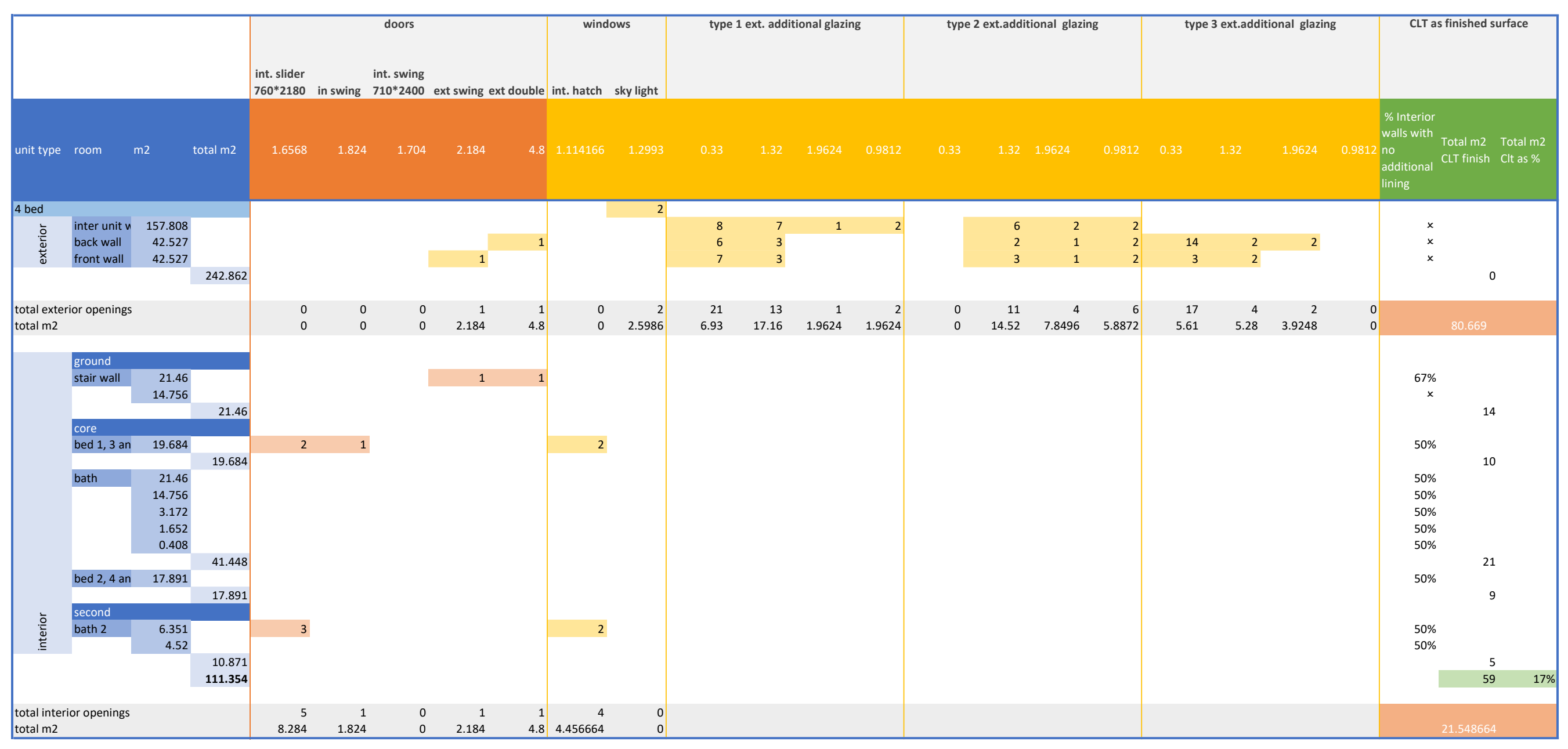

Table G1: 4 bedroom quantities. 


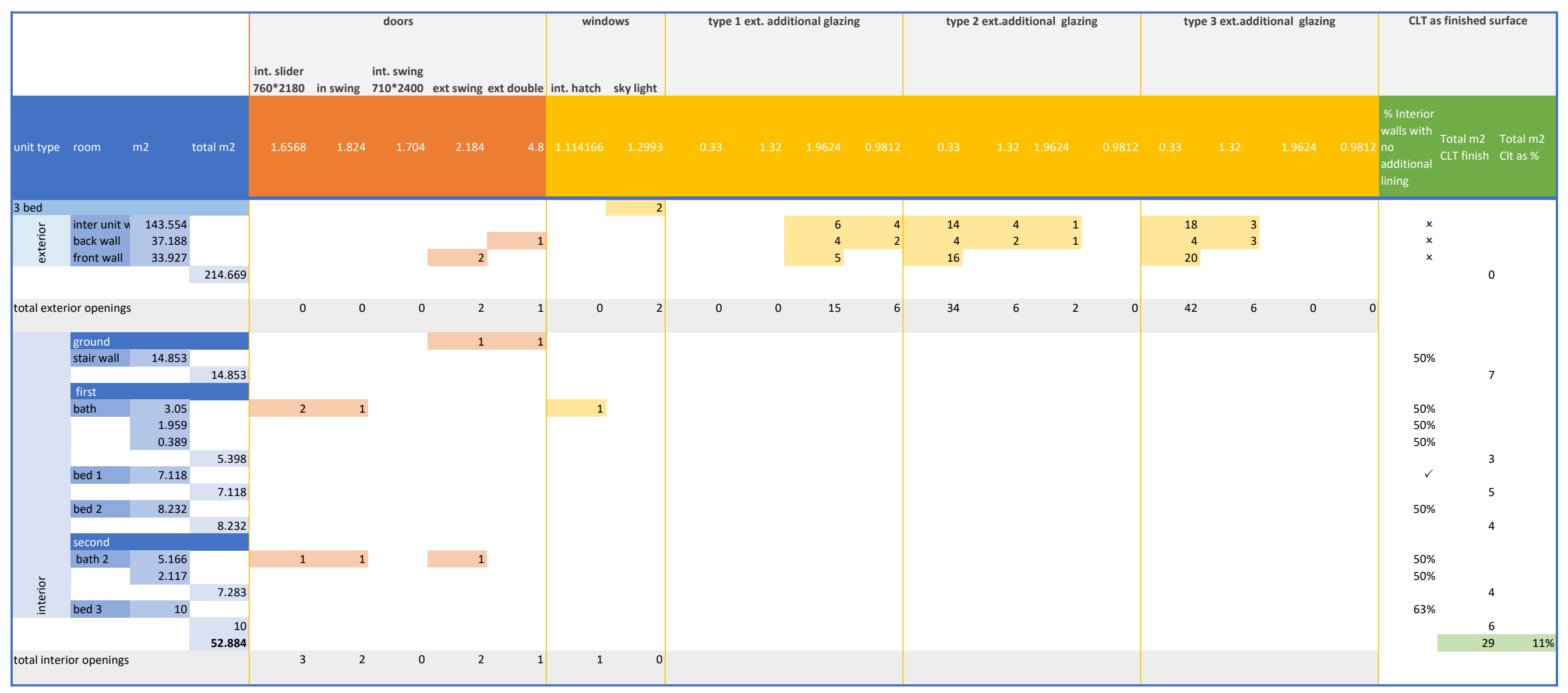




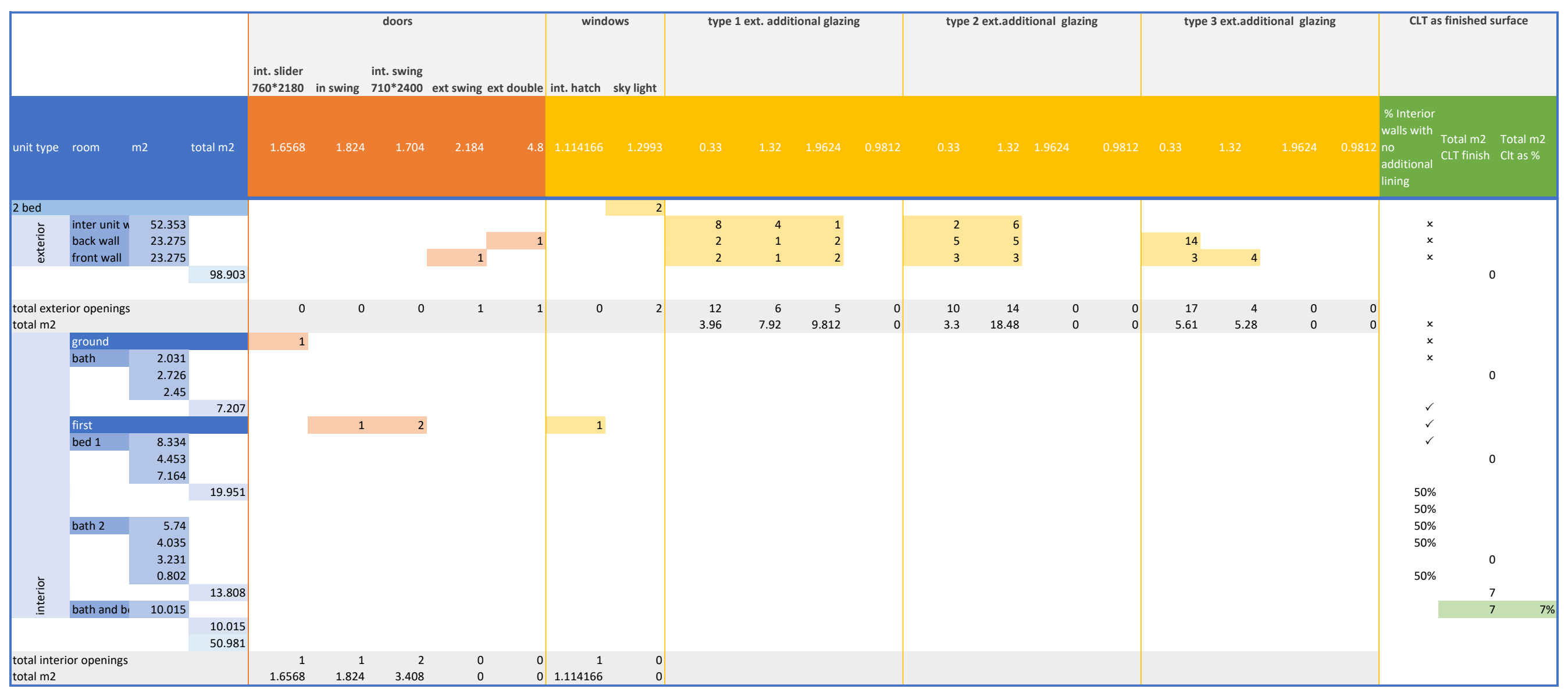

Table G3: 2 bedroom quantities. 


\section{Appendix J: Cost analysis material breakdown.}

\begin{tabular}{|c|c|c|c|c|c|c|}
\hline \multicolumn{2}{|c|}{ Cost comparison on specific building components } & \multicolumn{5}{|c|}{ Cost estimate } \\
\hline Type & Building component & hrs & Unit & $\$$ & notes & Rawlinsons or reference \\
\hline \multicolumn{7}{|c|}{ Site preperation } \\
\hline \multicolumn{7}{|c|}{ traditional } \\
\hline & Demolish and remove $x 2$ factory/warehouses & 0.27 & $\mathrm{~m} 2$ & $\$ \quad 214.68$ & & cost planning rates 1.1 \\
\hline & Site clearance & 0.13 & $\mathrm{~m} 2$ & 20.08 & & cost planning rates 1.2 \\
\hline \multicolumn{7}{|c|}{ Sustainable } \\
\hline & Partial demolition $50 \%$ charge $\times 2$ factory/warehouses & 0.27 & $\mathrm{~m} 2$ & 322.02 & & cost planning rates 1.1 \\
\hline & Site clearance & 0.13 & $\mathrm{~m} 2$ & 20.08 & & cost planning rates 1.2 \\
\hline Differ & & & & $\$$ & & \\
\hline
\end{tabular}

\section{Site}

\section{Site clearance}

demolision

\section{Cost per (m2)}

$\$$

Cost per (m2)

$\$$

$\$$

\section{Total site (m2)}

214.68
322.00

20.08

20.08

11763

Historical buildings

469

469

Site being cleared Total cost

Warehouses (m2) Total cost

$\begin{array}{ll}1474 \$ & 29,598 \\ 1474 \$ & 29,598\end{array}$

29,598

\section{Total}

Sustainable \$

\section{$2,454,193.84$}

$3,666,265.92$

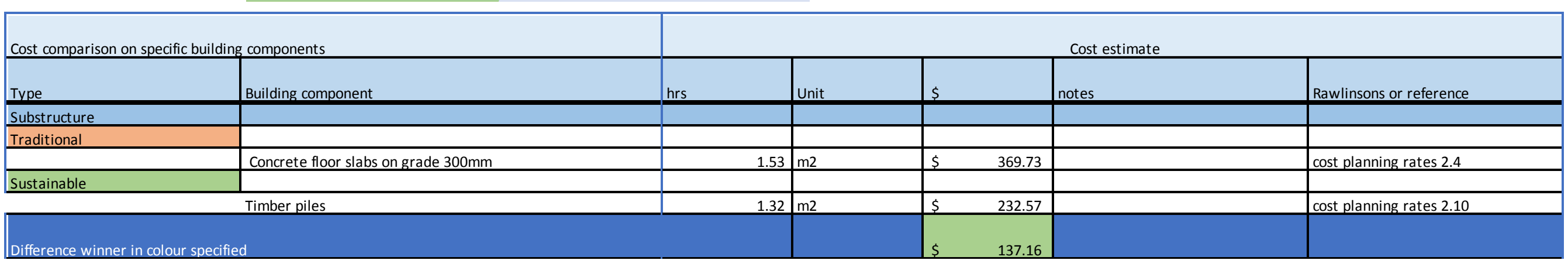

Table H1: Site cost breakdown. 


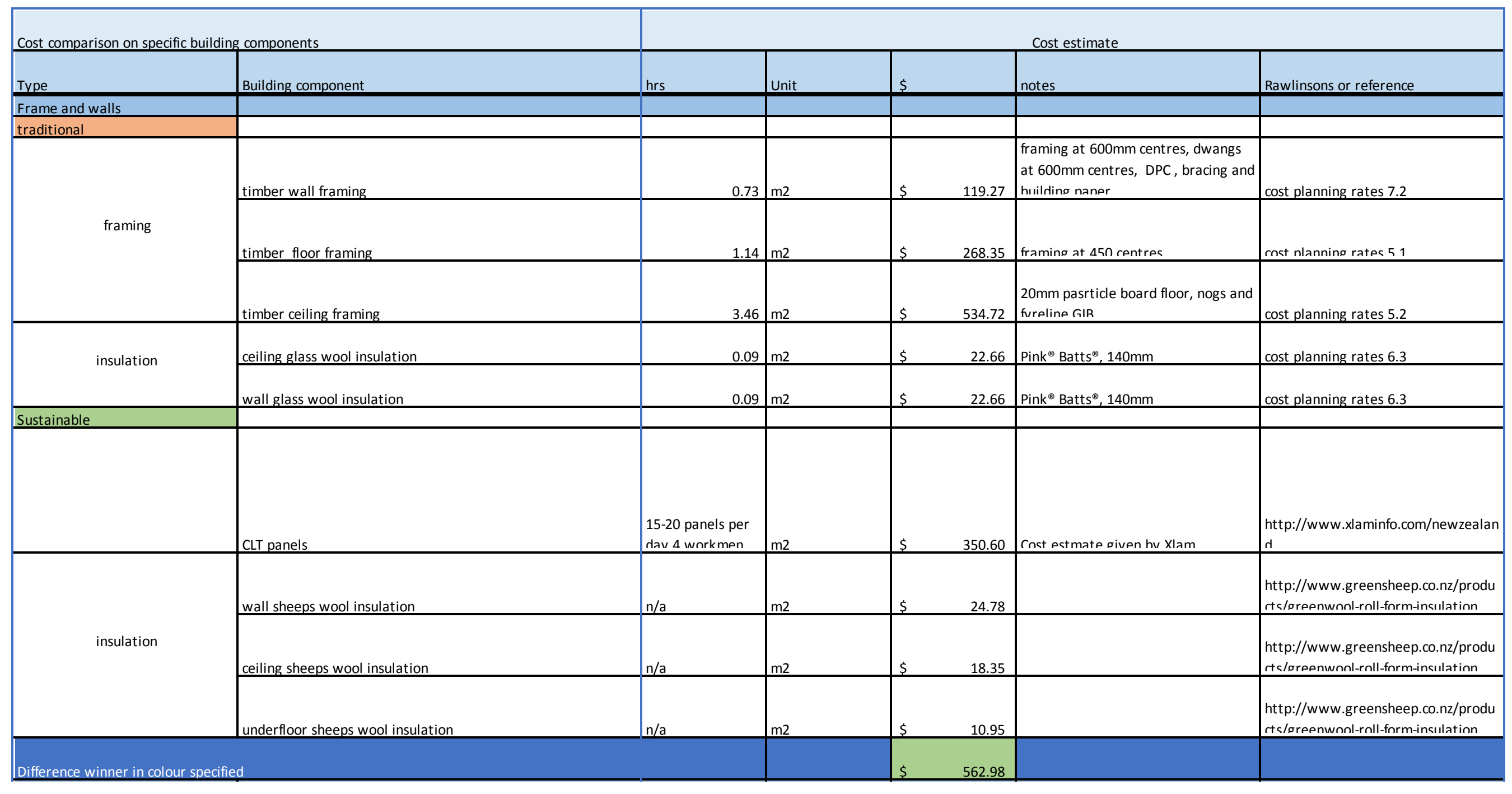




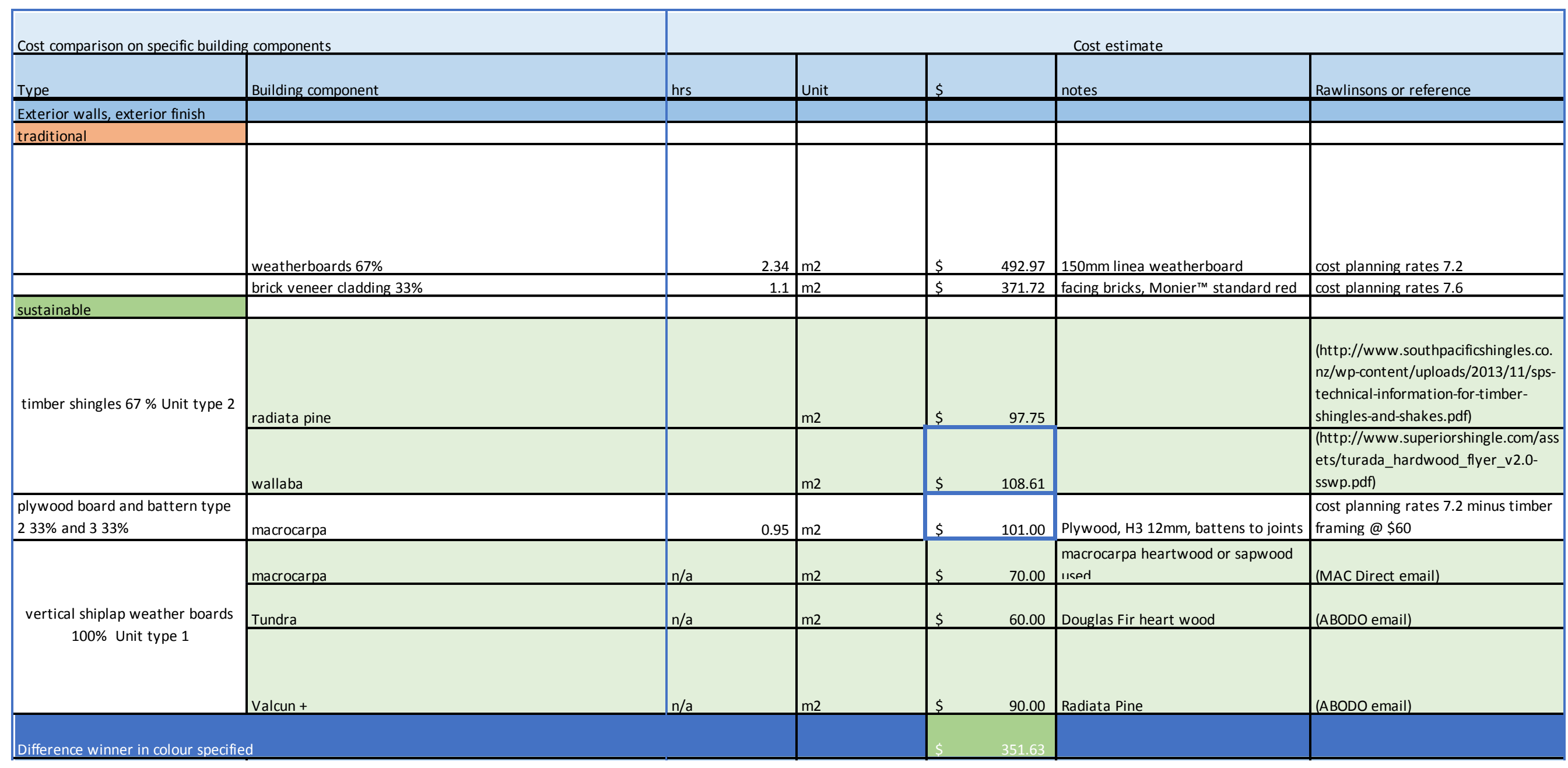

Table H3: Exterior walls and exterior finishes cost breakdown. 


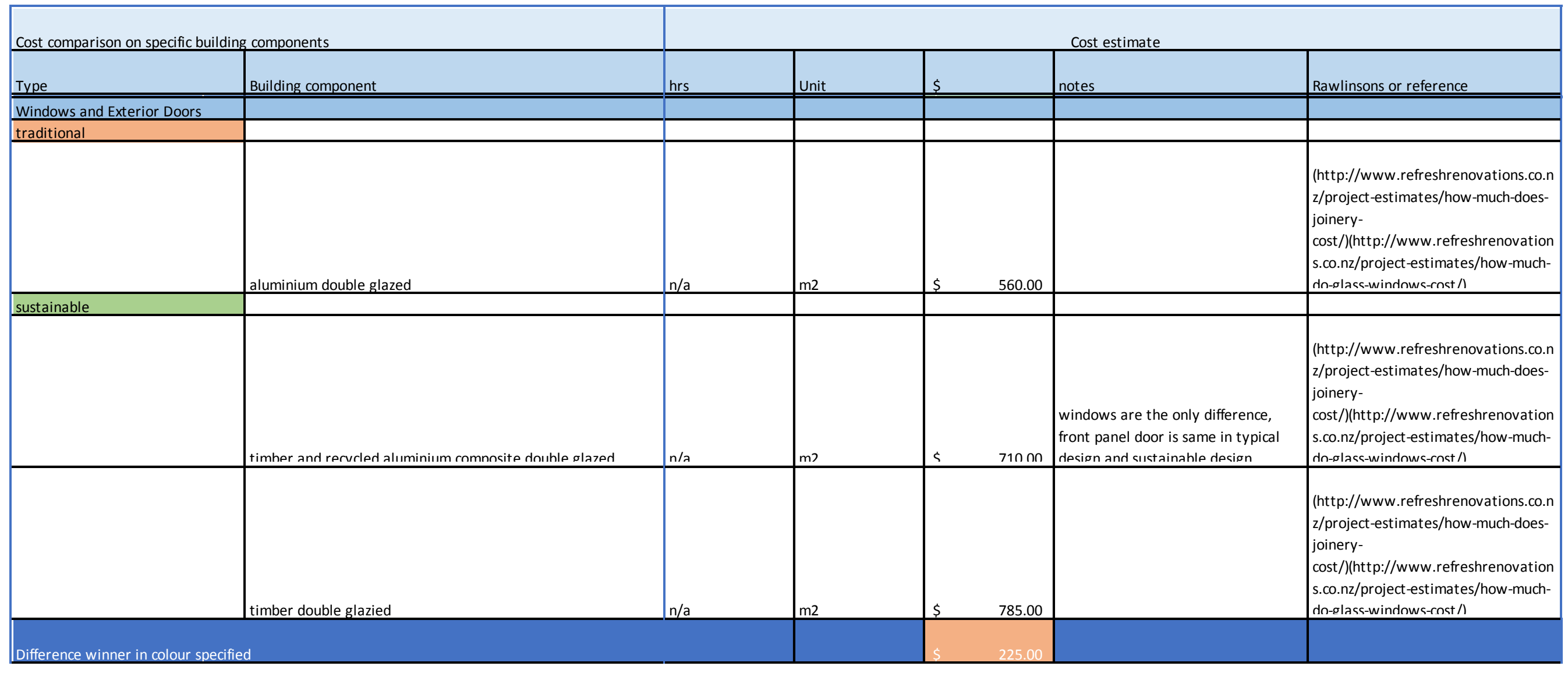




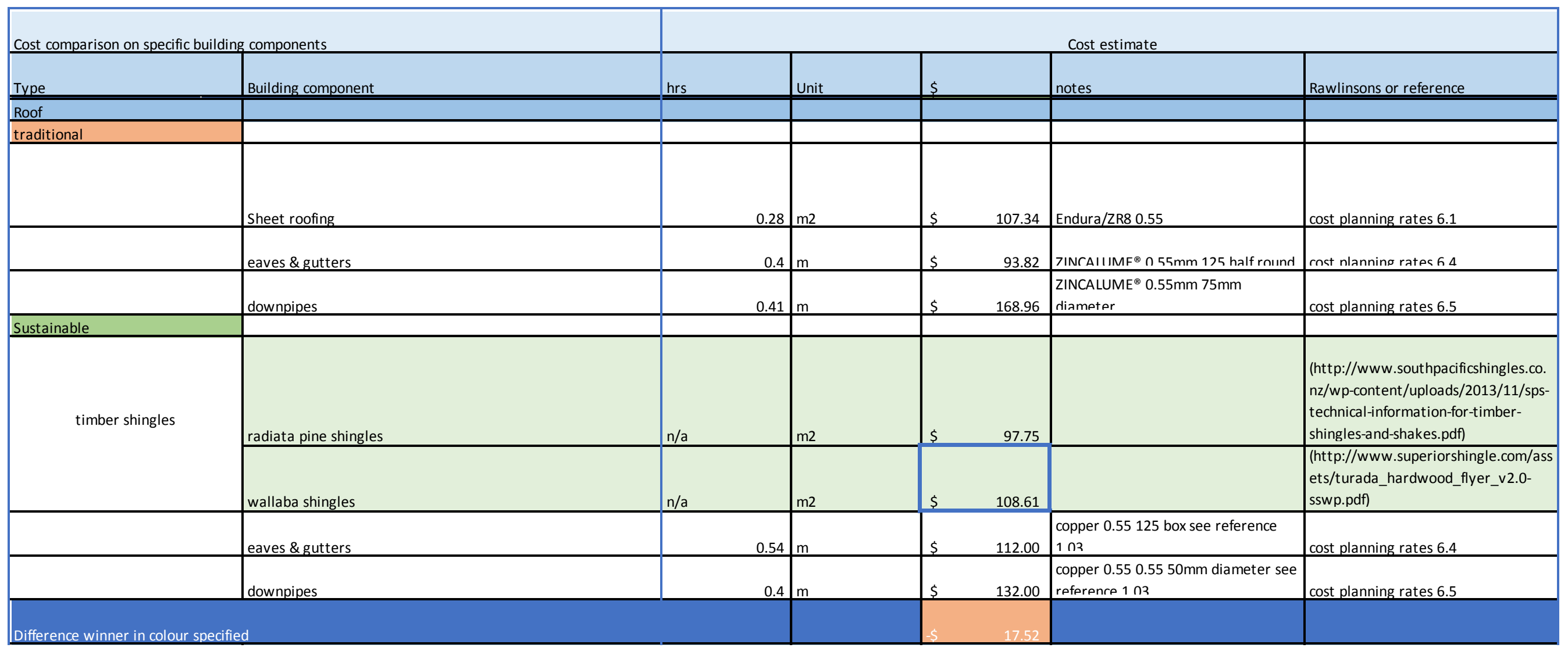




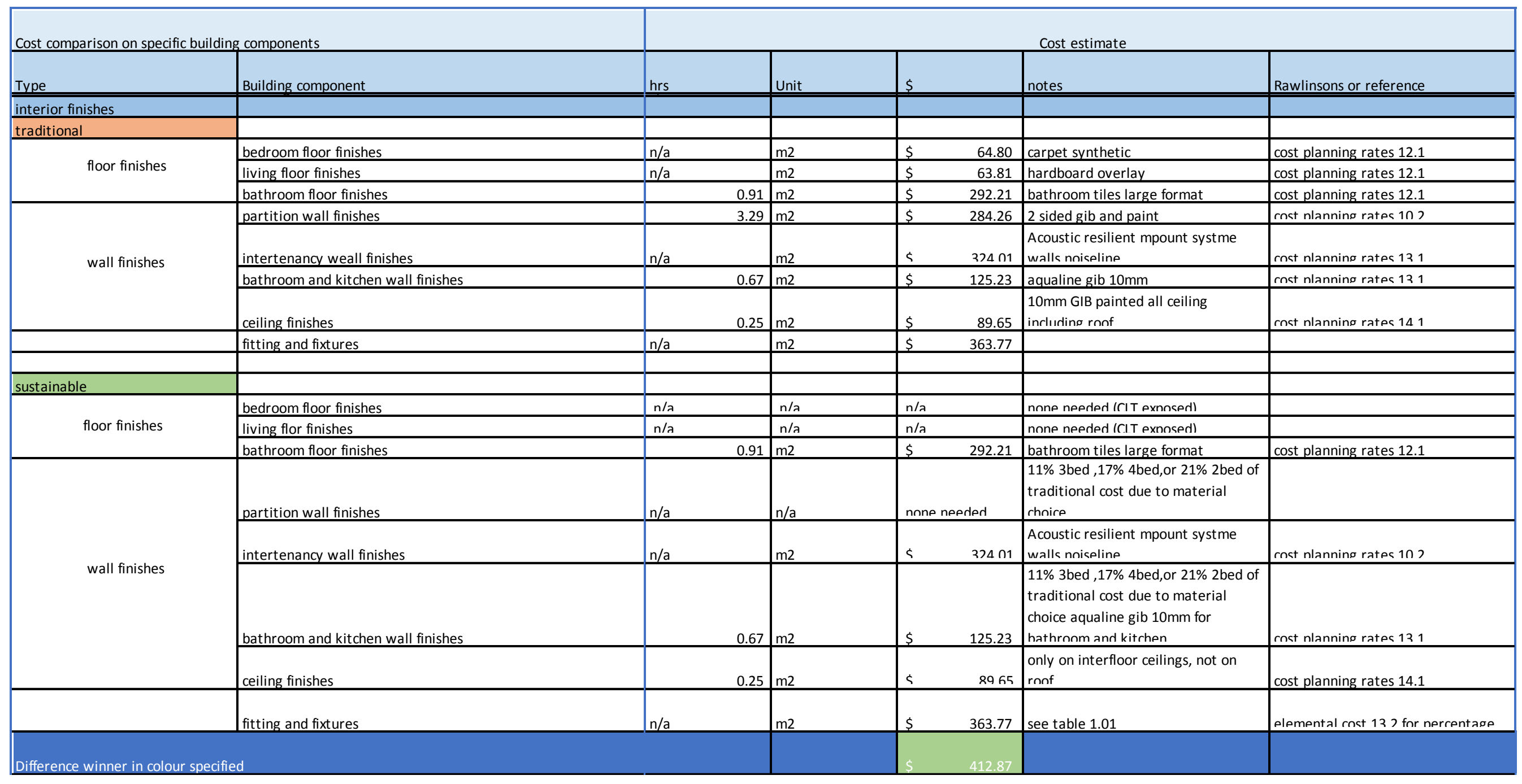

Table H6: Interior finishes cost breakdown. 


\begin{tabular}{|c|c|c|c|c|c|c|c|}
\hline \multicolumn{2}{|c|}{ Cost comparison on specific building components } & \multicolumn{6}{|c|}{ Cost estimate } \\
\hline Type & Building component & hrs & Unit & $\$$ & & notes & Rawlinsons or reference \\
\hline \multicolumn{8}{|l|}{ interior services } \\
\hline \multirow{3}{*}{$\begin{array}{l}\text { same for traditional and } \\
\text { sustainable }\end{array}$} & sanitary plumbing & $\mathrm{n} / \mathrm{a}$ & m2 & $\$$ & 218.92 & see table 1.01 & elemental rnst 13.) for nerrentage \\
\hline & electrical services & n/a & $\mathrm{m} 2$ & s & 182.42 & sep tahle $1 \mathrm{n} 1$ & elemental rost 13 ) for nerrentage \\
\hline & drainage & n/a & $\mathrm{m} 2$ & $\$$ & 54.72 & see table 1.01 & elemental cnst 13.) for nercentage \\
\hline
\end{tabular}

Table H7: Interior services cost breakdown.

\begin{tabular}{|c|c|c|c|c|c|c|c|}
\hline \multicolumn{2}{|c|}{ Cost comparison on specific building components } & \multicolumn{6}{|c|}{ Cost estimate } \\
\hline Type & Building component & hrs & Unit & $\$$ & & notes & Rawlinsons or reference \\
\hline \multicolumn{8}{|l|}{ exterior work and sundries } \\
\hline \multirow{3}{*}{$\begin{array}{l}\text { same for traditional and } \\
\text { sustainable }\end{array}$} & preliminaries & n/a & $\mathrm{m} 2$ & $\$$ & 168.74 & cee tahle 101 & elemental rnst 13 ) for nerrentage \\
\hline & margins & $\mathrm{n} / \mathrm{a}$ & m2 & $\$$ & 132.27 & see table 1.01 & elemental cost 13.7 for nerrentage \\
\hline & contingency & $\mathrm{n} / \mathrm{a}$ & m2 & $\$$ & 68.42 & see table 1.01 & elemental rnst 13 ) for nerrentage \\
\hline
\end{tabular}

Table H8: Exterior work and sundries cost breakdown. 
Wall framing

Wall insulation

Wall finishes

\section{Cladding}

Ext. windows and doors

Internal doors

\begin{tabular}{|c|c|c|c|c|}
\hline & Cost per (m2) & Area (m2) & Total cost & \\
\hline Traditional & 119 & 149.881 & $\$$ & 17,836 \\
\hline Sustainable & 350 & 149.881 & $\$$ & 52,458 \\
\hline Traditional & 23 & 98 & $\$$ & 2,221 \\
\hline Sustainable & 25 & 98 & $\$$ & 2,428 \\
\hline \multicolumn{5}{|l|}{ Traditional } \\
\hline Wet area & 125.23 & 30.28 & $\$$ & $3,791.96$ \\
\hline Internal & 284.26 & 75 & $\$$ & $21,319.50$ \\
\hline Intertenancy & 324.00 & 52 & $\$$ & $16,848.00$ \\
\hline \multicolumn{5}{|l|}{ Sustainable } \\
\hline Wet area & 125.23 & 30.28 & $\$$ & $3,791.96$ \\
\hline Internal & Not needed (CLT left exposed) & - & - & \\
\hline Intertenancy & Not needed (CLT left exposed) & - & - & \\
\hline Traditional & 452.72 & 42.587 & $\$$ & $19,279.98$ \\
\hline Sustainable & 101.00 & 42.587 & $\$$ & $4,301.29$ \\
\hline Traditional & 560.00 & 25.13 & $\$$ & $14,072.80$ \\
\hline \multirow[t]{2}{*}{ Sustainable } & 785.00 & 25.13 & $\$$ & $19,727.05$ \\
\hline & Cost per door & amount of doors & Total cost & \\
\hline Traditional & 284.00 & 4 & $\$$ & $1,136.00$ \\
\hline Sustainable & 284.00 & 4 & $\$$ & $1,136.00$ \\
\hline
\end{tabular}

Total

$\begin{array}{lll}\text { Traditional } & \$ & 96,504.77\end{array}$

$\begin{array}{lll}\text { Sustainable } \$ & 83,843.09\end{array}$

sanitary plumbing electrical services

drainage

stairs

Fixtures and fittings

\begin{tabular}{|lr|r|lr|}
\hline Cost per $(\mathrm{m} 2)$ & & Area $(\mathrm{m} 2)$ & & Total cost \\
\hline$\$$ & 218.00 & 50 & $\$$ & $10,900.00$ \\
\hline$\$$ & 182.42 & 80 & $\$$ & $14,593.60$ \\
\hline$\$$ & 54.72 & 50 & $\$$ & $2,736.00$ \\
\hline$\$$ & 50.00 & 5.3 & $\$$ & 265.00 \\
\hline$\$$ & 177.30 & 6.5 & $\$$ & $1,152.45$ \\
\hline
\end{tabular}

Total

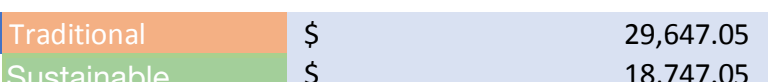

Table 12: 2 bedroom vertical building components, and internal components. 
Substructure

Floors framing

Floor finishes

Ceiling framing

Floor insulation

Ceiling insulation

Ceiling finishes

Roof Cladding

Roof eaves and gutters

Roof downpipes

\begin{tabular}{|c|c|c|c|c|}
\hline & Cost per (m2) & Area $(\mathrm{m} 2)$ & Total cost & \\
\hline Traditional & 370 & 50 & $\$$ & 18,487 \\
\hline Sustainable & 233 & 50 & $\$$ & 11,629 \\
\hline Traditional & 268 & 150 & $\$$ & 40,200 \\
\hline Sustainable & 350 & 150 & $\$$ & 52,500 \\
\hline \multicolumn{5}{|l|}{ Traditional } \\
\hline Bedrooms & 65 & 61.4 & $\$$ & $3,978.72$ \\
\hline Living spaces & 64 & 77 & $\$$ & $4,913.37$ \\
\hline Wet area & 292 & 11.6 & $\$$ & $3,389.64$ \\
\hline \multicolumn{5}{|l|}{ Sustainable } \\
\hline Bedrooms & Not needed (CLT left exposed) & - & - & \\
\hline Living spaces & Not needed (CLT left exposed) & - & - & \\
\hline Wet area & 292 & 11.6 & $\$$ & $3,387.20$ \\
\hline Traditional & 535 & 150 & $\$$ & 80,208 \\
\hline Sustainable & Ceilings are costed in floors & & & \\
\hline Traditional & $\begin{array}{l}\text { Not typical to have underfloor } \\
\text { insulation }\end{array}$ & & & \\
\hline Sustainable & 11 & 50 & $\$$ & 548 \\
\hline \begin{tabular}{|l|} 
Traditional \\
\end{tabular} & 23 & 100 & $\$$ & 2,266 \\
\hline Sustainable & 18 & 100 & $\$$ & 1,835 \\
\hline \begin{tabular}{|l|} 
Traditional \\
\end{tabular} & 90 & 100 & $\$$ & 8,965 \\
\hline Sustainable & 90 & 100 & $\$$ & 8,965 \\
\hline Traditional & 107 & 50 & $\$$ & 5,350 \\
\hline \multirow[t]{2}{*}{ Sustainable } & 108 & 50 & $\$$ & 5,400 \\
\hline & Cost per (m2) & Area (m) & Total cost & \\
\hline Traditional & 169 & 30 & $\$$ & 5,069 \\
\hline Sustainable & 112 & 30 & $\$$ & 3,360 \\
\hline Traditional & 169 & 8.1 & $\$$ & 1,369 \\
\hline Sustainable & 132 & 8.1 & $\$$ & 1,069 \\
\hline
\end{tabular}

Total

$\begin{array}{ll}\text { Traditional } & \$ \\ \text { Sustainable } & \$\end{array}$

$93,986.60$

$168,900.40$

Table 13: 3 bedroom horizontal building components 


\begin{tabular}{|c|c|c|c|c|c|}
\hline & & Cost per (m2) & Area $(\mathrm{m} 2)$ & Total cost & \\
\hline \multirow[t]{2}{*}{ Wall framing } & Traditional & 119 & 354.214 & $\$$ & 42,151 \\
\hline & Sustainable & 350 & 354.214 & $\$$ & 123,975 \\
\hline \multirow[t]{2}{*}{ Wall insulation } & Traditional & 23 & 242.862 & $\$$ & 5,503 \\
\hline & Sustainable & 25 & 242.862 & $\$$ & 6,018 \\
\hline \multirow[t]{8}{*}{ Wall finishes } & Traditional & & & & \\
\hline & Wet area & 125.23 & 52.319 & $\$$ & $6,551.91$ \\
\hline & Internal & 284.26 & 144.089 & $\$$ & $40,958.74$ \\
\hline & Intertenancy & 324.00 & 157.808 & $\$$ & $51,129.79$ \\
\hline & Sustainable & & & & \\
\hline & Wet area & 125.23 & 52.319 & $\$$ & $6,551.91$ \\
\hline & \begin{tabular}{|l|} 
Internal \\
\end{tabular} & Not needed (CLT left exposed) & - & - & \\
\hline & Intertenancy & Not needed (CLT left exposed) & - & - & \\
\hline \multirow[t]{2}{*}{ Cladding } & Traditional & 452.72 & 85.054 & $\$$ & $38,505.64$ \\
\hline & Sustainable & 106.10 & 85.054 & $\$$ & $9,024.12$ \\
\hline \multirow[t]{3}{*}{ Ext. windows and doors } & Traditional & 560.00 & 36.6848 & $\$$ & $20,543.49$ \\
\hline & Sustainable & 785.00 & 36.6848 & $\$$ & $28,797.57$ \\
\hline & & Cost per door & amount of doors & Total cost & \\
\hline \multirow[t]{2}{*}{ Internal doors } & Traditional & 284.00 & 6 & $\$$ & $1,704.00$ \\
\hline & Sustainable & 284.00 & 6 & $\$$ & $1,704.00$ \\
\hline Total & $\begin{array}{l}\text { Traditional } \\
\text { Sustainable }\end{array}$ & $\begin{array}{l}207,048.28 \\
176,070.62\end{array}$ & & & \\
\hline
\end{tabular}

\section{sanitary plumbing}

electrical services

drainage

stairs

Fixtures and fittings

\begin{tabular}{|lr|l|lr|}
\hline Cost per $(\mathrm{m} 2)$ & & Area $(\mathrm{m} 2)$ & & \multicolumn{2}{|l|}{ Total cost } \\
\hline$\$$ & 218.00 & 50 & $\$$ & $10,900.00$ \\
\hline$\$$ & 182.42 & 150 & $\$$ & $27,363.00$ \\
\hline$\$$ & 54.72 & 50 & $\$$ & $2,736.00$ \\
\hline$\$$ & 50.00 & 6 & $\$$ & 300.00 \\
\hline$\$$ & 177.30 & 11.6 & $\$$ & $2,056.68$ \\
\hline
\end{tabular}

Total

$\begin{array}{lll}\text { Traditional } & \$ & 43,355.68 \\ \text { Sustainable } & \$ & 32,455.68\end{array}$

Table 14: 4 bedroom vertical building components, and internal components. 